Modelos computacionais prognósticos de lesões traumáticas do plexo braquial em adultos

\author{
Luciana de Melo e Abud \\ DiSSERTAÇÃO APRESENTADA \\ AO \\ Instituto DE MATEMÁticA E EstatísticA \\ DA \\ UNIVERSIDADE DE SÃO PAULO \\ PARA \\ OBTENÇÃO DO TÍTULO \\ DE \\ Mestre em CiênCIAS \\ Programa: Ciência da Computação \\ Orientadora: Profa. Dra. Kelly Rosa Braghetto
}

Durante o desenvolvimento deste trabalho a autora recebeu auxílio financeiro da CAPES.

Este trabalho também é parte das atividades do Centro de Pesquisa, Inovação e Difusão em Neuromatemática (processo FAPESP: 2013/07699-0)

São Paulo, Junho de 2018 


\title{
Modelos computacionais prognósticos de lesões traumáticas do plexo braquial em adultos
}

\author{
Esta versão da dissertação contém as correções e alterações sugeridas \\ pela Comissão Julgadora durante a defesa da versão original do trabalho, \\ realizada em 20/06/2018. Uma cópia da versão original está disponível no \\ Instituto de Matemática e Estatística da Universidade de São Paulo.
}

Comissão Julgadora:

- Prof ${ }^{\mathrm{a}}$. Dr ${ }^{\mathrm{a}}$. Nina Sumiko Tomita Hirata - IME-USP

- Prof ${ }^{a}$. Dr ${ }^{\mathrm{a}}$. Claudia Domingues Vargas - UFRJ

- Prof. Dr. Marcelo de Souza Lauretto - EACH-USP 


\section{Agradecimentos}

Sou grata pela bênção de existirem em minha vida tantas pessoas às quais estendo minha gratidão:

Aos meus pais, por todo o apoio que sempre me deram, por serem um exemplo moral, de vida e de superação, e pelo amor incondicional que recebo todos dias. A vocês, sou grata a tantas coisas que nem cabem neste papel. Tudo que sou e conquisto hoje, foi graças a vocês.

Ao meu companheiro Anthony, que sempre acreditou no meu potencial mesmo nos meus momentos de insegurança, por todo o suporte, amor e carinho.

Aos meus irmãos, cunhados e sobrinhos, por toda a alegria e distração que me proporcionaram nos períodos de tensão e preocupação.

À minha orientadora Kelly e à Cristiane Patroclo, por todo o suporte, apoio e paciência comigo neste trabalho. Agradeço também aos professores Anatoli Iambartsev, Cláudia Vargas, Antonio Galves, Nina Hirata e Flávio Silva - que estiveram envolvidos no desenvolvimento e na qualificação do meu projeto, por todas as ideias, dicas e críticas fornecidas, que serviram para o aprimoramento deste trabalho.

Aos meus colegas IMEanos, agradeço por todo o companheirismo e toda a ajuda que recebi relacionada a questões acadêmicas e não acadêmicas nesses anos de Graduação e de Mestrado. Me sinto privilegiada de tê-los não só como colegas, mas como verdadeiros amigos.

Aos meus amigos do conjunto complementar ao IME, que por mais que perdessem a paciência com minhas inúmeras recusas para nossos encontros, nunca deixaram de me convidar, e sempre me apoiaram e alegraram com mensagens e visitas.

Por fim, mas de forma nenhuma menos importante, agradeço a Deus por todas as oportunidades, condições e bênçãos de minha vida, que me trouxeram até aqui. 


\section{Resumo}

\section{Abud, L. M. Modelos computacionais prognósticos de lesões traumáticas do plexo bra-}

quial em adultos. Dissertação (Mestrado) - Instituto de Matemática e Estatística, Universidade de São Paulo, São Paulo, 2018.

Estudos de prognóstico clínico consistem na predição do curso de uma doença em pacientes e são utilizados por profissionais da saúde com o intuito de aumentar as chances ou a qualidade de sua recuperação. Sob a perspectiva computacional, a criação de um modelo prognóstico clínico é um problema de classificação, cujo objetivo é identificar a qual classe (dentro de um conjunto de classes predefinidas) uma nova amostra pertence. Este projeto visa a criar modelos prognósticos de lesões traumáticas do plexo braquial, um conjunto de nervos que inervam os membros superiores, utilizando dados de pacientes adultos com esse tipo de lesão. Os dados são provenientes do Instituto de Neurologia Deolindo Couto (INDC) da Universidade Federal do Rio de Janeiro (UFRJ) e contêm dezenas de atributos clínicos coletados por meio de questionários eletrônicos. Com esses modelos prognósticos, deseja-se identificar de maneira automática os possíveis preditores do curso desse tipo de lesão. Árvores de decisão são classificadores frequentemente utilizados para criação de modelos prognósticos, por se tratarem de um modelo transparente, cujo resultado pode ser examinado e interpretado clinicamente. As Florestas Aleatórias, uma técnica que utiliza um conjunto de árvores de decisão para determinar o resultado final da classificação, podem aumentar significativamente a acurácia e a generalização dos modelos gerados, entretanto ainda são pouco utilizadas na criação de modelos prognósticos. Neste projeto, exploramos a utilização de florestas aleatórias nesse contexto, bem como a aplicação de métodos de interpretação de seus modelos gerados, uma vez que a transparência do modelo é um aspecto particularmente importante em domínios clínicos. A estimativa de generalização dos modelos resultantes foi feita por meio de métodos que viabilizam sua utilização sobre um número reduzido de instâncias, uma vez que os dados relativos ao prognóstico são provenientes de 44 pacientes do INDC. Além disso, adaptamos a técnica de florestas aleatórias para incluir a possível existência de valores faltantes, que é uma característica presente nos dados utilizados neste projeto. Foram criados quatro modelos prognósticos - um para cada objetivo de recuperação, sendo eles a ausência de dor e forças satisfatórias avaliadas sobre abdução do ombro, flexão do cotovelo e rotação externa no ombro. As acurácias dos modelos foram estimadas entre $77 \%$ e $88 \%$, utilizando o método de validação cruzada leave-one-out. Esses modelos evoluirão com a inclusão de novos dados, provenientes da contínua chegada de novos pacientes em tratamento no INDC, e serão utilizados como parte de um sistema de apoio à decisão clínica, de forma a possibilitar a predição de recuperação de um paciente considerando suas características clínicas.

Palavras-chave: modelo prognóstico, plexo braquial, aprendizado de máquina, florestas aleatórias. 


\section{Abstract}

Abud, L. M. Prognostic computational models for traumatic brachial plexus injuries in adults. Thesis (Master) - Instituto de Matemática e Estatística, Universidade de São Paulo, São Paulo, 2018.

Studies of prognosis refer to the prediction of the course of a disease in patients and are employed by health professionals in order to improve patients' recovery chances and quality. Under a computational perspective, the creation of a prognostic model is a classification task that aims to identify to which class (within a predefined set of classes) a new sample belongs. The goal of this project is the creation of prognostic models for traumatic injuries of the brachial plexus, a network of nerves that innervates the upper limbs, using data from adult patients with this kind of injury. The data come from the Neurology Institute Deolindo Couto (INDC) of Rio de Janeiro Federal University (UFRJ) and they are characterized by dozens of clinical features that are collected by means of electronic questionnaires. With the use of these prognostic models we intended to automatically identify possible predictors of the course of brachial plexus injuries. Decision trees are classifiers that are frequently used for the creation of prognostic models since they are a transparent technique that produces results that can be clinically examined and interpreted. Random Forests are a technique that uses a set of decision trees to determine the final classification results and can significantly improve model's accuracy and generalization, yet they are still not commonly used for the creation of prognostic models. In this project we explored the use of random forests for that purpose, as well as the use of interpretation methods for the resulting models, since model transparency is an important aspect in clinical domains. Model assessment was achieved by means of methods whose application over a small set of samples is suitable, since the available prognostic data refer to only 44 patients from INDC. Additionally, we adapted the random forests technique to include missing data, that are frequent among the data used in this project. Four prognostic models were created - one for each recovery goal, those being absence of pain and satisfactory strength evaluated over shoulder abduction, elbow flexion and external shoulder rotation. The models' accuracies were estimated between $77 \%$ and $88 \%$, calculated through the leave-one-out cross validation method. These models will evolve with the inclusion of new data from new patients that will arrive at the INDC and they will be used as part of a clinical decision support system, with the purpose of prediction of a patient's recovery considering his or her clinical characteristics.

Keywords: prognostic model, brachial plexus, machine learning, random forests. 


\section{Sumário}

$\begin{array}{ll}\text { Lista de Abreviaturas } & \text { ix }\end{array}$

Lista de Símbolos $\quad$ xi

Lista de Figuras $\quad$ xiii

Lista de Tabelas $\quad$ xvii

1 Introdução $\quad 1$

1.1 Contexto e Motivação . . . . . . . . . . . . . . . . . . . . . . . . 2

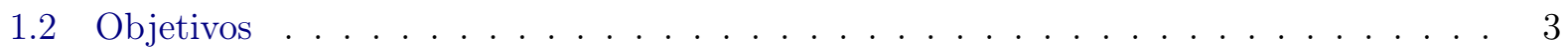

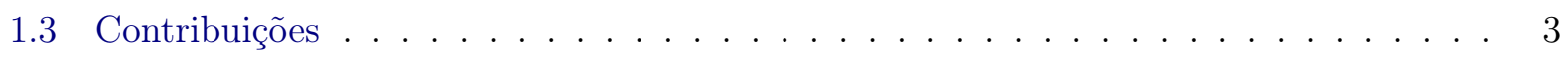

1.4 Organização do Trabalho . . . . . . . . . . . . . . . . . . . . . . 4

2 Conceitos $\quad 5$

2.1 Mineração de Dados . . . . . . . . . . . . . . . . . . . . 5

2.1.1 Aprendizado de Máquina . . . . . . . . . . . . . . . . . 6

2.1 .2 Classificação . . . . . . . . . . . . . . . . . . . . 7

2.1.2.1 Validação do Modelo . . . . . . . . . . . . . . . . . . . . . 7

2.1.2.2 Seleção de Atributos . . . . . . . . . . . . . . . . . . . . 9

2.1.2.3 Dados Faltantes . . . . . . . . . . . . . . . . . . . 10

2.1.2.4 Árvores de Decisão . . . . . . . . . . . . . . . . . . . . . . . 11

2.1.2.5 Florestas Aleatórias . . . . . . . . . . . . . . . 18

2.2 Modelo Prognóstico Clínico . . . . . . . . . . . . . . . . . . . . . 22

2.2.1 Criação do Modelo . . . . . . . . . . . . . . . . . . . . . . 22

2.2 .2 Validação do Modelo . . . . . . . . . . . . . . . . . . . . . 23

3 Trabalhos Relacionados $\quad 25$

3.1 Uso de Aprendizado de Máquina para Prognóstico de Lesões Neurológicas . . . . . . 25

3.2 Uso de Árvores e Florestas de Decisão para Prognóstico Clínico . . . . . . . . . . . . 26

3.3 Uso de Florestas de Decisão em Domínios de Alta Dimensionalidade . . . . . . . . . 28

4 Caracterização dos Dados $\quad 31$

5 Criação de Modelos Prognósticos de LTPBA com Florestas Aleatórias 41

5.1 Árvores MVB . . . . . . . . . . . . . . . . . . . . . . . 41

5.2 Processo de KDD . . . . . . . . . . . . . . . . . . . . . . 43 
5.2.1 Compreensão do Domínio . . . . . . . . . . . . . . . . . . . . . . 43

5.2 .2 Seleção dos Dados . . . . . . . . . . . . . . . . . . . . . 43

$5.2 .3 \quad$ Limpeza e Pré-Processamento . . . . . . . . . . . . . . . . . . . . . . . 44

5.2 .4 Transformação . . . . . . . . . . . . . . . . . . . . . . . 45

5.2 .5 Mineração de Dados . . . . . . . . . . . . . . . . . . . . . . 49

5.2 .6 Avaliação . . . . . . . . . . . . . . . . . . . . . . . 52

6 Resultados $\quad 53$

6.1 Criação dos Modelos . . . . . . . . . . . . . . . . . . . . . . . . 53

6.1 .1 Modelo Prognóstico de Dor . . . . . . . . . . . . . . . . . 53

6.1.2 Modelo Prognóstico de Força Muscular Avaliada sobre Abdução do Ombro . . 60

6.1.3 Modelo Prognóstico de Força Muscular Avaliada sobre Flexão do Cotovelo . 64

6.1.4 Modelo Prognóstico de Força Muscular Avaliada sobre Rotação Externa do

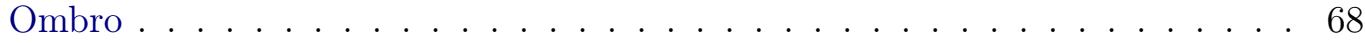

6.2 Classificação de Pacientes . . . . . . . . . . . . . . . . . . . . . . 73

6.2 .1 Modelo Prognóstico de Dor . . . . . . . . . . . . . . . . . . 73

6.2.2 Modelo Prognóstico de Força Muscular Avaliada sobre Abdução do Ombro . . 74

6.2.3 Modelo Prognóstico de Força Muscular Avaliada sobre Flexão do Cotovelo . . 75

6.2.4 Modelo Prognóstico de Força Muscular Avaliada sobre Rotação Externa do

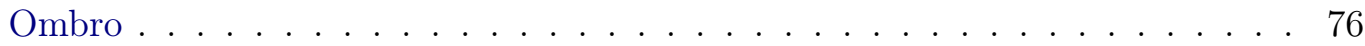

6.3 Considerações sobre os Resultados . . . . . . . . . . . . . . . . . . . . 77

7 Conclusões $\quad 79$

7.1 Principais Contribuições . . . . . . . . . . . . . . . . . . . 80

7.2 Limitações do Trabalho . . . . . . . . . . . . . . . . . . . . . . . . . 80

7.3 Sugestões para Pesquisas Futuras . . . . . . . . . . . . . . . . . . 81

$\begin{array}{lll}\text { A Excertos de Questionários do INDC-UFRJ } & 85\end{array}$

$\begin{array}{ll}\text { Referências Bibliográficas } & 107\end{array}$ 


\title{
Lista de Abreviaturas
}

\author{
AbdOmbro Abdução do Ombro \\ ADC Apoio à Decisão Clínica \\ FlexCotovelo Flexão do Cotovelo \\ INDC-UFRJ Instituto de Neurologia Deolindo Couto - Universidade Federal do Rio de Janeiro \\ KDD Descoberta de Conhecimento em Bancos de Dados (Knowledge Discovery in Databases) \\ LabNer Laboratório de Neurociências e Reabilitação \\ LTPBA Lesão Traumática do Plexo Braquial em Adultos \\ LOOCV Validação cruzada leave-one-out \\ MRC Medical Research Council \\ NES Neuroscience Experiments System \\ NeuroMat Centro de Pesquisa, Inovação e Difusão em Neuromatemática \\ OOB Out-Of-Bag \\ RotEOmbro Rotação Externa do Ombto
}




\section{Lista de Símbolos}

$\begin{array}{ll}\mathcal{D} & \text { Conjunto composto por dados de entrada } \\ \boldsymbol{x}=\left[x_{1}, \ldots, x_{N}\right] & \text { Instância, representada por um vetor de dimensão } N \\ y & \text { Rótulo de uma instância } \boldsymbol{x} \\ N & \text { Número de atributos no conjunto de dados } \\ M & \text { Número de instâncias no conjunto de dados } \\ h(\boldsymbol{x}) & \text { Modelo ou função de classificação } \\ f(\boldsymbol{x}) & \text { Função alvo a qual se deseja aproximar } \\ |Z| & \text { Tamanho do conjunto } Z \text { (número de elementos) } \\ \max (Z) & \text { Elemento máximo do conjunto } Z \\ I(A) & \text { Função indicadora. Assume } 1 \text { se a expressão A é verdadeira e } 0 \text { caso contrário } \\ \hat{\mu_{j}} & \text { Média amostral de um atributo } X_{j} \\ \hat{\sigma_{j}} & \text { Variância amostral de um atributo } X_{j}\end{array}$




\section{Lista de Figuras}

1.1 Ilustração do plexo braquial, destacado em amarelo. Adaptado de [GL18]. . . . . . . 1

2.1 Representação do fluxo básico das etapas do processo de KDD [FPsS96]. Extraído

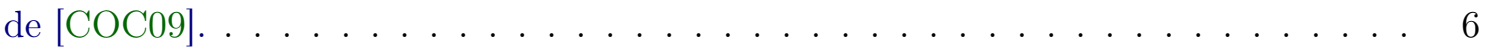

2.2 Exemplo de representação gráfica de uma Árvore de Decisão. . . . . . . . . . . . . . . 11

2.3 Representação gráfica do início da construção de uma Árvore de Decisão pelo algoritmo C4.5. . . . . . . . . . . . . . . . . . . . . . 15

2.4 Representação gráfica da Árvore de Decisão construída pelo algoritmo C4.5 . . . . . 16

4.1 Distribuição dos pacientes do INDC-UFRJ por faixa etária, em porcentagem. . . . . 33

4.2 Distribuição dos pacientes do INDC-UFRJ por lado da lesão. . . . . . . . . . . . . . 34

4.3 Frequência de cada evento que ocasionou as lesões dos pacientes do INDC-UFRJ. . . 34

4.4 Distribuição do período entre a avaliação de entrada e o primeiro retorno dos pacientes ao INDC para a avaliação de seguimento. . . . . . . . . . . . . . . . . 35

4.5 Distribuição do período entre a avaliação de entrada e o último retorno dos pacientes ao INDC para a avaliação de seguimento. . . . . . . . . . . . . . . . . 35

4.6 Distribuição do período entre a avaliação de entrada e a avaliação de seguimento dos pacientes que retornaram apenas uma vez ao INDC. . . . . . . . . . . . . 36

4.7 Frequência de respostas para a questão "Você sente dor atualmente?" do questionário de seguimento, considerando os preenchimentos do último retorno dos pacientes ao

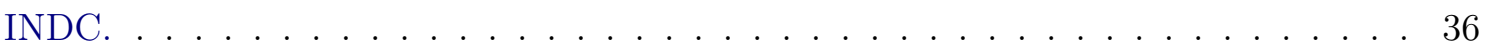

4.8 Frequência de respostas para a questão "Força muscular: Abdução do Ombro" do questionário de seguimento, considerando os preenchimentos do último retorno dos pacientes ao INDC . . . . . . . . . . . . . . . . . . . . . . 37

4.9 Frequência de respostas para a questão "Força muscular: Flexão do Cotovelo" do questionário de seguimento, considerando os preenchimentos do último retorno dos pacientes ao INDC . . . . . . . . . . . . . . . . . . . . 37

4.10 Frequência de respostas para a questão "Força muscular: Rotação Externa do Ombro" do questionário de seguimento, considerando os preenchimentos do último retorno dos

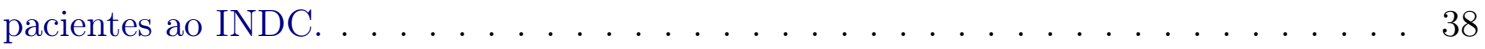

4.11 Distribuição do período de tempo entre a lesão e o primeiro procedimento cirúrgico dos pacientes do INDC-UFRJ. . . . . . . . . . . . . . . . . . 38

4.12 Frequência dos procedimentos realizados sobre os pacientes do INDC cujas informações se encontram nos preenchimentos da ficha "Avaliação Cirúrgica Unificada". 
6.1 Acurácias das florestas aleatórias quando aplicadas sobre atributos de importância média superior ou igual a cada valor de limiar, para o modelo prognóstico de dor.

6.2 Diagrama de caixa sobre os valores de importância para cada atributo, calculados com 25 florestas aleatórias, na criação do modelo prognóstico de dor. . . . . . . . . . 55

6.3 Contribuição dos valores do atributo "Sente dor após a lesão?" para cada paciente, para o modelo prognóstico de dor. . . . . . . . . . . . . . . . . . 55

6.4 Contribuição dos valores dos atributos relativos à sensibilidade superficial tátil, avaliadas sobre C6, C7 e C8, para o modelo prognóstico de dor. . . . . . . . . . . . . 56

6.5 Contribuição dos valores dos atributos relativos à sensibilidade superficial dolorosa, avaliadas sobre C6, C7 e C8, para o modelo prognóstico de dor. . . . . . . . . . . . . 57

6.6 Contribuição dos valores do atributo "Transferência realizada: Oberlin", para o modelo prognóstico de dor. . . . . . . . . . . . . . . . . . . . 57

6.7 Contribuição dos valores dos atributos "Força muscular avaliada sobre flexão dos dedos" e "Força muscular avaliada sobre adução dos dedos" para cada paciente, para o modelo prognóstico de dor.

6.8 Contribuição dos valores dos atributos "Tem história prévia de fratura?" e "Teve fratura associada à lesão?" para cada paciente, para o modelo prognóstico de dor. .

6.9 Acurácias das florestas aleatórias quando aplicada sobre atributos de importância média superior a cada valor de limiar, para o modelo prognóstico de força avaliada sobre abdução do ombro. . . . . . . . . . . . . . . . . . . . . . . .

6.10 Diagrama de caixa sobre os valores de importância para cada atributo, calculados com 25 florestas aleatórias, para a criação do modelo prognóstico de força muscular avaliada sobre abdução do ombro.

6.11 Contribuição dos valores dos atributos "Se faz uso de dispositivo auxiliar [Suporte de Ombro]" e "Se faz uso de dispositivo auxiliar [Tipoia]" para cada paciente, para o modelo prognóstico de força muscular avaliada sobre abdução do ombro. . . . . . . . .

6.12 Contribuição dos valores do atributo "Evento que levou ao trauma [Moto]", para o modelo prognóstico de força muscular avaliada sobre abdução do ombro.

6.13 Acurácias das florestas aleatórias quando aplicadas sobre atributos de importância média superior a cada valor de limiar, para o modelo prognóstico de força avaliada sobre flexão do cotovelo.

6.14 Diagrama de caixa sobre os valores de importância para cada atributo, calculados com 25 florestas aleatórias, na criação do modelo prognóstico de força muscular avaliada sobre flexão do cotovelo. . . . . . . . . . . . . . . . . . . . . . . . . .

6.15 Contribuição dos valores dos atributos "Se faz uso de dispositivo auxiliar [Suporte de Ombro]" e "Se faz uso de dispositivo auxiliar [Tipoia]" para cada paciente, para o modelo prognóstico de força muscular avaliada sobre flexão do cotovelo.

6.16 Contribuição dos valores do atributo "Força muscular avaliada sobre flexão do cotovelo", para o modelo prognóstico de força muscular avaliada sobre flexão do cotovelo.

6.17 Contribuição dos valores do atributo "Transferência realizada [Oberlin]", para o modelo prognóstico de força muscular avaliada sobre flexão do cotovelo.

6.18 Contribuição dos valores do atributo "Ficou desacordado?", para o modelo prognóstico de força muscular avaliada sobre flexão do cotovelo. 
6.19 Acurácias das florestas aleatórias quando aplicadas sobre atributos de importância média superior a cada valor de limiar, para o modelo prognóstico de força avaliada sobre rotação externa do ombro. . . . . . . . . . . . . . . . . . . . 69

6.20 Diagrama de caixa sobre os valores de importância para cada atributo, calculados com 25 florestas aleatórias, para a criação do modelo prognóstico de força muscular rotação externa do ombro. . . . . . . . . . . . . . . . . . . . . . . . 69

6.21 Contribuição dos valores dos atributos "Se faz uso de dispositivo auxiliar [Suporte de Ombro]" e "Se faz uso de dispositivo auxiliar [Tipoia]" para cada paciente, para o modelo prognóstico de força muscular avaliada sobre rotação externa do ombro. . . . 70

6.22 Contribuição dos valores dos atributos "Já fez alguma cirurgia do plexo braquial?" e "Qual o lado operado?" para cada paciente, para o modelo prognóstico de força muscular avaliada sobre rotação externa do ombro. . . . . . . . . . . . . . . . 71

6.23 Contribuição dos valores do atributo "Força muscular avaliada sobre abdução do ombro" para cada paciente, para o modelo prognóstico de força muscular avaliada sobre rotação externa do ombro. . . . . . . . . . . . . . . . . . . 71

6.24 Contribuição dos valores do atributo "Evento que levou ao trauma [Moto]" para cada paciente, para o modelo prognóstico de força muscular avaliada sobre rotação externa do ombro. . . . . . . . . . . . . . . . . . . . . . 72

6.25 Valores de contribuição dos atributos de um dos pacientes do INDC para o modelo prognóstico de dor. . . . . . . . . . . . . . . . . . . . . . 74

6.26 Valores de contribuição dos atributos de um dos pacientes do INDC para o modelo prognóstico de força muscular avaliada sobre abdução do ombro. . . . . . . . . . 75

6.27 Valores de contribuição dos atributos de um dos pacientes do INDC para o modelo prognóstico de força muscular avaliada sobre flexão do cotovelo. . . . . . . . . . 76

6.28 Valores de contribuição dos atributos de um dos pacientes do INDC para o modelo prognóstico de força muscular avaliada sobre rotação externa do ombro. . . . . . . . 77 


\section{Lista de Tabelas}

2.1 Matriz de Confusão para uma determinada classe $Y_{K}$ e um classificador $h$ sobre instâncias $\boldsymbol{x}$. . . . . . . . . . . . . . . . . . . . . . . . . . . . . . . . . . . . . . . . . 9

2.2 Exemplo fictício de conjunto de treinamento para a criação de um modelo preditivo de hipertensão em pacientes. . . . . . . . . . . . . . . . . . . . . . . . . . . . . . 13

2.3 Repartição do conjunto de treinamento de acordo com cada valor do atributo "Sexo". 14

2.4 Repartição do conjunto de treinamento comparando o valor do atributo "Idade" com o valor médio 31. . . . . . . . . . . . . . . . . . . . . . . . . . . . . . . . . 15

2.5 Instâncias no subconjunto resultante pela partição sobre "Exercício?" = Não. . . . 15

2.6 Repartição do conjunto de treinamento comparando o valor do atributo "Peso" com o valor médio 71. . . . . . . . . . . . . . . . . . . . . . . . . . . 16

5.1 Desempenho dos modelos criados sobre os dados dos pacientes do INDC para as abordagens C4.5 e MVB, em termos de acurácia média (e seu desvio padrão), precisão, cobertura e medida-F, considerando "Insatisfatório" como a classe positiva. . . . . . . 43

5.2 Desempenho dos modelos criados sobre os dados dos pacientes do INDC para as abordagens C4.5 e MVB, em termos de precisão, cobertura e medida-F, considerando "Sucesso" como a classe positiva. . . . . . . . . . . . . . . . . . . . . . . . . 43

5.3 Exemplo de junção de preenchimentos de diferentes pacientes para as questões "Qual o lado da lesão?" (Lado da lesão), "Força muscular avaliada sobre o lado esquerdo: Flexão de Punho" (Flexão de Punho Esquerdo) e "Força muscular avaliada sobre o lado direito: Flexão de Punho" (Flexão de Punho Direito) do questionário de Avaliação de Entrada. . . . . . . . . . . . . . . . . . . . . . . . . . . . . . . . . 46

5.4 Exemplo de unificação de preenchimentos de um mesmo paciente para as questões "Intervalo de tempo entre a lesão e a cirurgia" (Intervalo de tempo), "Procedimento realizado: Neurólise" (Procedimento: Neurólise) e "Procedimento realizado: Enxertia" (Procedimento: Enxertia) do questionário de Avaliação Cirúrgica. . . . . . . . . . . . 47

5.5 Categorias resultantes da transformação de atributos numéricos para categorizados para os campos referentes ao exame físico de amplitude de cada movimento. . . . . . 48

5.6 Número de instâncias, de atributos, de casos "Sucesso" e "Insatisfatório", e proporções de valores faltantes resultantes da transformação dos arquivos dos questionários de entrada, cirúrgico e de seguimento para prognóstico de dor, abdução do ombro (AbdOmbro), flexão do cotovelo (FlexCotovelo) e rotação externa do ombro (RotEOmbro). 49 
5.7 Acurácias médias (e seus respectivos desvios-padrão) dos modelos prognósticos de Dor, abdução do ombro (AbdOmbro), flexão do cotovelo (FlexCotovelo) e rotação externa do ombro (RotEOmbro), calculadas utilizando o método LOOCV. . . . . . . 50

5.8 Lista dos métodos e dos parâmetros utilizados na obtenção dos resultados da Tabela 5.750

6.1 Desempenho do modelo prognóstico de dor, em termos de acurácia média (e seu desvio padrão), precisão, cobertura e medida-F, considerando as respectivas classes como positivas. . . . . . . . . . . . . . . . . . . . . 60

6.2 Desempenho do modelo prognóstico de força avaliada sobre abdução do ombro, em termos de acurácia média (e seu desvio padrão), precisão, cobertura e medida-F, considerando as respectivas classes como positivas.

6.3 Desempenho do modelo prognóstico de força avaliada sobre flexão do cotovelo, em termos de acurácia média (e seu desvio padrão), precisão, cobertura e medida-F, considerando as respectivas classes como positivas. . . . . . . . . . . . . . . 68

6.4 Desempenho do modelo prognóstico de força avaliada sobre rotação externa do ombro, em termos de acurácia média (e seu desvio padrão), precisão, cobertura e medidaF, considerando as respectivas classes como positivas. . . . . . . . . . . . . . 72

7.1 Acurácia dos modelos prognósticos de dor e de forças musculares avaliadas sobre abdução do ombro (AbdOmbro), flexão do cotovelo (FlexCotovelo) e rotação externa do ombro (RotEOmbro) . . . . . . . . . . . . . . . . . . . . . 7 


\section{Capítulo 1}

\section{Introdução}

No período entre janeiro e dezembro de 2017, motocicletas foram responsáveis por 285.662 sinistros registrados pela seguradora Líder-DPVAT, correspondendo a $74 \%$ das indenizações pagas no ano, apesar de representarem apenas $27 \%$ da frota nacional de veículos. Desses sinistros, $79 \%$ foram relativos a casos de invalidez permanente, $14 \%$ a despesas médicas e $7 \%$ a casos de morte. Em relação aos acidentes de motocicleta que levaram a sequelas permanentes, $75 \%$ ocorreram em pessoas de 18 a 44 anos de idade - o que compreende a juventude e parte da população economicamente ativa [DPV17].

Uma vez que acidentes de motocicleta são os principais causadores de lesões do plexo braquial, a alta frequência desses acidentes acarreta um aumento no número de indivíduos com esse tipo de lesão $\left[\mathrm{FSM}^{+} 14\right]$.

O plexo braquial, ilustrado na Figura 1.1, corresponde a um conjunto de nervos que inervam os membros superiores e é responsável pela motricidade e sensibilidade dos braços, antebraços e mãos. Quando lesionado, pode resultar em fraqueza, perda de sensibilidade, dor e prejuízo funcional $\left[\mathrm{RCGFCP}^{+} 14\right]$. Essas limitações podem comprometer diversas atividades profissionais, do dia-a-dia ou de lazer, provocando frequentemente consequências emocionais, sociais e econômicas [dA15].

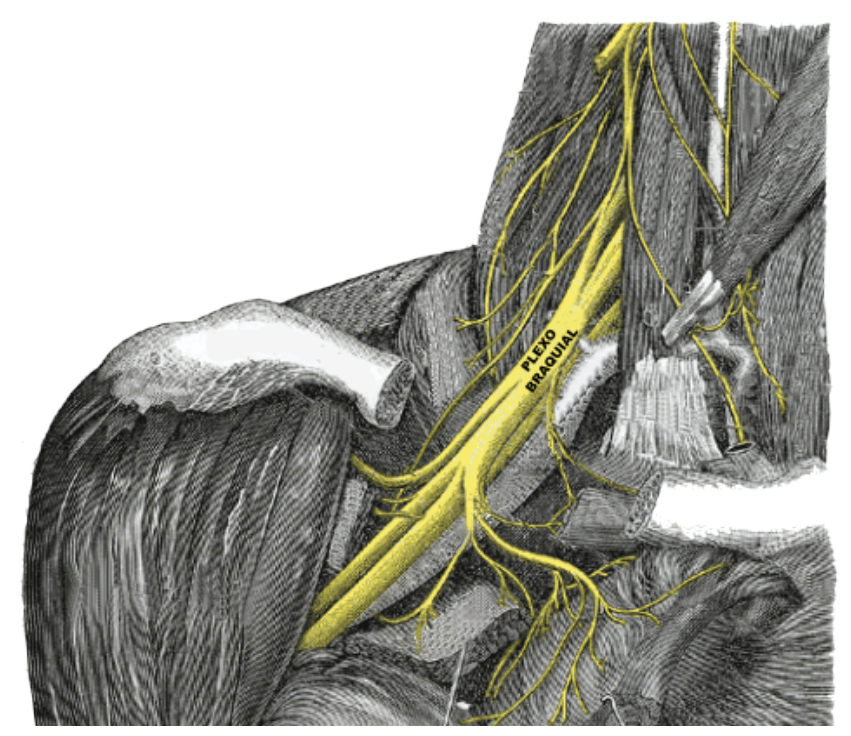

Figura 1.1: Ilustração do plexo braquial, destacado em amarelo. Adaptado de [GL18].

Devido à não familiaridade dos profissionais da saúde em geral com esse tipo de lesão, por vezes os pacientes são encaminhados para centros especializados tardiamente, o que diminui suas chances de recuperação [vDSTS93].

Uma vez que ainda não existem modelos preditores prognósticos bem definidos para lesões traumáticas do plexo braquial em adultos (LTPBA), uma ferramenta capaz de identificá-los a partir 
da análise de dados clínicos e sociodemográficos de pacientes, bem como de estimar a evolução da lesão, poderia auxiliar profissionais da saúde no planejamento do tratamento mais adequado, visando aumentar as chances de sua recuperação.

\subsection{Contexto e Motivação}

O Instituto de Neurologia Deolindo Couto (INDC) da Universidade Federal do Rio de Janeiro (UFRJ) conduz pesquisas que visam amparar progressos no tratamento de patologias do sistema nervoso. Em particular, em um projeto com colaboração do Centro de Pesquisa, Inovação e Difusão em Neuromatemática - NeuroMat [Neu] (sediado no IME-USP), o INDC-UFRJ vem estudando a plasticidade do cérebro humano no contexto de tratamentos de reabilitação de pacientes com LTPBA.

No banco de dados do INDC, os pacientes são caracterizados por atributos sociodemográficos e clínicos e também por diferentes tipos de medidas eletrofisiológicas (como, por exemplo, sinais de Eletroencefalografia e de Eletromiografia). Os dados clínicos são obtidos por meio do preenchimento de fichas de avaliação, desenvolvidas por uma equipe multidisciplinar no formato de questionários eletrônicos. A partir da análise dos dados dos pacientes do INDC, deseja-se criar modelos prognósticos de lesões do plexo braquial em adultos.

O termo prognóstico é comumente utilizado no domínio clínico para se referir à predição do curso de uma lesão ou doença e suas chances de recuperação. Esse procedimento é realizado tipicamente por um profissional da saúde, que se baseia em dados da literatura, experiência prévia e julgamento pessoal. Entretanto, o emprego de modelos prognósticos clínicos podem automatizar parte desse processo, auxiliando os profissionais da saúde a tomarem decisões mais precisas e menos enviesadas, baseando-se em dados de pacientes cujos resultados de recuperação são conhecidos [Vog09]. Esses modelos também podem ser úteis para encontrar, de maneira automática, possíveis preditores da resposta de recuperação dos pacientes.

Um modelo prognóstico pode ser criado por meio de técnicas de Mineração de Dados e Aprendizado de Máquina, de forma que a partir da análise de dados de pacientes cuja recuperação da doença alvo do modelo é conhecida, seja possível estimar a recuperação de novos pacientes diagnosticados $\left[\mathrm{RCK}^{+} 11\right]$. O bom desempenho dessas técnicas depende da disponibilização de um grande volume de dados confiáveis para análise, caracterizados por uma quantidade suficientemente menor de atributos. Entretanto, ao contrário de muitos outros domínios, os conjuntos de dados disponíveis no domínio clínico são em geral pequenos. Por exemplo, os dados do INDC são provenientes de 109 pacientes, dos quais apenas 44 possuem dados relativos ao prognóstico da lesão, e são caracterizados por centenas de atributos.

Assim, um dos principais desafios enfrentados na criação de modelos prognósticos utilizando técnicas de Aprendizado de Máquina consiste na adaptação e utilização de métodos que possibilitem lidar com a insuficiência do número de pacientes cujos dados estão disponíveis para análise e, ao mesmo tempo, com o grande volume de atributos candidatos a preditores que os caracterizam [BZ08].

Além disso, uma característica bastante importante que deve ser considerada na criação de modelos prognósticos é a transparência do modelo. Para que possam ser utilizados na prática por profissionais da saúde, esses modelos devem deixar explícitos os fatores que os levaram a uma determinada predição, que devem ser clinicamente coerentes para que os resultados possam ser utilizados no processo de tomada de decisão [WA95]. Esse requisito impõe restrições em termos da escolha das técnicas que podem ser aplicadas, uma vez que algumas delas são consideradas geradoras de modelos caixa-preta, ou então demandam o entendimento e o uso de métodos complementares que possibilitem a interpretação de seus modelos. 


\subsection{Objetivos}

O objetivo principal deste projeto de mestrado é utilizar métodos de Mineração de Dados e técnicas de Aprendizado de Máquina (em particular, Florestas Aleatórias) para a criação de modelos prognósticos de LTPBA, visando também encontrar os possíveis preditores do curso da lesão. Até o momento, não foram desenvolvidos modelos desse tipo no domínio de LTPBA.

Com o auxílio de neurocientistas e profissionais da área médica envolvidos neste projeto, foi definida a criação de quatro modelos prognósticos, visando os objetivos de recuperação de dor, recuperação de força muscular avaliada sobre abdução do ombro, recuperação de força muscular avaliada sobre flexão do cotovelo e recuperação de força muscular avaliada sobre rotação externa do ombro.

Assim, para a criação desses modelos prognósticos e a identificação de seus preditores, podemos sumarizar os objetivos deste projeto por:

- Utilização e adaptação da técnica de Florestas Aleatórias sobre os dados dos pacientes do INDC para a criação de quatro modelos prognósticos de LTPBA;

- Aplicação de métodos de interpretação de Floresta Aleatórias a fim de encontrar os preditores do curso de LTPBA em relação aos quatro fatores;

- Avaliação do desempenho dos modelos obtidos utilizando métodos que viabilizem sua utilização sobre dados caracterizados por um número reduzido de instâncias.

\subsection{Contribuições}

As principais contribuições pretendidas neste trabalho são:

- Criação de quatro modelos prognósticos de LTPBA utilizando Florestas Aleatórias e métodos de Mineração de Dados, para que possam ser utilizados futuramente em um sistema de apoio à decisão clínica;

- Identificação de preditores do curso de LTPBA;

- Adaptação da técnica de Florestas Aleatórias para viabilizar sua aplicação sobre dados caracterizados pela presença de valores faltantes, que é um aspecto presente nos dados do INDC;

- Implementação de métodos desenvolvidos para a interpretação dos modelos gerados por Florestas Aleatórias, visando sua transparência.

Foram criados quatro modelos prognósticos - um para cada objetivo de recuperação, sendo eles a ausência de dor e forças satisfatórias avaliadas sobre abdução do ombro, flexão do cotovelo e rotação externa no ombro.

Por meio de um método de interpretação de Florestas Aleatórias, foram identificados os atributos mais importantes em cada modelo. O fator mais relevante apontado para o prognóstico de recuperação de força sobre abdução do ombro foi o trauma ter sido causado por acidente de moto, enquanto que para os modelos de força avaliada sobre flexão de cotovelo e rotação externa do ombro foram apontados como mais importantes os atributos relativos ao uso de tipoia e de suporte de ombro e à força avaliada sobre seus movimentos na primeira avaliação feita no INDC. Já para o modelo relativo à dor, o atributo identificado como o mais relevante foi a constatação de presença de dor pelos pacientes quando chegam ao INDC logo pela primeira vez. As acurácias dos modelos foram estimadas entre $77 \%$ e $88 \%$, utilizando o método de validação cruzada leave-one-out frequentemente utilizado sobre dados de poucas instâncias.

Esses modelos evoluirão com a inclusão de novos dados, provenientes da contínua chegada de novos pacientes em tratamento no INDC, e serão utilizados como parte de um sistema de apoio à decisão clínica. 


\subsection{Organização do Trabalho}

Este trabalho está organizado da seguinte forma:

- O Capítulo 2 apresenta os principais conceitos relacionados a este trabalho, que se referem às áreas de Mineração de Dados e à técnica de Florestas Aleatórias, bem como à criação e validação de Modelos Prognósticos sob uma perspectiva computacional;

- O Capítulo 3 discute trabalhos relacionados ao contexto de modelos prognósticos computacionais clínicos, que foram utilizados para identificar precauções e dificuldades envolvidas no processo;

- O Capítulo 4 contém uma visão geral sobre os dados do INDC-UFRJ utilizados neste projeto;

- No Capítulo 5 a proposta desenvolvida neste projeto de mestrado é descrita, incluindo o método e as formas de avaliação que foram utilizadas;

- O Capítulo 6 apresenta os resultados da aplicação dos métodos desenvolvidos neste projeto;

- Por fim, o Capítulo 7 contém considerações finais sobre os resultados obtidos neste trabalho, bem como sobre suas limitações e possíveis trabalhos futuros relacionados. 


\section{Capítulo 2}

\section{Conceitos}

Neste projeto, visamos criar modelos prognósticos de lesões traumáticas do plexo braquial em adultos (LTPBA) utilizando técnicas de Mineração de Dados e Aprendizado de Máquina, de forma a encontrar de maneira automática os possíveis preditores de recuperação de pacientes.

Assim, apresentamos as principais terminologias e técnicas de Mineração de Dados e Aprendizado de Máquina utilizadas neste projeto na Seção 2.1. Na seção 2.2, apresentamos os conceitos relacionados a prognóstico clínico sob uma perspectiva computacional.

\subsection{Mineração de Dados}

Segundo Berry e Linoff [BL97], mineração de dados pode ser definida como "a exploração e análise de uma grande quantidade de dados com o objetivo de descobrir padrões e regras significativos". Alguns autores utilizam o termo como sinônimo de Descoberta de Conhecimento em Bancos de Dados (do inglês Knowledge Discovery in Databases - KDD), enquanto outros definem mineração de dados como um dos passos envolvidos no processo de descoberta de conhecimento [FPsS96]. Independente do termo e definição utilizados, o processo de exploração e análise de dados é composto por uma sequência iterativa dos seguintes passos [Han05]:

1. Compreensão do domínio. A primeira fase envolve o entendimento e levantamento de conceitos e conhecimentos prévios envolvidos no domínio ao qual se deseja aplicar o processo de $K D D$, bem como a delimitação de seu objetivo e requisitos.

2. Seleção. Nessa etapa, deve-se identificar e selecionar os dados relevantes a serem considerados no problema, que podem vir de diferentes fontes e possuir diferentes formatos.

3. Limpeza e pré-processamento. Dados são suscetíveis a inconsistências, ruídos (erros ou variâncias em valores de dados) e incompletude (ausência de valores), devido a erros de digitação, mensuração ou transmissão de dados, principalmente quando são volumosos ou originados de diferentes fontes. Uma vez que a qualidade dos dados interfere diretamente na eficiência dos algoritmos de mineração, deve-se aplicar técnicas de limpeza de dados e de pré-processamento para tratar esses problemas nos dados antes de usá-los na mineração.

4. Transformação. Para que possam ser utilizados pelos algoritmos de mineração, os dados devem ser armazenados e formatados de forma adequada, originando atributos que os caracterizam.

5. Mineração de dados. Essa fase se inicia com a escolha do método de mineração de dados a ser utilizado, que deve ser feita com base no domínio e no objetivo do processo de descoberta de conhecimento delimitado na etapa 1 . Podem ser utilizados métodos de sumarização, classificação, regressão, entre outros. Após a definição do método, deve ser feita a escolha de uma técnica que permita a descoberta de conhecimento a partir dos dados, além da exploração de seus modelos e de parâmetros que podem ser utilizados, visando atender os requisitos do 
domínio. A técnica escolhida pode pertencer a diferentes áreas, como Estatística, Reconhecimento de Padrões, Recuperação de Informação, Aprendizado de Máquina, entre outras. Por fim, ocorre a aplicação da técnica escolhida de forma a buscar por padrões, correlações ou regras significativos a partir dos dados.

6. Avaliação. O resultado obtido na etapa 5 deve ser interpretado e avaliado, frequentemente com o auxílio dos especialistas do domínio. Isso pode envolver a visualização dos padrões ou correlações encontrados ou dos modelos obtidos. O processo pode voltar a qualquer um dos estágios anteriores caso, por exemplo, o resultado não seja satisfatório.

O processo de $K D D$ pode envolver iterações significativas e ciclos entre etapas. Seu fluxo básico segue a representação ilustrada na Figura 2.1.

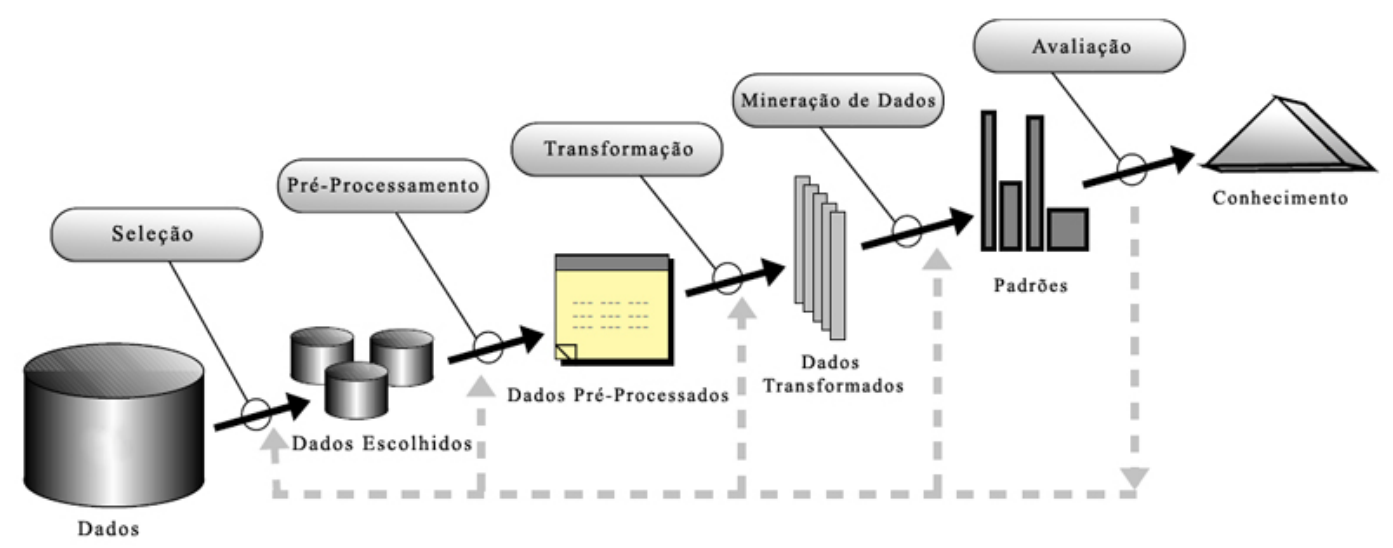

Figura 2.1: Representação do fluxo básico das etapas do processo de KDD [FPsS96]. Extraído de [COC09].

\subsubsection{Aprendizado de Máquina}

A área de Aprendizado de Máquina se concentra na construção de programas de computadores que aprendem (i.e., automaticamente melhoram seu desempenho) a partir da análise de dados e, desse modo, suas técnicas são bastante utilizadas no contexto de Mineração de Dados [Han05, Mit97].

Um problema de aprendizado tipicamente envolve os seguintes elementos [SSBD14, AMMIL12]:

- $\boldsymbol{x}$ : uma instância ou um dado de entrada, representada por um vetor $\boldsymbol{x}=\left[x_{1}, x_{2}, \ldots, x_{N}\right]$ de dimensão $N$, em que cada $x_{j}$ é denominado atributo de $\boldsymbol{x}$, com $1 \leq j \leq N$.

- $\mathcal{X}_{j}$ : domínio de um atributo $x_{j}$, com $1 \leq j \leq N$, sendo $N$ a dimensão dos dados de entrada.

$-x_{j} \in \mathcal{X}_{j}$ é denominado atributo numérico discreto se $\mathcal{X}_{j}$ corresponder a um conjunto numérico discreto (por exemplo, $\mathcal{X}_{j}=\mathbb{N}$ ), e é denominado atributo numérico contínuo se $\mathcal{X}_{j}$ corresponder a um conjunto numérico contínuo (por exemplo, $\mathcal{X}_{j}=\mathbb{R}$ ).

$-x_{j} \in \mathcal{X}_{j}$ é denominado atributo categorizado se $\mathcal{X}_{j}$ corresponder a um conjunto finito e discreto composto por cadeias de símbolos. Ainda, um atributo categorizado pode ser nominal se os valores de seu domínio não apresentarem ordem (por exemplo, $x_{j}$ representando um atributo Cor e $\mathcal{X}_{j}=\{$ Amarelo, Azul $\}$ ), ou ordinal se os valores de $\mathcal{X}_{j}$ admitirem ordenação, permitindo comparações de desigualdade da forma "menor que" e "maior que" (por exemplo, $x_{j}$ representando Educação, com $\mathcal{X}_{j}=\{$ Fundamental, Médio, Superior\}).

- $\mathcal{X}$ : domínio de $\boldsymbol{x}$, dado por $\mathcal{X}=\mathcal{X}_{1} \times \mathcal{X}_{2} \times \cdots \times \mathcal{X}_{N}$, em que $N$ é a dimensão de $\boldsymbol{x}$ e $\mathcal{X}_{j}$ corresponde ao domínio de cada atributo $x_{j}$ de $\boldsymbol{x}$, com $1 \leq j \leq N$.

- Y : domínio dos dados de saída, ou conjunto de rótulos; 
- D: conjunto composto por $M$ dados de entrada, intitulado conjunto de treinamento. Cada elemento de $\mathcal{D}$ é denominado instância de treinamento. As técnicas de aprendizado de máquina podem ser classificadas levando em conta a estrutura desse conjunto:

- Técnicas de aprendizado supervisionado: recebem um conjunto de entrada da forma $\mathcal{D}=$ $\left\{\left(\boldsymbol{x}_{1}, y_{1}\right),\left(\boldsymbol{x}_{2}, y_{2}\right), \ldots,\left(\boldsymbol{x}_{M}, y_{M}\right)\right\}$, com $\left(\boldsymbol{x}_{i}, y_{i}\right) \in \mathcal{X} \times \mathcal{Y}$, em que cada $y_{i}$ é denominado rótulo de $\boldsymbol{x}_{i}$, com $1 \leq i \leq M$.

- Técnicas de aprendizado não supervisionado: recebem um conjunto de entrada da forma $\mathcal{D}=\left\{\boldsymbol{x}_{1}, \boldsymbol{x}_{2}, \ldots, \boldsymbol{x}_{M}\right\}$ (dados não rotulados), com $\mathcal{D} \subseteq \mathcal{X}$.

Como definido anteriormente, $\boldsymbol{x}_{i}$ corresponde a um dado de entrada representado por um vetor de atributos de dimensão $N$, da forma $\boldsymbol{x}_{i}=\left[x_{i, 1}, x_{i, 2}, \ldots, x_{i, N}\right]$, com $1 \leq i \leq M \mathrm{e}$ $x_{i, j} \in \mathcal{X}_{j}, \operatorname{com} 1 \leq j \leq N$

- $h: \mathcal{X} \rightarrow \mathcal{Y}$ : função a ser utilizada pelo algoritmo para rotular novas instâncias ao final do processo de aprendizado, também denominada hipótese, preditor ou modelo ${ }^{1}$. A hipótese é selecionada a partir de um conjunto $\mathcal{H}$ de hipóteses candidatas que podem ser consideradas pelo algoritmo de aprendizado, com base no conjunto $\mathcal{D}$ de dados de treinamento.

- $f: \mathcal{X} \rightarrow \mathcal{Y}$ : função alvo desconhecida a qual se deseja aprender ou aproximar, de forma que, no contexto de técnicas de aprendizado supervisionado, $f\left(\boldsymbol{x}_{i}\right)=y_{i}, \forall\left(\boldsymbol{x}_{i}, y_{i}\right) \in \mathcal{D}$, com $1 \leq i \leq M$.

\subsubsection{Classificação}

A classificação é uma subárea de Aprendizado de Máquina que compreende técnicas de aprendizado supervisionado, em que os rótulos dos dados de treinamento pertencem a um domínio discreto e finito pré-definido $\mathcal{Y}=\left\{Y_{1}, Y_{2}, \ldots, Y_{K}\right\}$ e são denominados de classes. Dessa forma, a tarefa de um classificador consiste em predizer a classe $\hat{y} \in \mathcal{Y}$ de uma instância $\boldsymbol{x}$ não rotulada $(h(\boldsymbol{x})=\hat{y})$ [ZJ14].

\subsubsection{Validação do Modelo}

Um fator importante a ser considerado em um problema de classificação é a validação do modelo gerado pelo algoritmo, de forma a avaliar sua aproximação, definida como a capacidade de rotular instâncias de treinamento corretamente, e sua generalização, que corresponde à habilidade de rotular corretamente instâncias que diferem das utilizadas na construção do modelo (ou seja, que não pertencem ao conjunto de treinamento) [AMMIL12].

Quando um modelo apresenta uma boa aproximação quando aplicado ao conjunto de treinamento, mas uma má generalização (baixa porcentagem de acerto quando aplicado a dados diferentes das instâncias de treinamento), dizemos que ocorre sobreajuste (do inglês overfitting), o que é indesejável uma vez que a utilidade do modelo na prática depende de seu desempenho sobre dados não analisados previamente. Isso pode ocorrer quando o modelo se ajusta aos ruídos existentes nos dados, quando o conjunto de treinamento não é suficientemente representativo para o domínio ou quando o volume de dados no conjunto de treinamento é muito pequeno [Dom12].

Uma forma de estimar a generalização de um modelo consiste em separar o conjunto $\mathcal{D}$ de treinamento de tamanho $M$ em duas partes disjuntas: um conjunto $\mathcal{D}_{\text {treino }}$ contendo instâncias de treinamento e um conjunto $\mathcal{D}_{\text {teste }}$ com $S$ elementos da forma $\left(\boldsymbol{x}_{s}, y_{s}\right)$. O conjunto $\mathcal{D}_{\text {treino será }}$ utilizado pelo algoritmo para a construção do modelo no que chamamos de fase de treinamento. Em seguida, no que denominamos fase de teste, as instâncias $\boldsymbol{x}_{s}$ de $\mathcal{D}_{\text {teste }}$ serão aplicadas ao modelo $h$, de modo que seja calculada a taxa de acerto $A(h)$ (também chamada de acurácia). A computação dessa taxa é feita comparando os rótulos originais $y_{s}$ de $\boldsymbol{x}_{s}$ aos rótulos $\hat{y}_{s}=h\left(\boldsymbol{x}_{s}\right)$, com $s \in\{i$ :

\footnotetext{
${ }^{1}$ Apesar de serem conceitualmente diferentes [AMMIL12], os termos modelo e hipótese são frequentemente usados como sinônimos [Han05].
} 
$1 \leq i \leq M$ e $\boldsymbol{x}_{i} \in \mathcal{D}_{\text {teste }}$, de forma que $A(h)$ expresse uma estimativa para a capacidade de generalização do modelo. O cálculo é feito da seguinte forma [AMMIL12]:

$$
A(h)=\frac{1}{S}\left|\left\{(\boldsymbol{x}, y) \in \mathcal{D}_{\text {teste }}: h(\boldsymbol{x})=y\right\}\right| .
$$

Essa abordagem permite uma boa estimativa da capacidade de generalização do modelo, entretanto, além de depender de uma divisão representativa dos dados entre os conjuntos de treino e teste, reduzir o número de instâncias de treinamento para utilizá-las no conjunto de teste pode resultar em um modelo inferior em termos de generalização e aproximação em domínios cujo volume de dados disponíveis é pequeno [RTL09].

Para contornar esse problema, uma alternativa consiste em utilizar o método de validação cruzada $k$-fold. Nesse método, o conjunto $\mathcal{D}$ de treinamento é inicialmente dividido em $k$ conjuntos disjuntos, $\mathcal{D}_{1}, \mathcal{D}_{2}, \ldots, \mathcal{D}_{k}$, de aproximadamente mesmo tamanho, e em seguida são executadas $k$ iterações de treinamento e teste. Na iteração $l, 1 \leq l \leq k$, é construído um modelo $h_{l}$ considerando $\mathcal{D}-\mathcal{D}_{l}$ como conjunto de treinamento e, na fase de teste, a acurácia $A\left(h_{l}\right)$ do modelo é calculada sobre $\mathcal{D}_{l}$, que nesse contexto chamamos de conjunto de validação. Assim, a acurácia do modelo $h$ é calculada considerando a média das acurácias de cada iteração do processo de validação cruzada [Han05]. As equações são dadas por:

$$
\begin{gathered}
A\left(h_{l}\right)=\frac{1}{\left|\mathcal{D}_{l}\right|}\left|\left\{(\boldsymbol{x}, y) \in \mathcal{D}_{l}: h_{l}(\boldsymbol{x})=y\right\}\right|, \mathrm{e} \\
A(h)=\frac{1}{k} \sum_{l=1}^{k} A\left(h_{l}\right) .
\end{gathered}
$$

Contudo, a acurácia calculada por essa abordagem é uma estimativa relativamente otimista para a generalização, sendo em geral, menos fiável do que quando calculada pelo método anterior.

O método de validação cruzada leave-one-out cross validation (LOOCV) [RTL09], é um caso especial de validação cruzada $k$-fold quando $k=M$, sendo $M$ o número de instâncias no conjunto $\mathcal{D}$. Nesse caso, apenas uma instância é utilizada no conjunto de validação em cada iteração, e sendo assim, sua utilização é viável em domínios cujo volume de dados disponíveis é escasso.

Por outro lado, em aplicações cujos dados não apresentam balanceamento de classes (por exemplo, $90 \%$ das instâncias pertencem a uma determinada classe e apenas $10 \%$ pertencem à outra), um modelo que classifica todas as instâncias como pertencentes à classe majoritária apresenta um ótimo desempenho segundo a métrica de acurácia, o que é indesejável. Para esses casos, existem outras formas de estimar o desempenho de um classificador que podem ser aplicadas, como as métricas precisão, cobertura (ou sensibilidade), medida-F (F-Score) e AUC (do inglês Area Under the Curve - área sob a curva), que avaliam o erro de predição dos classificadores considerando em seu cálculo as classes das instâncias [Han05].

Essas métricas utilizam os conceitos de "verdadeiros positivos", "verdadeiros negativos", "falsos positivos" e "falsos negativos" com relação a uma determinada classe $Y \in \mathcal{Y}$. Os casos verdadeiros positivos (VP) correspondem às instâncias que foram atribuídas à classe $Y$ pelo classificador e cujo rótulo verdadeiramente pertence a essa classe, enquanto que os falsos positivos $(\mathrm{FP})$ correspondem às instâncias atribuídas à classe $Y$ e que possuem rótulo pertencente a uma outra classe. Similarmente, os verdadeiros negativos (VN) correspondem às instâncias que pertencem a uma classe diferente de $Y$ e que não foram atribuídas a $Y$ pelo classificador, ao passo que os falsos negativos (FN) correspondem àquelas que pertencem a $Y$ mas foram classificadas pelo modelo como pertencentes a uma classe diferente. A Tabela 2.1 apresenta a matriz de confusão (ou tabela de contingência) que sumariza esses elementos.

Considerando esses conceitos, a métrica de precisão $(P)$ representa o quanto o modelo classifica corretamente as instâncias classificadas como $Y$, enquanto que a métrica de cobertura $(C)$ está relacionada à eficácia do classificador em identificar as instâncias que pertencem à classe $Y$ [SL09]. 


\begin{tabular}{|l|c|c|}
\hline & $\boldsymbol{h}(\boldsymbol{x})=\boldsymbol{Y}$ & $\boldsymbol{h}(\boldsymbol{x}) \neq \boldsymbol{Y}$ \\
\hline $\boldsymbol{f}(\boldsymbol{x})=\boldsymbol{Y}$ & VP & FN \\
\hline $\boldsymbol{f}(\boldsymbol{x}) \neq \boldsymbol{Y}$ & FP & VN \\
\hline
\end{tabular}

Tabela 2.1: Matriz de Confusão para uma determinada classe $Y_{K}$ e um classificador h sobre instâncias $\boldsymbol{x}$.

Assim, temos:

$$
P=\frac{V P}{V P+F P} \text { e } C=\frac{V P}{V P+F N} .
$$

A medida-F, por sua vez, consiste em uma média harmônica das medidas de predição e cobertura, tipicamente dada por:

$$
\text { medida- } \mathrm{F}=\frac{2 P C}{P+C} .
$$

Por fim, a métrica $A U C$ avalia a habilidade do classificador de evitar casos falsos positivos e falsos negativos, sendo calculada por:

$$
A U C=\frac{1}{2}\left(\frac{V P}{V P+F N}+\frac{V N}{V N+F P}\right) .
$$

\subsubsection{Seleção de Atributos}

A quantidade de dados disponíveis para análise e sua dimensionalidade são outros fatores importantes a serem considerados em um problema de classificação. O bom desempenho de uma técnica de classificação em termos de generalização depende do volume de dados (i.e., quantidade de instâncias) que pode ser utilizado na fase de treinamento. Utilizar uma quantidade pequena de instâncias que são representadas por uma quantidade grande de atributos para a aplicação de uma técnica de classificação acarreta no sobreajuste do modelo e, consequentemente, baixa generalização. Tipicamente, é necessário um número de instâncias muito maior do que o número de atributos utilizados para representá-las, a fim de se construir um bom modelo em termos de generalização [FZTKN12].

Dessa forma, em domínios cujos dados disponíveis são poucos e os atributos que os representam são numerosos, pode ser necessária a redução da dimensionalidade das instâncias a partir de um processo manual (quando, por exemplo, os especialistas do domínio possuem conhecimento prévio de quais atributos são relevantes para o problema) ou automático, como a aplicação de técnicas de transformação de dados (como, por exemplo, Análise de Componentes Principais) ou de seleção de atributos. Além de favorecer a construção de um modelo com melhor capacidade de generalização, a redução de dimensionalidade possibilita um melhor entendimento e visualização dos dados, bem como reduz a quantidade de recursos necessários para armazenamento e processamento dos dados.

O uso de técnicas de transformação de dados para redução de dimensionalidade, de modo geral, apresenta um alto custo computacional e pode alterar a representação original dos dados. Dessa forma, o uso de técnicas de seleção de atributos costuma ser preferível [SIL07].

Técnicas de seleção de atributos buscam encontrar, de forma automática, um subconjunto tipicamente pequeno de atributos mais relevantes para a construção de um bom modelo, a partir do conjunto total de atributos dos dados do problema. Elas essencialmente podem ser classificadas em três tipos [GE03]:

- Filtros: selecionam um subconjunto de variáveis consideradas relevantes, segundo um determinado critério, em uma etapa de pré-processamento. São independentes do tipo de técnica a ser utilizada na criação do modelo, uma vez que o classificador receberá como entrada o conjunto de dados já reduzidos aos atributos selecionados pelo filtro. Esse tipo de método tipicamente ignora interações entre atributos, o que pode levar à exclusão de variáveis que são de fato relevantes. 
- Invólucros (do inglês wrappers): a seleção de atributos é feita utilizando a técnica de classificação escolhida. De modo geral, nesse tipo de técnica calcula-se o desempenho do classificador sobre vários subconjuntos de atributos, sendo selecionado o subconjunto que levou ao melhor desempenho. Esse tipo de método pode apresentar um alto custo computacional, além de um risco maior de produzir modelos que sofrem de sobreajuste.

- Embutidos (do inglês embedded): a seleção é feita implicitamente pela técnica de classificação utilizada no processo de treinamento. Esses métodos são mais eficientes computacionalmente, além de permitir que se utilize todos os dados de treinamento no processo, uma vez que não é necessário separar conjuntos de teste ou validação para calcular o desempenho do classificador em cada passo. Entretanto, são específicos a determinadas técnicas de classificação (e.g., Árvores de Decisão).

Assim, a escolha do método de seleção de atributos a ser utilizado deve levar em conta a natureza dos dados e, por vezes, a própria técnica de classificação escolhida.

\subsubsection{Dados Faltantes}

Um outro problema enfrentado com frequência em aplicações que utilizam dados reais é a criação de um modelo a partir de um conjunto de dados que possui valores desconhecidos. Valores faltantes podem ocorrer por diversos motivos, como pelo mal funcionamento de um equipamento utilizado para registrar os dados, pela adição de novos atributos (de forma que apenas instâncias coletadas mais recentemente possuam valores para eles), pela não aplicabilidade do atributo a uma determinada instância, entre outros [Bra13].

Considere um conjunto de dados $X$ de $M$ instâncias e $N$ atributos, e que possui valores faltantes. Para uma instância $\boldsymbol{x} \in X$, considere $\boldsymbol{x}_{\text {obs }}$ uma partição dos atributos de $\boldsymbol{x}$ cujos valores são todos observados (i.e., não faltantes) e $\boldsymbol{x}_{\text {falt }}$ uma partição cujos valores são faltantes, de forma que $\boldsymbol{x}=\left(\boldsymbol{x}_{\mathrm{obs}}, \boldsymbol{x}_{\mathrm{falt}}\right)$. Ainda, seja $R$ um vetor indicador em que cada entrada $R_{j}$ vale 1 se $x_{j}$ corresponde a um valor faltante em $\boldsymbol{x}$ e 0 caso contrário, $j \in\{1, \ldots, N\}$.

Considerando esses conceitos, pode-se classificar a ausência de valores em uma instância em três tipos [HHUS14, SG02]:

- Completamente aleatória (missing completely at random - MCAR): nesse caso, a probabilidade de um atributo apresentar valores faltantes para a instância é independente dos valores observados de outros atributos. Assim, temos:

$$
\mathbb{P}(R \mid \boldsymbol{x})=\mathbb{P}(R)
$$

- Aleatória (missing at random - MAR): a probabilidade de um atributo apresentar valores faltantes depende de valores de outros atributos observados, como por exemplo, o campo para uma questão sobre um paciente não foi preenchido pois um determinado valor para o campo de outra questão foi observado. Desse modo, temos:

$$
\mathbb{P}(R \mid \boldsymbol{x})=\mathbb{P}\left(R \mid \boldsymbol{x}_{\mathrm{obs}}\right)
$$

- Não aleatória (missing not at random - MNAR): a ausência do valor do atributo não é nem completamente aleatória e nem aleatória. Isso ocorre quando a ausência é causada por eventos que não são controlados ou observados, ou é relacionada ao próprio motivo que levou à sua ausência ${ }^{2}$ [Ass12]. Assim, temos:

$$
\mathbb{P}(R \mid \boldsymbol{x})=\mathbb{P}\left(R \mid \boldsymbol{x}_{\mathrm{obs}}, \boldsymbol{x}_{\text {falt }}\right)
$$

\footnotetext{
${ }^{2}$ Por exemplo, em uma determinada pesquisa pessoas de alta renda podem preferir não informar seus faturamentos mensais. Nesse caso, o evento que levou à ausência do valor do atributo "renda familiar" está relacionado ao próprio valor que ele assumiria.
} 
Algumas estratégias podem ser adotadas para lidar com dados faltantes na criação de modelos. A primeira consiste em eliminar todas as instâncias que possuem um valor faltante para qualquer atributo. Entretanto, em domínios cujos dados são escassos, a criação do modelo pode se tornar inviável pelo baixo número de instâncias que estarão disponíveis para o treinamento. Além disso, quando os dados faltantes não são do tipo MCAR, o resultado pode ser enviesado, uma vez que as instâncias completas podem não ser suficientemente representativas.

Outra abordagem, conhecida como imputação, consiste na substituição de cada valor faltante de um atributo por alguma medida estatística simples, como média, mediana ou moda dos valores observados para o atributo, ou mais complexa, como a esperança condicional. No caso mais simples, essa estratégia apresenta, em geral, resultados enviesados para qualquer tipo de valor faltante. No caso mais complexo, pode apresentar resultados não enviesados quando a ausência dos valores é do tipo MAR ou MCAR, mas frequentemente falha nos casos de MNAR [SG02].

Uma estratégia alternativa seria considerar os valores faltantes como uma categoria a mais (como, por exemplo, "NaN", sigla do termo em inglês not a number), de forma que os domínios $\mathcal{X}_{j}$ de atributos passam a ser $\mathcal{X}_{j} \cup\{\mathrm{NaN}\}$. Pode-se ainda utilizar alguma técnica de classificação que lide com valores faltantes sem que seja necessário um pré-processamento, como as Árvores de Decisão e, consequentemente, Florestas Aleatórias [HTF09].

\subsubsection{4 Árvores de Decisão}

Uma Árvore de Decisão é uma técnica de classificação que se baseia em uma estrutura composta por nós internos, que representam testes sobre os valores de atributos, e nós folhas (ou nós terminais), que representam atribuições de classes. Os galhos da árvore representam possíveis valores para os testes dos nós internos nos quais têm origem [Mit97]. Quando um nó $n$ descende de um nó $p$ por meio de um galho, dizemos que $n$ é um nó filho de $p$, e que $p$ é o nó pai de $n$.

A Figura 2.2 ilustra a representação gráfica de uma Árvore de Decisão para dados que são representados por um vetor de atributos $\left[x_{1}, x_{2}, x_{3}\right]$ e cujo conjunto de classes é $\left\{y_{1}, y_{2}\right\}$. Nesse exemplo, $x_{1}$ e $x_{2}$ se apresentam como atributos categorizados (que podem assumir valores em $\left\{v_{1}, v_{2}, v_{3}\right\}$ e $\left\{v_{5}, v_{6}\right\}$, respectivamente) e $x_{3}$ se trata de um atributo numérico ou de um atributo categorizado ordinal (que admite relação de ordem sobre as categorias).

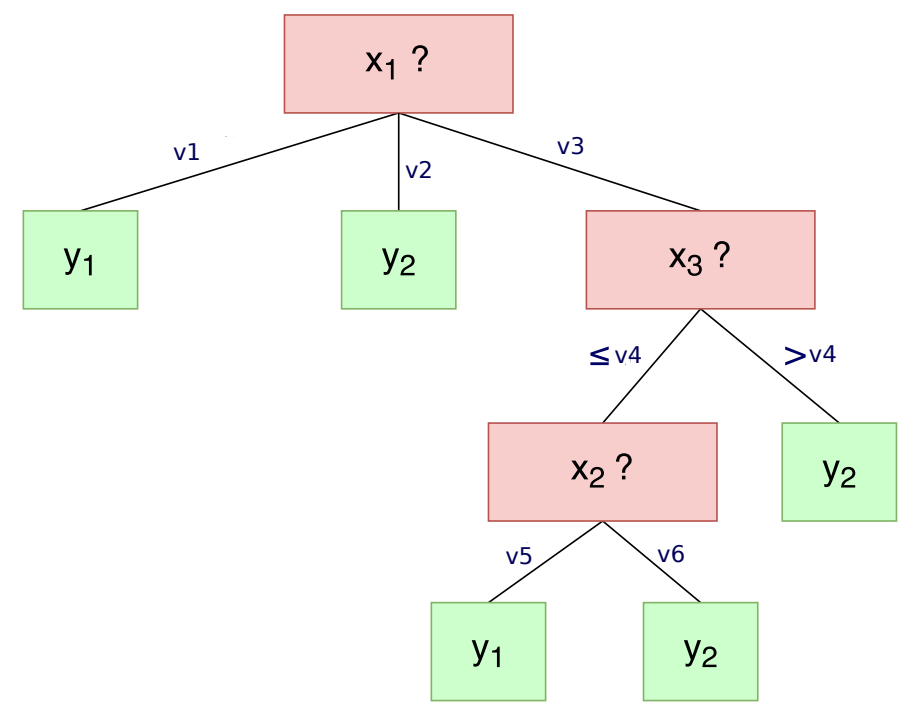

Figura 2.2: Exemplo de representação gráfica de uma Árvore de Decisão.

Para classificar uma instância não rotulada $\boldsymbol{x}$, testam-se os atributos especificados pelos nós da árvore, começando a partir do nó raiz (ou nó inicial), seguindo os galhos referentes aos valores assumidos por cada atributo de $\boldsymbol{x}$ até chegar em um nó folha. Por exemplo, seguindo a Árvore de Decisão da Figura 2.2, para uma instância $\boldsymbol{x}=\left[x_{1}=v_{3}, x_{2}=v_{5}, x_{3}=v_{4}\right]$ seria retornado $h(\boldsymbol{x})=y_{1}$ (a instância seria classificada como $y_{1}$ ). 
Existem vários algoritmos que geram árvores de decisão, sendo o Iterative Dichotomiser 3 (ID3) [Qui86], o C4.5 (sucessor do ID3) [Qui93] e o Classification and Regression Trees (CART) [BFOS84] os mais conhecidos. Esses algoritmos são variações de um algoritmo principal que emprega uma busca gulosa ${ }^{3}$ sobre o espaço de possibilidades de árvores de decisões [Mit97], que pode ser bem ilustrado pelo método C4.5.

O C4.5 considera um teste estatístico de ganho de informação para a escolha dos atributos que irão compor os nós da árvore. A ideia do critério de ganho de informação, que se baseia em Teoria da Informação, consiste na observação de que a transferência de uma mensagem (que pode ser um texto, som, imagem, vídeo ou simplesmente uma observação) não depende de seu conteúdo, mas sim da quantidade de bits ${ }^{4}$ necessários para sua transmissão [Sha48]. Essa quantidade pode ser medida como o negativo do logaritmo na base 2 da frequência observada da mensagem, e pode ser utilizada para calcular sua informação. Por exemplo, se existem 8 possíveis mensagens igualmente prováveis, a informação transmitida por qualquer uma delas pode ser codificada em $-\log _{2}(1 / 8)=3$ bits.

No contexto de árvores de decisão, uma mensagem equivale a uma classe observada. Dessa forma, se em um conjunto de instâncias classificadas são observadas, por exemplo, 4 classes igualmente prováveis, a quantidade de bits necessários para representar cada uma delas corresponde a $-\log _{2}(1 / 4)=2$ bits. Entretanto, se uma das classes for observada com uma frequência de 1/2, a quantidade de bits necessários para representá-la no conjunto equivale a $-\log _{2}(1 / 2)=1$ bit. Assim, quanto menos diverso o conjunto, menos bits são necessários para sua representação. Essa métrica pode ser vista, portanto, como uma métrica de impureza (diversidade) do conjunto, de forma que uma quantidade baixa de informação, calculada em bits, indica maior pureza. Um conjunto totalmente puro contém apenas uma classe observada para todas as instâncias e possui informação nula.

Assim, considere um conjunto $\mathcal{I}=\left\{\boldsymbol{x}_{i} \in \mathcal{X} \mid 1 \leq i \leq M\right\}$ de instâncias e um conjunto $\mathcal{S}=$ $\left\{y_{i} \in \mathcal{Y} \mid y_{i}=f\left(\boldsymbol{x}_{i}\right), 1 \leq i \leq M\right\}$ de suas classes observadas, com $\mathcal{Y}=\left\{Y_{1}, \ldots, Y_{K}\right\}$. A frequência observada de uma "mensagem" (classificação) $y_{i}=Y_{L}$ retirada aleatoriamente de $\mathcal{S}$, com $i \in$ $\{1, \ldots, M\}$ e $Y_{L} \in \mathcal{Y}$, é dada por

$$
\frac{\operatorname{freq}\left(Y_{L}, \mathcal{S}\right)}{|\mathcal{S}|}
$$

em que $\operatorname{freq}\left(Y_{L}, \mathcal{S}\right)=\mid\left\{y_{i} \in \mathcal{S}\left|y_{i}=Y_{L}, i \in\{1, \ldots, M\}\right|\right.$. Desse modo a informação pode ser medida por:

$$
-\log _{2}\left(\frac{\operatorname{freq}\left(Y_{L}, \mathcal{S}\right)}{|\mathcal{S}|}\right) .
$$

Para calcular a impureza de $\mathcal{S}$, podemos utilizar a métrica de entropia do conjunto, definida por:

$$
\operatorname{entropia}(\mathcal{S})=-\sum_{k=1}^{K}\left(\frac{\operatorname{freq}\left(Y_{k}, \mathcal{S}\right)}{|\mathcal{S}|}\right) \log _{2}\left(\frac{\operatorname{freq}\left(Y_{k}, \mathcal{S}\right)}{|\mathcal{S}|}\right)
$$

Se $\mathcal{S}$ for um conjunto totalmente puro contendo apenas a classe $Y_{L}, L \in\{1, \ldots, K\}$, teremos $\frac{\operatorname{freq}\left(Y_{L}, \mathcal{S}\right)}{|\mathcal{S}|}=1$ e $\frac{\operatorname{freq}\left(Y_{k}, \mathcal{S}\right)}{|\mathcal{S}|}=0, \forall k: 1 \leq k \leq K, k \neq L$. Assim, temos:

$$
\operatorname{entropia}(\mathcal{S})=-\left(\frac{\operatorname{freq}\left(Y_{L}, \mathcal{S}\right)}{|\mathcal{S}|} \cdot \log _{2} \frac{\operatorname{freq}\left(Y_{L}, \mathcal{S}\right)}{|\mathcal{S}|}+\sum_{\substack{k=1 \\ k \neq L}}^{K} \frac{\operatorname{freq}\left(Y_{k}, \mathcal{S}\right)}{|\mathcal{S}|} \cdot \log _{2} \frac{\operatorname{freq}\left(Y_{k}, \mathcal{S}\right)}{|\mathcal{S}|}\right)=
$$

\footnotetext{
${ }^{3}$ Um algoritmo guloso faz uma escolha pelo ótimo local em cada etapa, com a esperança de encontrar um ótimo global [CSRL01].

${ }^{4}$ Menor unidade de armazenamento ou transmissão de dados. Um bit possui um único valor, que pode ser 0 ou 1.
} 


$$
=-\left(1 \cdot \log _{2} 1+\sum_{\substack{k=1 \\ k \neq L}}^{K} 0 \cdot \log _{2} 0\right)=0 .
$$

Pode-se ainda calcular a redução de entropia (i.e., impureza) causada pela partição do conjunto $\mathcal{S}$ em subconjuntos $\mathcal{S}_{v_{1}}, S_{v_{2}}, \ldots, \mathcal{S}_{v_{Q}}$, de acordo com algum atributo $A$ que assume valores categorizados $v_{1}, v_{2}, \ldots, v_{Q}$, estimando assim o ganho de informação de $\mathcal{S}$ e $A$, definido por:

$$
\operatorname{ganho}(\mathcal{S}, A)=\operatorname{entropia}(\mathcal{S})-\sum_{q=1}^{Q} \frac{\left|\mathcal{S}_{v_{q}}\right|}{|\mathcal{S}|} \cdot \operatorname{entropia}\left(\mathcal{S}_{v_{q}}\right)
$$

Assim, se $\mathcal{S}$ for um conjunto não puro com $\operatorname{entropia}(\mathcal{S})=1$ e ao ser particionado de acordo com um atributo $A$ de possíveis valores $v_{1}$ e $v_{2}$, resultar em dois subconjuntos $\mathcal{S}_{v_{1}}$ e $\mathcal{S}_{v_{2}}$ puros (ou seja, com entropia $\left(\mathcal{S}_{v_{1}}\right)=0$ e entropia $\left.\left(\mathcal{S}_{v_{2}}\right)=0\right)$, teremos:

$$
\operatorname{ganho}(\mathcal{S}, A)=1-\left(\frac{\left|\mathcal{S}_{v_{1}}\right|}{|\mathcal{S}|} \cdot 0+\frac{\left|\mathcal{S}_{v_{2}}\right|}{|\mathcal{S}|} \cdot 0\right)=1
$$

Desse modo, quanto maior o ganho de informação, maior a diferença entre a entropia do conjunto e a soma das entropias dos subconjuntos, o que indica um aumento de pureza nas repartições. Por outro lado, quando os subconjuntos possuem a mesma impureza que o conjunto antes de ser repartido, o ganho de informação é nulo.

A partir dessas definições, o algoritmo C4.5 constrói uma árvore de decisão utilizando uma abordagem "de cima para baixo", começando com o nó raiz e atribuindo a ele o atributo que sozinho classifica melhor as instâncias de treinamento (isso é, resulta em subconjuntos mais puros em relação às classes), considerando o critério de ganho de informação.

Para exemplificar o funcionamento do algoritmo, considere o conjunto de treinamento fictício na Tabela 2.2, sem significado real clínico, em que se deseja construir um modelo preditivo de hipertensão em pessoas. Cada linha apresenta o sexo (feminino ou masculino), idade (em anos), peso (em kilos), realização regular de exercícios físicos (sim ou não) e presença de hipertensão (sim ou não) de um determinado paciente.

\begin{tabular}{|c|c|c|c|c|}
\hline Sexo & Idade & Peso (kg) & Exercício? & Hipertensão \\
\hline Masculino & 50 & 80,5 & Não & Sim \\
\hline Masculino & 25 & 72 & Sim & Não \\
\hline Feminino & 71 & 70 & Não & Não \\
\hline Feminino & 43 & 95,4 & Não & Sim \\
\hline Masculino & 50 & 97,1 & Sim & Não \\
\hline Feminino & 37 & 65,8 & Sim & Não \\
\hline Masculino & 65 & 82,3 & Não & Sim \\
\hline Masculino & 38 & 93 & Sim & Não \\
\hline
\end{tabular}

Tabela 2.2: Exemplo fictício de conjunto de treinamento para a criação de um modelo preditivo de hipertensão em pacientes.

Para construir a árvore de decisão, o algoritmo C4.5 irá calcular o ganho de informação obtido ao particionar o conjunto de treinamento de acordo com os valores possíveis para cada um dos atributos, e irá atribuir ao nó raiz aquele que apresentar o maior ganho.

Inicialmente, o conjunto $\mathcal{S}$ de classificações é composto por $\{$ Sim, Não, Não, Sim, Não, Não, Sim, Não \} (coluna "Hipertensão"), e então temos:

$$
\operatorname{entropia}(\mathcal{S})=-\left(\frac{\operatorname{freq}(\operatorname{Sim}, \mathcal{S})}{|\mathcal{S}|} \log _{2} \frac{\operatorname{freq}(\operatorname{Sim}, \mathcal{S})}{|\mathcal{S}|}+\frac{\operatorname{freq}(\mathrm{Não}, \mathcal{S})}{|\mathcal{S}|} \log _{2} \frac{\operatorname{freq}(\mathrm{Não}, \mathcal{S})}{|\mathcal{S}|}\right)=
$$




$$
-\left(\frac{3}{8} \log _{2}\left(\frac{3}{8}\right)+\frac{5}{8} \log _{2}\left(\frac{5}{8}\right)\right)=0,9544 .
$$

Considere a repartição do conjunto de acordo com os valores do atributo "Sexo" na Tabela 2.3.

$\left.\begin{array}{|c|c|}\hline \text { Sexo } & \text { Hipertensão } \\ \hline \text { Masculino } & \text { Sim } \\ \hline \text { Masculino } & \text { Não } \\ \hline \text { Masculino } & \text { Não } \\ \hline \text { Masculino } & \text { Sim } \\ \hline \text { Masculino } & \text { Não } \\ \hline \text { Feminino } & \text { Não } \\ \hline \text { Feminino } & \text { Não } \\ \hline \text { Feminino } & \text { Sim }\end{array}\right\} \mathcal{S}_{\mathrm{M}}$

Tabela 2.3: Repartição do conjunto de treinamento de acordo com cada valor do atributo "Sexo".

Temos $\mathcal{S}_{\mathrm{M}}=\{\operatorname{Sim}$, Não, Não, Sim, Não $\}$ e $\mathcal{S}_{\mathrm{F}}=\{$ Não, Não, Sim $\}$, e portanto:

$$
\begin{aligned}
& \operatorname{entropia}\left(\mathcal{S}_{\mathrm{M}}\right)=-\left(\frac{2}{5} \log _{2}\left(\frac{2}{5}\right)\right)-\left(\frac{3}{5} \log _{2}\left(\frac{3}{5}\right)\right)=0,971, \\
& \operatorname{entropia}\left(\mathcal{S}_{\mathrm{F}}\right)=-\left(\frac{2}{3} \log _{2}\left(\frac{2}{3}\right)\right)-\left(\frac{1}{3} \log _{2}\left(\frac{1}{3}\right)\right)=0,918 .
\end{aligned}
$$

Desse modo, temos o seguinte ganho de informação:

$$
\begin{aligned}
\operatorname{ganho}(\mathcal{S}, \text { Sexo })= & \operatorname{entropia}(\mathcal{S})-\left(\frac{\left|\mathcal{S}_{\mathrm{M}}\right|}{|\mathcal{S}|} \operatorname{entropia}\left(\mathcal{S}_{\mathrm{M}}\right)+\frac{\left|\mathcal{S}_{\mathrm{F}}\right|}{|\mathcal{S}|} \operatorname{entropia}\left(\mathcal{S}_{\mathrm{F}}\right)\right)= \\
& 0,9544-\left(\frac{5}{8} \cdot 0,971+\frac{3}{8} \cdot 0,918\right)=0,003
\end{aligned}
$$

Similarmente, é possível calcular o ganho de informação ao repartirmos o conjunto $\mathcal{S}$ de acordo com os valores do atributo "Exercício?", obtendo:

$$
\begin{aligned}
\operatorname{ganho}(\mathcal{S}, \operatorname{Exercício?})= & \operatorname{entropia}(\mathcal{S})-\left(\frac{\left|\mathcal{S}_{\text {Sim }}\right|}{|\mathcal{S}|} \operatorname{entropia}\left(\mathcal{S}_{\text {Sim }}\right)+\frac{\left|\mathcal{S}_{\text {Não }}\right|}{|\mathcal{S}|} \operatorname{entropia}\left(\mathcal{S}_{\text {Não }}\right)\right)= \\
& 0,9544-\left(\frac{4}{8} \cdot 0+\frac{4}{8} \cdot 0,811\right)=0,548 .
\end{aligned}
$$

Como podemos observar, os atributos "Sexo" e "Exercício?" são do tipo categorizados. No caso de atributos numéricos (discretos ou contínuos), a repartição dos conjuntos é feita considerando a média de cada par de valores ordenados assumidos pelo atributo. Assim, considere o conjunto $\left\{v_{1}, v_{2}, \ldots, v_{Q}\right\}$ como sendo a ordenação dos valores que um atributo $A$ assume em $\mathcal{S}$. Para cada par $\left(v_{j}, v_{j+1}\right), 1 \leq j \leq Q-1$, serão calculados os ganhos de informação ao repartir o conjunto $\mathcal{S}$ em $\mathcal{S}_{1}$ e $\mathcal{S}_{2}$, de forma que $\mathcal{S}_{1}$ contenha instâncias cujo valor $a_{i}$ para $A$ seja tal que $a_{i} \leq\left(\frac{v_{j}+v_{j+1}}{2}\right)$ e $\mathcal{S}_{2}$ tal que $a_{i}>\left(\frac{v_{j}+v_{j+1}}{2}\right)$.

Seguindo com o exemplo, considere o atributo "Idade" cuja ordenação dos valores assumidos no conjunto de treinamento corresponde a $\{25,37,38,43,50,65,71\}$. Para cada par $(25,37),(37,38)$, $(38,43),(43,50),(50,65),(65,71)$, será calculado o ganho de informação ao repartir $\mathcal{S}$ comparando os valores de "Idade" com a média de cada par. Para o par $(25,37)$, temos $\frac{(25+37)}{2}=31$ e assim obtemos as repartições ilustradas na Tabela 2.4. 


$\left.\begin{array}{|c|c|}\hline \text { Idade } & \text { Hipertensão } \\ \hline 25 & \text { Não } \\ \hline 50 & \text { Sim } \\ \hline 71 & \text { Não } \\ \hline 43 & \text { Sim } \\ \hline 50 & \text { Não } \\ \hline 37 & \text { Não } \\ \hline 65 & \text { Sim } \\ \hline 38 & \text { Não } \\ \mathcal{S}_{1}\end{array}\right\} \mathcal{S}_{2}$

Tabela 2.4: Repartição do conjunto de treinamento comparando o valor do atributo "Idade" com o valor médio 31.

Desse modo, o ganho de informação é obtido por:

$$
\begin{aligned}
\operatorname{ganho}(\mathcal{S}, \text { Idade }=31) & =\operatorname{entropia}(\mathcal{S})-\left(\frac{\left|\mathcal{S}_{1}\right|}{|\mathcal{S}|} \operatorname{entropia}\left(\mathcal{S}_{1}\right)+\frac{\left|\mathcal{S}_{2}\right|}{|\mathcal{S}|} \operatorname{entropia}\left(\mathcal{S}_{2}\right)\right)= \\
& 0,9544-\left(\frac{1}{8} \cdot 0+\frac{7}{8} \cdot 0,985\right)=0,092 .
\end{aligned}
$$

Suponha que mesmo após calcular o ganho de informação para todos pares de valores mencionados para o atributo "Idade" e também para o atributo "Peso", o atributo "Exercício?" tenha apresentado o maior valor para ganho de informação. Nesse caso, ele será atribuído ao nó da raiz e serão criados nós filhos para cada um de seus valores possíveis (Sim e Não), como ilustrado na Figura 2.3. O número descrito dentro de cada nó na árvore representa o número de instâncias no subconjunto resultante pela partição.

Como entropia $\left(\mathcal{S}_{\mathrm{Sim}}\right)=0$, cria-se um nó de decisão com a classe majoritária (no caso, "Hipertensão" = Não). Por outro lado, o subconjunto $\mathcal{S}_{\text {Não }}$ pode ainda ser particionado, uma vez que não alcançou a pureza desejada.

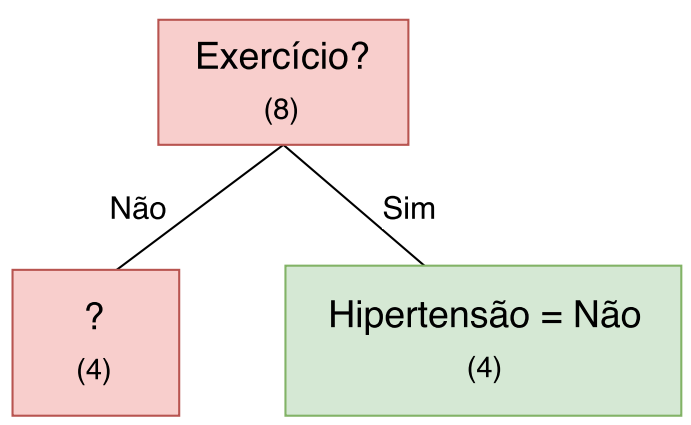

Figura 2.3: Representação gráfica do início da construção de uma Árvore de Decisão pelo algoritmo C4.5.

\begin{tabular}{|c|c|c|c|c|}
\hline Sexo & Idade & Peso (kg) & Exercício? & Hipertensão \\
\hline Masculino & 50 & 80,5 & Não & Sim \\
\hline Feminino & 71 & 70 & Não & Não \\
\hline Feminino & 43 & 95,4 & Não & Sim \\
\hline Masculino & 65 & 82,3 & Não & Sim \\
\hline
\end{tabular}

Tabela 2.5: Instâncias no subconjunto resultante pela partição sobre "Exercício?" = Não.

Assim, o processo se repete para os nós filhos, atribuindo a $\mathcal{S}$ o conjunto originado pela repartição. Na continuação do exemplo, o ganho de informação será máximo para o atributo "Peso", considerando o par de valores $(70,72)$. Dessa forma, o atributo irá compor o próximo nó marcado 
com ? na Figura 2.3, resultando na repartição ilustrada na Tabela 2.6.

$\left.\begin{array}{|c|c|}\hline \text { Peso } & \text { Hipertensão } \\ \hline 70 & \text { Não } \\ \hline 80,5 & \text { Sim } \\ \hline 95,4 & \text { Sim }\end{array}\right\} \mathcal{S}_{1}$

Tabela 2.6: Repartição do conjunto de treinamento comparando o valor do atributo "Peso" com o valor médio 71.

Como ambos os conjuntos $\mathcal{S}_{1}$ e $\mathcal{S}_{2}$ são puros, são criados nós de decisão para cada um deles, resultando na árvore representada na Figura 2.4.

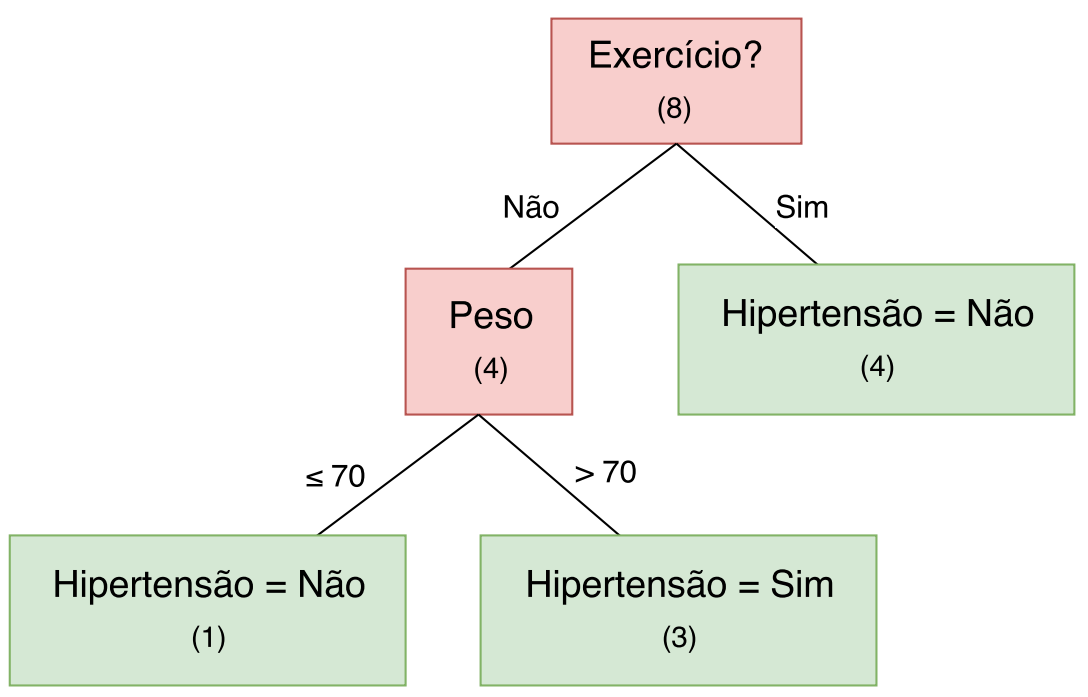

Figura 2.4: Representação gráfica da Árvore de Decisão construída pelo algoritmo C4.5.

Apesar do valor médio comparado corresponder a 71, o algoritmo $\mathrm{C} 4.5$ exibe nos galhos de teste de atributos contínuos o maior valor do atributo no conjunto de treino que não excede o valor médio a ser comparado, para que só apareçam nos galhos valores que são observados no conjunto de treino.

Caso não fosse possível encontrar conjuntos puros e nem reparticioná-los (pois, por exemplo, todas as instâncias apresentaram o mesmo valor para os atributos a serem testados), seria criado um nó de decisão com a classe mais frequente dentre as instâncias do subconjunto.

Os algoritmos ID3 e CART são muito similares ao algoritmo C4.5, com a diferença de que o funcionamento do algoritmo ID3 depende de que os atributos sejam todos categorizados, enquanto que o CART gera apenas árvores binárias. Além disso, o algoritmo CART utiliza um critério diferente do ganho de informação para a escolha dos atributos que irão compor os nós. O processo recursivo de construção de uma árvore de decisão pode ser generalizado pelo Algoritmo 1 [Mit97].

Outro aspecto interessante do algoritmo C4.5 é a capacidade de criar modelos utilizando dados com valores faltantes para os atributos, sem exigir que sejam tratados previamente (como por exemplo, substituindo-os pela média, mediana ou moda dos valores não faltantes para o atributo).

Para que isso seja possível, algumas modificações são feitas nos processos de escolha dos atributos para compor os nós, de repartição e de classificação. O critério de ganho de informação de um atributo passa a considerar no cálculo a proporção $N F$ de seus valores que não são faltantes. Além disso, o conjunto $\mathcal{S}$ passa a considerar apenas as classificações das instâncias cujos valores para o atributo não são faltantes. Sendo $A$ um atributo de categorias $\left\{v_{1}, \ldots, v_{Q}\right\}$ e $x_{i A}$ o valor que 


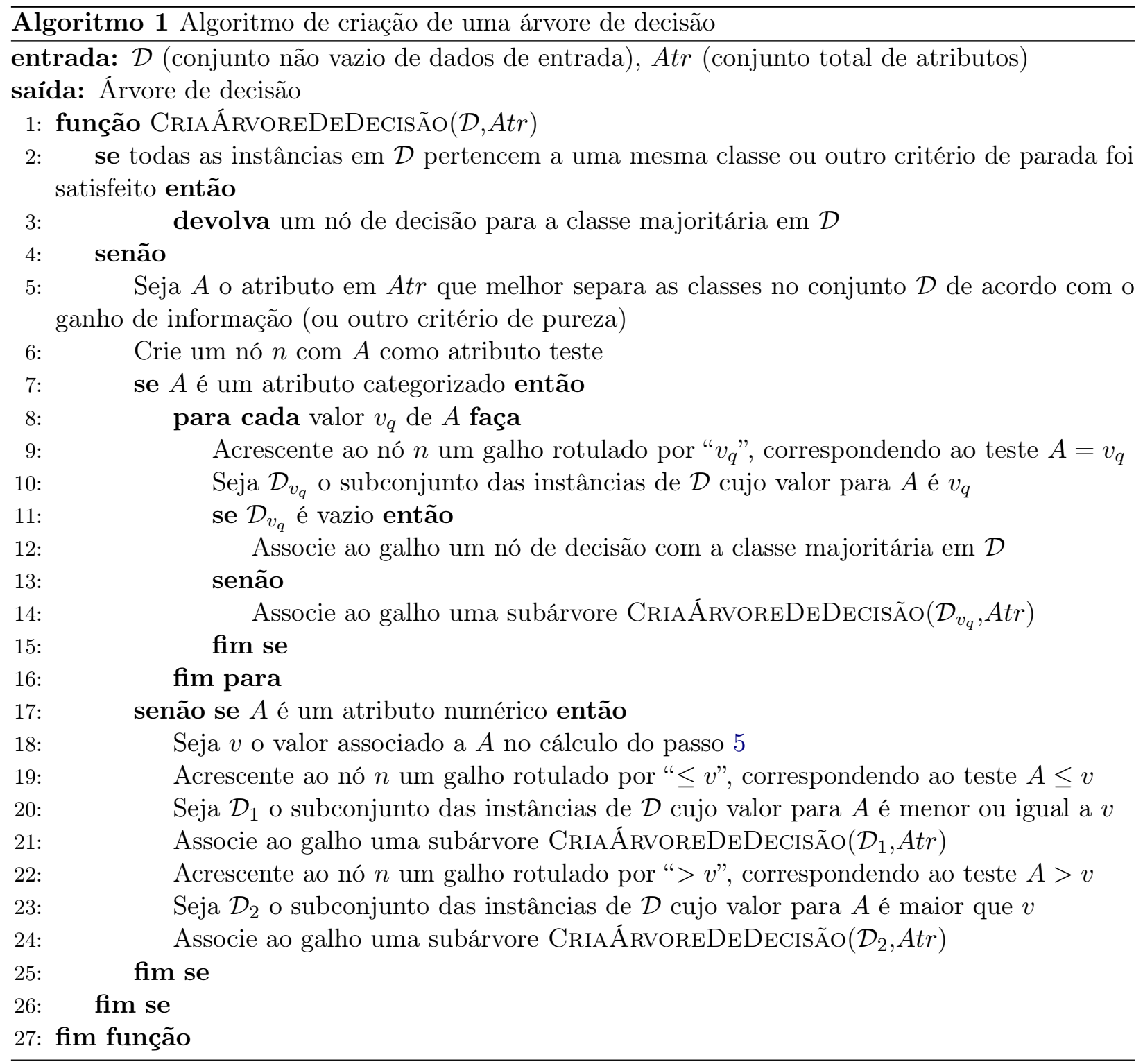

atributo $A$ assume em uma instância $\boldsymbol{x}_{i}$, temos:

$$
\operatorname{ganho}(\mathcal{S}, A)=N F \cdot\left(\operatorname{entropia}(\mathcal{S})-\sum_{q=1}^{Q} \frac{\left|\mathcal{S}_{v_{q}}\right|}{|\mathcal{S}|} \cdot \operatorname{entropia}\left(\mathcal{S}_{v_{q}}\right)\right),
$$

$\operatorname{com} N F=\frac{\left|\left\{x_{i A} \neq ?: 1 \leq i \leq|\mathcal{S}|\right\}\right|}{|\mathcal{S}|}$.

A repartição das instâncias nos nós em subconjuntos também é modificada. A presença de uma instância no subconjunto definido pelo nó é indicada por um valor de peso calculado pela probabilidade da instância pertencer ao nó. Dessa forma, a cada nó $n$ cujo subconjunto conta com $m$ instâncias $\left[\boldsymbol{x}_{1}, \boldsymbol{x}_{2}, \ldots, \boldsymbol{x}_{m}\right]$, será associado um vetor de pesos $\boldsymbol{p}_{n}=\left[p_{1, n}, p_{2, n}, \ldots, p_{m, n}\right]$, com $1 \leq m \leq M$.

Seja $A$ o atributo teste associado ao nó $n$, de categorias $\left\{v_{1}, v_{2}, \ldots, v_{Q}\right\}$, e $S_{n}$ o conjunto de classificações das instâncias do subconjunto definido em $n$. Ainda, sejam $n_{v_{1}}, n_{v_{2}}, \ldots, n_{v_{Q}}$ os nós filhos de $n$ pelos ramos relativos aos valores $v_{1}, v_{2}, \ldots, v_{Q}$, respectivamente .

Se $\boldsymbol{x}_{i}$ é uma instância com $x_{i A}=v_{q}$ para algum $q \in\{1, \ldots, Q\}$, então:

$$
p_{i, n_{v_{q}}}=p_{i, n}
$$


Entretanto, se o valor $x_{i A}$ for desconhecido, teremos:

$$
p_{i, n_{v_{q}}}=p_{i, n} \cdot \frac{\left|\mathcal{S}_{v_{q}}\right|}{\left|S_{n}\right|} .
$$

Para $n$ sendo o nó raiz, temos $p_{i, n}=1, \forall i \in\{1, \ldots, M\}$.

Já no processo de classificação, se a instância a ser rotulada possui valor desconhecido para o atributo $A$ teste de um nó $n$, todas as possibilidades de valores para $A$ na árvore são exploradas e sua probabilidade de pertencer a cada classe é combinada aritmeticamente. Uma vez que essa abordagem permite que existam vários caminhos que levem uma instância a partir da raiz da árvore até nós de decisão, a classificação da instância é dada em termos de uma distribuição de probabilidade, de forma que a classe de maior probabilidade é atribuída como a classe final da instância.

Em suma, Árvores de Decisão são um modelo transparente, ou seja, cujo resultado pode ser interpretado, examinado ou visualizado, e robusto mesmo quando alguns dados de treinamento possuem erros, seja nos valores de seus atributos ou mesmo em suas classes, ou quando alguns de seus atributos possuem valores desconhecidos (ausentes). Além disso, permitem que o processo de seleção de atributos aconteça de forma implícita (seleção embutida), uma vez que apenas atributos com bons valores para o critério de separação (e.g., ganho de informação) são selecionados para compor a árvore. Por outro lado, Árvores de Decisão em geral produzem modelos que sofrem de sobreajuste, com baixa capacidade de generalização, além de encontrar com frequência soluções não ótimas (modelos cuja aproximação é máxima local), uma vez que os algoritmos utilizam, com frequência, uma estratégia gulosa [DOM02].

\subsubsection{Florestas Aleatórias}

Florestas Aleatórias (ou Florestas de Decisão Aleatórias), introduzidas por Leo Breiman [Bre01], são uma forma de conjunto de classificadores (em inglês, emsemble of classifiers) cuja decisão é feita considerando decisões individuais dos classificadores que as compõem. Um conjunto de classificadores possuirá maior capacidade de aproximação e generalização que a técnica de seus classificadores individuais que o compõem se seus classificadores base possuírem uma boa acurácia (maior do que se fosse adotada uma estratégia aleatória de classificação) e forem independentes entre si [Die00]. Essa abordagem se baseia na ideia de que os erros cometidos por um classificador podem ser compensados por outro classificador, desde que seus erros não sejam correlacionados [RT14].

Especificamente, uma Floresta Aleatória é um conjunto de classificadores formado por uma combinação de $T$ Árvores de Decisão da forma $h_{t}(\boldsymbol{x})=h\left(\boldsymbol{x}, \Theta_{t}\right)$, em que cada $\Theta_{t}$ é um vetor aleatório independente identicamente distribuído (i.i.d.), com $1 \leq t \leq T$, utilizado para determinar o subconjunto de instâncias que será utilizado na construção de cada árvore. Cada uma das Árvores de Decisão que compõem a floresta atribui um voto para a classe de $\boldsymbol{x}$, sendo retornada pela Floresta de Decisão a classe com maior número de votos [Bre01].

Para construir as árvores $h\left(\boldsymbol{x}, \Theta_{t}\right)$ não correlatas entre si que compõem uma Floresta Aleatória, utiliza-se uma abordagem de aleatorização, de forma que cada árvore é construída a partir de um subconjunto das instâncias de treinamento determinado a partir de $\Theta_{t}$, com $1 \leq t \leq T$, e de um subconjunto aleatório de atributos de tamanho $p$ para a seleção do atributo teste para cada um de seus nós, com $p \ll N$ [Bre01]. A abordagem de aleatorização é utilizada visando à diminuição da correlação entre as árvores que compõem a floresta, aumentando assim sua capacidade de generalização, além de propiciar a robustez do modelo em caso de existir ruídos no conjunto de dados [Pau12]. O processo de criação de uma floresta aleatória pode ser generalizado pelo Algoritmo 2.

Uma vez que na criação de uma árvore existe um subconjunto dos dados de treinamento que não foi utilizado na sua construção, é possível utiliza-los como um conjunto de teste para a árvore. Dessa forma, é formado um conjunto de instâncias chamado de $O O B_{t}$ (do inglês out-of-bag, cuja tradução literal corresponde a "fora do saco") para cada árvore $t$, composto pelas instâncias que não 


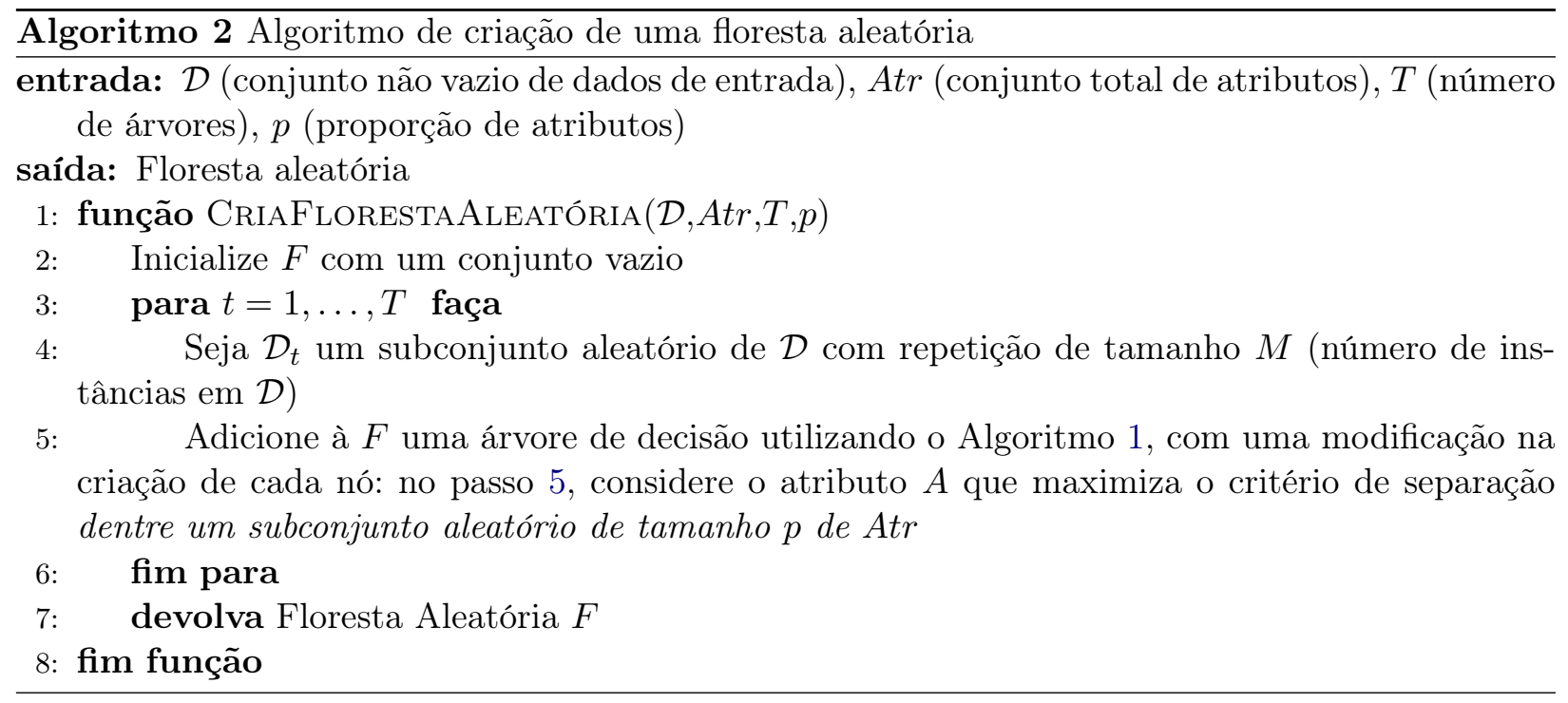

foram utilizadas em sua construção.

Assim, considere o conjunto $O O B=\bigcup_{t=1}^{T} O O B_{t}$. Podemos calcular o erro OOB de uma Floresta de Decisão $h$ da seguinte maneira:

$$
\begin{aligned}
& \operatorname{erro} \operatorname{OOB}(h)=\frac{\sum_{\boldsymbol{x}_{i} \in O O B} \operatorname{errooob}\left(h, \boldsymbol{x}_{i}\right)}{|O O B|}, \mathrm{com}
\end{aligned}
$$

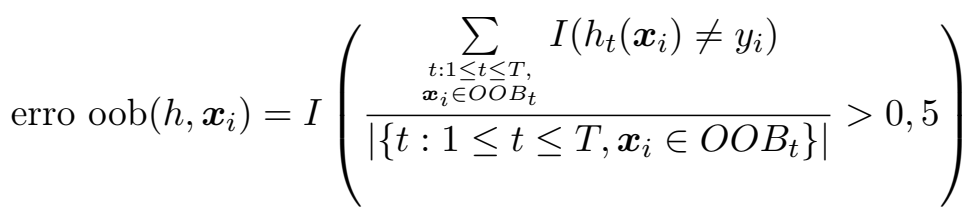

onde $I(\mathcal{E})$ é uma função indicadora que assume 1 se a expressão $\mathcal{E}$ é verdadeira e 0 em caso contrário.

Em outras palavras, o erro OOB pode ser interpretado como a taxa média de erro da classificação de "sub-florestas" formadas pelas árvores que possuem a instância $\boldsymbol{x}$ em seu conjunto OOB, para cada instância $\boldsymbol{x}$. O cálculo do erro OOB pode ser utilizado como uma estimativa para o erro de generalização do modelo, desde que se utilize um número de árvores suficientemente grande, permitindo que não seja necessário separar um conjunto de dados para teste ou validação [Bre01].

Os principais parâmetros de uma Floresta Aleatória são o número de árvores $(T)$ e o tamanho do subconjunto de atributos a ser considerado para a construção de cada árvore. Apesar de não ser um modelo muito sensível à mudança de valores para seus parâmetros, quanto maior o número de árvores em uma floresta, maior a estabilidade e consistência de sua classificação, bem como da precisão do erro de generalização. Porém, o seu custo computacional aumenta com o número de árvores. Em relação ao tamanho do subconjunto de atributos para cada árvore, o valor padrão utilizado em aplicações corresponde à raiz quadrada do número de atributos no conjunto de dados, e geralmente produz bons resultados [DUA06, LW02].

Florestas de Decisão apresentam, em geral, acurácia e poder de generalização maiores que Árvores de Decisão, além de apresentarem bons resultados em problemas em que o número de atributos é consideravelmente maior do que o de instâncias, sem exigir uma escolha refinada de seus parâmetros. Além disso, apresenta robustez mesmo quando os dados possuem valores faltantes ou ruídos [DUA06]. Entretanto, o custo computacional da criação de seus modelos pode ser bastante elevado [LCLC17].

Apesar da transparência das Florestas Aleatórias não ser explícita como é nas Árvores de Decisão, existem formas de interpretação de seu modelo, viabilizando sua utilização em domínios que exigem transparência dos modelos [Bre01, PPRN13]. 


\subsection{Interpretação do modelo}

Uma forma de transparência de um modelo de Floresta Aleatória pode ser obtida por meio do cálculo de importância dos atributos utilizados em sua criação, introduzido por Leo Breiman [Bre01].

Seja $A$ um atributo e considere os conjuntos $O O B_{t}$ de cada árvore $t, 1 \leq t \leq T$. Seja ainda $\widetilde{O O B_{t}}$ o conjunto de todas as instâncias de $O O B_{t}$ com seus valores para $A$ permutados aleatoriamente entre si. A importância do atributo $A$ pode ser calculada da seguinte maneira:

$$
\begin{gathered}
\text { Importância }(A)=\frac{\sum_{t=1}^{T}\left(\text { erro } \widetilde{O O B_{t}}-\text { erro } \mathrm{OOB}_{t}\right)}{T}, \text { em que } \\
\text { erro } \widetilde{O O B_{t}}=\frac{\sum_{\boldsymbol{x}_{i} \in \widetilde{O O B}} I\left(h_{t}\left(\boldsymbol{x}_{i}\right) \neq y_{i}\right)}{\mid \widetilde{O O B_{t} \mid}} \mathrm{e} \\
\text { erro } \mathrm{OOB}_{t}=\frac{\sum_{\boldsymbol{x}_{i} \in O O B_{t}} I\left(h_{t}\left(\boldsymbol{x}_{i}\right) \neq y_{i}\right)}{\left|O O B_{t}\right|} .
\end{gathered}
$$

A ideia desse método se baseia na noção de que se o atributo não está associado ao resultado (i.e., à classe final), então a permutação de seus valores nas instâncias não deve afetar a classificação e, dessa forma, não deve influenciar a taxa de erro. Por outro lado, se o atributo for relevante, a inclusão de ruído nos seus valores irá aumentar a taxa de erro e, assim, seu valor de importância será maior.

Janitza et al. [JSB13] propuseram uma adaptação para esse método, que considera a medida AUC de desempenho (descrita na Seção 2.1.2.1) ao invés da taxa de erro de classificação, visando um menor enviesamento da medida de importância calculada sobre florestas construídas por dados não balanceados. Para isso, em seu cálculo só são consideradas as classificações de árvores cujos conjuntos OOB contêm instâncias de ambas as classes. Esse cálculo é dado por:

$$
\operatorname{Importância~}_{\mathrm{AUC}}(A)=\frac{\sum_{t \in T^{*}}\left(\mathrm{AUC} \mathrm{OOB}_{t}-\mathrm{AUC} \widetilde{O O B_{t}}\right)}{\left|T^{*}\right|},
$$

em que $\mathrm{AUC} \mathrm{OOB}_{t}$ corresponde à medida AUC calculada sobre os dados do conjunto $O O B_{t}$, AUC $\widetilde{O O B}_{t}$ à medida AUC calculada sobre as instâncias do conjunto $O O B_{t}$ após seus valores para o atributo A serem permutados aleatoriamente entre si, e $T^{*}$ sendo o conjunto dos índices das árvores que foram construídas utilizando conjuntos OOB que contêm instâncias de ambas as classes.

Uma outra adaptação desse cálculo de importância foi proposta por Hapfelmeier et al. para que sua utilização fosse viável na presença de atributos que possuem valores faltantes [HHUS14]. Em vez de calcular o erro causado pela permutação dos valores para o atributo $A$ das instâncias no conjunto $O O B_{t}$ de uma árvore $t$, calcula-se o erro quando as instâncias são atribuídas de forma aleatória a um nó filho $n_{v}$ do nó $n$ que contém o atributo $A$ como teste, com probabilidade $\frac{\left|\mathcal{S}_{n_{v}}\right|}{\left|\mathcal{S}_{n}\right|}$. Desse modo, o valor que as instâncias assumem para o atributo não importa, uma vez que eles não são utilizados diretamente no cálculo da importância.

O método adaptado apresenta o mesmo resultado que o método original sobre atributos que não possuem valores faltantes, em termos do ranqueamento dos atributos de acordo com suas importâncias. Além disso, apresentaram resultados robustos em experimentos com valores faltantes dos tipos MCAR, MAR e até mesmo MNAR.

Um outro método de interpretação foi desenvolvido por Kuz'min et al. [KPAA11] por meio do cálculo de contribuição dos atributos de cada instância utilizada no treinamento de Florestas Aleatórias. Entretanto, o método foi proposto para problemas de regressão - em que a predição se dá em valores numéricos. A generalização do cálculo de contribuição de atributos foi desenvolvida 
por Palczewska et al. [PPRN13] para que pudesse ser aplicado em problemas de classificação.

Diferentemente da medida de importância, o cálculo da contribuição de atributos é feito para cada instância, e permite que se saiba se o seu valor para um atributo levou a uma influência negativa ou positiva em relação a uma determinada classe.

O cálculo utilizado nesse método envolve os seguintes conceitos:

- Vetor $\boldsymbol{Y}_{\text {frac }}^{n} \in \mathbb{R}^{K}$, em que cada elemento $Y_{\text {frac }, k}^{n}$ é dado por:

$$
Y_{\text {frac }, k}^{n}=\frac{\left|\left\{\boldsymbol{x}_{i} \in S(n): y_{i}\right\}=Y_{k}\right|}{|S(n)|}, 1 \leq k \leq K,
$$

em que $S(n)$ corresponde ao subconjunto de instâncias na partição do nó $n$. Desse modo, o elemento de $\boldsymbol{Y}_{\text {frac }}^{n}$ na posição $k$ corresponde à fração de instâncias na partição do nó $n$ de uma árvore que pertencem à classe $Y_{k}, k \in\{1, \ldots, K\}^{5}$.

- Incremento local $\boldsymbol{I} \boldsymbol{L}_{A}^{f}$ de um nó $f$ filho relativo ao atributo $A$ e ao nó $p$ pai, dado por:

$$
\boldsymbol{I} \boldsymbol{L}_{A}^{f}=\left\{\begin{array}{l}
\boldsymbol{Y}_{\text {frac }}^{f}-\boldsymbol{Y}_{\text {frac }}^{p}, \text { se o atributo } A \text { corresponde ao atributo teste no nó pai } p \\
\mathbf{0}_{K}, \text { caso contrário }
\end{array}\right.
$$

em que $\mathbf{0}_{K}$ corresponde a um vetor de dimensão $K$ que contém 0 em todas as posições.

$\mathrm{O}$ incremento local de um atributo $A$ representa o quanto a probabilidade de uma determinada instância pertencer a cada classe é afetada pelo valor de $A$.

- Contribuição $\boldsymbol{C} \boldsymbol{A}_{i, t}^{A}$ de um atributo $A$ na árvore $t$ para uma instância $\boldsymbol{x}_{i}$, dada por:

$$
\boldsymbol{C} \boldsymbol{A}_{i, t}^{A}=\sum_{n \in \mathcal{C}\left(\boldsymbol{x}_{i}, t\right)} \boldsymbol{I} \boldsymbol{L}_{A}^{n}
$$

em que $\mathcal{C}\left(\boldsymbol{x}_{i}, t\right)$ denota o conjunto de nós no caminho da classificação de $\boldsymbol{x}_{i}$ pela árvore $t$.

Com isso, a contribuição $\boldsymbol{C} \boldsymbol{A}_{i}^{A}$ do atributo $A$ na instância $\boldsymbol{x}_{i}$ pode ser calculada por:

$$
\boldsymbol{C} \boldsymbol{A}_{i}^{A}=\frac{1}{T} \sum_{t=1}^{T} \boldsymbol{C} \boldsymbol{A}_{i, t}^{A} .
$$

Se for fixada uma classe como alvo de uma possível análise (por exemplo, "Hipertensão" = Não), é possível avaliar quais valores de atributos apresentaram uma contribuição positiva ou negativa para esse resultado. Esse tipo de análise é bastante útil em domínios que se deseja avaliar com mais detalhe a influência dos atributos na criação do modelo, e principalmente para obter a transparência da classificação de novas instâncias (de forma a avaliar quais valores tiveram maior contribuição para o resultado) [PPRN13]. Além disso, vale notar que enquanto o cálculo de importância de atributos é feito sobre instâncias nos conjuntos $O O B_{t}$ de cada árvore $t$, o cálculo de contribuição de atributos é feito sobre suas instâncias de treino (para avaliar as contribuições dos atributos na criação do modelo) ou sobre instâncias novas (com o objetivo de obter a transparência de sua classificação). Assim, esse método não se trata de uma alternativa ao método do cálculo de importância de variáveis, e sim de um complemento.

\footnotetext{
${ }^{5}$ Como $\sum_{k=1}^{K} Y_{\text {frac }, k}^{n}=1$, a dimensionalidade de $\boldsymbol{Y}_{\text {frac }}^{n}$ poderia ser reduzida para K-1, já que um dos elementos pode ser calculado a partir dos demais. Neste texto, entretanto, mantivemos a dimensionalidade $K$ por simplicidade.
} 


\subsection{Modelo Prognóstico Clínico}

Sistemas de Apoio à Decisão Clínica (ADC) são sistemas que auxiliam profissionais da saúde nos processos de avaliações específicas de pacientes ou de tomada de decisão clínica [BI12]. Esse suporte pode ser dado por diversas formas, como, por exemplo, geração automática de alertas e lembretes, reconhecimento e interpretação de imagens médicas, e utilização de modelos computacionais preditivos, construídos a partir de dados clínicos e sociodemográficos de pacientes.

Em particular, o uso de modelos computacionais preditivos no contexto clínico é vantajoso pela capacidade de se processar uma grande quantidade de dados de forma mais rápida e eficaz, sendo possível identificar padrões ou correlações que não seriam notados de outra forma [KSK $\left.{ }^{+} 14\right]$. Ainda, em um projeto de pesquisa realizado por Kawamoto et al. [KHBL05], verificou-se que o uso de modelos computacionais em sistemas de ADC foi um dos quatro fatores mais relevantes que levaram a uma significativa melhora da prática clínica em 70 estudos. Os principais objetivos do uso de modelos computacionais em sistemas de ADC se resumem em diagnóstico, planejamento de tratamento e prognóstico clínico [BZ08].

Estudos de prognóstico clínico, em particular, visam à predição do curso de uma doença e são utilizados por profissionais de saúde na escolha de tratamentos aplicáveis, de forma a aumentar as chances ou a qualidade da recuperação dos pacientes [Jas90]. Assim, modelos computacionais prognósticos investigam o desenvolvimento de uma doença em pacientes baseando-se em seus atributos clínicos e sociodemográficos e podem ser utilizados por sistemas de ADC com o objetivo de auxiliar no processo de predição do curso da doença de pacientes. Quando o conhecimento em um domínio clínico relativo ao prognóstico é escasso, ou quando está disponível apenas a poucos especialistas do domínio e não é aplicado em termos práticos, a utilização de um modelo computacional visando a otimização do processo de prognóstico pode ser bastante proveitosa. Além disso, seu uso pode evitar erros cometidos por profissionais de saúde, como os de subestimar evidências importantes ou tomar decisões enviesadas (se baseando fortemente em casos individuais de suas experiências) [Vog09].

Para aumentar sua confiabilidade e sua aceitação pelos profissionais da saúde, um modelo prognóstico que compõe um sistema de apoio à decisão médica deve possuir credibilidade clínica, obtida por fatores como [WA95]:

- Inclusão de dados clinicamente relevantes e de qualidade (com poucos ruídos ou erros) para a construção do modelo;

- Simplicidade na aquisição de dados, aplicação e utilização do modelo;

- Validação da metodologia empregada na criação do modelo;

- Transparência do modelo, permitindo que seja avaliado e examinado por profissionais da saúde. A predição do modelo só deve ser considerada se os fatores envolvidos possuírem significado clínico.

\subsubsection{Criação do Modelo}

Sob a perspectiva computacional, a criação de um modelo prognóstico clínico pode ser abordada como um problema de extração de conhecimento sobre um conjunto de dados utilizando técnicas de classificação, de forma que cada paciente corresponda a uma instância, os atributos correspondam a seus dados clínicos e sociodemográficos e as classes representem o prognóstico. Dependendo do objetivo do problema, o prognóstico de pacientes pode ser obtido por meio de predição de sobrevivência, identificação de grupos de risco, estimativa do tempo de recuperação (ou mortalidade), predição de eventos clínicos relacionados à terapia ou predição do curso da doença [Vog09].

Nesse contexto, um modelo de prognóstico pode ser construído utilizando o processo de $K D D$ descrito na Seção 2.1, com o objetivo de obter um modelo que realiza predições confiáveis e que possam auxiliar profissionais da saúde a aprimorarem o processo prognóstico. Em termos de análise dos dados, no processo de Mineração de Dados podem ser identificados os preditores mais significativos e as correlações entre os atributos e o prognóstico. Para isso, a escolha da técnica a ser aplicada 
deve ser feita visando a interpretabilidade do modelo e a confiabilidade dos resultados (e.g., pode ser preferível a escolha de um classificador cuja resposta possa ser retornada juntamente com um valor de probabilidade) [BZ08].

Para que todo esse processo seja possível, os dados disponíveis para o problema devem primeiramente passar pelas etapas de seleção, limpeza, pré-processamento e transformação. Essas etapas podem muitas vezes se tornar um processo complexo no domínio clínico, pois seus dados são tipicamente caracterizados por diferentes tipos de atributos (numéricos, categorizados, ou até mesmo de séries temporais), além de serem frequentemente propensos a ruídos e a apresentar valores faltantes. O processo pode se apresentar ainda mais complexo uma vez que os dados transformados devem seguir uma estrutura específica para cada tipo de técnica.

\subsubsection{Validação do Modelo}

Para que um modelo prognóstico possa ser utilizado na prática por profissionais da saúde, é necessário que seu desempenho seja satisfatório para pacientes diferentes daqueles cujos dados foram utilizados na sua criação. Dessa forma, é indispensável que se realize a validação do modelo. O processo de validação de um modelo prognóstico pode ser feito considerando dois tipos de estratégias: validação laboratorial e validação clínica [Vog09]. A validação clínica é realizada com a participação de profissionais da saúde, que analisam seus resultados e avaliam a viabilidade de se utilizar o modelo em um contexto prático. A validação laboratorial, por sua vez, concentra-se no desempenho do modelo em termos de sua acurácia ${ }^{6}$, e pode ser classificada em validação interna e externa.

A validação interna do modelo é feita considerando seu desempenho em termos de classificação quando aplicado a pacientes de uma mesma população subjacente à da amostra utilizada em sua construção, e pode ser feita utilizando as abordagens de validação descritas na Seção 2.1.2.1. Já a validação externa considera o desempenho do modelo sobre pacientes de populações diferentes das da amostra utilizada na construção e validação interna do modelo, no que diz respeito, por exemplo, à localização, período de tempo ou métodos usados na coleta dos dados. Esse tipo de validação é mais confiável em termos de avaliação da generalização do modelo [AR00].

\footnotetext{
${ }^{6}$ Apesar de se referir a uma métrica de desempenho por si só, a expressão "acurácia" também é utilizada como um termo geral para se referir ao poder preditivo de um modelo.
} 


\section{Capítulo 3}

\section{Trabalhos Relacionados}

O aumento da disponibilidade de recursos computacionais estimulou profissionais da saúde a buscarem métodos e ferramentas que pudessem auxiliar na automatização do processo de tomada de decisão no domínio clínico, impulsionando a criação de modelos preditivos para apoio à decisão médica. No domínio prognóstico, a partir de um conjunto de dados de pacientes cujos resultados de recuperação são conhecidos e registrados, esses modelos são capazes de identificar indicadores prognósticos e correlações entre os atributos dos pacientes, e através da interpretação de seus resultados, podem auxiliar profissionais da saúde na escolha do tratamento mais adequado a um determinado paciente com condições similares [SBF79, $\left.\mathrm{RCK}^{+} 11\right]$.

Técnicas de Mineração de Dados e Aprendizado de Máquina são frequentemente utilizadas para gerar modelos prognósticos, como, por exemplo, Redes Neurais [OM97, HTTTF13, BBL $\left.{ }^{+} 07\right]$, Redes Bayesianas [JBS ${ }^{+}$03, SL98, $\mathrm{SBS}^{+}$13], Regressão Logística $\left[\mathrm{SMP}^{+}\right.$08, $\mathrm{ASS}^{+}$02], Máquinas de Vetores de Suporte [EN12] e Árvores de Decisão [ASS ${ }^{+}$02, RK04, $\mathrm{BMD}^{+}$16, MS09, HSWS12]. Essas técnicas são utilizadas em diferentes domínios, como para prognóstico de pacientes diagnosticados com leucemia [HTTTF13], AIDS [OM97], câncer [BBL ${ }^{+}$07, SL98, SBS ${ }^{+}$13, EN12], lesões cerebrais traumáticas ou severas $\left[\mathrm{LLT}^{+} 15, \mathrm{ASS}^{+} 02, \mathrm{RK} 04, \mathrm{MCCG}^{+} 13\right]$, entre outros.

\subsection{Uso de Aprendizado de Máquina para Prognóstico de Lesões Neurológicas}

Em relação ao domínio de lesões neurológicas, a maior parte dos modelos prognósticos desenvolvidos concentram-se no campo de lesões cerebrais traumáticas.

Rovlias e Kotsou [RK04], por exemplo, empregaram a técnica de Árvores de Decisão (mais especificamente, a técnica $C A R T$ ) na análise de dados de 345 pacientes diagnosticados com lesão cerebral severa, com o objetivo de criar um modelo para predizer o resultado da recuperação de um paciente 6 meses após a ocorrência da lesão, identificando quais atributos são mais significativos. Para a criação do modelo, foram selecionados como atributos 16 indicadores prognósticos que se mostraram relevantes em estudos médicos e estatísticos anteriores, sendo 14 deles atributos clínicos e 2 sociodemográficos. O modelo resultante obteve uma acurácia média de 86,14\%, calculada utilizando validação cruzada.

Marcano-Cedeño et al. [ $\left.\mathrm{MCCG}^{+} 13\right]$, por sua vez, utilizaram técnicas de Redes Neurais com o objetivo de predizer a eficácia de aplicação de tarefas de reabilitação sobre pacientes com lesões cerebrais. Foram utilizados dados provenientes de 250 pacientes, sendo selecionados para análise 9 atributos (7 clínicos e 2 sociodemográficos). Os pacientes foram classificados de acordo com a observação de seus progressos (se houve progresso ou não) em relação à função cognitiva de memória, avaliados a partir dos resultados de execuções de tarefas de reabilitação cognitiva. Nesse caso, o modelo gerado obteve acurácia de 78,7\%, também calculada utilizando validação cruzada.

Diversos outros modelos foram desenvolvidos no domínio de lesões cerebrais $\left[\mathrm{LLT}^{+} 15, \mathrm{SMP}^{+} 08\right.$, HSWS12], muitos dos quais foram abordados por Mushkudiani et al. [ $\mathrm{MHH}^{+} 08$ ] em uma revisão bibliográfica sobre o tema. 
Ainda no domínio de lesões neurológicas, Berney et al. [BGOD11] desenvolveram um modelo de predição do tratamento mais adequado para pacientes com lesão da medula espinhal, com o objetivo de auxiliar no processo de tomada de decisão de profissionais da saúde em relação à escolha entre duas opções de tratamento. Foi utilizada a técnica de Árvore de Decisão aplicada a dados de 96 pacientes diagnosticados com lesão medular aguda, caracterizados por 9 atributos (2 sociodemográficos e 7 clínicos), identificados por especialistas como candidatos relevantes a preditores, dos quais 3 foram identificados pelo modelo como sendo significativos. O modelo resultante obteve uma acurácia de 82,3\%. Modelos prognósticos de lesões medulares com objetivos relativamente diferentes foram desenvolvidos por Hou et al. [HLZ $\left.{ }^{+} 15\right]$ e Wilson et al. $\left[\mathrm{WGF}^{+} 12\right]$, por meio da técnica de Regressão Logística.

No entanto, no domínio particular de lesões do plexo braquial, ainda não foram desenvolvidos modelos prognósticos por meio de técnicas de Aprendizado de Máquina ou Mineração de Dados. Jaspers et al. [JvDvdH89] implementaram um sistema de apoio à decisão clínica no domínio de lesões do plexo braquial chamado PLEXUS, com o objetivo de auxiliar profissionais da saúde no processo de diagnóstico de pacientes nesse domínio. Também era pretendido o desenvolvimento de um modelo prognóstico de lesões do plexo braquial, porém, como os autores não dispunham de uma quantidade suficiente de dados confiáveis na época, a implementação do modelo não foi realizada. Assim, apenas foram realizadas algumas análises mais simples, e foram abordados alguns conceitos e problemas envolvidos no processo de extração de conhecimento a partir de dados de pacientes com lesão no plexo braquial visando à construção de um modelo prognóstico [Jas90].

No sistema PLEXUS, era pretendido criar um modelo prognóstico a partir dos dados de pacientes que descrevessem a condição inicial e o estado da lesão, os tratamentos que foram aplicados e os procedimentos cirúrgicos realizados, de forma que incluíssem aspectos clínicos, psicossociais e informações sobre atividades cotidianas e de utilização de dispositivos auxiliares. Como parte da iniciativa para a coleta desses dados, em 1984 foi implementado no centro de reabilitação de De Hoogstraat ${ }^{1}$ um sistema de coleta de dados por meio de preenchimento de questionários em papel. Porém, esse sistema não chegou a ser utilizado como parte da rotina clínica, e assim a coleta de dados não foi possível.

Uma segunda iniciativa de aquisição de dados foi então realizada, por meio de uma análise retrospectiva de 116 registros clínicos de pacientes com lesões do plexo braquial que foram tratados no mesmo centro de reabilitação, dos quais apenas 49 possuíam uma quantidade razoável de dados que poderiam ser utilizados. Foram coletados dados referentes ao diagnóstico, estado inicial da lesão, função de sensibilidade e motricidade, e a tratamentos aplicados a cada paciente, totalizando 128 atributos. Esses pacientes foram categorizados em recuperação possível ou impossível para a parte superior do braço e para a parte inferior. Dos 49 pacientes, 18 não puderam ser categorizados segundo esse critério pela ausência de valores para os dados relacionados a essa classificação. Assim, a partir de uma análise simplificada sobre 31 pacientes, foi verificado que pacientes que procuraram o centro de reabilitação tardiamente mostraram uma recuperação inferior, ao contrário dos que começaram um tratamento logo após a ocorrência da lesão. Porém, outras correlações que poderiam ter sido identificadas pela aplicação de técnicas computacionais (i.e., de Aprendizado de Máquina) não foram exploradas, sendo apenas abordada a correlação entre o período entre a lesão e o início do tratamento dos pacientes.

\subsection{Uso de Árvores e Florestas de Decisão para Prognóstico Clínico}

Uma das técnicas mais frequentemente utilizadas para criação de modelos prognósticos são as Árvores de Decisão, uma vez que possibilitam uma simples interpretação e entendimento de seus resultados, possibilitando sua validação por profissionais da saúde [CW07].

Andrews et al. [ASS ${ }^{+}$02], por exemplo, utilizaram a técnica de Árvores de Decisão na análise de dados de 121 pacientes diagnosticados com lesão traumática cerebral visando à criação de um modelo

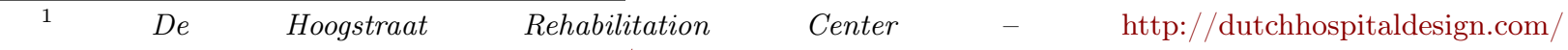
rehabilitation-centre-de-hoogstraat-utrecht-nl/
} 
para predizer o resultado da recuperação (boa ou ruim) de um paciente 12 meses após o diagnóstico. A recuperação foi considerada ruim se resultou ao paciente deficiência severa, estado vegetativo ou morte, e foi considerada boa se resultou em deficiência moderada ou boa reabilitação. Curiosamente, o modelo resultante apontou correlações entre atributos que não tinham sido exploradas antes no domínio, levantando novas hipóteses a serem clinicamente estudadas e que podem levar à descoberta de novos conhecimentos na área de prognóstico de lesões cerebrais. Essa possibilidade de descoberta pode ser bastante útil para apontar atributos e correlações que podem ser relevantes em domínios onde não existem indicadores prognósticos bem definidos.

Apesar de bastante utilizadas no domínio prognóstico, Árvores de Decisão tendem a sofrer de sobreajuste, ou seja, podem resultar em modelos muito complexos que não possuem um bom poder de generalização [Pau12]. Esse risco é ainda maior em domínios cujos dados são caracterizados por um pequeno número de instâncias e um grande número de atributos. Uma possível alternativa seria utilizar Florestas Aleatórias neste contexto, visando obter maiores generalização e acurácia nos modelos gerados. Entretanto, Florestas Aleatórias são menos utilizadas na criação de modelos prognósticos, provavelmente por serem consideradas como uma técnica não transparente. Contudo, existem métodos que permitem sua interpretação, calculando a importância de atributos para a classificação [Bre01, PPRN13]. Os resultados dos trabalhos de Ward et al. [WPDM06], Boughorbel et al. [BAAE16] e Shaikhina et al. [SLD $\left.{ }^{+} 17\right]$ mostram a viabilidade de sua utilização para criação de modelos prognósticos.

Ward et al. [WPDM06] utilizaram a técnica de Florestas Aleatórias para criar um modelo de predição de mortalidade a partir dos dados de 3.839 pacientes diagnosticados com lúpus. Foram considerados cerca de 65 atributos como candidatos a preditores de mortalidade; o modelo resultante apontou 10 deles como os mais relevantes, por meio de um método de interpretação do modelo desenvolvido por Breiman [Bre01]. A média do erro de classificação obtida foi de 11,9\%, o que demonstrou o potencial de se utilizar Florestas Aleatórias nesse contexto.

Resultados ainda mais significativos foram obtidos por Boughorbel et al. [BAAE16], que compararam a performance de oito técnicas para a criação de modelos prognósticos de câncer de mama, entre elas Florestas Aleatórias, Redes Neurais, Modelo Linear Generalizado, Máquinas de Vetores de Suporte e k Vizinhos mais Próximos (do inglês $k$ Nearest Neighbors - $k N N$ ), utilizando dados de 1.981 pacientes e considerando 11 atributos. Florestas Aleatórias obtiveram uma performance superior aos demais modelos em termos de acurácia e generalização, o que evidencia a vantagem de serem utilizadas na criação de modelos prognósticos.

Entretanto, como os trabalhos de Ward et al. [WPDM06] e Boughorbel et al. [BAAE16] utilizaram uma quantidade relativamente grande de dados, eles não evidenciam a efetividade do uso de Florestas Aleatórias para criação de modelos preditivos em domínios cujo conjunto de dados de pacientes é reduzido. Essa condição foi explorada por Shaikhina et al. [SLD ${ }^{+} 17$ ], que avaliaram a viabilidade de se utilizar Florestas Aleatórias para criar um modelo para predizer a resposta (rejeição ou não rejeição) de pacientes submetidos a transplantes de rim. Foram utilizados para análise 80 pacientes representados por 14 atributos e o modelo resultante obteve uma acurácia de 81,9\%.

Apesar de apresentarem resultados significativos, esses trabalhos utilizam apenas um método para a interpretação dos modelos gerados pelas Florestas Aleatórias, desenvolvido por Leo Breiman [Bre01]. Contudo, esse método de interpretação é relativamente simplificado e não permite distinguir influências negativas e positivas dos atributos em relação às classes. Métodos complementares foram desenvolvidos visando a interpretação dos modelos obtidos por Florestas de Decisão, como os propostos por Kuz'min et al. [KPAA11] e Palczewska et al. [PPRN13], e poderiam ser explorados no contexto de modelos prognósticos.

Além disso, nessas abordagens foi utilizado um número pequeno de atributos candidatos a indicadores prognósticos, dos quais um subconjunto foi apontado pelo modelo resultante como contendo indicadores relevantes. O problema da alta dimensionalidade não foi abordado em nenhum desses trabalhos. 


\subsection{Uso de Florestas de Decisão em Domínios de Alta Dimensio- nalidade}

O problema da alta dimensionalidade $(N>>M)$ dos dados no contexto de modelos prognósticos foi tratado por Zhang et al. [ZOW $\left.{ }^{+} 17\right]$, que abordaram a exploração de cinco técnicas de seleção de atributos a serem aplicadas a um grande número de indicadores candidatos e oito técnicas de classificação para a criação de um modelo prognóstico de câncer de pulmão. Os atributos foram extraídos de imagens médicas e de dados clínicos e sociodemográficos de 112 pacientes diagnosticados com um tipo de câncer de pulmão. Das técnicas analisadas, Florestas Aleatórias apresentaram, na média, o melhor resultado, juntamente com Análise de Componentes Principais (do inglês Principal Component Analysis - PCA), uma técnica de redução de dimensionalidade aplicada para seleção de atributos [GE03]. Ainda que tenha sido a maior acurácia obtida nos experimentos, seu valor estimado foi de $70 \%$, o que pode ser considerado como uma performance média.

A alta dimensionalidade dos dados, porém, não é um problema frequentemente abordado no domínio de modelos prognósticos. Por outro lado, em domínios clínicos que envolvem predição utilizando dados de genes humanos, o desafio de construir modelos utilizando dados de apenas dezenas de pacientes caracterizados por um grande número de atributos (na ordem de milhares) é bastante comum. Tipicamente, esses tipos de modelos têm como objetivo a seleção dos genes mais relevantes para a predição alvo (como por exemplo, presença ou não de câncer), de forma a identificar genes relevantes com o propósito de interpretação (e.g., para identificar genes cuja relevância ainda não foi investigada para pesquisas futuras), ou a identificar o menor conjunto de genes que podem ser utilizados para predição na prática clínica.

Díaz-Uriarte e Alvarez de Andrés [DUA06] utilizaram Florestas Aleatórias nesse segundo contexto, de modo que a seleção de atributos foi realizada utilizando a própria técnica em uma abordagem de invólucro (descrita na Seção 2.1.2.2). Para encontrar o menor número de genes para predição, primeiramente foram calculadas as importâncias de cada um dos atributos (i.e., genes) utilizando o método de importância de atributos desenvolvido por Leo Breiman [Bre01]. Depois, foi aplicado um processo iterativo em que, em cada passo, foi criada uma Floresta Aleatória descartando uma fração dos genes menos importantes, e calculando sua acurácia em termos do erro OOB. O subconjunto de genes que levou a maior acurácia (subtraída do erro padrão das acurácias da amostra) foi selecionado para compor o modelo final.

Apesar dessa abordagem ter resultado em um pequeno subconjunto de genes que levaram a modelos com bons valores de acurácia, foi observada uma instabilidade na seleção dos atributos: em diferentes execuções do mesmo procedimento sobre subconjuntos dos dados utilizados, os genes que haviam sido previamente selecionados para o modelo final acabaram não aparecendo com frequência. Genuer et al. [GPTM10] também propuseram um método de seleção de atributos do tipo invólucro para domínios de alta dimensionalidade utilizando Florestas Aleatórias. Porém, enquanto o foco da proposta de Díaz-Uriarte e Alvarez de Andrés foi encontrar o menor número de atributos que sejam suficientes para a criação de um modelo preditor, e não identificar os atributos relevantes com o propósito de interpretação, Genuer et al. propuseram um método para alcançar esse segundo objetivo.

O método consiste em, primeiramente, ordenar os atributos de forma decrescente, considerando a média de suas importâncias calculadas por 50 Florestas Aleatórias, de 500 árvores cada uma. Depois, seleciona-se um valor de "corte" de forma que atributos que apresentem importância menor que esse valor não sejam considerados nos próximos passos. A regra utilizada para escolha desse valor, entretanto, é em geral conservadora, no sentido de que o valor escolhido leva a eliminação de poucos atributos. Depois do ranqueamento e eliminação, são calculadas as médias dos erros OOB para outras 50 Florestas Aleatórias construídas primeiramente utilizando apenas o atributo mais relevante, e depois acrescentando a cada passo o próximo atributo mais importante, até incluir todos os atributos considerados após a eliminação. O resultado do modelo final, em termos da acurácia (calculada utilizando o método de validação cruzada), se mostrou competitivo. Porém, além de ser computacionalmente intensivo, esse método leva em geral à seleção de um grande número atributos 
para compor o modelo final, o que pode ser indesejável para dados caracterizados por poucas instâncias. 


\section{Capítulo 4}

\section{Caracterização dos Dados}

Neste projeto, iremos utilizar dados de pacientes do Instituto de Neurologia Deolindo Couto (INDC) da Universidade Federal do Rio de Janeiro (UFRJ) no processo de criação de um modelo prognóstico de LTPBA.

O INDC é uma unidade de ensino, pesquisa e extensão que compõe o complexo médico-hospitalar da UFRJ [IND]. Em particular, o Laboratório de Neurociências e Reabilitação (LabNeR) do INDC vem trabalhando na investigação dos mecanismos de plasticidade cerebral no contexto de tratamentos de reabilitação de pacientes com lesões do plexo braquial, através de medidas fisiológicas e questionários clínicos.

Os dados coletados em experimentos conduzidos em projetos científicos em andamento no INDC estão sendo registrados em um banco de dados e gerenciados por meio de uma ferramenta de software livre chamada Neuroscience Experiments System (NES) [NES], desenvolvida no Centro de Pesquisa, Inovação e Difusão em Neuromatemática (NeuroMat) [Neu]. Esse banco de dados visa amparar progressos na compreensão do funcionamento cerebral, assim como no tratamento de patologias do sistema nervoso.

O NES propicia a reprodutibilidade dos experimentos, estabelecendo um formato padrão para a representação e armazenamento dos dados produzidos nos experimentos de um mesmo laboratório ou grupo de pesquisa. Além disso, o NES garante que todo dado de experimento registrado no banco de dados mantido por ele esteja devidamente acompanhado de suas informações de proveniência. Assim, assegura-se uma melhor qualidade dos dados e facilita-se sua anonimização, compartilhamento público e reutilização.

No estágio atual de seu desenvolvimento, o banco de dados mantido pelo NES contém dezenas de características sociodemográficas e clínicas sobre alguns dos participantes dos experimentos conduzidos pelo INDC diagnosticados com lesões no plexo braquial. Esses dados são coletados por meio do preenchimento de fichas de avaliação estruturadas por questionários eletrônicos, criados e mantidos com o auxílio da ferramenta de software livre LimeSurvey [lim].

Quando um paciente é avaliado pela primeira vez no INDC, um pesquisador ou profissional da saúde preenche um questionário de admissão, intitulado "Avaliação de Entrada Unificada", com informações sobre: histórico prévio (traumatismos, cirurgias e dor), características da lesão do plexo (data da ocorrência da lesão, evento que levou ao trauma, traumatismos associados), tratamentos em curso (fisioterapia, cirurgia, medicações), exame físico (inspeção, sensibilidade, motricidade, presença de dor) e localização da lesão. Quando o paciente retorna para uma próxima avaliação, aplica-se um novo questionário, intitulado "Avaliação de Seguimento Unificado", em que se repetem perguntas sobre tratamentos em curso (fisioterapia, cirurgia, medicações) e exame físico (inspeção, sensibilidade, força, presença de dor), visando avaliar a evolução do quadro do paciente. Ainda, se o paciente foi submetido a uma ou mais cirurgias do plexo, é feito o preenchimento de um outro questionário intitulado "Avaliação Cirúrgica Unificada" com informações sobre cada procedimento cirúrgico realizado.

O NES possui uma funcionalidade de extração de respostas de questionários, que permite que arquivos de formato CSV (comma-separated values) contendo as respostas dos pacientes de uma 
forma estruturada sejam gerados. Para cada questionário, é possível realizar a extração de forma a obter um arquivo contendo todos seus preenchimentos, cada qual identificado pelo código do participante que o realizou. As colunas do arquivo representam campos correspondentes às questões (e por vezes as opções de resposta) do questionário, ou a dados relativos ao participante (por exemplo, código de identificação). Dessa forma, os valores dos campos de uma linha representam as respostas dadas por um participante e os dados referentes a ele.

A maior parte dos campos dos questionários consistem em opções de questões de múltipla escolha, que podem ser utilizadas para gerar atributos que representam os pacientes. Nesse caso, os atributos serão categorizados, uma vez que seus possíveis valores correspondem às opções de múltipla escolha da questão. Um exemplo de uma pergunta dessa forma é "Tem história prévia de fratura?", cujas opções de resposta são "Sim", "Não" ou "Não informado/ Não avaliado".

Os campos que não consistem em questões de múltipla escolha são relativos a datas e a exames físicos de motricidade. Esses exames físicos avaliam a força e a amplitude de diferentes movimentos de membros superiores, como, por exemplo, flexão de cotovelo, extensão de cotovelo, rotação externa do ombro, abdução do ombro, flexão de punho, entre outros. A amplitude é medida em graus, enquanto que a força é medida na escala muscular MRC (Medical Research Council). Essa escala apresenta valores que variam de 0 a 5 , sendo 0 correspondente a ausência de contração muscular, 1 a contração muscular visível (mas sem movimento), 2 a movimento ativo presente desde que eliminada a gravidade, 3 a movimento ativo presente contra a gravidade (mas não contra uma resistência), 4 a movimento ativo contra a gravidade e resistência (porém ainda aquém do normal) e 5 a força normal [Bri76].

Muitas questões relativas à lesão do plexo braquial são feitas separadamente para cada membro superior (esquerdo e direito), uma vez que podem existir pacientes com ambos os lados lesionados. Assim, alguns campos aparecem duas vezes - uma vez considerando o lado direito e outra o lado esquerdo (por exemplo, "Rotação Externa de ombro direito (em graus)" e "Rotação Externa de ombro esquerdo (em graus)").

Além disso, existem campos que correspondem a uma questão e suas opções de resposta, como por exemplo, "Indique o evento que levou ao trauma de plexo braquial direito [Acidentes motociclísticos]", "Indique o evento que levou ao trauma de plexo braquial direito [Acidentes automobilísticos]", "Indique o evento que levou ao trauma de plexo braquial direito [Lesão por arma de fogo]", entre outros. Nesse caso, suas opções de preenchimento podem ser "Sim", "Não" ou "N/A" (representado que a pergunta não é aplicável ao paciente pois o lado referido na pergunta não corresponde ao seu lado lesionado).

Existem ainda questões que só se aplicam quando algumas determinadas respostas são dadas a questões anteriores. Por exemplo, a questão "Se está fazendo fisioterapia, indique com que frequência" só se aplica a pacientes cuja resposta à questão "Está fazendo fisioterapia?" seja "Sim". Desse modo, os pacientes cuja resposta à pergunta anterior seja diferente de "Sim" apresentam um valor em branco para o campo relativo a essa questão.

Para ilustrar a estrutura dos questionários, partes dos questionários de Avaliação de Entrada, Avaliação Cirúrgica e de Avaliação de Seguimento, que são preenchidos com dados dos pacientes do INDC-UFRJ, são apresentadas no Apêndice A.

Neste projeto, estão sendo utilizados dados provenientes de questionários preenchidos por 109 pacientes do INDC-UFRJ, dentre os quais 17 são do sexo feminino e 92 do sexo masculino. A distribuição dos pacientes por faixa etária está ilustrada no gráfico da Figura 4.1. A distribuição dos pacientes em relação ao lado lesionado e aos eventos que levaram à lesão de acordo com o lado lesionado se encontram nas figuras 4.2 e 4.3. É possível que uma lesão tenha sido provocada por mais de um evento.

Idealmente, os pacientes deveriam retornar ao laboratório após 6 meses de seu preenchimento da avaliação de entrada, porém essa situação não é observada na prática. Enquanto todos os 109 pacientes possuem um preenchimento para o questionário de avaliação de entrada, apenas 46 deles possuem um ou mais preenchimentos para o questionário de avaliação de seguimento. Dos 46 participantes, 21 retornaram ao INDC mais de uma vez, sendo que a média do período entre os 
retornos desses pacientes corresponde a 10 meses. Considerando apenas os últimos retornos de cada paciente, o período mais curto entre o retorno e a lesão foi de 5 meses, enquanto o mais longo foi de 92 meses.

O gráfico da Figura 4.4 sumariza o período de tempo em meses entre a lesão e a avaliação de seguimento do primeiro retorno dos 21 pacientes que voltaram mais de uma vez ao INDC (i.e., possuem mais de um preenchimento para o questionário de seguimento). O gráfico da Figura 4.5, por sua vez, mostra o período de tempo entre a lesão e o último retorno desses mesmos pacientes ao INDC. Já o gráfico da Figura 4.6 sumariza o período entre a lesão e o retorno dos outros 25 pacientes, que retornaram ao INDC uma única vez.

Em relação aos dados de interesse provenientes do questionário de seguimento, os gráficos das figuras 4.7, 4.8, 4.9 e 4.10 ilustram a frequência de dor e das avaliações de força muscular sobre abdução do ombro, flexão do cotovelo e rotação externa do ombro, respectivamente, considerando os dados do último retorno de cada paciente ao INDC.

Dos 109 pacientes, 59 possuem resposta "Sim" para a questão "Já fez alguma cirurgia do plexo braquial?" no questionário avaliação de entrada. Entretanto, apenas 28 possuem um ou mais preenchimentos para o questionário de avaliação cirúrgica. Isso ocorre porque alguns pacientes chegam ao INDC pela primeira vez após já terem sido submetidos a alguma cirurgia do plexo braquial, da qual não é possível obter as informações necessárias para o preenchimento do questionário de avaliação cirúrgica (pois, por exemplo, a cirurgia foi realizada em alguma outra instituição).

A distribuição dos intervalos de tempo entre a lesão e o primeiro procedimento cirúrgico de cada paciente está ilustrada na Figura 4.11, e a quantidade de cada tipo de procedimento realizada sobre os pacientes se encontra na Figura 4.12. Um paciente pode ter realizado mais de um procedimento, do mesmo tipo ou de outro.

Os dados anonimizados dos pacientes foram disponibilizados publicamente pelo INDC em um banco de dados de experimentos em neurociência aberto construído pelo NeuroMat, e que pode ser acessado pelo sítio $W e b$

http://neuromatdb.numec.prp.usp.br/experiments/brachial-plexus-injury-database/ ${ }^{1}$.

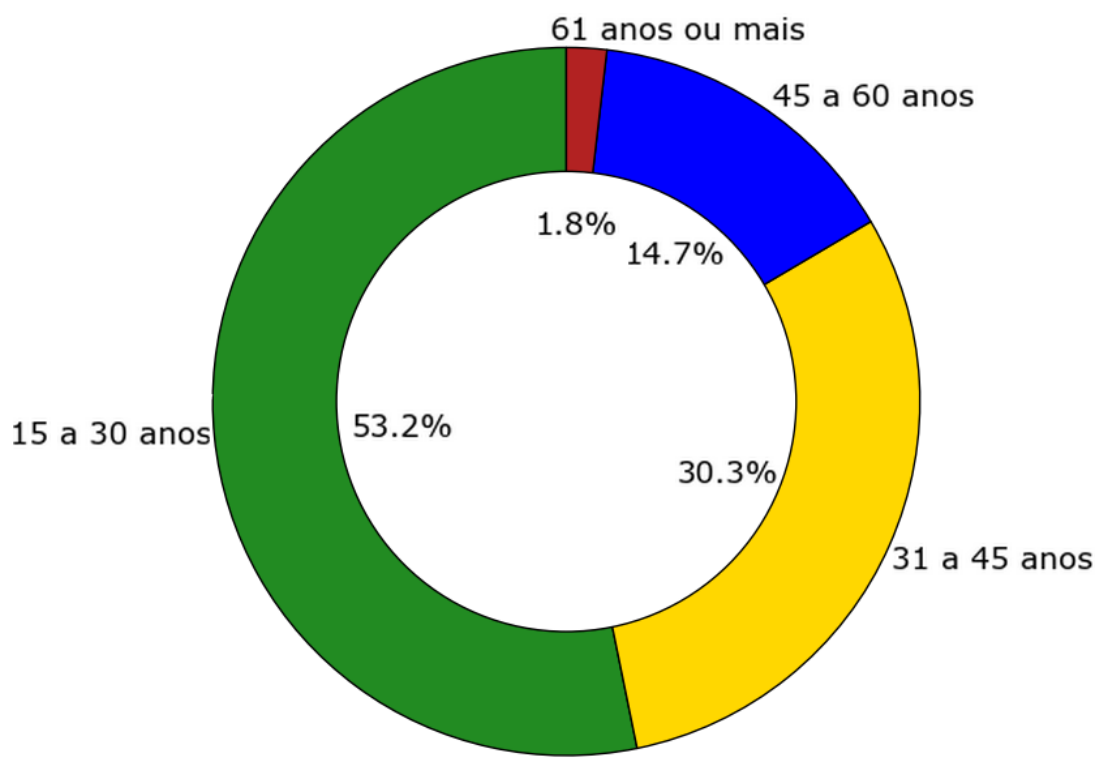

Figura 4.1: Distribuição dos pacientes do INDC-UFRJ por faixa etária, em porcentagem.

\footnotetext{
${ }^{1}$ Acesso em $17 / 05 / 2018$
} 


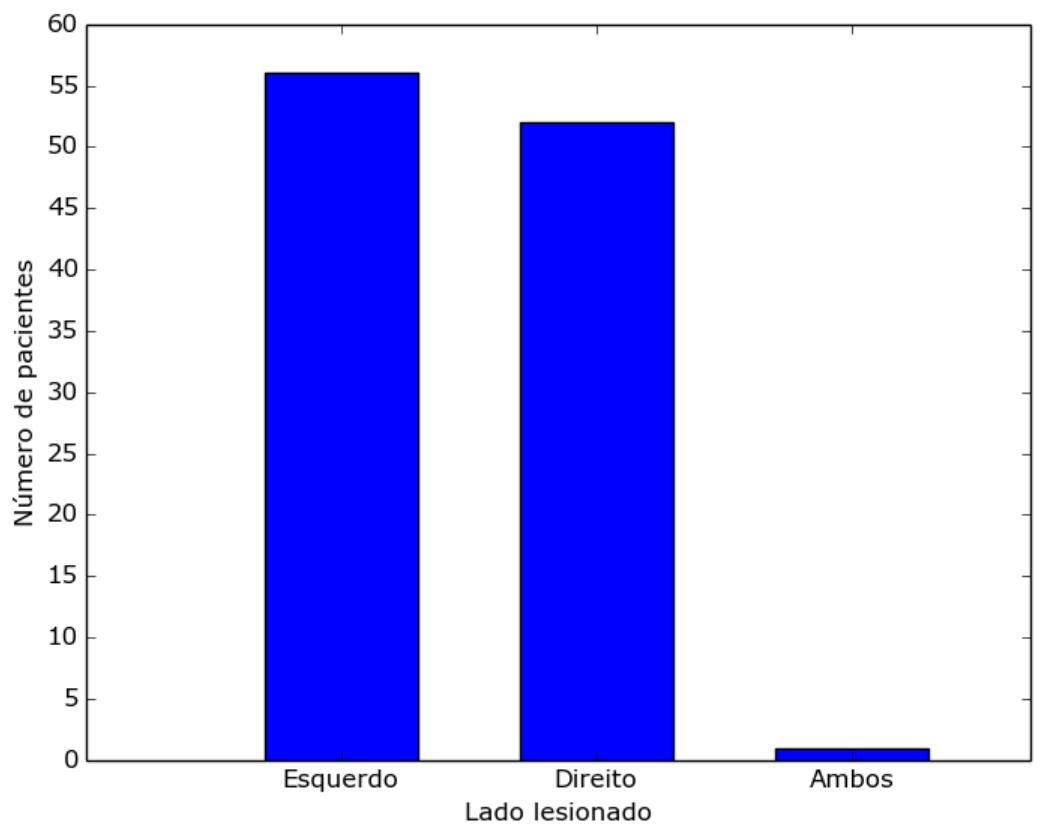

Figura 4.2: Distribuição dos pacientes do INDC-UFRJ por lado da lesão.

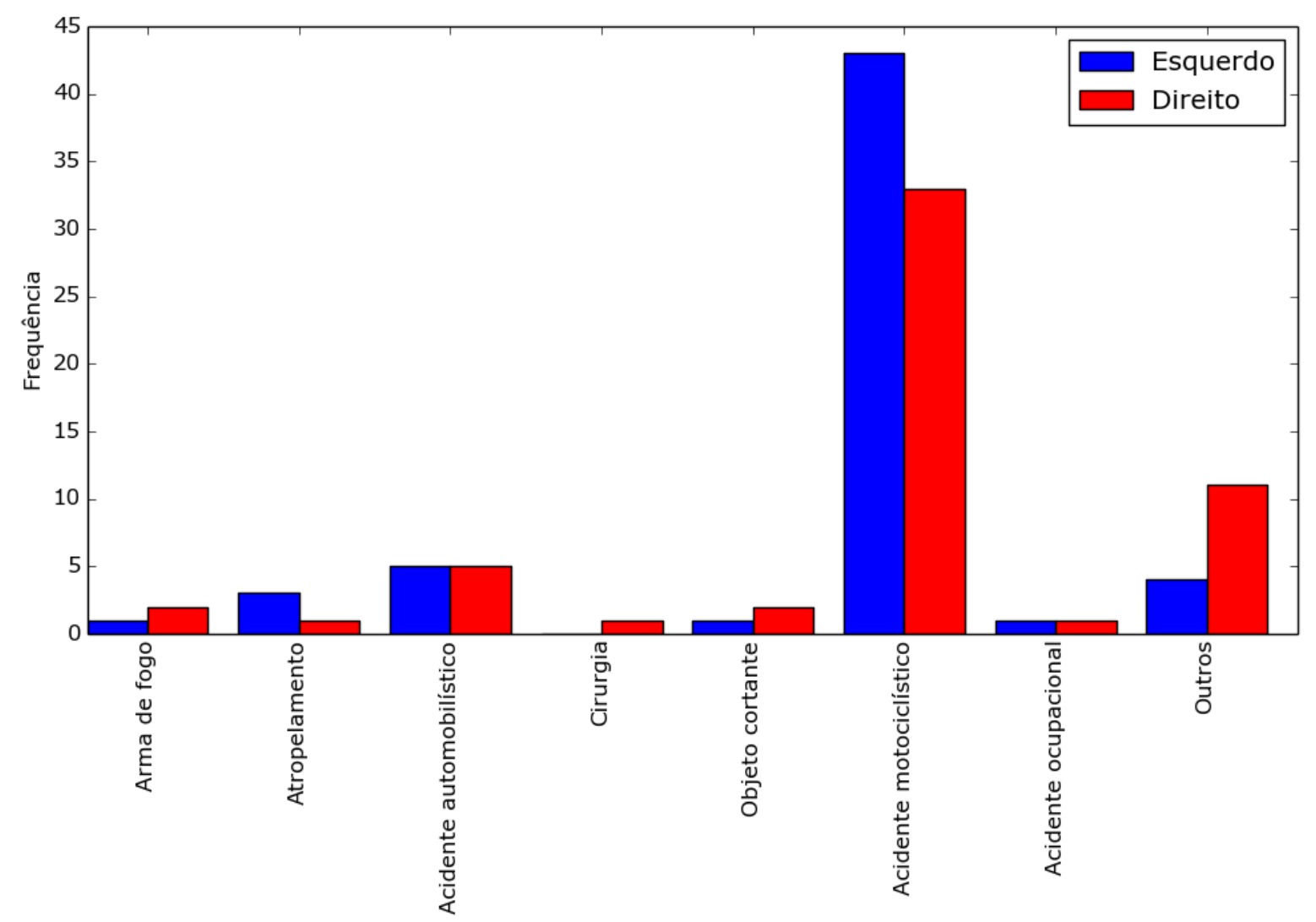

Figura 4.3: Frequência de cada evento que ocasionou as lesões dos pacientes do INDC-UFRJ. 


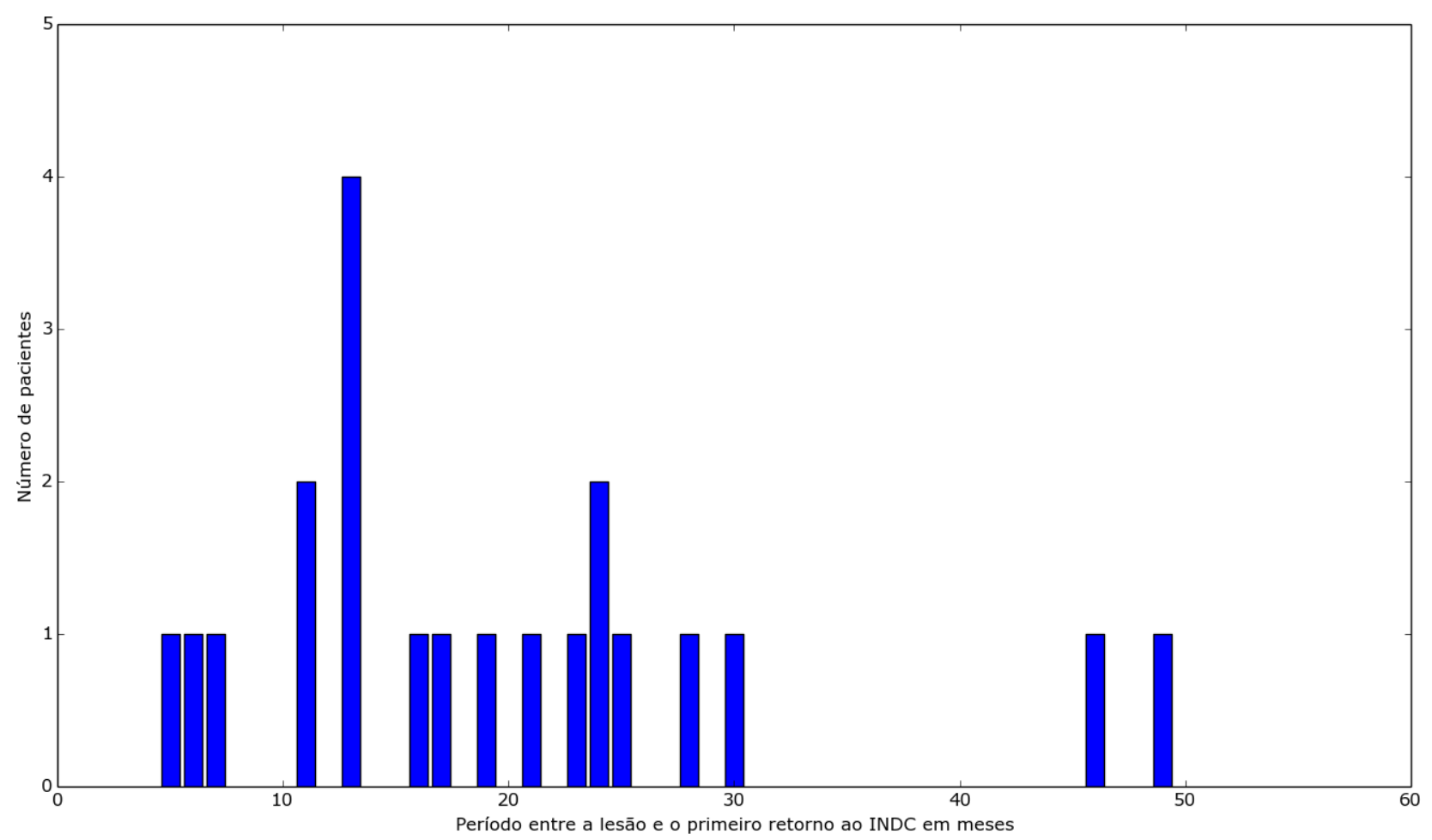

Figura 4.4: Distribuição do período entre a avaliação de entrada e o primeiro retorno dos pacientes ao INDC para a avaliação de seguimento.

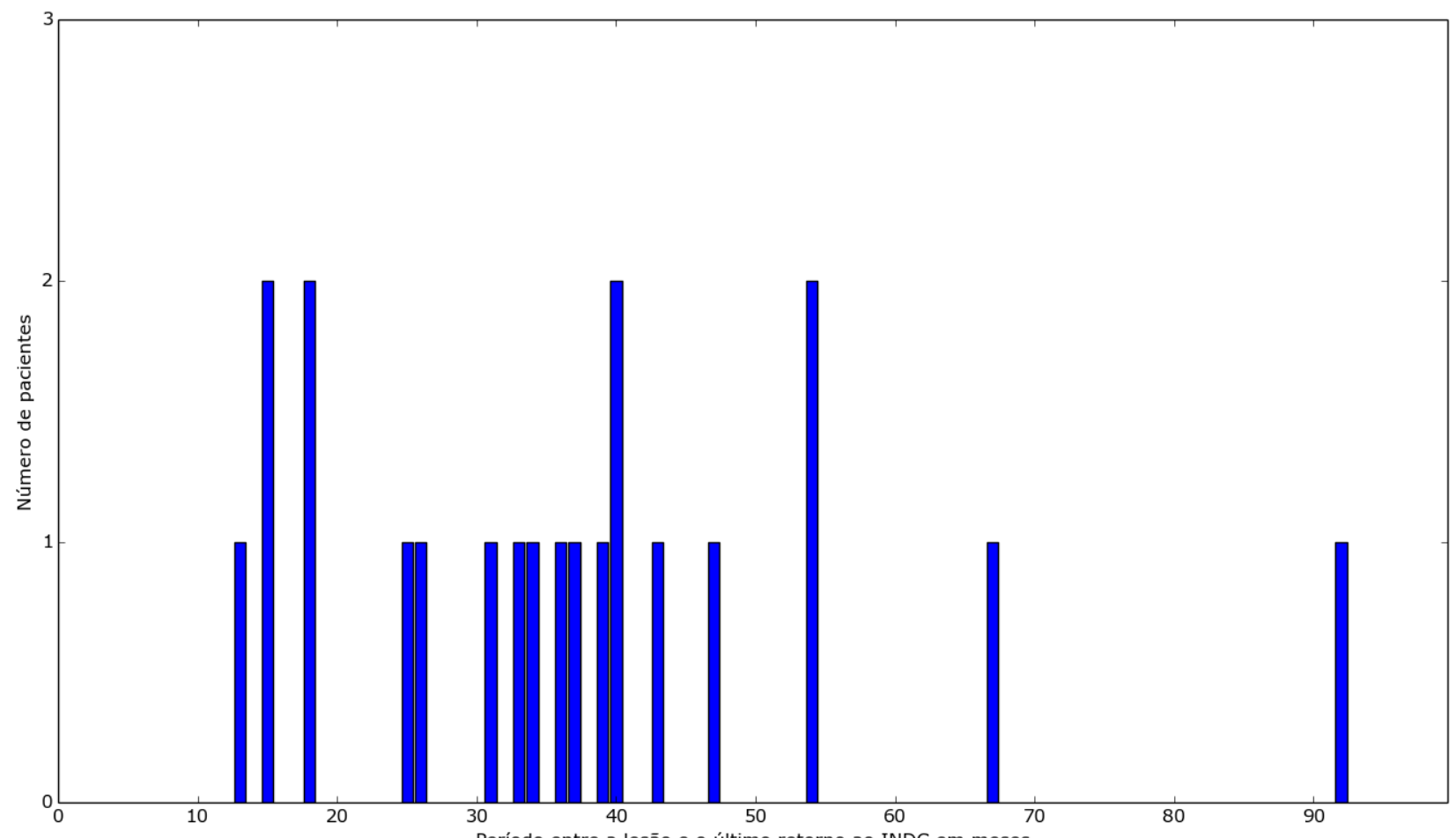

Figura 4.5: Distribuição do período entre a avaliação de entrada e o último retorno dos pacientes ao INDC para a avaliação de seguimento. 


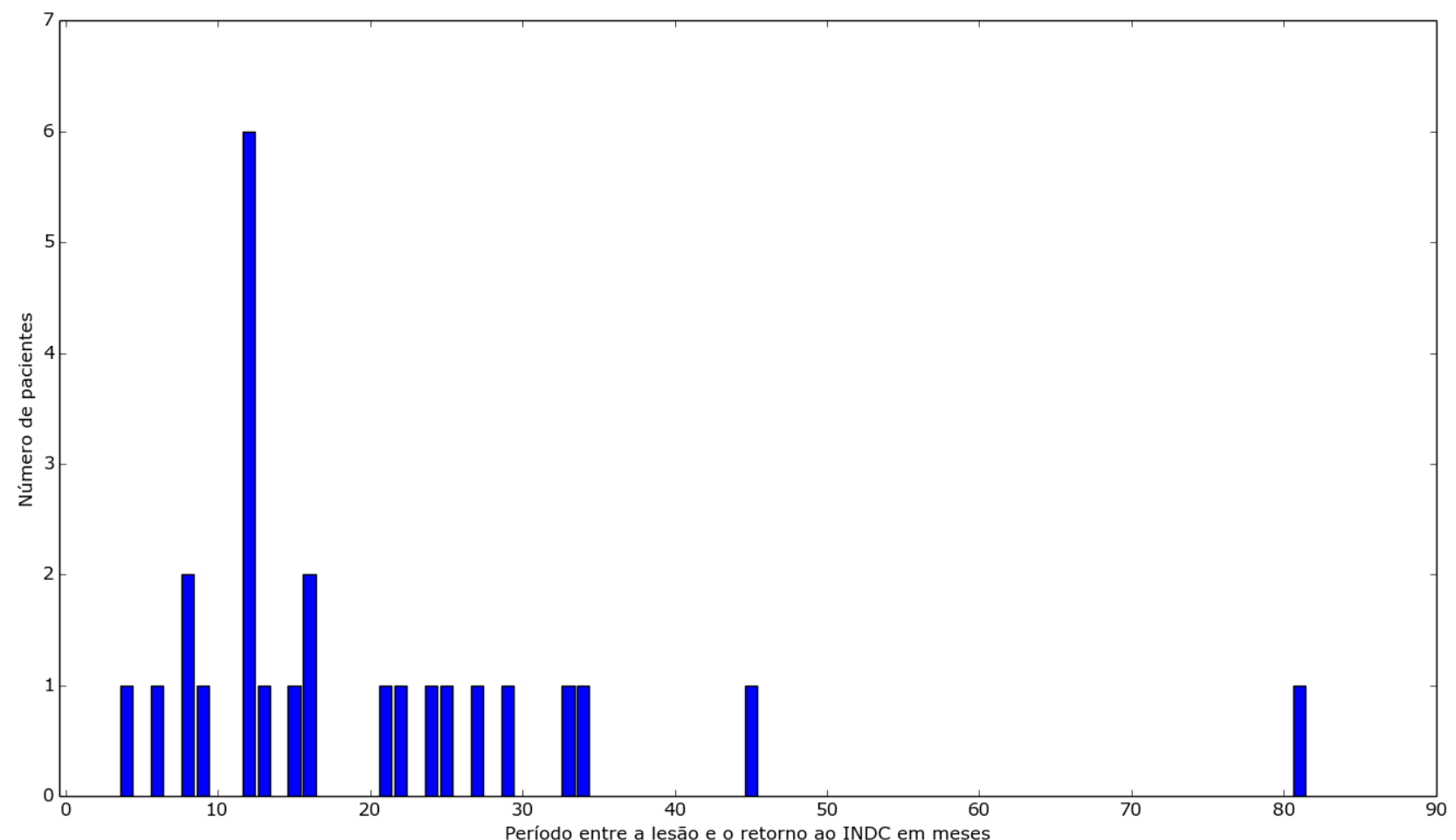

Figura 4.6: Distribuição do periodo entre a avaliação de entrada e a avaliação de seguimento dos pacientes que retornaram apenas uma vez ao INDC.

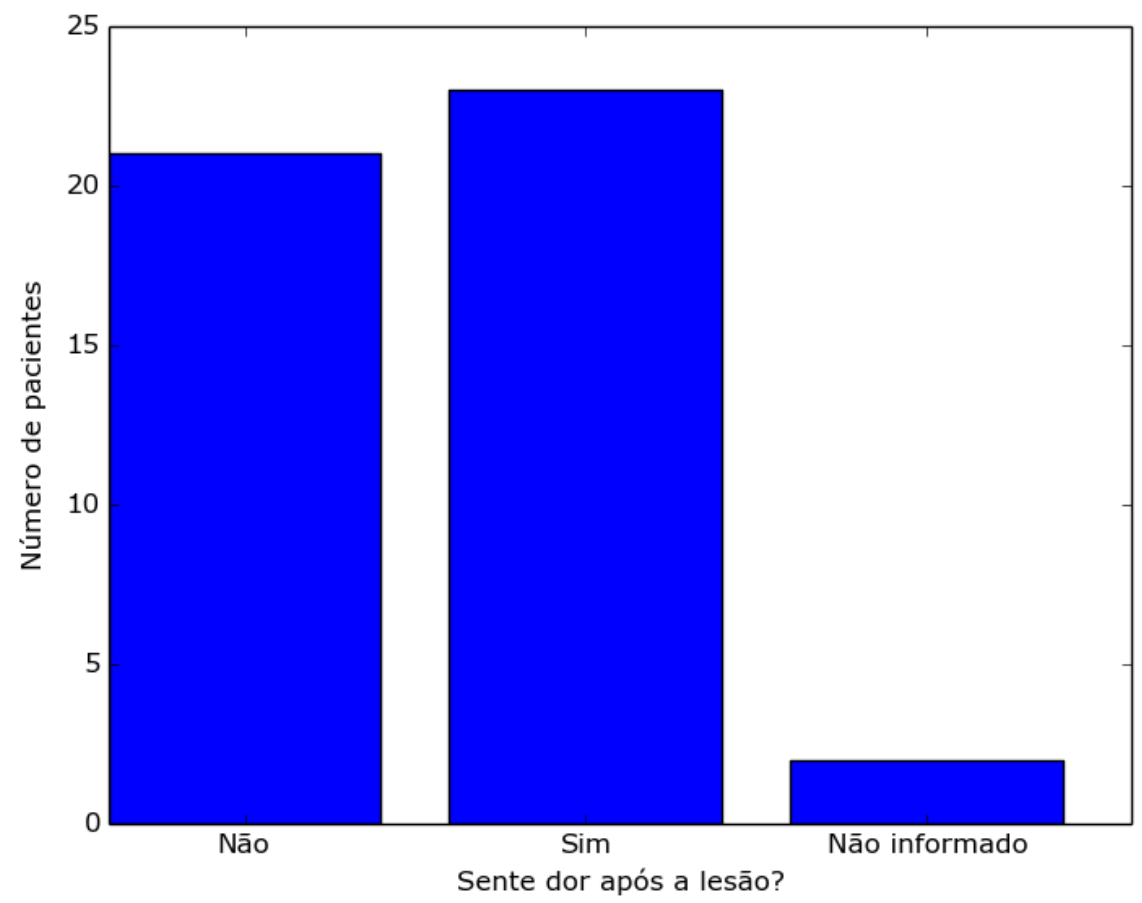

Figura 4.7: Frequência de respostas para a questão "Você sente dor atualmente?" do questionário de seguimento, considerando os preenchimentos do último retorno dos pacientes ao INDC. 


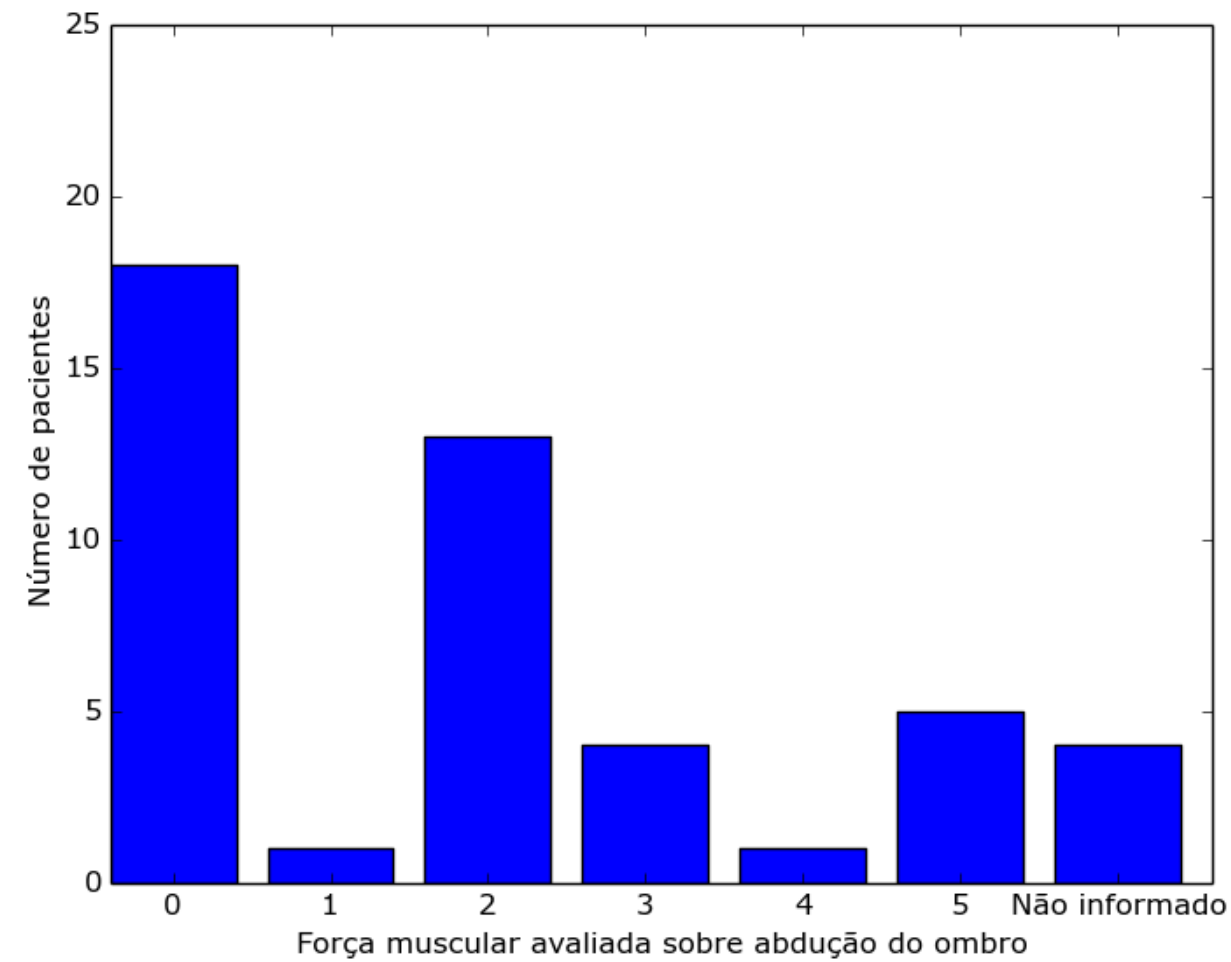

Figura 4.8: Frequência de respostas para a questão "Força muscular: Abdução do Ombro" do questionário de seguimento, considerando os preenchimentos do último retorno dos pacientes ao INDC.

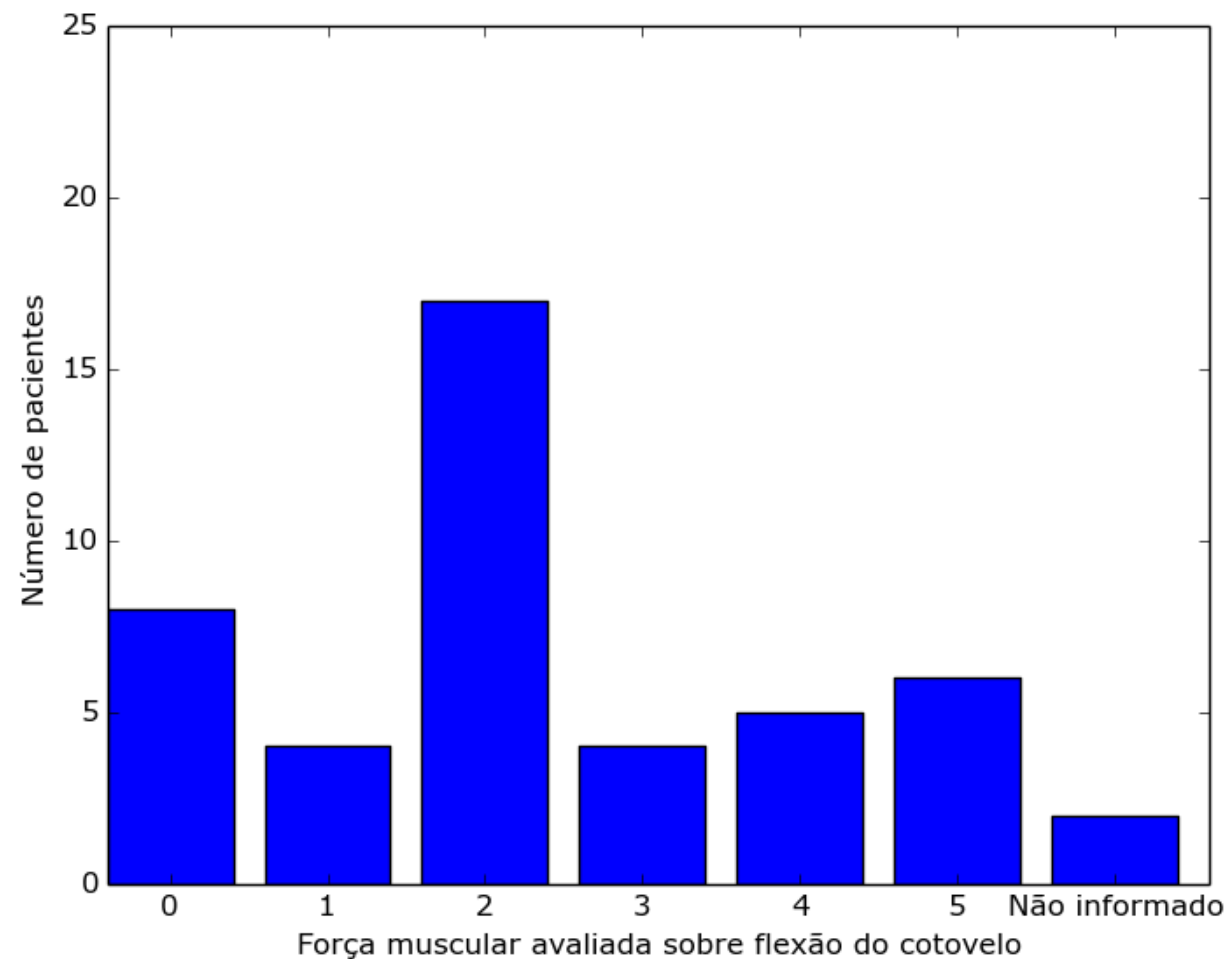

Figura 4.9: Frequência de respostas para a questão "Força muscular: Flexão do Cotovelo" do questionário de seguimento, considerando os preenchimentos do último retorno dos pacientes ao INDC. 


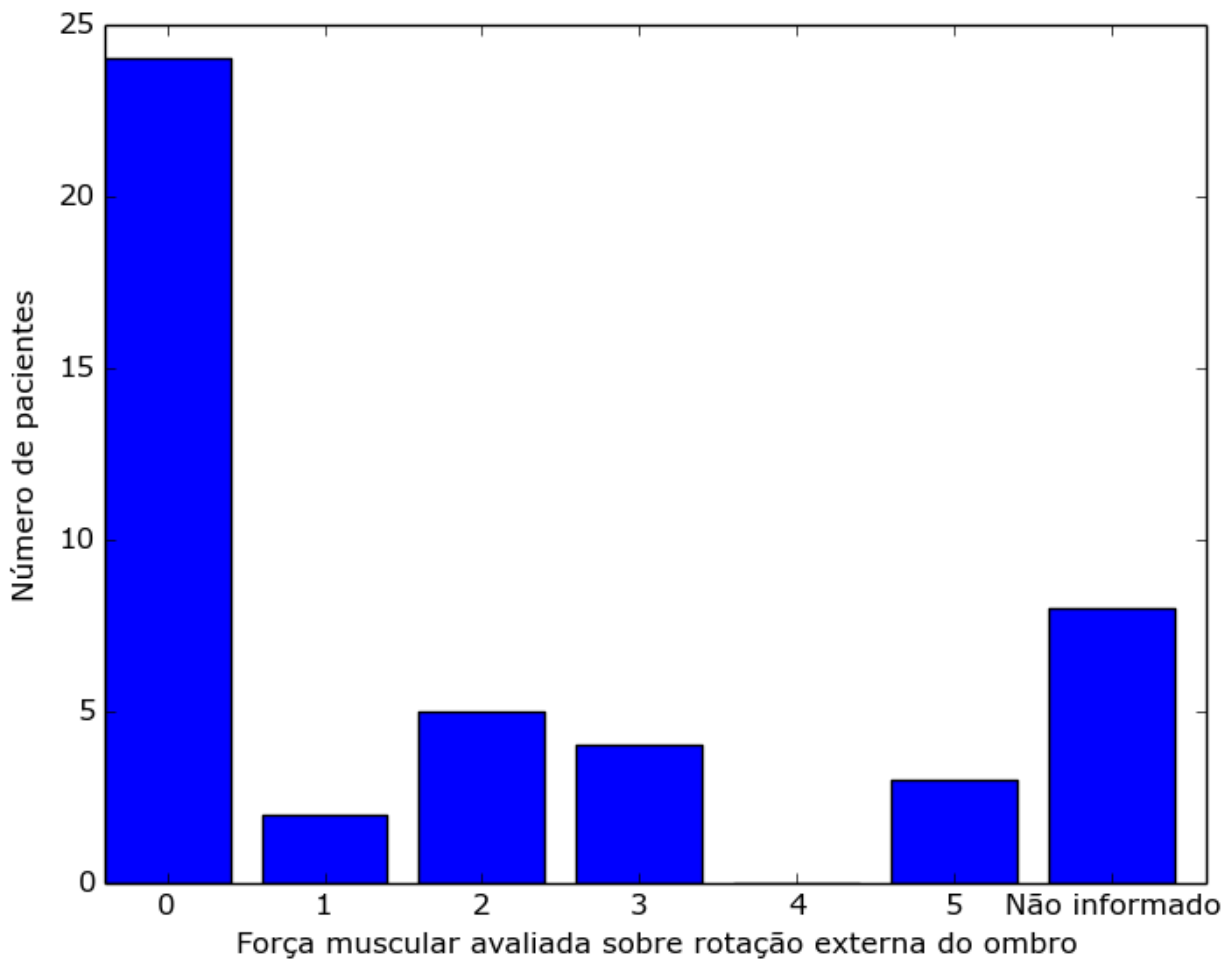

Figura 4.10: Frequência de respostas para a questão "Força muscular: Rotação Externa do Ombro" do questionário de seguimento, considerando os preenchimentos do último retorno dos pacientes ao INDC.

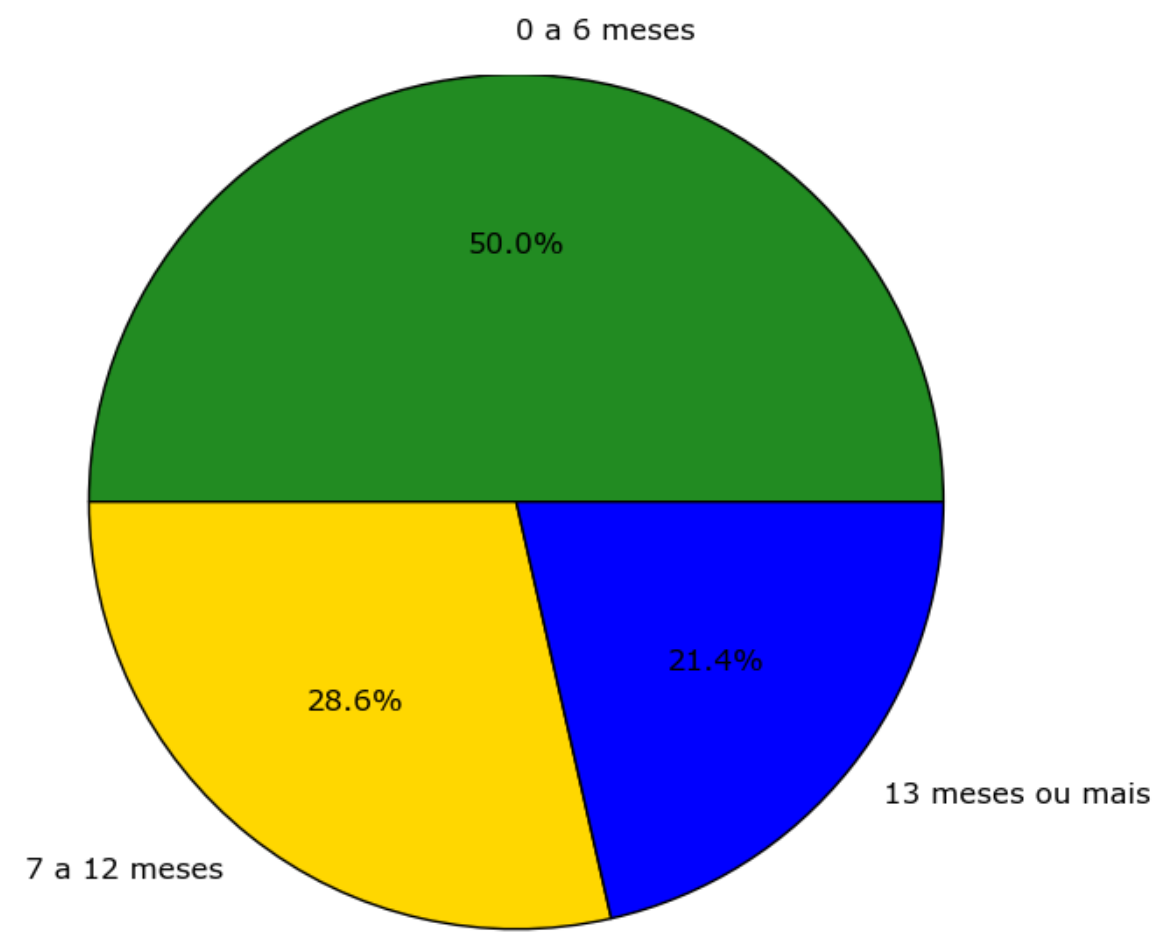

Figura 4.11: Distribuição do período de tempo entre a lesão e o primeiro procedimento cirúrgico dos pacientes do INDC-UFRJ. 


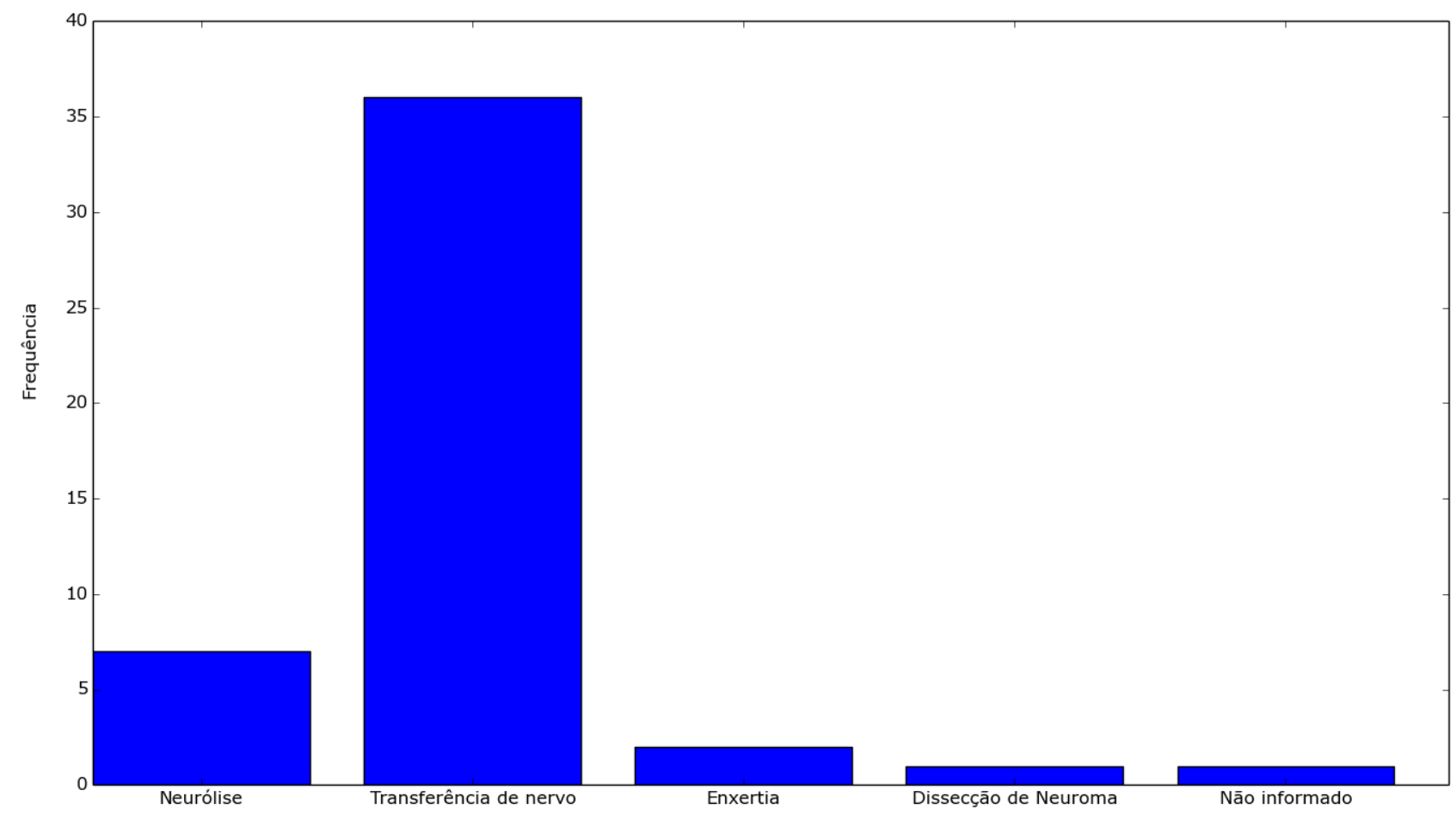

Figura 4.12: Frequência dos procedimentos realizados sobre os pacientes do INDC cujas informações se encontram nos preenchimentos da ficha "Avaliação Cirúrgica Unificada". 


\section{Capítulo 5}

\section{Criação de Modelos Prognósticos de LTPBA com Florestas Aleatórias}

O objetivo principal deste projeto é utilizar métodos de Mineração de Dados e a técnica de Florestas Aleatórias para a criação de modelos prognósticos de LTPBA, visando também encontrar os possíveis preditores do curso da lesão. Até o momento, não foram desenvolvidos modelos desse tipo no domínio de LTPBA. Assim, neste capítulo descreveremos o processo e a metodologia empregada para a criação desses modelos.

O problema de se obter modelos prognósticos computacionais por meio do processo de descoberta de conhecimento (KDD), visando a predição do curso da lesão do plexo braquial em pacientes diagnosticados e a identificação de atributos candidatos a preditores, envolve diversas questões clínicas. Para o tratamento dessas questões, este trabalho se apoiou na interação com pesquisadores do Laboratório de Neurociências e Reabilitação (LabNeR) do INDC-UFRJ envolvidos com a investigação da lesão do Plexo Braquial, em particular, com a médica neurologista Cristiane Borges Patroclo e a Profa. Dra. Claudia Domingues Vargas, coordenadora do LabNeR. Dentre as pesquisas em desenvolvimento atualmente no LabNeR, encontra-se a validação dos preditores e dos modelos prognósticos resultantes deste trabalho de mestrado.

As ferramentas utilizadas no desenvolvimento deste trabalho foram pandas [pan] e Scikitlearn $\left[\mathrm{PVG}^{+} 11\right]$ - bibliotecas de código aberto de estruturação, análise e mineração de dados para Python [Pyt]. Todo o código-fonte dos programas de análise desenvolvidos neste projeto é aberto e está disponível na plataforma GitHub no sítio Web: https://github.com/luumelo14/ prognostic-model ${ }^{1}$.

\section{1 Árvores MVB}

Uma vez que valores faltantes são frequentes nos dados utilizados para a criação dos modelos, foram consideradas duas abordagens:

1. Criação das árvores de decisão que compõem a floresta utilizando o algoritmo C4.5 (Seção 2.1.2.4), que considera a presença de dados faltantes;

2. Adição de um galho rotulado por "NaN" para todos os nós das árvores que compõem a floresta, representando a possível presença de valores faltantes.

Essa segunda abordagem foi desenvolvida neste projeto para que fosse possível a aplicação do método de contribuição de atributos, descrito na Seção 2.1.2.5.1, com o objetivo de obter uma certa transparência no processo de classificação dos modelos. Isso foi necessário uma vez que esse método originalmente não considera a possível presença de valores faltantes nos dados. Para fins de notação, iremos nos referir a essa abordagem por MVB (Missing Value Branch).

\footnotetext{
${ }^{1}$ Acesso em $17 / 05 / 2018$
} 
O algoritmo de Florestas Aleatórias foi modificado para criar, para cada nó de uma árvore, um galho adicional para o valor "NaN" (representando o valor faltante) ${ }^{2}$. Assim, as instâncias que possuem valor faltante para um atributo teste de um determinado nó serão atribuídas ao subconjunto definido pelo nó relativo a esse galho. Se nenhuma instância utilizada na construção da árvore possuir valor faltante para um certo atributo, o galho é associado a um nó filho "vazio" (i.e., sem instâncias em seu subconjunto). Isso é feito para possibilitar a classificação de novas instâncias (ou de instâncias no conjunto OOB da árvore) que podem apresentar valores faltantes para o atributo. Nesse caso, a esse nó "vazio" é atribuída a classe mais frequente no subconjunto do seu nó pai.

O Algoritmo 3 sumariza o processo de construção das árvores de decisão utilizando a abordagem MVB.

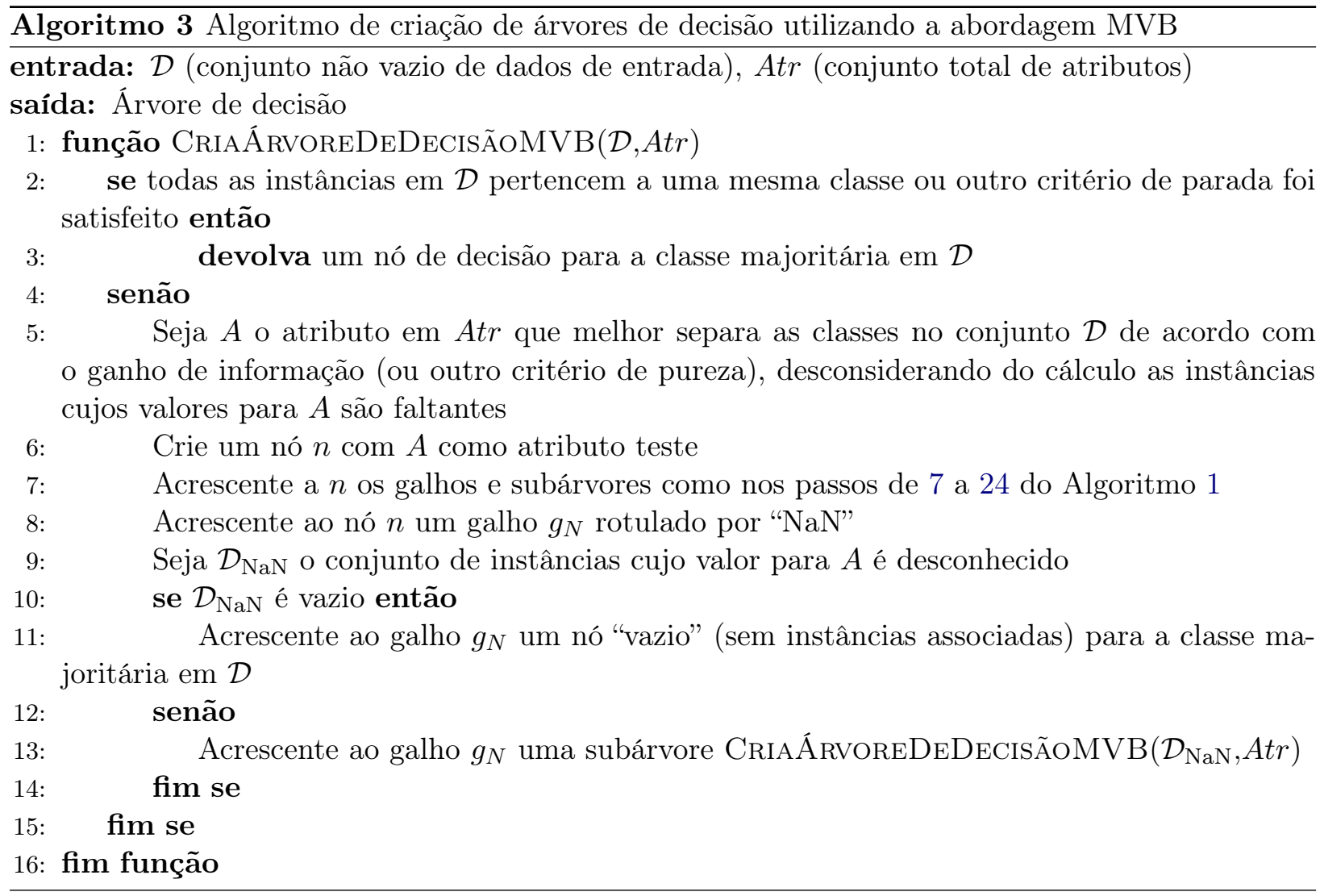

Para avaliar o desempenho dessa adaptação, foram criadas árvores de decisão sobre os dados dos pacientes do INDC - uma construída pelo método C4.5 e outra pelo método MVB, e suas acurácias foram calculadas utilizando o método de validação cruzada LOOCV. Para simplificar a estrutura das árvores, seu crescimento foi limitado até a profundidade 2 (ou seja, foram criados nós de decisão para os nós filhos de profundidade 3 - os "netos" do nó raiz). Essa simplificação foi realizada dessa forma porque o objetivo dessa análise não foi encontrar ou avaliar a importância dos preditores dos modelos criados, mas sim verificar a estrutura e o desempenho dos modelos obtidos pelo método MVB.

A Tabela 5.1 apresenta as acurácias médias (e seus desvios-padrão), precisões, coberturas e medidas-F das árvores de decisão criadas para cada um dos modelos, considerando "Insatisfatório" como classe positiva. Já a Tabela 5.2 apresenta o resultado dessa mesma análise sobre a classe "Sucesso" como classe positiva. Vale ressaltar que a acurácia não se altera ao mudarmos a classe positiva, já que não considera os conceitos de verdadeiros e falsos positivos em seu cálculo.

Para os modelos de força muscular, o modelo construído pelo método MVB obteve resultados semelhantes ou superiores ao método C4.5, apresentando resultados um pouco inferiores apenas

\footnotetext{
${ }^{2}$ Pelo uso da biblioteca pandas, valores desconhecidos ou faltantes são representados pelo valor "NaN".
} 


\begin{tabular}{|l|c|c|c|c|c|c|c|c|}
\hline \multirow{2}{*}{ Modelo } & \multicolumn{2}{|c}{ Acurácia } & \multicolumn{2}{c|}{ Precisão } & \multicolumn{2}{c|}{ Cobertura } & \multicolumn{2}{c|}{ Medida-F } \\
\cline { 2 - 8 } & $\mathbf{C 4 . 5}$ & MVB & C4.5 & MVB & C4.5 & MVB & C4.5 & MVB \\
\hline Dor & $\mathbf{5 0 \%} \pm 0,5$ & $47,72 \% \pm 0,49$ & $52,17 \%$ & $50 \%$ & $52,17 \%$ & $52,17 \%$ & $52,17 \%$ & $51,06 \%$ \\
\hline AbdOmbro & $69 \% \pm 0,46$ & $\mathbf{7 6 , 1 9 \%} \pm 0,42$ & $74,36 \%$ & $88,55 \%$ & $90,62 \%$ & $90,62 \%$ & $81,69 \%$ & $85,29 \%$ \\
\hline FlexCotovelo & $\mathbf{9 0 , 9 \%} \pm 0,29$ & $\mathbf{9 0 , 9 \%} \pm 0,29$ & $87,87 \%$ & $87,87 \%$ & $100 \%$ & $100 \%$ & $93,55 \%$ & $93,55 \%$ \\
\hline RotEOmbro & $84,2 \% \pm 0,36$ & $\mathbf{8 6 , 8 4 \%} \pm 0,34$ & $90,32 \%$ & $90,62 \%$ & $90,32 \%$ & $93,55 \%$ & $90,32 \%$ & $92,06 \%$ \\
\hline
\end{tabular}

Tabela 5.1: Desempenho dos modelos criados sobre os dados dos pacientes do INDC para as abordagens C4.5 e MVB, em termos de acurácia média (e seu desvio padrão), precisão, cobertura e medida-F, considerando "Insatisfatório" como a classe positiva.

\begin{tabular}{|l|c|c|c|c|c|c|c|c|}
\hline \multirow{2}{*}{ Modelo } & \multicolumn{2}{|c}{ Acurácia } & \multicolumn{2}{c|}{ Precisão } & \multicolumn{2}{c|}{ Cobertura } & \multicolumn{2}{c|}{ Medida-F } \\
\cline { 2 - 9 } & $\mathbf{C 4 . 5}$ & MVB & C4.5 & MVB & C4.5 & MVB & C4.5 & MVB \\
\hline Dor & $\mathbf{5 0 \%} \pm 0,5$ & $47,72 \% \pm 0,49$ & $47,62 \%$ & $45 \%$ & $47,62 \%$ & $42,86 \%$ & $47,62 \%$ & $43,9 \%$ \\
\hline AbdOmbro & $69 \% \pm 0,46$ & $\mathbf{7 6 , 1 9 \%} \pm 0,42$ & $0 \%$ & $50 \%$ & $0 \%$ & $30 \%$ & $0 \%$ & $37,49 \%$ \\
\hline FlexCotovelo & $\mathbf{9 0 , 9 \%} \pm 0,29$ & $\mathbf{9 0 , 9 \%} \pm 0,29$ & $100 \%$ & $100 \%$ & $73,33 \%$ & $73,33 \%$ & $84,61 \%$ & $84,61 \%$ \\
\hline RotEOmbro & $84,2 \% \pm 0,36$ & $\mathbf{8 6 , 8 4 \%} \pm 0,34$ & $57,14 \%$ & $66,67 \%$ & $57,14 \%$ & $57,14 \%$ & $57,14 \%$ & $61,54 \%$ \\
\hline
\end{tabular}

Tabela 5.2: Desempenho dos modelos criados sobre os dados dos pacientes do INDC para as abordagens C4.5 e MVB, em termos de precisão, cobertura e medida-F, considerando "Sucesso" como a classe positiva.

para o modelo de dor. Além disso, o método possui a vantagem de construir árvores para compor uma floresta aleatória de modo a permitir a aplicação do método de contribuição de atributos, que provê uma certa transparência do processo de classificação do modelo final. Desse modo, o método MVB escolhido para a construção das florestas aleatórias para a criação dos modelos prognósticos deste trabalho.

\subsection{Processo de KDD}

As etapas do processo de KDD para a criação dos modelos prognósticos foram feitas conforme descrito nas seções a seguir.

\subsubsection{Compreensão do Domínio}

Tendo como objetivo a predição de recuperação dos pacientes com LTPBA, bem como a identificação de possíveis preditores, devem ser definidos então os alvos que irão representar o estado da recuperação dos pacientes. Com o auxílio dos neurocientistas envolvidos no projeto, foram definidos quatro problemas de classificação diferentes, um para cada alvo:

- Predição de recuperação de dor

- Predição de recuperação de força muscular avaliada sobre abdução do ombro

- Predição de recuperação de força muscular avaliada sobre flexão do cotovelo

- Predição de recuperação de força muscular avaliada sobre rotação externa do ombro

A criação de quatro modelos prognósticos de forma separada foi determinada por conta da possibilidade de os preditores do curso da lesão não serem os mesmos para cada alvo (i.e., dor e força muscular avaliada sobre abdução do ombro, flexão do cotovelo e rotação externa do ombro).

\subsubsection{Seleção dos Dados}

Os dados foram obtidos do banco de dados abertos de experimentos em neurociência desenvolvido pelo NeuroMat (o NeuroMat DB). O dataset com os dados anonimizados dos pacientes do INDC com lesão do plexo braquial está disponível nesse banco no sítio Web http://neuromatdb. numec.prp.usp.br/experiments/brachial-plexus-injury-database/ ${ }^{3}$. Esse dataset contém preenchimentos de questionários aplicados a pacientes do INDC-UFRJ na forma de arquivos CSV, como

${ }^{3}$ Acesso em $17 / 05 / 2018$ 
explicado no Capítulo 4. Os questionários considerados na análise foram "Avaliação de Entrada Unificada", "Avaliação Cirúrgica Unificada" e "Avaliação de Seguimento Unificado". A estrutura completa desses questionários é apresentada no Apêndice A. Do questionário de Avaliação Cirúrgica, foram consideradas apenas as questões que indicam o tipo de procedimento realizado, o sítio do procedimento (quais nervos, raízes, etc.) e o intervalo de tempo entre a lesão e o primeiro procedimento cirúrgico de cada paciente. Já do questionário de Avaliação de Seguimento, foram apenas selecionados o período entre a lesão e o último retorno ao INDC e a coluna relativa ao prognóstico do modelo a ser construído, sendo em cada caso:

- Prognóstico de dor: questão "Você sente dor atualmente?"

- Prognóstico de força muscular avaliada sobre abdução do ombro: questão "Força muscular avaliada: Abdução do Ombro"

- Prognóstico de força muscular avaliada sobre flexão do cotovelo: questão "Força muscular avaliada: Flexão do Cotovelo"

- Prognóstico de força muscular avaliada sobre rotação externa do ombro: questão "Força muscular avaliada: Rotação Externa do Ombro"

Do questionário de Avaliação de Entrada, foram selecionadas as questões relativas a:

- História prévia: de fratura, de cirurgias (ortopédica ou craniofacial, cerebral, de nervo em membro superior), de traumatismo (cranioencefálico, raquimedular) e de dor;

- Características da lesão: lado da lesão, se o paciente ficou desacordado, idade do paciente por ocasião da lesão, evento que levou ao trauma, se houve alguma lesão associada ao trauma (fratura, luxação glenoumeral, cirurgia ortopédica ou craniofacial, traumatismo cranioencefálico, cirurgia cerebral, traumatismo raquimedular, dreno de tórax, lesão vascular associada)

- Tratamentos: uso de tipoia, uso de algum medicamento com ação sobre o sistema nervoso (opióides, antidepressivos, anticonvulsivantes, neurolépticos), se foi realizada alguma cirurgia do plexo braquial ou de dor;

- Exames físicos: subluxação glenoumeral, escápula alada, sinal de Horner, edema, cicatriz da cirugia de plexo, alteração de trofismo, postura escoliótica, sinal de Tinel, sensibilidade superficial tátil e dolorsa (avaliadas sobre C5, C6, C7, C8 e T1), artrestesia e cinestesia (avaliadas sobre indicador, cotovelo, ombro), palestesia (avaliada sobre terço lateral da clavícula, epicôndilo lateral do úmero e cabeça da ulna), amplitude de movimento (flexão de ombro, extensão de ombro, abdução do ombro, rotação externa do ombro, flexão de cotovelo, extensão de cotovelo, supinação de antebraço, pronação de antebraço, flexão de punho, extensão de punho), força muscular (avaliada sobre flexão, abdução, rotação externa e rotação interna do ombro, elevação e abdução e rotação superior da escápula, flexão e extensão de cotovelo, supinação e pronação de antebraço, flexão e extensão do punho, flexão, extensão, abdução e adução dos dedos e oponência do polegar.

\subsubsection{Limpeza e Pré-Processamento}

A etapa de limpeza e pré-processamento e a etapa de transformação (Seção 5.2.4) correspondem às tarefas que mais demandam tempo em processos de descoberta de conhecimento [CPSK07].

Um fator importante considerado neste projeto foi a presença de valores faltantes, que são bastante frequentes nos dados referentes aos preenchimentos dos questionários do INDC, tanto pela estrutura das questões e dos campos dos questionários quanto pela própria caracterização do domínio clínico. O processo para tratar valores em branco nos dados é relativamente complexo, pois a semântica do valor faltante não é sempre a mesma em diferentes campos.

Por exemplo, o não preenchimento de campos gerados por questões cujas respostas são numéricas (por exemplo, mensuração de força muscular) implica em valores que são de fato faltantes, ou seja, desconhecidos. Na maioria desses casos, a ausência de valores é do tipo MNAR. Entretanto, 
alguns dos valores ausentes nos dados provenientes do INDC foram ocasionados por uma evolução dos questionários, em que foram adicionadas mais questões cujas respostas foram preenchidas para novos pacientes. Para que os dados das respostas anteriores de outros pacientes não fossem perdidos, uniram-se os preenchimentos de forma que as respostas dos pacientes anteriores para as novas questões ficassem em branco. Nesse caso, a ausência de valores para esses campos pode ser considerada do tipo MCAR.

Por outro lado, no caso de questões que dependem de outras questões prévias, os valores ausentes podem possuir a semântica de que a questão não é aplicável para o paciente, como o exemplo dado no Capítulo 4 relativo ao campo da questão "Se está fazendo fisioterapia, indique com que frequência" do questionário de entrada. O valor desse campo estará em branco para um paciente quando sua resposta para a questão "Está fazendo fisioterapia?" for "Não" ou "Não informado". No primeiro caso, o valor faltante indica que a pergunta não é aplicável ao paciente, pois ele não está fazendo fisioterapia (ausência do tipo MAR). No segundo caso, o valor faltante indica que a frequência é desconhecida, pois não foi informado se o paciente está fazendo fisioterapia (ausência do tipo MNAR).

Neste projeto, uma etapa de pré-processamento foi implementada de forma a tratar valores faltantes de semântica "não aplicável", adicionando aos atributos uma categoria correspondente. Os demais campos sem preenchimento, bem como os de preenchimento "Não informado / Não avaliado" foram considerados como valores faltantes, não sofrendo mudanças pelo pré-processamento. Dessa forma, a exploração desse tipo de dado ficou a cargo do algoritmo de Florestas Aleatórias utilizado na etapa de mineração (Seção 5.2.5).

Entretanto, para que também fosse possível aplicar outras técnicas de classificação, foi implementada a possibilidade de se utilizar os métodos de imputação por média, mediana e moda para tratar dados faltantes, como mencionado na Seção 2.1.2.3. Para isso, foi utilizada a função Imputer do módulo preprocessing da biblioteca Scikit-learn. Porém, esse tipo de tratamento pode comprometer seriamente a construção dos modelos sobre os dados do INDC, uma vez que a maior parte dos dados faltantes envolvidos neste trabalho são do tipo MNAR, e também considerando as taxas relativamente altas de ausência de valores de cada atributo.

\subsubsection{Transformação}

Para criar instâncias a partir dos dados dos pacientes, é necessário definir os atributos que as caracterizam e as classes que representam os prognósticos.

Como mencionado na Seção 2, as respostas dos questionários no dataset dos pacientes com lesão traumática do plexo braquial estão no formato de um arquivo CSV para cada questionário, em que cada coluna a corresponde a uma questão e cada linha corresponde a um preenchimento de um paciente.

Muitas questões relativas à lesão traumática do plexo braquial em adultos são feitas separadamente para o membro esquerdo e o membro direito, sendo gerados dois campos de mesma representatividade e significado, cada qual relativo a um lado. Esses campos geram atributos separados que podem ser aplicados a um classificador. Entretanto, esses campos representam semanticamente um mesmo atributo e, sendo assim, poderiam ser unificados, recebendo o valor de acordo com o lado lesionado do paciente. Isso porque, em termos de prognóstico, apenas dados referentes ao lado lesionado são relevantes.

Por exemplo, os campos referentes às questões "Rotação Externa de ombro esquerdo (em graus)" e "Rotação Externa de ombro esquerdo (em graus)" gerariam apenas um campo "Rotação Externa de ombro (em graus)". Assim, para pacientes com lesão no plexo braquial do lado esquerdo, o campo unificado receberia o valor do campo "Rotação Externa de ombro esquerdo (em graus)" (similar para o lado direto). Contudo, com a adoção dessa forma de representação, linhas no arquivo referentes a pacientes com lesão em ambos os membros devem ser replicadas, de forma que exista uma linha para cada lado lesionado. Esse tipo de transformação é vantajoso por auxiliar a diminuir a dimensionalidade (i.e., o número de atributos) do problema, um dos desafios envolvidos neste projeto. A Tabela 5.3 apresenta um exemplo de transformação de preenchimentos de pacientes para 
uma questão similar.

\begin{tabular}{|c|c|l|l|}
\hline Código do Paciente & Lado da lesão & $\begin{array}{l}\text { Flexão de Punho } \\
\text { Esquerdo }\end{array}$ & $\begin{array}{l}\text { Flexão de Punho } \\
\text { Direito }\end{array}$ \\
\hline P1000 & Direito & 5 & 2 \\
\hline P2000 & Esquerdo & 0 & 5 \\
\hline P3000 & Ambos & 1 & 0 \\
\hline \multicolumn{2}{|l}{} \\
& $\downarrow$
\end{tabular}

\begin{tabular}{|c|c|c|}
\hline Código do Paciente & Lado da lesão & Flexão de Punho \\
\hline P1000 & Direito & 2 \\
\hline P2000 & Esquerdo & 0 \\
\hline P3000 & Esquerdo & 1 \\
\hline P3000 & Direito & 0 \\
\hline
\end{tabular}

Tabela 5.3: Exemplo de junção de preenchimentos de diferentes pacientes para as questões "Qual o lado da lesão?" (Lado da lesão), "Força muscular avaliada sobre o lado esquerdo: Flexão de Punho " (Flexão de Punho Esquerdo) e "Força muscular avaliada sobre o lado direito: Flexão de Punho" (Flexão de Punho Direito) do questionário de Avaliação de Entrada.

Como os dados da ficha de seguimento estão relacionados ao estado da lesão após um período entre a avaliação de entrada e o retorno, eles podem ser considerados como descritores do estado da recuperação da lesão, ou seja, referentes ao prognóstico relativo a um certo período de tempo após a ocorrência da lesão. Se os períodos de retorno dos pacientes fossem distribuídos de maneira uniforme, seria possível selecionar dados relativos ao prognóstico da lesão de cada paciente após 6 meses da lesão, 12 meses, 15 meses, etc. Entretanto, devido à grande variação dos períodos de retornos dos pacientes do INDC ao laboratório (figuras 4.5 e 4.6), a definição de um determinado período de retorno a ser considerado na seleção dos dados de prognóstico reduziria significativamente o número de pacientes cujos dados poderiam ser utilizados, o que tornaria a análise conduzida neste projeto inviável. Foram então considerados os preenchimentos relativos ao último retorno de cada paciente (i.e., retornos mais recentes), uma vez que a recuperação de lesões do plexo braquial pode ser possível em até 5 anos após a ocorrência da lesão [SAI $\left.{ }^{+} 13\right]$.

Desse modo, para cada modelo, foi selecionada apenas uma coluna (unificada para os casos dos modelos prognósticos de força muscular) do questionário de Avaliação de Seguimento para gerar as classes (prognóstico) do problema.

As classes dos quatros modelos prognósticos correspondem a "Sucesso" e "Insatisfatório". Para o modelo prognóstico de dor, foi considerado sucesso um paciente não sentir dor em seu último retorno ao laboratório. Assim, nesse modelo, cada paciente foi associado à classe "Sucesso" se possuía preenchimento "Não" para a questão "Você sente dor após a lesão?" do questionário de Avaliação de Seguimento, e "Insatisfatório" caso a resposta fosse "Sim".

No caso dos modelos de prognóstico de força muscular, foi considerado sucesso um valor superior ou igual a 3 na escala muscular MRC para o movimento relativo ao prognóstico. Desse modo, no caso do modelo prognóstico de força muscular avaliada sobre flexão do cotovelo, os pacientes foram associados à classe "Sucesso" se seus valores para o preenchimento da questão "Força muscular: Flexão do Cotovelo" no questionário de Avaliação de Seguimento foram superiores ou igual a três, e "Insatisfatório" caso contrário (análogo para os modelos prognósticos de força muscular avaliada sobre Abdução do Ombro e Rotação Externa do Ombro). Os pacientes que possuem valor desconhecido para o atributo proveniente da ficha de seguimento que se refere ao prognóstico alvo do modelo foram desconsiderados em sua construção. Assim, o número de pacientes em cada modelo pode ser diferente, já que alguns podem possuir valor desconhecido para um atributo alvo e conhecido para outro.

Os atributos podem ser obtidos pela junção das colunas dos arquivos gerados pelos questionários 
de Avaliação de Entrada e de Avaliação Cirúrgica, com cada linha correspondendo ao preenchimento agrupado de um paciente para ambos questionários. Dessa forma, cada preenchimento de um paciente corresponde a uma instância. Porém, para que isso seja possível, é necessário unificar os preenchimentos do questionário de Avaliação Cirúrgica de um mesmo paciente. Isso pode ser feito unindo as respostas positivas de cada preenchimento do paciente para as questões relativas ao tipo e ao sítio de cada procedimento realizado. Em relação ao intervalo de tempo entre a lesão e a cirurgia, pode-se considerar o intervalo do primeiro procedimento cirúrgico realizado. Um exemplo dessa unificação para as questões "Intervalo de tempo entre a lesão e a cirurgia", "Procedimento realizado: Neurólise" e "Procedimento realizado: Enxertia" do questionário de Avaliação Cirúrgica se encontra ilustrado na Tabela 5.4.

\begin{tabular}{|c|c|l|l|}
\hline Código do Paciente & Intervalo de tempo & $\begin{array}{l}\text { Procedimento: } \\
\text { Neurólise }\end{array}$ & $\begin{array}{l}\text { Procedimento: } \\
\text { Enxertia }\end{array}$ \\
\hline P1000 & 130 & Sim & Não \\
\hline P1000 & 168 & Não & Sim \\
\hline \multicolumn{4}{|c|}{$\downarrow$} \\
\hline Código do Paciente & Intervalo de tempo & $\begin{array}{l}\text { Procedimento: } \\
\text { Neurólise }\end{array}$ & $\begin{array}{l}\text { Procedimento: } \\
\text { Enxertia }\end{array}$ \\
\hline P1000 & 130 & Sim & Sim \\
\hline
\end{tabular}

Tabela 5.4: Exemplo de unificação de preenchimentos de um mesmo paciente para as questões "Intervalo de tempo entre a lesão e a cirurgia" (Intervalo de tempo), "Procedimento realizado: Neurólise" (Procedimento: Neurólise) e "Procedimento realizado: Enxertia" (Procedimento: Enxertia) do questionário de Avaliação Cirúrgica.

Uma outra transformação implementada foi a atribuição do valor do atributo relativo à questão "Já fez alguma cirurgia do plexo braquial?" do questionário de Avaliação de Entrada. O valor desse atributo para cada paciente se refere à sua resposta dada para essa questão em sua primeira avaliação no INDC. Entretanto, para fins de análise, a informação relevante diz respeito ao paciente ter realizado alguma cirurgia até o momento do preenchimento do questionário de seguimento de onde o prognóstico (i.e., classe) está sendo retirado. Dessa forma, foi feita uma transformação de forma que fosse atribuído o valor "Sim" para a questão "Já fez alguma cirurgia do plexo braquial?" para os pacientes que possuem ao menos um preenchimento para o questionário de Avaliação Cirúrgica, ou que possuem resposta "Sim" para a questão "Fez alguma cirurgia do plexo braquial desde a última avaliação?" em algum preenchimento do questionário de Avaliação de Seguimento.

Uma vez que Florestas Aleatórias lidam com atributos categorizados, não é necessário transformálos em numéricos. Porém, essa transformação é necessária para avaliarmos o desempenho de outras técnicas de classificação sobre os dados dos pacientes do INDC, de forma a analisar a viabilidade da escolha do método de Florestas Aleatórias. A aplicação de técnicas como Redes Neurais, Regressão Linear, Regressão Logística e Máquinas de Vetores de Suporte demanda a transformação de atributos categorizados para numéricos.

Visando essa transformação, um tratamento natural seria considerar a conversão de todos os atributos categóricos para numerais, transformando, por exemplo, as categorias "Sim" e "Não" nos valores 0 e 1, respectivamente (abordagem direta). Entretanto, essa conversão implica no estabelecimento de uma ordem entre as categorias, o que não faz sentido para dados categorizados nominais (não ordinais) que possuem mais de duas categorias, podendo assim interferir no desempenho dos classificadores. Uma alternativa seria criar, para cada atributo categorizado, atributos binários para cada categoria possível, que valem 1 se a categoria corresponde à resposta do paciente e 0 caso contrário (abordagem binária) [GS98]. Porém, essa abordagem resulta em um crescimento considerável da dimensionalidade do problema, uma vez que aumenta o número de atributos que representam os pacientes [AH98]. 
Não obstante, para a aplicação de classificadores como Máquinas de Vetores de Suporte, pode ser necessário realizar uma normalização dos valores dos atributos, para que a diferença de escalas não afete seu desempenho. Uma forma de normalização, denominada normalização-z (do inglês $z$-normalization), consiste em substituir o valor assumido por cada atributo por seu Escore Padronizado, dado por:

$$
x_{i, j}^{\prime}=\frac{x_{i, j}-\hat{\mu}_{j}}{\hat{\sigma}_{j}}
$$

em que $x_{i, j}^{\prime}$ refere-se ao novo valor assumido pelo atributo $x_{j}$ na instância $\boldsymbol{x}_{i}$, enquanto que $x_{i, j}$ corresponde ao seu valor original. Ainda, $\hat{\mu_{j}}$ corresponde à média amostral do atributo $x_{j}$ e $\hat{\sigma}_{j}{ }^{2}$ à sua variância amostral [ZJ14]. Após a normalização, a média amostral do atributo será $\hat{\mu}_{j}^{\prime}=0$ e a variância ${\hat{\sigma_{j}^{\prime}}}^{2}=1$. Essa transformação pode ser feita utilizando o método StandardScaler da biblioteca Scikit-learn.

A transformação inversa a essa - de atributos numéricos para categorizados - também foi implementada, visando facilitar a análise e a visualização da interpretação dos modelos pelo método de contribuição de atributos. Os valores dos atributos referentes ao exame físico de força muscular foram categorizados em "Maior ou igual a 3" e "Menor que 3", enquanto que os valores do atributo "Idade por ocasião da lesão" foram transformados em "Maior ou igual a 30 anos" e "Menor que 30 anos". Já os atributos relativos ao exame físico de amplitude foram categorizados de acordo com o tipo de movimento avaliado. A Tabela 5.5 apresenta os tipos de movimentos e as categorias resultantes das transformações. A separação dos valores em categorias foi feita de acordo com as orientações dos especialistas do domínio.

\begin{tabular}{|l|c|}
\hline Movimento & \multicolumn{1}{|c|}{ Categorias resultantes } \\
\hline Flexão do ombro & "Maior ou igual a 180" e "Menor que 180" \\
\hline Extensão do ombro & "Maior ou igual a 50" e "Menor que 50" \\
\hline Abdução do ombro & "Maior ou igual a 170" e "Menor que 170" \\
\hline Rotação externa do ombro & "Maior ou igual a 60" e "Menor que 60" \\
\hline Flexão do cotovelo & "Maior ou igual a 40" e "Menor que 40" \\
\hline Extensão do cotovelo & "Maior ou igual a 180" e "Menor que 180" \\
\hline Supinação de antebraço & "Maior ou igual a 80" e "Menor que 80" \\
\hline Pronação de antebraço & "Maior ou igual a 80" e "Menor que 80" \\
\hline Flexão do punho & "Maior ou igual a 60" e "Menor que 60" \\
\hline Extensão do punho & "Maior ou igual a 60" e "Menor que 60" \\
\hline
\end{tabular}

Tabela 5.5: Categorias resultantes da transformação de atributos numéricos para categorizados para os campos referentes ao exame físico de amplitude de cada movimento.

Em suma, a etapa de transformação foi implementada neste projeto de forma a:

- Unificar os campos de questões relativas às avaliações sobre o lado esquerdo e o lado direito dos membros superiores;

- Selecionar os valores dos dados da Avaliação de Seguimento do retorno mais recente do paciente ao INDC para compor os valores de prognóstico para as classes;

- Transformar os valores das classes para "Instatisfatório" e "Sucesso";

- Unificar os preenchimentos do questionário de Avaliação de Cirurgia de um mesmo paciente;

- Transformar os valores para o atributo "Já fez alguma cirurgia do plexo braquial?" considerando preenchimentos das fichas de Avaliação Cirúrgica e de Avaliação de Seguimento;

- Transformar atributos numéricos relativos aos exames físicos de força muscular e amplitude de movimento e à idade do paciente por ocasião da lesão em atributos categorizados, para favorecer a interpretação dos modelos; 
- Opcionalmente, transformar atributos categorizados em numéricos, utilizando a abordagem direta ou binária.

O número de instâncias e de atributos provenientes dos arquivos resultantes dessas transformações (exceto a opcional) para cada modelo está listado na Tabela 5.6, bem como sua a proporção média de valores faltantes. Foram desconsideradas colunas sem nenhum preenchimento ou cujos valores são os mesmos para todas as linhas.

\begin{tabular}{|l|c|c|c|c|c|}
\hline Modelo & Instâncias & Atributos & "Sucesso" & "Insatisfatório" & $\begin{array}{c}\text { Proporção de valores } \\
\text { faltantes }\end{array}$ \\
\hline Dor & 44 & 180 & 21 & 23 & $42,44 \%$ \\
\hline AbdOmbro & 42 & 180 & 10 & 32 & $43,59 \%$ \\
\hline FlexCotovelo & 44 & 180 & 15 & 29 & $42,51 \%$ \\
\hline RotEOmbro & 38 & 179 & 7 & 31 & $39,38 \%$ \\
\hline
\end{tabular}

Tabela 5.6: Número de instâncias, de atributos, de casos "Sucesso" e "Insatisfatório", e proporções de valores faltantes resultantes da transformação dos arquivos dos questionários de entrada, cirúrgico e de seguimento para prognóstico de dor, abdução do ombro (AbdOmbro), flexão do cotovelo (FlexCotovelo) e rotação externa do ombro (RotEOmbro).

\subsubsection{Mineração de Dados}

Para avaliarmos a viabilidade de utilizarmos a técnica de Florestas Aleatórias sobre os dados dos pacientes do INDC, foram analisados o seu desempenho e o de técnicas de classificação que são frequentemente utilizadas na criação de modelos prognósticos. As técnicas utilizadas foram Regressão Linear, Regressão Logística, Redes Neurais, Máquina de Vetores de Suporte (SVM), Árvores de Decisão e Florestas Aleatórias implementadas na biblioteca Scikit-learn da linguagem Python $\left[\mathrm{PVG}^{+} 11, \mathrm{Pyt}\right]$.

Para que essas técnicas pudessem ser aplicadas e seus desempenhos pudessem ser comparados, os atributos categorizados foram transformados em numéricos, utilizando a abordagem direta descrita na Seção 5.2.4, e os valores faltantes foram substituídos pela média dos valores presentes (que passaram a ser numéricos), utilizando o método de imputação mencionado na Seção 2.1.2.3. Em seguida, foi aplicada uma normalização dos valores dos atributos, também descrita na Seção 5.2.4. Como mencionado anteriormente, essa transformação pode prejudicar o desempenho dos classificadores, uma vez que é adicionada uma ordenação entre as categorias que não necessariamente existe semanticamente.

Após o pré-processamento e a transformação, as técnicas foram aplicadas, calculando-se a acurácia média de cada um dos modelos por meio do método de validação cruzada leave-one-out (LOOCV). Os resultados são mostrados na Tabela 5.7. Os nomes dos métodos e os parâmetros utilizados estão listados na Tabela 5.8.

A Floresta Aleatória foi o classificador que obteve o melhor desempenho nos modelos prognósticos de dor e de força muscular avaliada sobre abdução do ombro e flexão do cotovelo, e apesar de não corresponder à técnica que obteve a maior acurácia para o modelo prognóstico de força muscular avaliada sobre rotação externa do ombro, seu desempenho se mostrou competitivo quando comparado com o classificador que obteve o melhor resultado. Além disso, a técnica em si possui a vantagem de não ser necessário transformar os dados em numéricos e dispensa o uso da imputação para valores faltantes. Esse último fator é importante uma vez que a imputação é uma estratégia que pode enviesar a construção do modelo sobre os dados do INDC, já que seus valores faltantes não são do tipo MCAR.

Assim, para a criação dos modelos prognósticos para o INDC não foi necessário aplicar a transformação dos atributos para números. A transformação inversa (de números para categorias), por outro lado, foi utilizada para viabilizar a interpretação dos modelos resultantes. Além disso, uma vez que a presença de valores faltantes nos dados não foi eliminada, foi necessário utilizar as árvores 


\begin{tabular}{|c|c|c|c|c|c|c|}
\hline Modelo & $\begin{array}{l}\text { Regressão } \\
\text { Linear }\end{array}$ & $\begin{array}{l}\text { Regressão } \\
\text { Logística }\end{array}$ & $\begin{array}{l}\text { Rede } \\
\text { Neural }\end{array}$ & SVM & $\begin{array}{l}\text { Árvore de } \\
\text { Decisão }\end{array}$ & $\begin{array}{l}\text { Floresta } \\
\text { Aleatória }\end{array}$ \\
\hline Dor & $\begin{array}{ll}50,75 \% & \pm \\
0,183 & \end{array}$ & $\begin{array}{ll}61,87 \% & \pm \\
0,129 & \end{array}$ & $\begin{array}{l}60,6 \% \pm \\
0,052\end{array}$ & $\begin{array}{l}59,59 \% \\
\pm 0,147\end{array}$ & $\begin{array}{ll}60,35 \% \quad \pm \\
0,15\end{array}$ & $\begin{array}{l}\mathbf{6 2 , 6 2} \% \quad \pm \\
0,146\end{array}$ \\
\hline AbdOmbro & $\begin{array}{ll}45,76 \% \quad \pm \\
0,183 & \\
\end{array}$ & $\begin{array}{l}53,44 \% \\
0,167 \\
\end{array}$ & $\begin{array}{l}\mathbf{7 7 , 7 8} \% \\
\pm 0,001 \\
\end{array}$ & $\begin{array}{l}77,25 \% \\
\pm 0,041 \\
\end{array}$ & $\begin{array}{l}65,61 \% \\
0,131 \\
\end{array}$ & $\begin{array}{ll}\mathbf{7 7 , 7 8} & \pm \\
0,094 \% & \\
\end{array}$ \\
\hline FlexCotovelo & $\begin{array}{ll}49,24 \% & \pm \\
0,152 & \end{array}$ & $\begin{array}{ll}46,71 \% \quad \pm \\
0,147\end{array}$ & $\begin{array}{l}66,67 \% \\
\pm 0,001\end{array}$ & $\begin{array}{l}64,89 \% \\
\pm 0,085\end{array}$ & $\begin{array}{ll}60,10 \% \quad \pm \\
0,145\end{array}$ & $\begin{array}{l}\mathbf{7 1 , 2 1} \% \quad \pm \\
0,085\end{array}$ \\
\hline RotEOmbro & $\begin{array}{ll}54,27 \% \quad \pm \\
0,158 & \\
\end{array}$ & $\begin{array}{l}59,53 \% \\
0,133 \\
\end{array}$ & $\begin{array}{l}29,27 \% \\
\pm 0,001\end{array}$ & $\begin{array}{l}\mathbf{8 7 , 5 \%} \pm \\
0,065\end{array}$ & $\begin{array}{ll}75,32 \% \quad \pm \\
0,105\end{array}$ & $\begin{array}{ll}84,54 \% \quad \pm \\
0,083\end{array}$ \\
\hline
\end{tabular}

Tabela 5.7: Acurácias médias (e seus respectivos desvios-padrão) dos modelos prognósticos de Dor, abdução do ombro (AbdOmbro), flexão do cotovelo (FlexCotovelo) e rotação externa do ombro (RotEOmbro), calculadas utilizando o método LOOCV.

\begin{tabular}{|c|c|c|}
\hline Algoritmo & $\begin{array}{l}\text { Nome do método no Scikit- } \\
\text { learn }\end{array}$ & Valores dos parâmetros utilizados \\
\hline Regressão Linear & linear_model.SGDClassifier & $\begin{array}{l}\text { alpha= } \quad 0,0001, \quad \text { epsilon }=0,1, \\
\text { loss ='squared_loss', } \\
\text { penalty='l1', random_state }=9\end{array}$ \\
\hline Regressão Logística & linear_model.LogisticRegression & $\begin{array}{l}\text { penalty }=\text { 'l2', solver }=\text { 'liblinear', } \\
\text { random state }=9\end{array}$ \\
\hline Rede Neural & neural_network.MLPClassifier & $\begin{array}{l}\text { activation }=\text { 'logistic', } \\
\text { hidden_layer_sizes }=(100,), \\
\text { learning_rate='constant', } \\
\text { early_stopping }=\text { True, max_iter }=300, \\
\text { random_state }=9\end{array}$ \\
\hline SVM & svm.SVC & $\begin{array}{l}C=1,0, \text { kernel='sigmoid', } \\
\text { random state }=9\end{array}$ \\
\hline Árvore de Decisão & tree.DecisionTreeClassifier & $\begin{array}{l}\text { criterion='entropy', } \text { max_depth }=\text { None, } \\
\text { min_samples_split }=2, \text { random_state }=9\end{array}$ \\
\hline Floresta Aleatória & ensemble.RandomForestClassifier & $\begin{array}{l}\text { criterion='entropy', } \quad \text { max_depth }=\text { None, } \\
\text { min_samples_split }=2, \text { bootstrap }=\text { True, } \\
\text { max_features='sqrt', n_estimators }=100, \\
\text { random_state }=9\end{array}$ \\
\hline
\end{tabular}

Tabela 5.8: Lista dos métodos e dos parâmetros utilizados na obtenção dos resultados da Tabela 5.7

MVB (Seção 5.1), para que a aplicação do método de contribuição de atributos sobre os modelos gerados fosse possível.

Em relação aos parâmetros utilizados para as florestas aleatórias na criação dos modelos, a escolha foi feita da seguinte forma:

- Número de árvores na floresta: primeiramente, foram criadas 25 florestas aleatórias para cada número de árvores em $[100,1.000,5.000,7.500,10.000]$, com diferentes valores de semente, e foi avaliada a instabilidade de suas acurácias calculadas pelo erro OOB. Para as florestas criadas utilizando 100 árvores e 1.000 árvores, não houve estabilidade, ou seja, as florestas apresentaram diferentes valores de acurácia para o mesmo conjunto de dados. Para os números de árvores maiores ou iguais a 5.000, houve estabilidade. O mesmo processo foi feito então para os valores $[2.000,3.000,4.000]$, mas os resultados ainda foram instáveis. Dessa forma, o número de árvores escolhido para as florestas foi 5.000, por ser o menor número explorado que alcançou uma estabilidade entre 25 florestas.

- Quantidade de atributos a serem aleatoriamente selecionados para a construção de cada árvore: o valor padrão sugerido por Leo Breiman [Bre01] para esse parâmetro corresponde à raiz quadrada do número de atributos que caracterizam os dados utilizados (ou seja, $\sqrt{N}$ ). 
Esse valor é comumente utilizado em aplicações de Florestas Aleatórias e já foi apontado em experimentos como uma boa escolha para esse parâmetro [DUA06, LW02, WYL16] e, portanto, também foi adotado neste trabalho.

- Reposição na seleção aleatória de instâncias: o método original de Florestas Aleatórias seleciona um subconjunto aleatório de instâncias com reposição para a construção de cada árvore. Entretanto, é possível realizar a seleção sem reposição, de forma a selecionar um número levemente menor de instâncias no conjunto OOB e assim construir as árvores com um número maior de exemplos de treino. A seleção sem reposição para a construção de florestas aleatórias não afeta o seu desempenho [SBV15]. Assim, para os modelos de dor e de força avaliada sobre flexão do cotovelo, a seleção foi realizada sem reposição. Já para os modelos de força avaliada sobre abdução do ombro e sobre rotação externa do ombro, cujos dados são caracterizados por um alto desbalanceamento de classes, a seleção foi realizada em duas etapas - primeiramente, selecionando uma amostra aleatória com reposição das instâncias pertencentes à classe minoritária, e depois completando esse conjunto com uma seleção sem reposição das instâncias pertencentes à classe majoritária. Essa estratégia é uma adaptação do método de Florestas Aleatórias Balanceadas, introduzidas por Chen et al. [CLB04]. O valor utilizado para o parâmetro $d$ relativo ao número de instâncias a serem selecionadas no subconjunto de treino para cada árvore foi de $0,8 M$ ( $80 \%$ das instâncias dos dados de entrada), resultando em um conjunto OOB de tamanho $0,2 M$.

- Profundidade das árvores: é possível limitar o crescimento das árvores de uma floresta até um certo nível de profundidade. Entretanto, para conjuntos de dados não balanceados, limitar o crescimento das árvores pode fazer com que instâncias da classe minoritária não tenham a chance de chegar a nós terminais, portanto, é preferível deixar que as árvores cresçam até sua profundidade máxima [JSB13]. Assim, o crescimento das árvores das florestas construídas neste trabalho não foi limitado.

- Seleção aleatória dos atributos: o algoritmo original de Florestas Aleatórias considera a seleção de subconjuntos aleatórios de atributos de tamanho $p$ para a criação de cada nó de suas árvores. Por outro lado, em domínios cujos dados são caracterizados por um grande número de atributos e um número limitado de instâncias, a pré-seleção de um subconjunto aleatório de atributos de tamanho $p$ antes da criação de cada árvore pode levar a modelos de melhor desempenho [LTTT12, Sku02, Ho98]. Desse modo, essa estratégia foi utilizada para a construção dos modelos.

O Algoritmo 4 descreve o processo de construção das florestas aleatórias utilizadas para a criação dos modelos prognósticos sobre os dados dos pacientes do INDC.

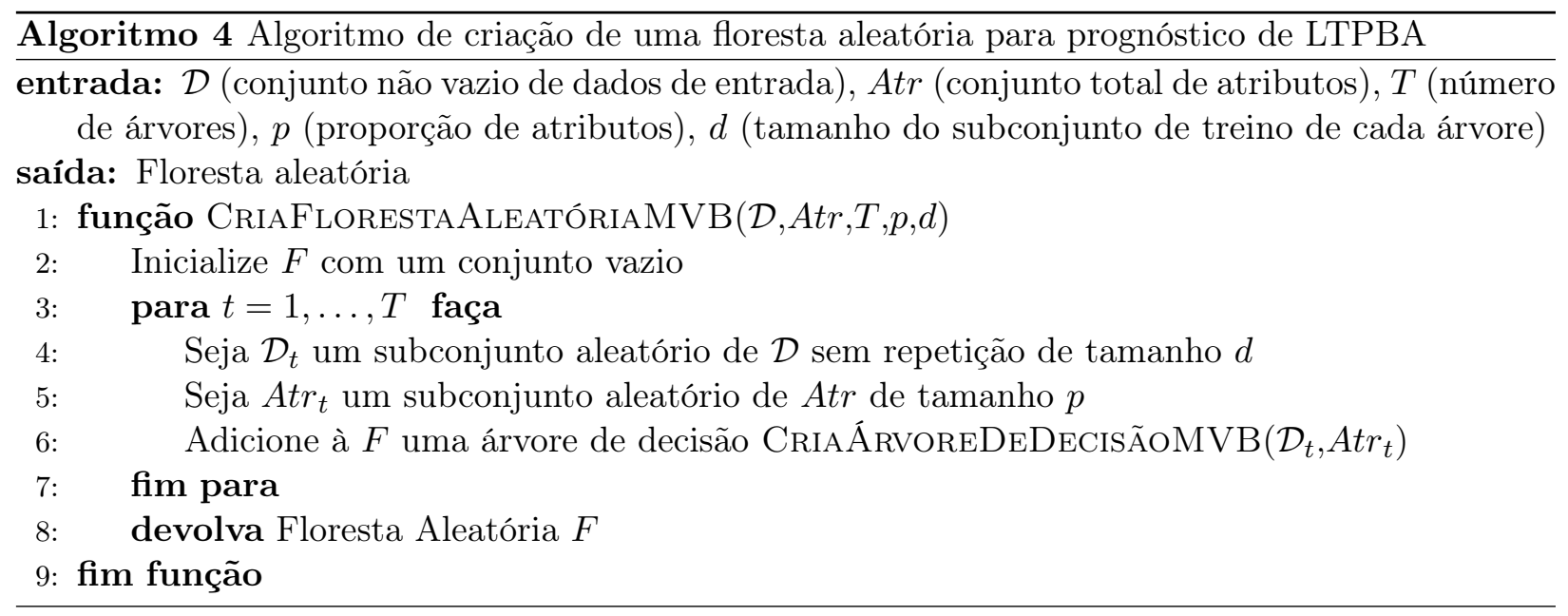

Uma vez definidos os parâmetros para a criação das florestas, foi adotado um processo de seleção de atributos, descrito pelos seguintes passos: 
1. Criam-se 25 florestas aleatórias de $5.001^{4}$ árvores utilizando todos os dados;

2. Para cada floresta $F$ criada no passo anterior, são calculadas as importâncias $v i_{A, F}$ de cada atributo $A$, multiplicadas pela frequência de seus valores não faltantes (de forma que atributos com muitos valores ausentes possuam valor de importância reduzida). O cálculo da importância é feito utilizando uma combinação do método desenvolvido por Hapfelmeier et al. [HHUS14] (para o cálculo de importância de Leo Breiman [Bre01] sobre dados que possuem valores faltantes) e o método de Janitza et al. [JSB13] (para dados caracterizados por um desbalanceamento de classes), ambos descritos na Seção 2.1.2.5.

3. A média dos valores calculados no passo 2 é então atribuída para cada atributo $A$, constituindo assim seu valor de relevância $v r_{A}$, calculado por $v r_{A}=f r(A) \cdot \overline{v i}_{A}$, com $f r(A)$ sendo a frequência de valores não faltantes de $A$ no conjunto de dados, e $\overline{v i}_{A}=\frac{\sum_{F \in F_{25}} v i_{A, F}}{25}$.

4. Seja $V$ o conjunto dos valores de relevância obtidos no passo 3 em ordem crescente. Para cada valor (também denominado limiar) de relevância $v$ em $V$, cria-se uma nova floresta aleatória de 5001 árvores utilizando apenas os atributos de relevância maior ou igual a $v$, começando pelo menor valor de relevância, ou seja, considerando primeiramente todos os atributos, e a cada passo diminuindo um atributo. As acurácias das florestas em termos do erro OOB são armazenadas a cada passo;

5. Os atributos cujas relevâncias são superiores ou iguais ao valor de relevância que levou à melhor acurácia no passo anterior são selecionados para compor o modelo final. A melhor acurácia foi selecionada considerando o valor mais próximo da acurácia máxima subtraída do erro padrão das acurácias. Essa estratégia é utilizada com o intuito de diminuir o risco de sobreajuste [DUA06, GPTM10]. Em caso de empate, foi selecionado o limiar de maior valor (i.e., que define a seleção de um menor número de atributos).

Esse método é relativamente similar à proposta de Genuer et al. [GPTM10] (descrita na Seção 3.3), com a diferença no número de florestas utilizadas nos passos 1 e 4. Neste projeto, foi utilizado um número maior de árvores em cada floresta e, portanto, existe uma maior estabilidade que torna desnecessário o uso de mais de uma floresta no passo 4. Outra diferença se encontra na abordagem considerada: enquanto que o método de Genuer et al. considera primeiramente os atributos mais relevantes e a cada passo inclui os de menor relevância, o método aplicado neste trabalho considera primeiramente todos os atributos, e a cada passo remove os menos relevantes. Essa última estratégia foi utilizada no método de seleção de atributos desenvolvido por Díaz-Uriarte e Alvarez de Andrés [DUA06] (também descrito na Seção 3.3).

Por fim, os atributos retornados pelo método de seleção de atributos são utilizados para construir uma nova floresta aleatória de 5.001 árvores, que constituirá o modelo final.Vale ressaltar que esse processo é feito para a construção de cada um dos modelos mencionados na Seção 5.2.1.

O método de contribuição de atributos descrito na Seção 2.1.2.5 pode ser então aplicado ao modelo final, de forma a obter uma transparência do modelo em termos da contribuição dos valores de cada atributo.

\subsubsection{Avaliação}

A avaliação dos modelos resultantes foi feita sobre as métricas de acurácia, precisão, cobertura e medida-F, utilizando o método de validação cruzada leave-one-out (Seção 2.1.2.1), que apesar de apresentar em geral uma alta variância [HTF09], é mais viável para aplicações com poucas instâncias disponíveis [RTL09].

Discussões iniciais (apresentadas no Capítulo 6) sobre a relevância dos preditores identificados para cada modelo foram feitas com o auxílio da médica neurologista Cristiane Borges Patroclo. Entretanto, a validação clínica desses preditores constitui por si só um tema para outros projetos de pesquisa e está sendo abordada pela médica em seu trabalho de doutorado.

\footnotetext{
${ }^{4}$ Foi escolhido um número ímpar de árvores para evitar empate na votação da classificação de uma instância.
} 


\section{Capítulo 6}

\section{Resultados}

Neste capítulo, apresentamos os resultados da aplicação dos métodos descritos no Capítulo 5 para a criação de cada um dos quatro modelos prognósticos - de dor e de forças musculares avaliadas sobre abdução do ombro, flexão do cotovelo e rotação externa do ombro - bem como o resultado do processo de classificação de pacientes pelos modelos construídos.

Na Seção 6.1 são apresentados os preditores selecionados para cada modelo. Uma breve discussão sobre a relevância desses preditores é realizada considerando os resultados do método de contribuição de atributos desenvolvido por Palczewska et al. [PPRN13], detalhado na Seção 2.1.2.5.1. Uma vez que esse método retorna um valor de contribuição para cada atributo e cada instância, foram produzidos gráficos de forma que cada paciente do conjunto de dados seja representado no gráfico como um ponto $(a, b)$, com $b$ correspondendo ao valor que a instância assume para o atributo e $a$ o seu valor de contribuição.

Como o cálculo de contribuição de um atributo considera a influência de seu valor na probabilidade de uma instância ser classificada como "Sucesso", os valores de contribuição negativos representam uma influência negativa com relação à classe "Sucesso" (e, portanto, positiva com relação à classe "Insatisfatório"). Os pacientes representados por "o" são os que passaram por alguma cirurgia no período entre a lesão e seu último retorno ao INDC, enquanto que os representados por um " $\mathrm{x}$ " não passaram por nenhuma cirurgia. Ainda, os elementos em azul representam os pacientes cujo prognóstico é de sucesso, enquanto que os em vermelho correspondem aos de caso insatisfatório. No caso do prognóstico de dor, foram considerados casos de sucesso os pacientes que não apresentam dor em seu último retorno ao INDC, enquanto que no caso dos modelos prognósticos de força muscular, foram aqueles que apresentaram força maior ou igual a 3 na escala MRC em seu último retorno ao INDC.

Já na Seção 6.2, exemplificamos o processo de classificação de um paciente por cada modelo, e apresentamos a contribuição de seus valores para os atributos envolvidos, utilizando o mesmo método de contribuição de atributos acima. Apesar de envolver apenas instâncias do conjunto de treinamento, os autores do método mostram que é plausível aplicá-lo sobre instâncias "novas" (i.e., que não fazem parte do conjunto de dados sobre o qual um modelo foi construído), de forma a identificar as contribuições de seus valores no processo de sua classificação.

Para todos os modelos foram utilizados os preenchimentos de um paciente que possui respostas para os questionários de Avaliação de Entrada e de Avaliação Cirúrgica, mas não para o questionário de Avaliação de Seguimento.

\subsection{Criação dos Modelos}

\subsubsection{Modelo Prognóstico de Dor}

A criação do modelo prognóstico de dor foi realizada utilizando o arquivo referente ao prognóstico de dor, obtido pelas transformações não opcionais descritas na Seção 5.2.4. Assim, aplicando o método de seleção de atributos descrito na Seção 5.2.5, obtivemos as acurácias (calculadas pelo 
erro OOB) de florestas aleatórias construídas considerando uma certa quantidade de atributos mais relevantes, ou seja, de relevância superior ou igual a um certo limiar. O gráfico da Figura 6.1 apresenta essas acurácias de acordo com cada limiar. O elemento destacado em vermelho corresponde ao limiar escolhido para a construção do modelo final. Vale ressaltar que o modelo final foi selecionado considerando o que obteve a acurácia mais próxima da acurácia máxima subtraída do erro padrão das acurácias. Essa estratégia é utilizada com o intuito de diminuir o risco de sobreajuste e lidar com possíveis instabilidades [DUA06, GPTM10].

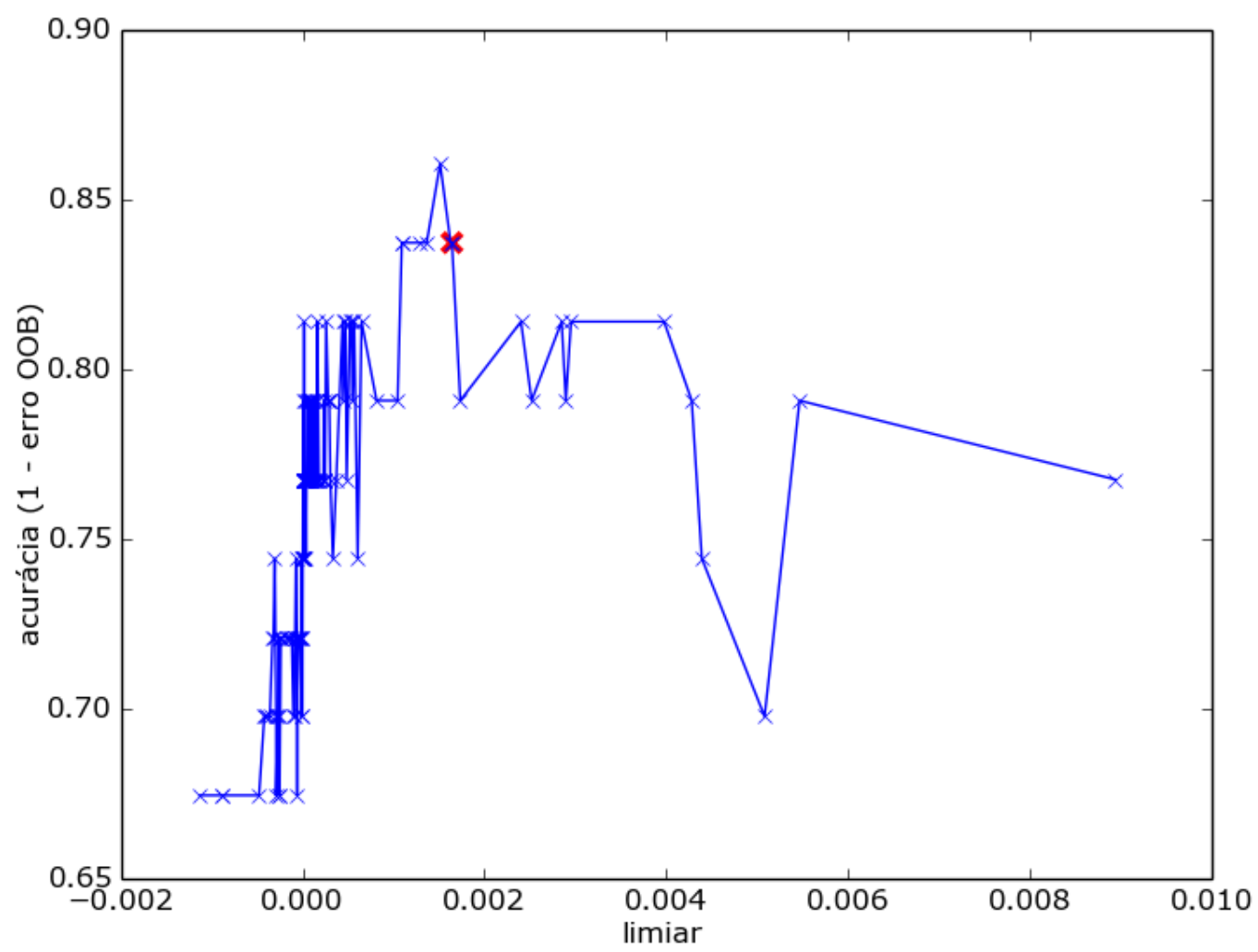

Figura 6.1: Acurácias das florestas aleatórias quando aplicadas sobre atributos de importância média superior ou igual a cada valor de limiar, para o modelo prognóstico de dor.

O diagrama de caixa da Figura 6.2 apresenta os valores de relevância dos atributos cuja relevância média é superior ao limiar selecionado, calculados pelas 25 florestas aleatórias no passo 3 da etapa de mineração, descrita na Seção 5.2.5.

Os atributos selecionados para compor o modelo final foram (ordenados pelo maior valor médio de importância):

- "Sente dor após a lesão?";

- "Sensibilidade superficial tátil [C7]";

- "Transferência realizada: Oberlin";

- "Sensibilidade superficial dolorosa [C7]";

- "Sensibilidade superficial tátil [C8]";

- "Período entre a lesão e a primeira consulta no INDC";

- "Sensibilidade superficial tátil [C6]" ;

- "Força muscular avaliada sobre flexão dos dedos";

- "Sensibilidade superficial dolorosa [C8]";

- "Tem história prévia de fratura?"; 


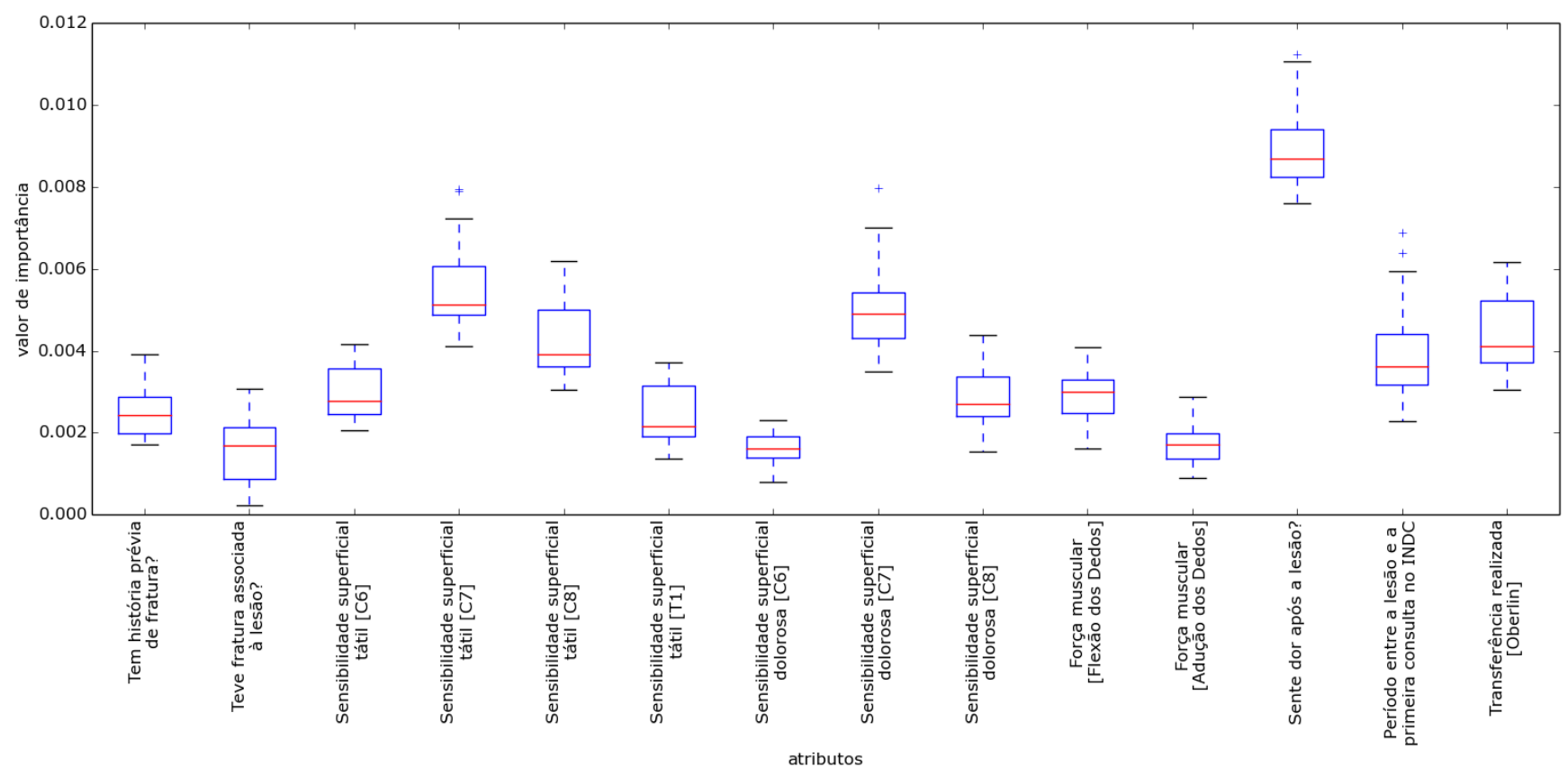

Figura 6.2: Diagrama de caixa sobre os valores de importância para cada atributo, calculados com 25 florestas aleatórias, na criação do modelo prognóstico de dor.

- "Sensibilidade superficial tátil [T1]";

- "Força muscular avaliada sobre adução dos dedos";

- "Teve fratura associada à lesão";

O preditor de maior relevância para o prognóstico de dor está relacionado ao paciente sentir dor quando chega o INDC pela primeira vez. O gráfico da Figura 6.3 apresenta a contribuição de cada valor para esse atributo, sendo eles "Sim" (S), "Não" (N). O valor "NaN" representa os valores "Não informado/ Não avaliado" ou valores em branco.

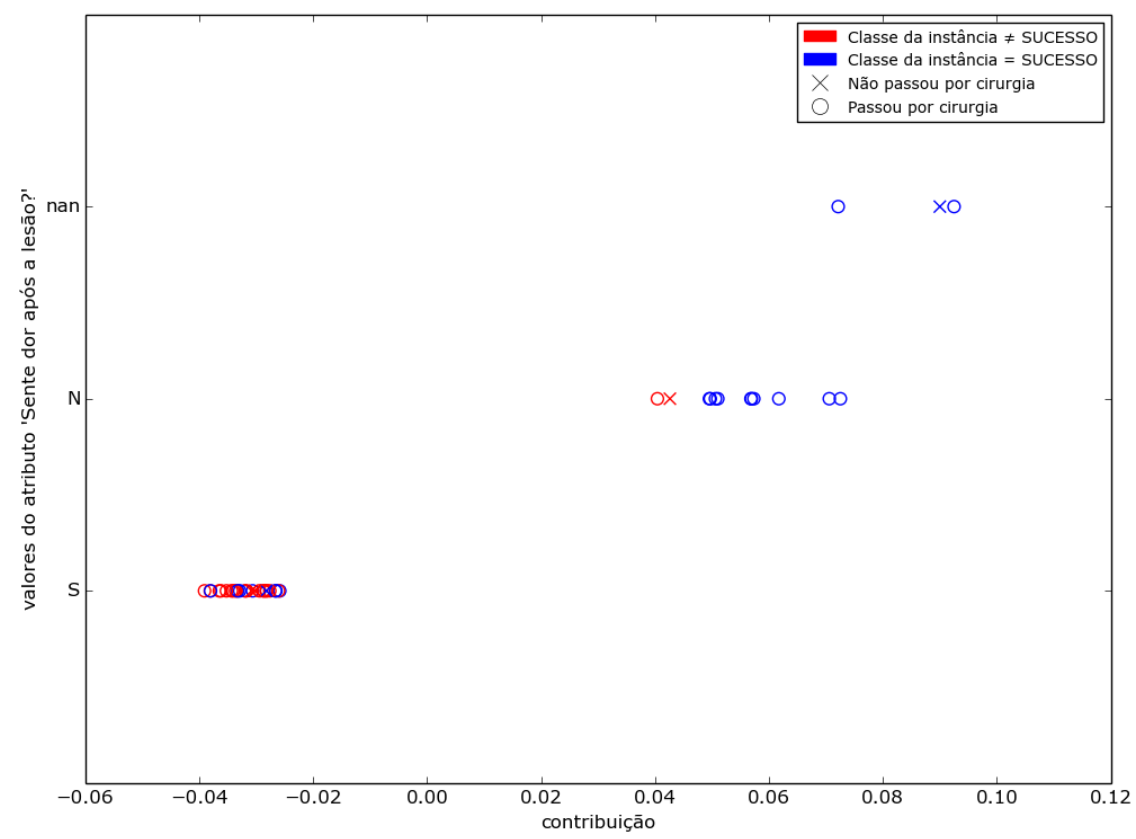

Figura 6.3: Contribuição dos valores do atributo "Sente dor após a lesão?" para cada paciente, para o modelo prognóstico de dor.

Pelo gráfico, vemos que respostas "Não" para a questão "Sente dor após a lesão?" do questionário 
de entrada apresentam contribuições positivas para a classe "Sucesso" e que, com exceção de duas instâncias, os pacientes que apresentam essa resposta continuam não sentindo dor no momento do retorno ao INDC. Assim, se um paciente chega ao INDC pela primeira vez não apresentando dor, há grandes chances de que continuará não apresentando dor no futuro. Embora as duas particulares instâncias que possuem resposta "Não" para essa questão e resultado insatisfatório tenham apresentado valores de contribuição positivos para o atributo, seu valores de contribuição para outros atributos relativos a sensibilidade tátil e dolorosa apresentam valores negativos.

Os gráficos de contribuição para esses atributos são apresentados nas Figuras 6.4 e 6.5. O valor "SEM" se refere à resposta "Sem alterações", enquanto que o valor "ALTER" se refere às respostas "Hipotrofia", "Atrofia" e "Hipertrofia" para os atributos relativos à sensibilidade superficial tátil, e às respostas "Hipoalgesia", "Hiperalgesia" e "Analgesia" para os relativos à sensibilidade superficial dolorosa. Nota-se que não ter apresentado alterações nas avaliações de sensibilidade superficial contribuiu positivamente para a classificação dos pacientes em "Sucesso".

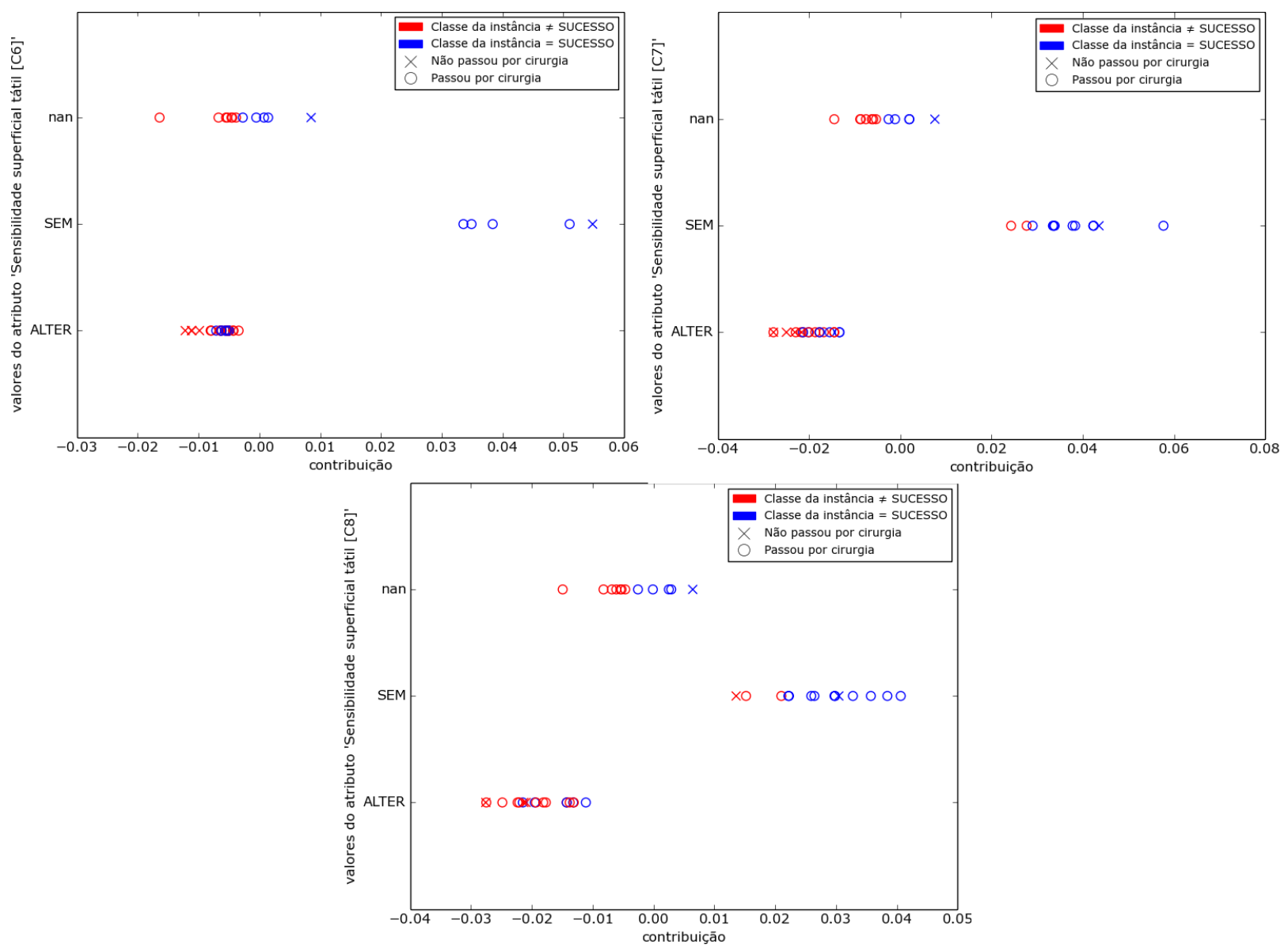

Figura 6.4: Contribuição dos valores dos atributos relativos à sensibilidade superficial tátil, avaliadas sobre C6, C7 e C8, para o modelo prognóstico de dor.

Em relação aos valores faltantes ("NaN"), seria esperado que apresentassem contribuições quase nulas, uma vez que idealmente esse valor não deveria afetar significativamente a classificação das instâncias. Porém, como os dados dos pacientes do INDC possuem uma grande proporção de valores faltantes, é comum que apresentem valores altos (negativos ou positivos) de contribuição.

As contribuições dos valores do atributo "Transferência realizada: Oberlin" se encontram na Figura 6.6. Respostas "Sim" (representadas por "Y") apresentaram valores positivos, enquanto que respostas "Não" (representadas por "N") apresentaram contribuições negativas. O valor "Não aplicável" para essa questão corresponde aos preenchimentos dos pacientes que não realizaram nenhuma cirurgia do plexo braquial.

O procedimento de Oberlin está, na realidade, relacionado à recuperação motora da flexão do 


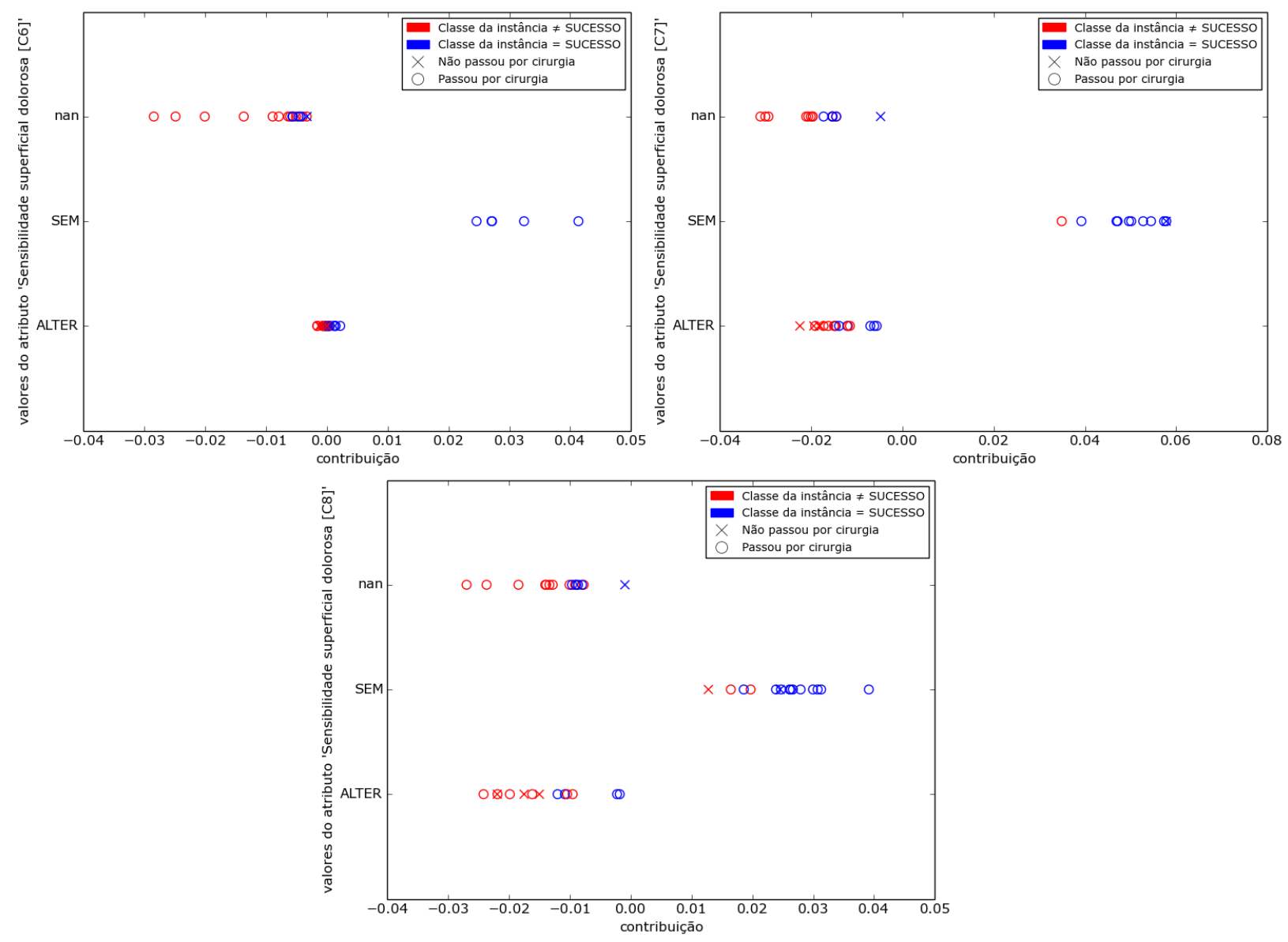

Figura 6.5: Contribuição dos valores dos atributos relativos à sensibilidade superficial dolorosa, avaliadas sobre C6, C7 e C8, para o modelo prognóstico de dor.

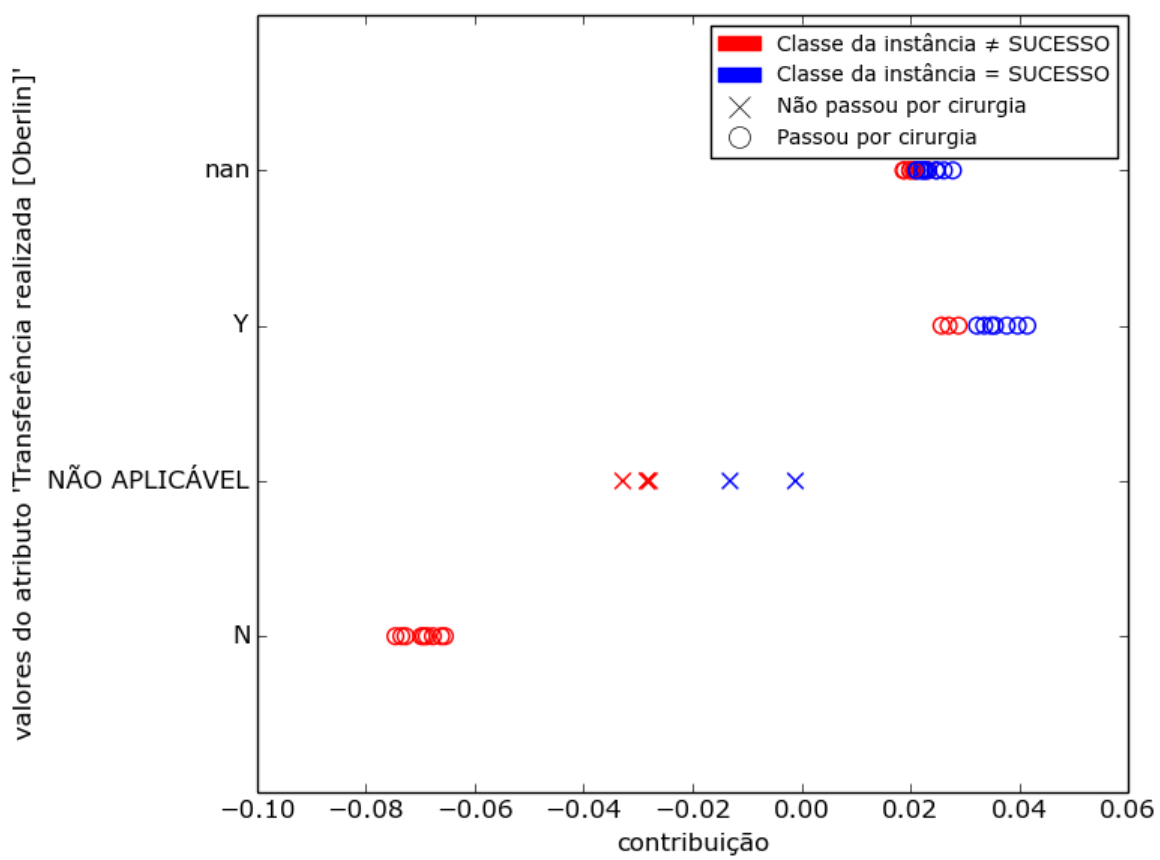

Figura 6.6: Contribuição dos valores do atributo "Transferência realizada: Oberlin", para o modelo prognóstico de dor. 
cotovelo: trata-se de uma transferência nervosa intraplexual (que utiliza um nervo da estrutura do plexo braquial) com o objetivo de tentar restaurar a flexão do cotovelo. É curioso que os valores "Sim" para esse atributo tenha apresentado contribuições positivas, uma vez que o objetivo da cirurgia está relacionado a uma recuperação motora, e não de sensibilidade. Isso sugere que pode existir uma correlação entre a recuperação motora e a de dor em pacientes. Embora esses dois fatores seja tratados frequentemente como fatores independentes, existem hipóteses de que eles estão relacionados [MRBB17].

Já em relação aos atributo "Força muscular avaliada sobre flexão dos dedos" e "Força muscular avaliada sobre adução dos dedos", os gráficos da Figura 6.7 ilustram as contribuições de seus valores em cada instância.
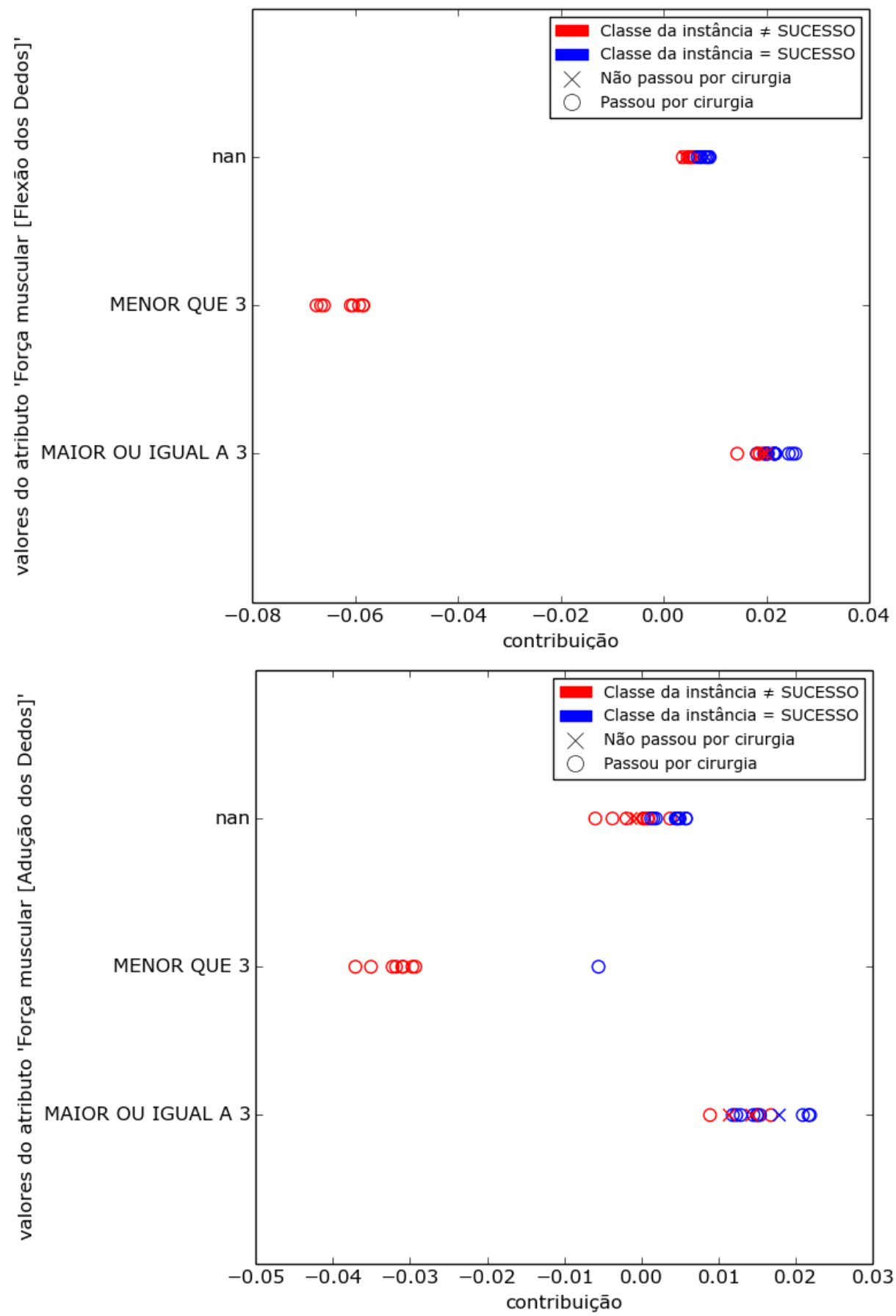

Figura 6.7: Contribuição dos valores dos atributos "Força muscular avaliada sobre flexão dos dedos" $e$ "Força muscular avaliada sobre adução dos dedos" para cada paciente, para o modelo prognóstico de dor. 
Nesse caso, apresentar força menor ou igual a 3 obteve contribuições bastante negativas com relação ao prognóstico de recuperação de dor. É interessante notar que ambos os movimentos cujas avaliações foram apontadas como relevantes estão associados a movimentos das mãos (principalmente ao movimento de preensão - o mesmo de utilizado para segurar ou agarrar objetos). Assim, pode ser que exista uma relação entre a motricidade das mãos e a constatação futura de dor pelo paciente.

Com relação aos atributos "Tem história prévia de fratura" e "Teve fratura associada à lesão?", cujas contribuições estão apresentadas na Figura 6.8, vemos que respostas "Sim" apresentaram contribuições negativas para a classe "Sucesso", enquanto que respostas "Não" apresentaram valores negativos.
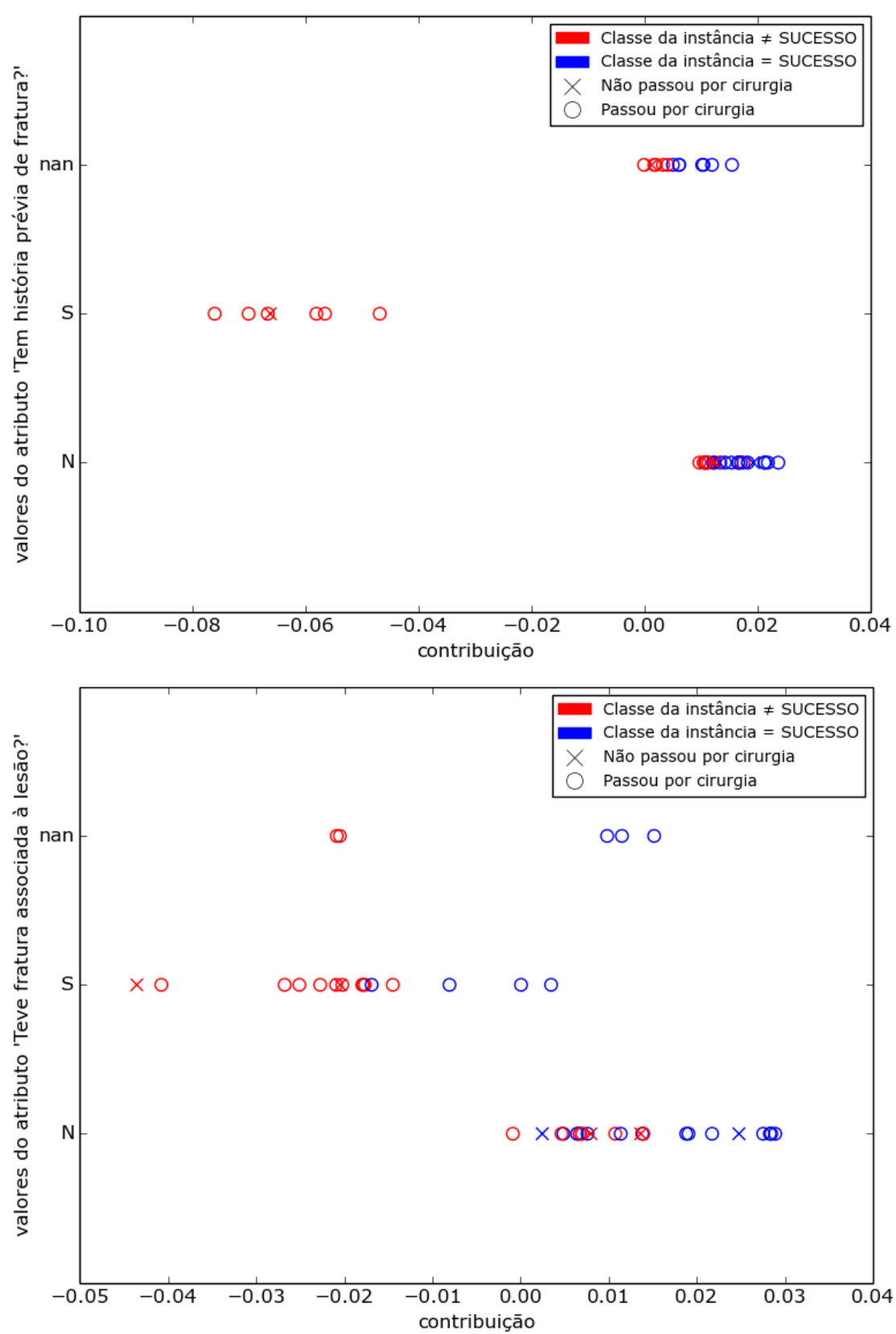

Figura 6.8: Contribuição dos valores dos atributos "Tem história prévia de fratura?" e "Teve fratura associada à lesão?" para cada paciente, para o modelo prognóstico de dor.

Apesar de essa situação ocorrer para ambos os atributos, podemos ver que no caso de "Tem história prévia de fratura?", todos os pacientes que apresentaram resposta "Sim" realmente obtiveram 
resultados insatisfatórios, o que não ocorreu com o atributo relativo à existência de fratura associada à lesão. Desse modo, pode ser que pacientes que já passaram por um evento doloroso como uma fratura apresentem uma predisposição para sentir dor por conta da lesão do plexo braquial.

Entretanto, para poder analisar melhor as possíveis correlações existentes, seria necessário primeiramente avaliar os sítios das lesões prévias e associadas, pois existe a possibilidade de que não exista relação entre as fraturas e a lesão (caso tenham ocorrido em membros inferiores, por exemplo). Porém, caso essa relação exista, é possível que a fratura tenha piorado a gravidade da lesão e portanto, da sensação de dor.

Díaz-Uriarte e Alvarez de Andrés [DUA06] argumentam que o erro OOB não corresponde a uma boa aproximação do erro de generalização do modelo quando, no processo de seleção de atributos utilizando florestas aleatórias, for utilizado como critério de seleção. Nesse caso, o erro OOB (e portanto a acurácia calculada a partir dele) pode corresponder a um valor enviesado. Desse modo, a avaliação do modelo foi realizada pelo método de validação cruzada LOOCV. A acurácia média obtida foi de 77,27\%. A Tabela 6.1 apresenta a acurácia média (e seu desvio padrão), precisão, cobertura e medida-F do modelo resultante, considerando cada uma das classes como positiva. Vale ressaltar que a acurácia não se altera ao mudarmos a classe positiva, já que não considera os conceitos de verdadeiros e falsos positivos em seu cálculo.

\begin{tabular}{|c|l|c|c|c|}
\hline Classe & Acurácia & Precisão & Cobertura & Medida-F \\
\hline Sucesso & $\begin{array}{l}77,27 \% \\
\pm 0,419\end{array}$ & $71,43 \%$ & $78,94 \%$ & $75 \%$ \\
\hline Insatisfatório & $\begin{array}{l}77,27 \% \\
\pm 0,419\end{array}$ & $91,3 \%$ & $76 \%$ & $84 \%$ \\
\hline
\end{tabular}

Tabela 6.1: Desempenho do modelo prognóstico de dor, em termos de acurácia média (e seu desvio padrão), precisão, cobertura e medida- $F$, considerando as respectivas classes como positivas.

\subsubsection{Modelo Prognóstico de Força Muscular Avaliada sobre Abdução do Om- bro}

Com relação ao prognóstico de força muscular avaliada sobre abudção do ombro, a aplicação do método de seleção descrito na Seção 5.2.5 resultou nos seguintes atributos:

- "Evento que levou ao trauma [Moto]";

- "Se faz uso de dispositivo auxiliar [Suporte de Ombro]";

- "Se faz uso de dispositivo auxiliar [Tipoia]";

A Figura 6.9 apresenta as acurácias das florestas envolvidas no processo de seleção de atributos, e a Figura 6.10 apresenta o diagrama de caixas sobre os valores de importância dos atributos selecionados, calculados por essas florestas. 


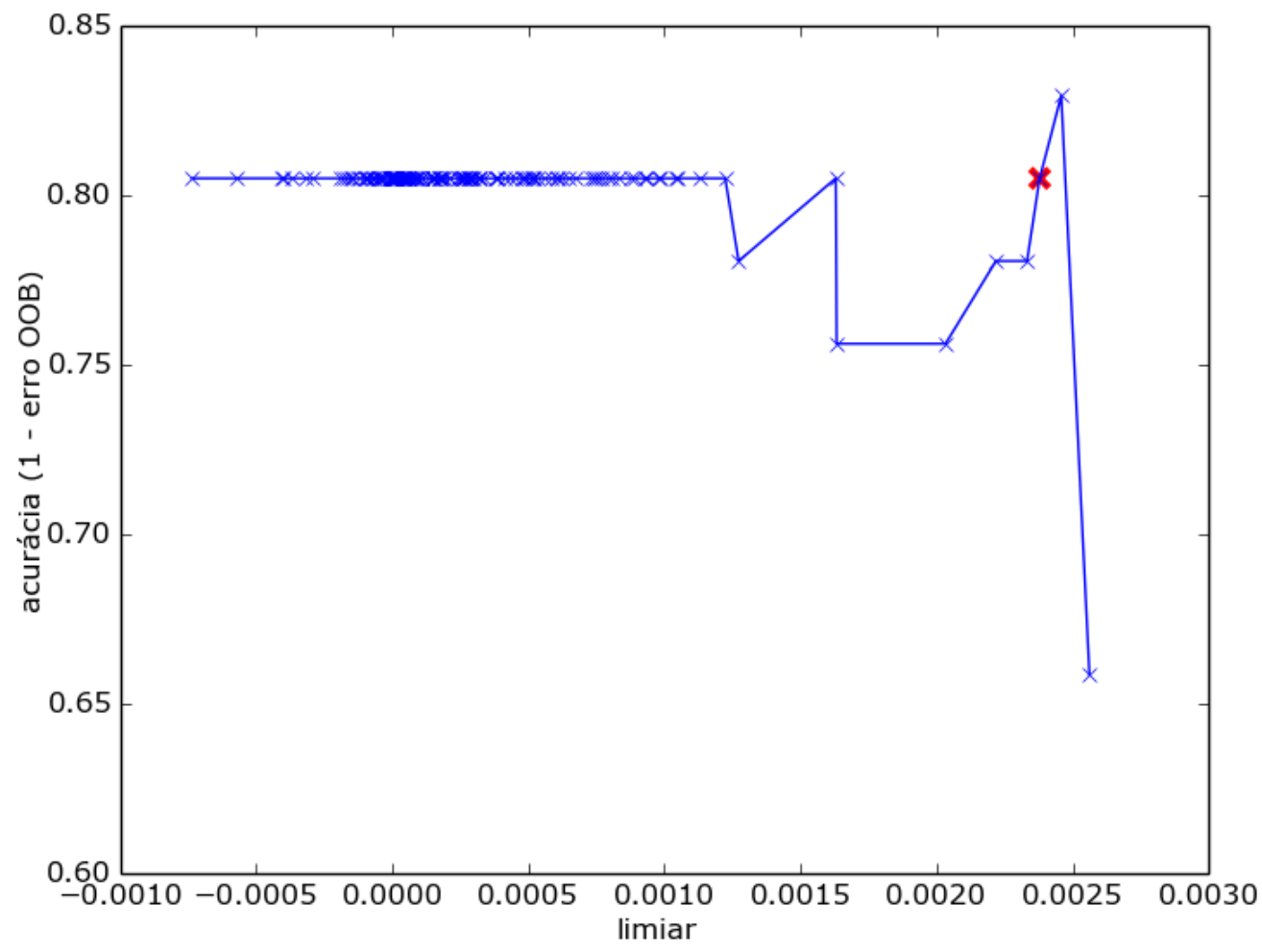

Figura 6.9: Acurácias das florestas aleatórias quando aplicada sobre atributos de importância média superior a cada valor de limiar, para o modelo prognóstico de força avaliada sobre abdução do ombro.

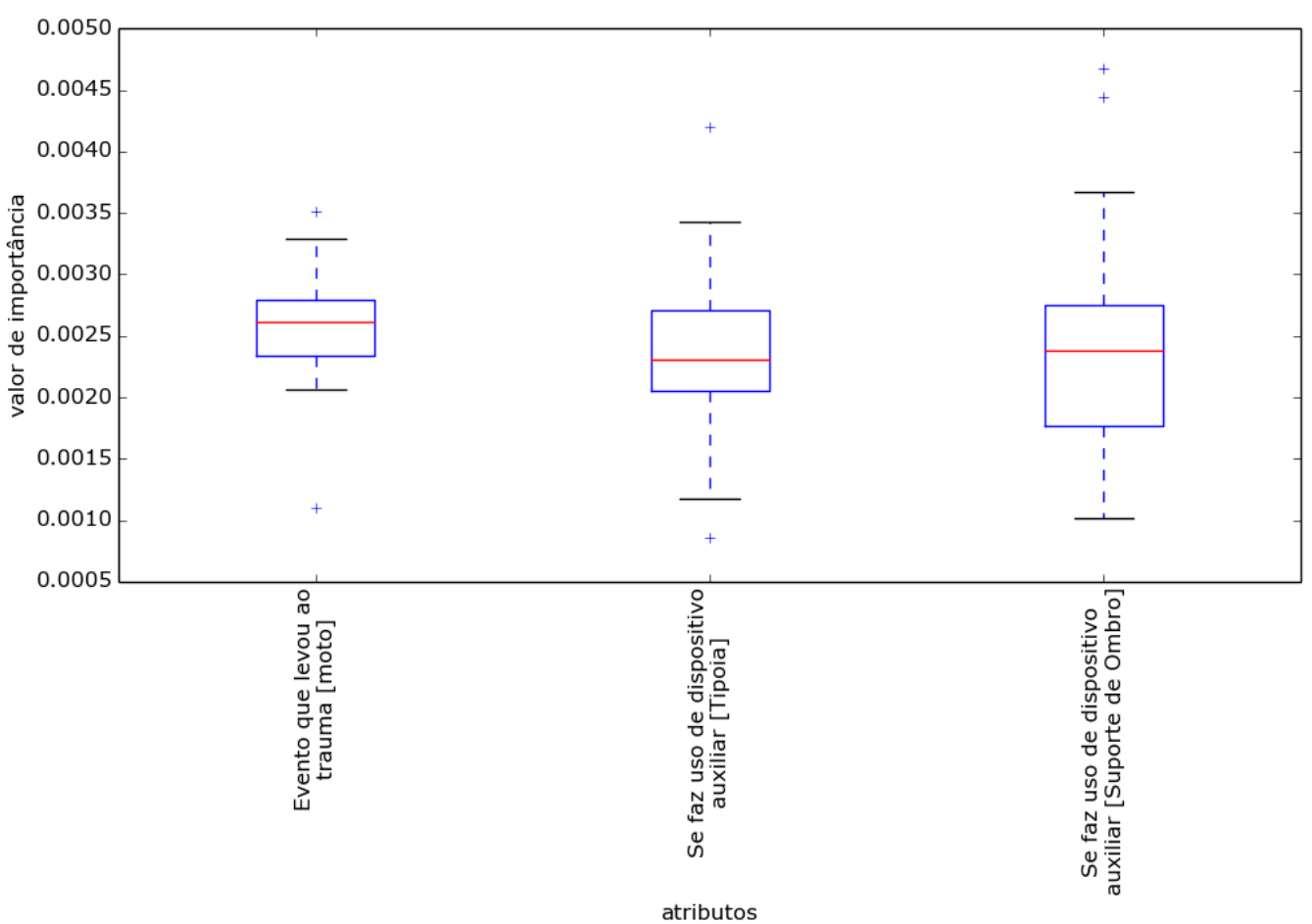

Figura 6.10: Diagrama de caixa sobre os valores de importância para cada atributo, calculados com 25 florestas aleatórias, para a criação do modelo prognóstico de força muscular avaliada sobre abdução do ombro. 
Na Figura 6.11, o valor "NaN" (representado por "nan") se refere a valores desconhecidos (equivalente a respostas em branco ou "Não informado/ Não avaliado"), enquanto que o valor "Não aplicável" corresponde aos preenchimentos cuja resposta para a pergunta "Faz uso de dispositivo auxiliar?" é negativa. Para ambos os tipos de dispositivos auxiliares, o valor "Não aplicável" apresentou uma alta contribuição. Os pacientes que apresentam esse valor de resposta para essas perguntas correspondem àqueles que possuem resposta negativa para a questão "Faz uso de dispositivo auxiliar?" do questionário de entrada. Nesse caso, houve uma correlação entre os pacientes que não utilizaram nenhum dispositivo auxiliar e o prognóstico positivo para força muscular avaliada sobre abdução do ombro, que poderia ser entendida de duas formas: ou existe um certo comprometimento da recuperação de força ocasionado pela imobilização por conta do uso de um dispositivo auxiliar, ou não houve a necessidade desses pacientes utilizarem um dispositivo auxiliar por conta de possuírem uma lesão menos agravada e, portanto, que apresenta maior chances de recuperação.

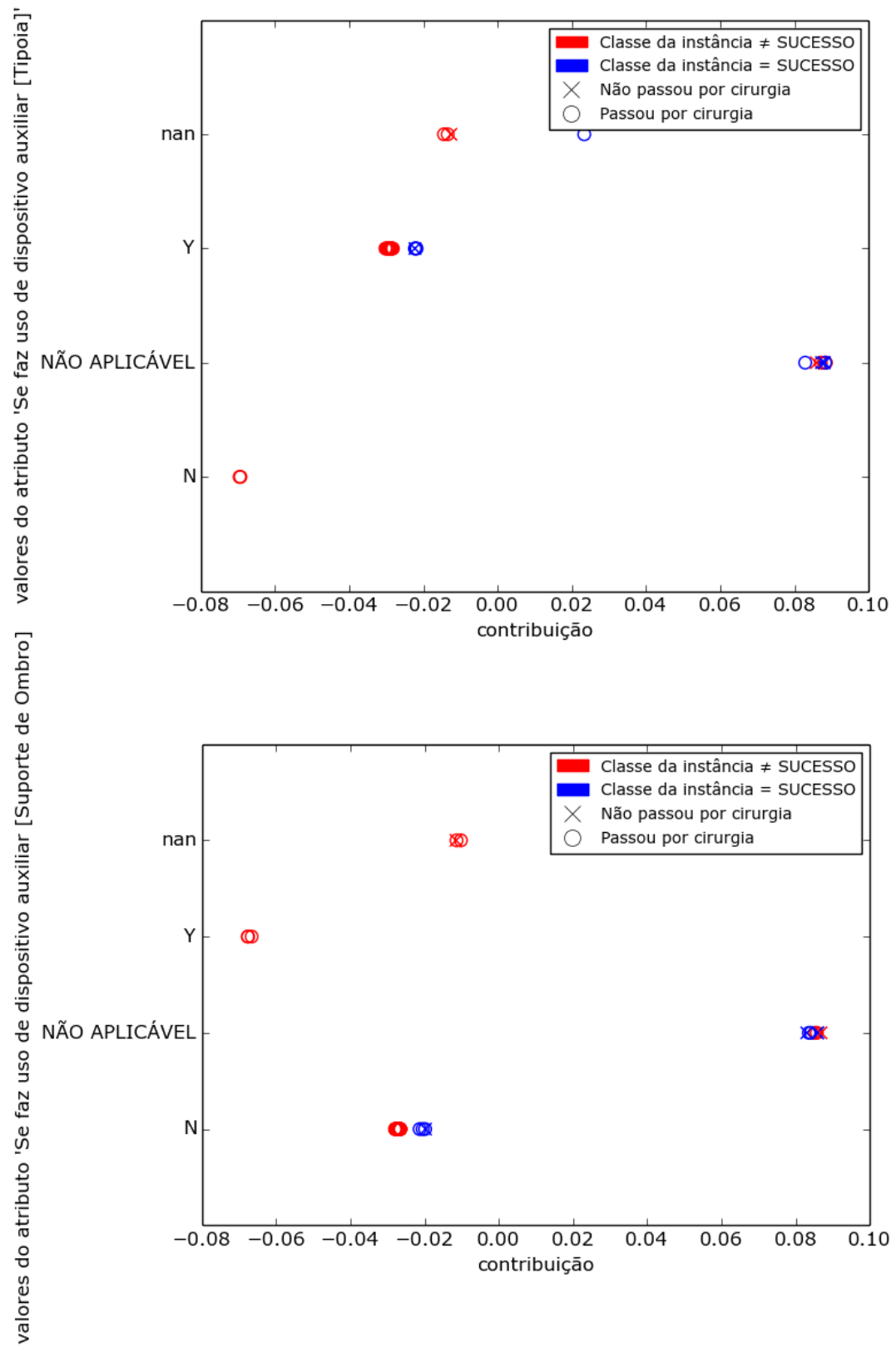

Figura 6.11: Contribuição dos valores dos atributos "Se faz uso de dispositivo auxiliar [Suporte de Ombro]" e "Se faz uso de dispositivo auxiliar [Tipoia]" para cada paciente, para o modelo prognóstico de força muscular avaliada sobre abdução do ombro. 
Já na Figura 6.12 vemos que a resposta positiva para a questão "Evento que levou ao trauma [Moto]" obteve uma contribuição negativa com relação à classe "Sucesso", enquanto que a resposta "Não" obteve uma contribuição positiva. É possível que a seleção desse atributo como um preditor para o modelo prognóstico relativo à abdução do ombro tenha ocorrido por conta de que acidentes de moto ocasionam, em geral, lesões nas raízes superiores (e.g., C5), e que podem ser mais graves do que lesões ocasionadas por outro tipo de evento.

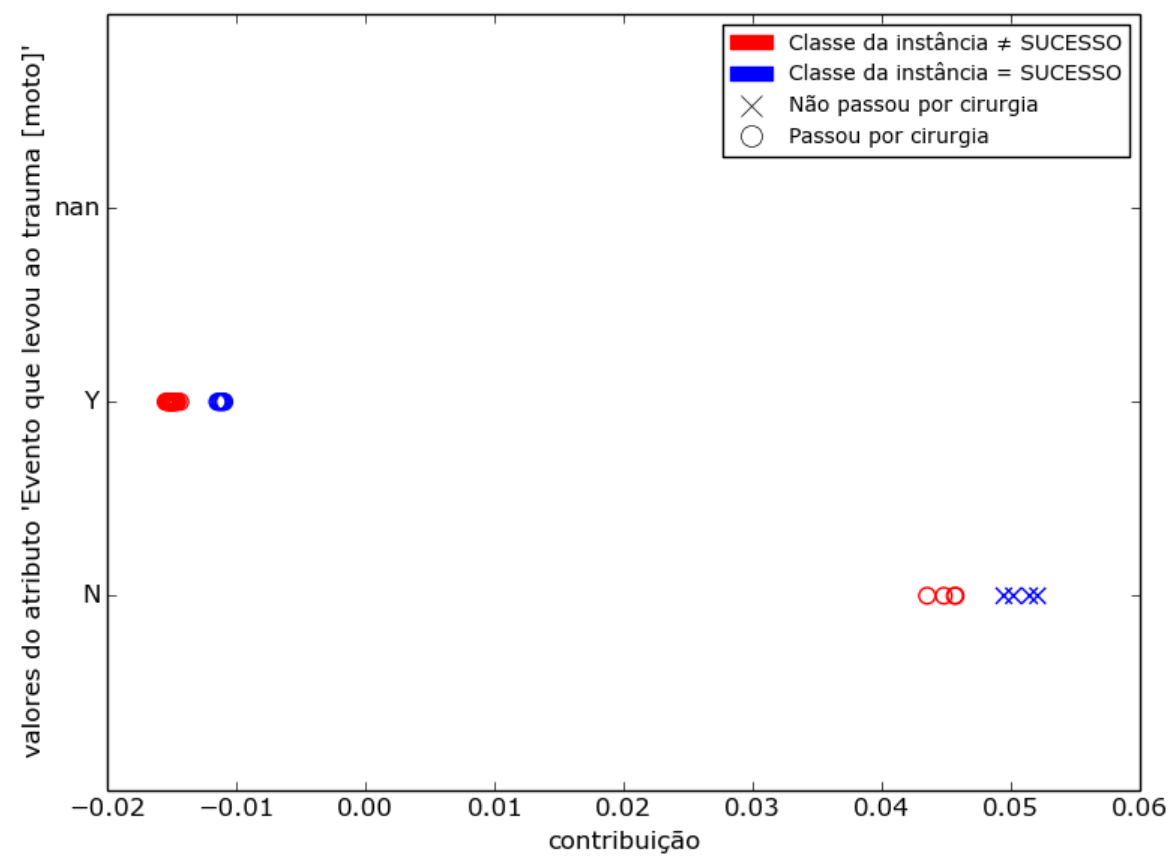

Figura 6.12: Contribuição dos valores do atributo "Evento que levou ao trauma [Moto]", para o modelo prognóstico de força muscular avaliada sobre abdução do ombro.

A acurácia do modelo final calculada pelo método de validação cruzada LOOCV foi de 80,95\%. A Tabela 6.2 apresenta o desempenho do modelo final avaliado sobre acurácia, precisão, cobertura e medida-F.

\begin{tabular}{|c|l|c|c|c|}
\hline Classe & Acurácia & Precisão & Cobertura & Medida-F \\
\hline Sucesso & $\begin{array}{l}80,95 \% \\
\pm 0,3927\end{array}$ & $50 \%$ & $62,5 \%$ & $55,55 \%$ \\
& & & \\
\hline Insatisfatório & $\begin{array}{l}80,95 \% \\
\pm 0,3927\end{array}$ & $90,62 \%$ & $85,29 \%$ & $87,87 \%$ \\
& & & \\
\hline
\end{tabular}

Tabela 6.2: Desempenho do modelo prognóstico de força avaliada sobre abdução do ombro, em termos de acurácia média (e seu desvio padrão), precisão, cobertura e medida-F, considerando as respectivas classes como positivas. 


\subsubsection{Modelo Prognóstico de Força Muscular Avaliada sobre Flexão do Cotovelo}

Em relação ao modelo prognóstico de força muscular avaliada sobre flexão do cotovelo, os atributos selecionados foram:

- "Se faz uso de dispositivo auxiliar [Suporte de Ombro]";

- "Se faz uso de dispositivo auxiliar [Tipoia]";

- "Força muscular avaliada sobre flexão do cotovelo";

- "Ficou desacordado?";

- "Transferência realizada [Oberlin]".

As acurácias das florestas no processo de seleção estão apresentadas no gráfico da Figura 6.13, e o diagrama de caixas sobre seus valores de importância para atributos que foram selecionados para o modelo final está ilustrado na Figura 6.14.

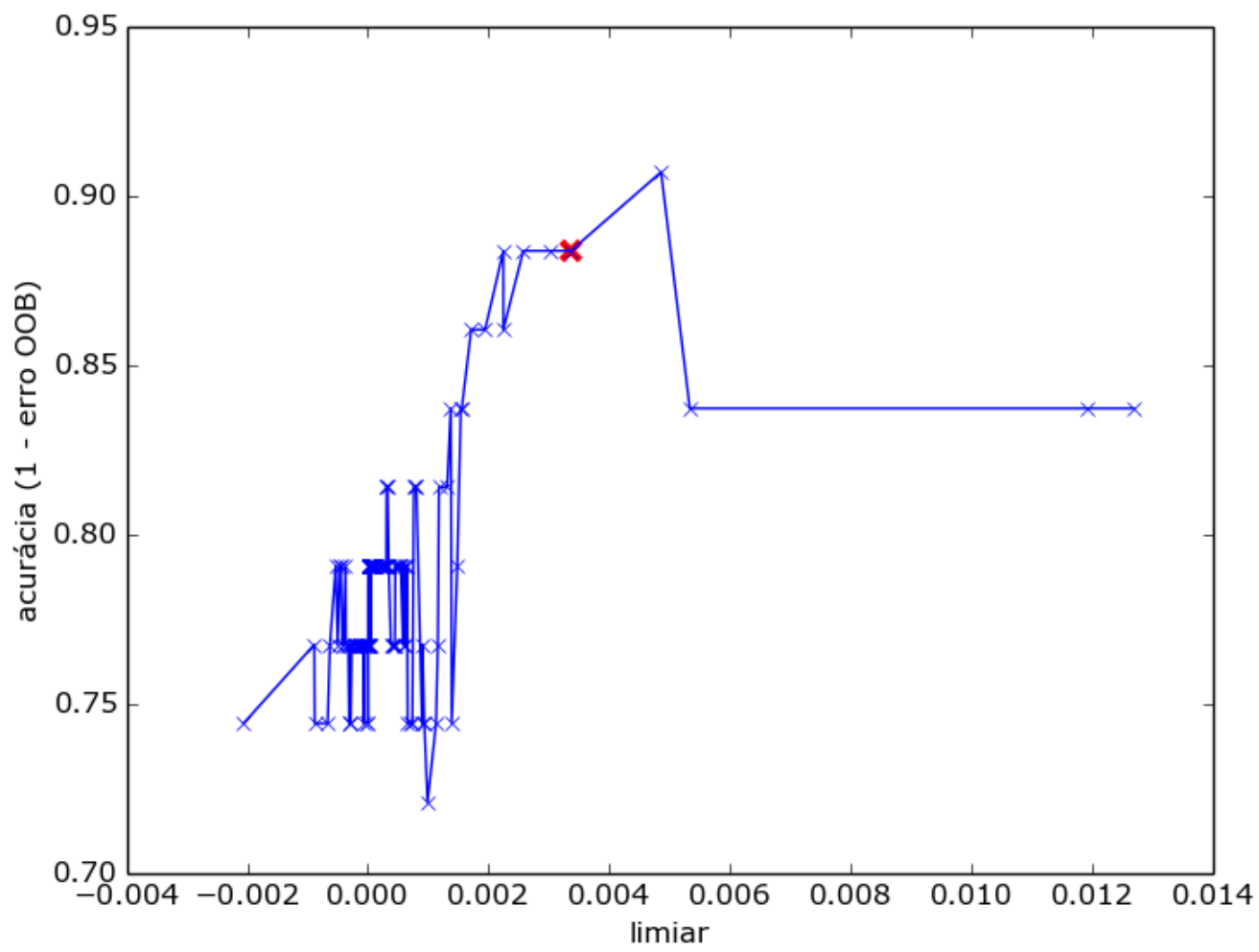

Figura 6.13: Acurácias das florestas aleatórias quando aplicadas sobre atributos de importância média superior a cada valor de limiar, para o modelo prognóstico de força avaliada sobre flexão do cotovelo. 


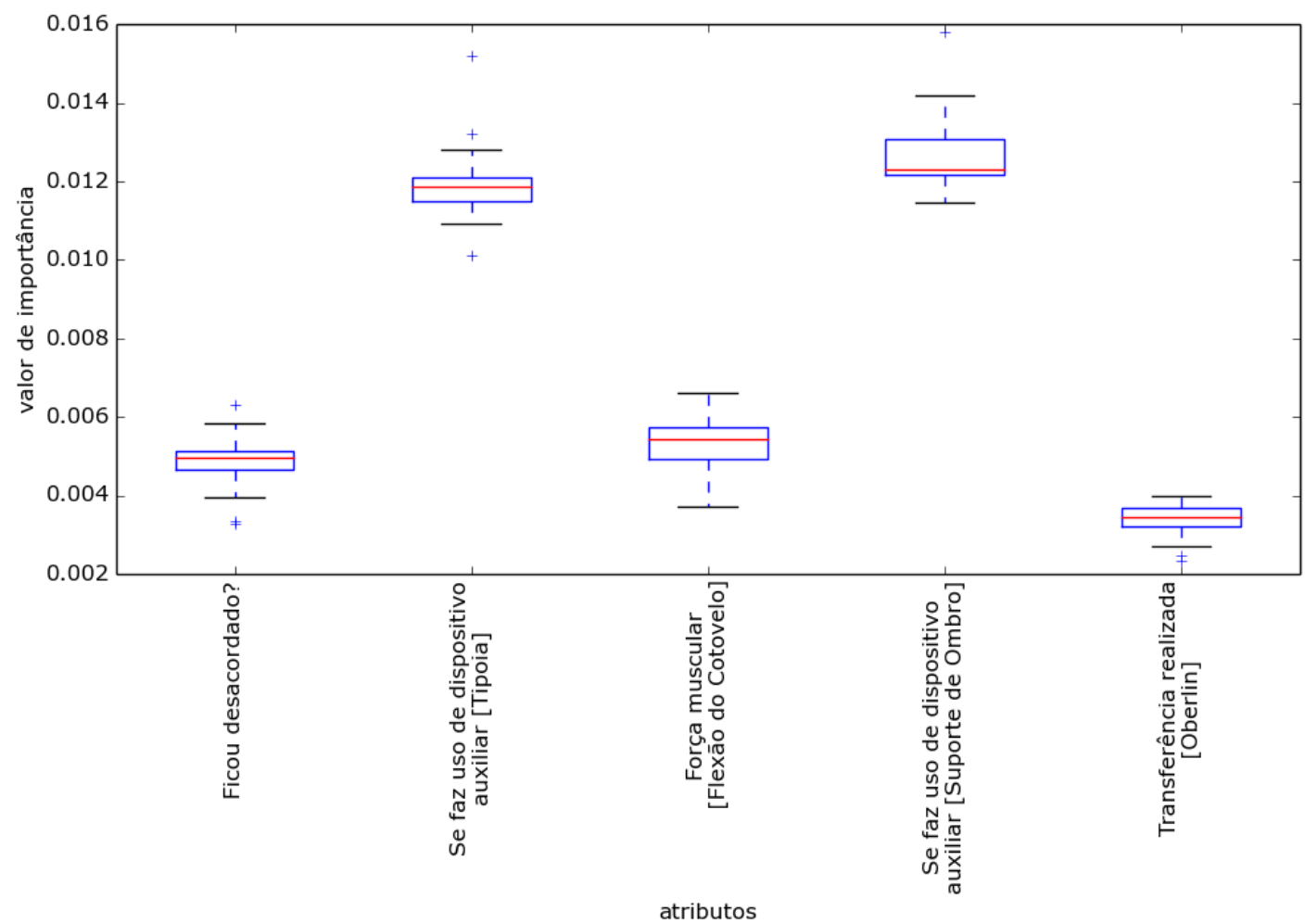

Figura 6.14: Diagrama de caixa sobre os valores de importância para cada atributo, calculados com 25 florestas aleatórias, na criação do modelo prognóstico de força muscular avaliada sobre flexão do cotovelo.

Para este modelo, os atributos "Se faz uso de dispositivo auxiliar [Suporte de Ombro]" e "Se faz uso de dispositivo auxiliar [Tipoia]" apresentam contribuições relativamente parecidas se comparadas com o modelo prognóstico de abdução do ombro (Figura 6.11): o valor "Não aplicável" apresentou contribuições positivas para ambos atributos, como vemos na Figura 6.15.

Com relação ao atributo "Força muscular avaliada sobre flexão do cotovelo" (Figura 6.16), como esperado, ocorre a mesma observação com relação ao atributo "Sente dor após a lesão?" do questionário de Avaliação de Entrada para o modelo prognóstico de dor: pacientes que apresentam força muscular satisfatória (maior ou igual a 3 na escala MRC) possuem mais chances de apresentarem um resultado satisfatório.

A contribuições do atributo "Transferência realizada [Oberlin]", por sua vez, está ilustrada na Figura 6.17. Como mencionado anteriormente, o procedimento de Oberlin está justamente relacionado à recuperação motora da flexão do cotovelo. No gráfico, porém, pacientes que realizaram esse procedimento não apresentaram contribuições significativas, enquanto que aqueles que realizaram algum procedimento cirúrgico que não o de Oberlin apresentaram contribuições negativas. Uma hipótese que pode ser levantada para esses pacientes é a de que a escolha desse procedimento pode ter sido impedida por conta da gravidade da lesão (que inviabiliza uma transferência intraplexual, por exemplo), o que prejudica suas chances de recuperação.

Por fim, o gráfico de contribuições do atributo "Ficou desacordado?" se encontra na Figura 6.18. Curiosamente, pacientes que ficaram desacordados apresentaram contribuições negativas, enquanto que o oposto ocorreu com que aqueles que não ficaram desacordados. É possível que exista alguma relação entre esse fator e a gravidade da lesão, que propicia maiores chances de recuperação. Entretanto, seria vantajosa a aplicação de análises estatísticas para verificar a correlação entre esse preditor e a recuperação da força muscular sobre flexão do cotovelo.

O modelo resultante pela criação de uma floresta aleatória contendo os atributos selecionados apresentou acurácia de 88,63\%, calculada utilizando o método de validação cruzada LOOCV. A Tabela 6.3 apresenta o desempenho do modelo final avaliado sobre acurácia, precisão, cobertura e medida-F. 


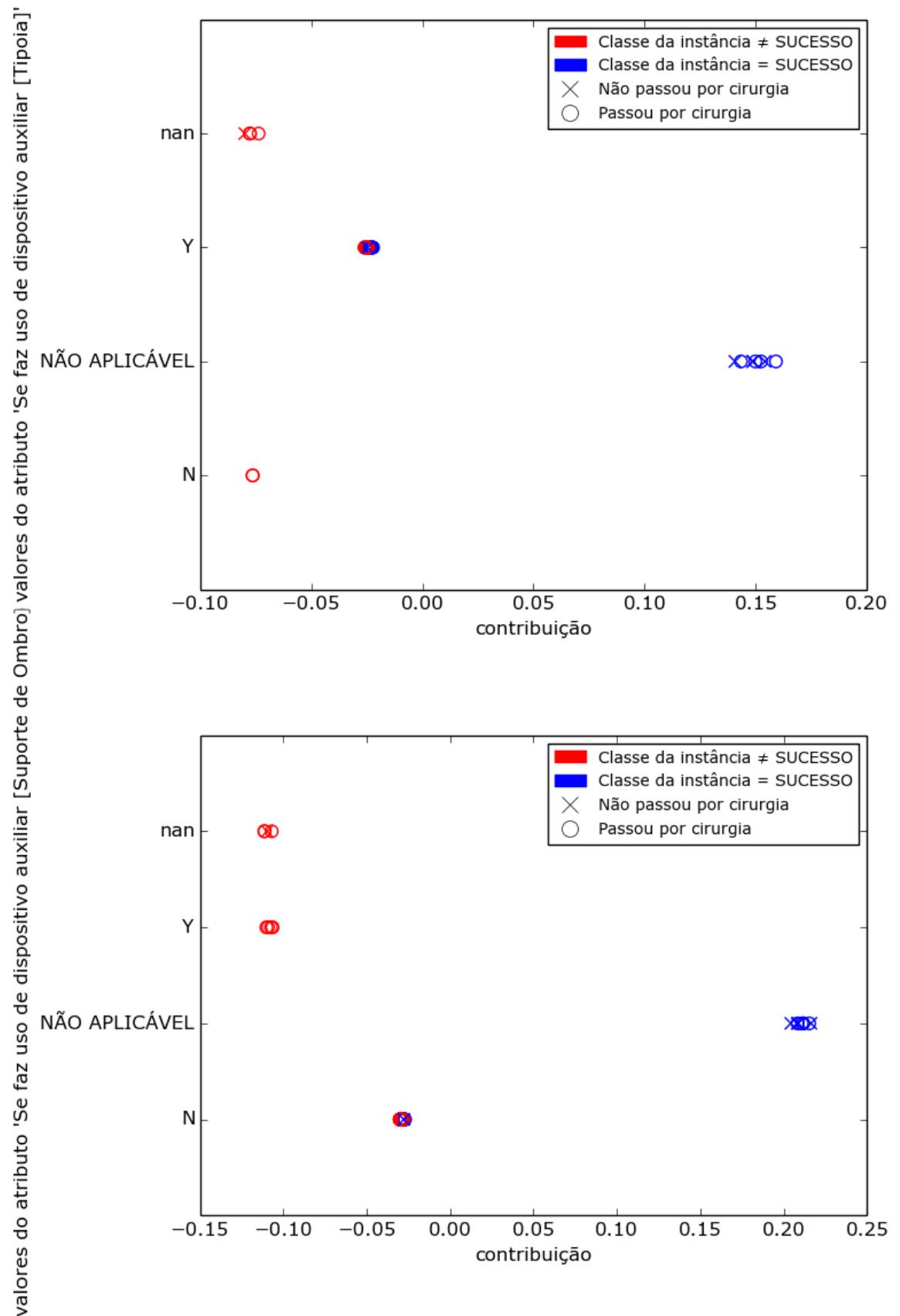

Figura 6.15: Contribuição dos valores dos atributos "Se faz uso de dispositivo auxiliar [Suporte de Ombro/" e "Se faz uso de dispositivo auxiliar [Tipoia]" para cada paciente, para o modelo prognóstico de força muscular avaliada sobre flexão do cotovelo. 


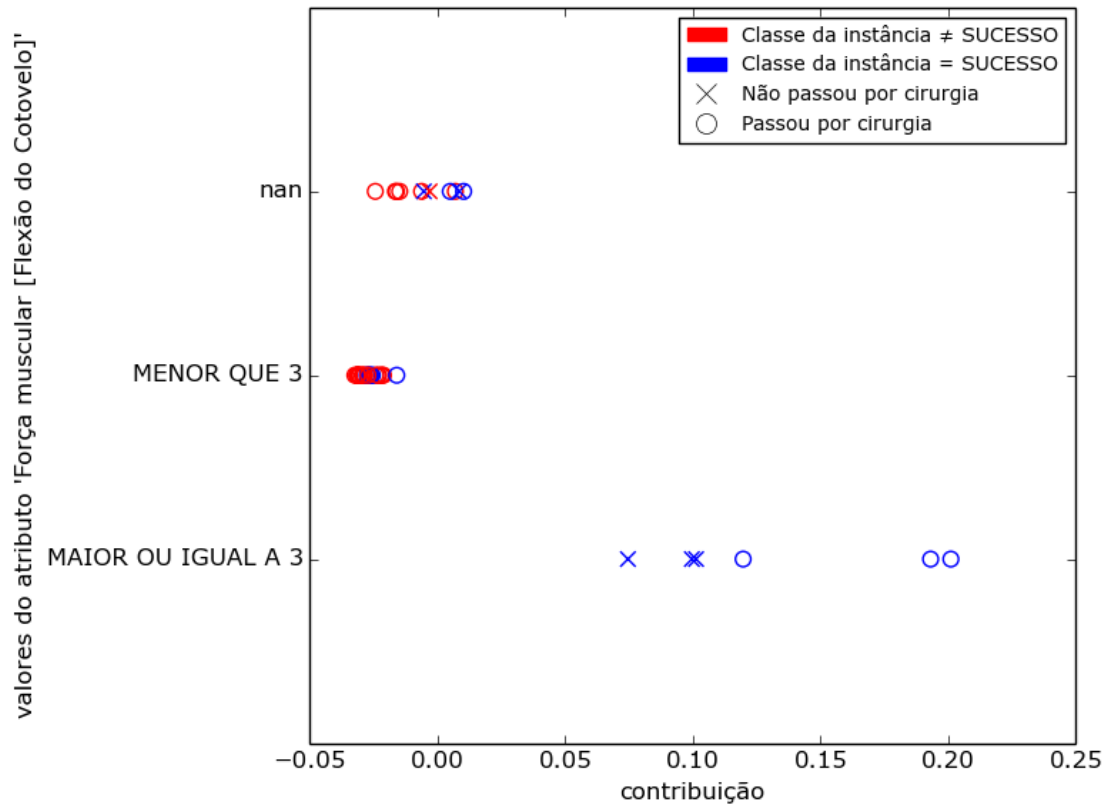

Figura 6.16: Contribuição dos valores do atributo "Força muscular avaliada sobre flexão do cotovelo", para o modelo prognóstico de força muscular avaliada sobre flexão do cotovelo.

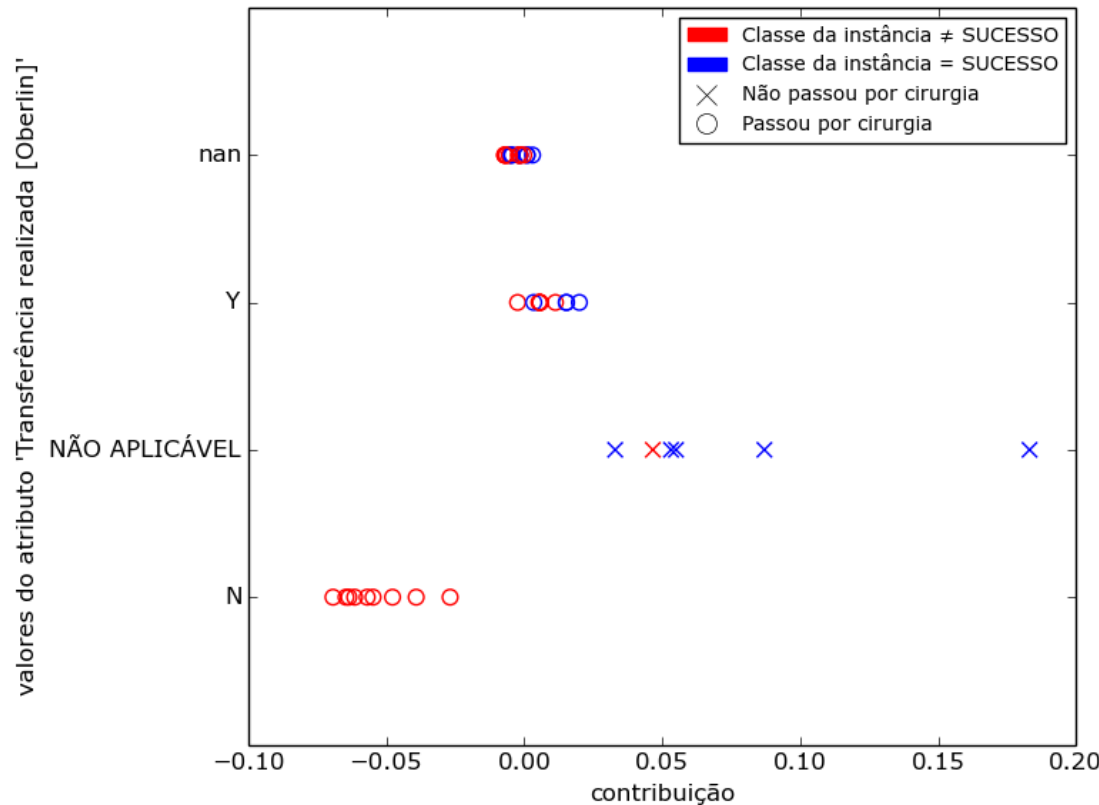

Figura 6.17: Contribuição dos valores do atributo "Transferência realizada [Oberlin]", para o modelo prognóstico de força muscular avaliada sobre flexão do cotovelo. 


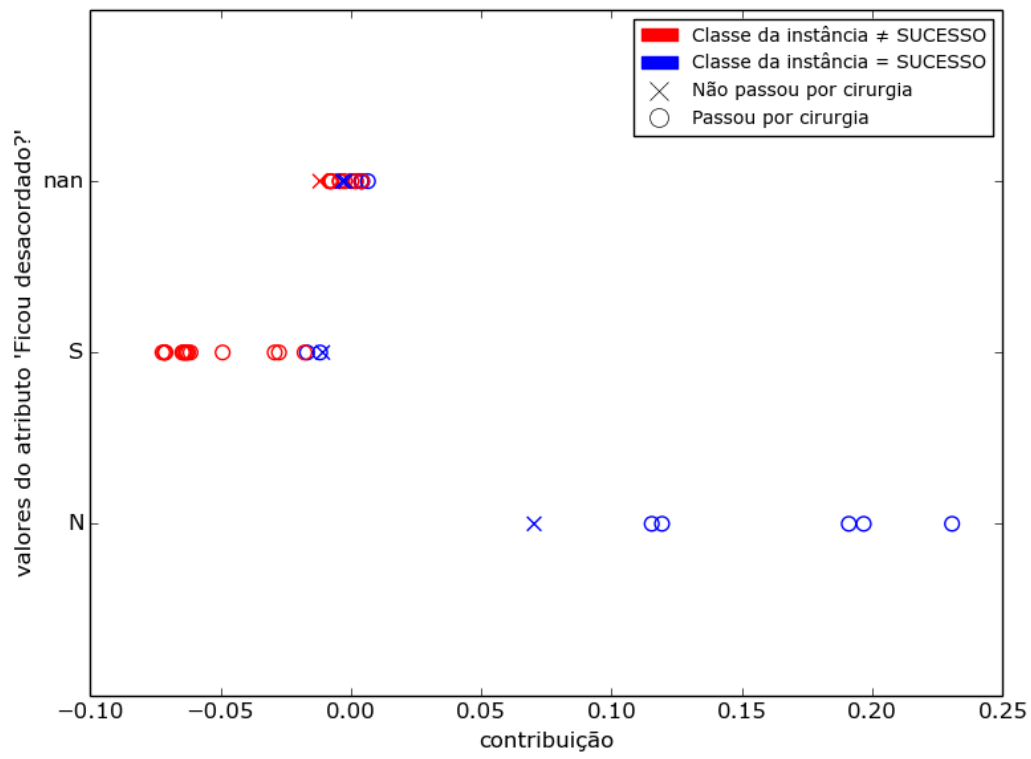

Figura 6.18: Contribuição dos valores do atributo "Ficou desacordado?", para o modelo prognóstico de força muscular avaliada sobre flexão do cotovelo.

\begin{tabular}{|c|c|c|c|c|}
\hline Classe & Acurácia & Precisão & Cobertura & Medida-F \\
\hline Sucesso & $88,63 \% \pm 0,3173$ & $66,67 \%$ & $100 \%$ & $80 \%$ \\
\hline Insatisfatório & $88,63 \% \pm 0,3173$ & $100 \%$ & $85,29 \%$ & $92,06 \%$ \\
\hline
\end{tabular}

Tabela 6.3: Desempenho do modelo prognóstico de força avaliada sobre flexão do cotovelo, em termos de acurácia média (e seu desvio padrão), precisão, cobertura e medida-F, considerando as respectivas classes como positivas.

\subsubsection{Modelo Prognóstico de Força Muscular Avaliada sobre Rotação Externa do Ombro}

A aplicação do método de seleção descrito na Seção 5.2.5 resultou nos seguintes atributos:

- "Se faz uso de dispositivo auxiliar [Suporte de Ombro]";

- "Se faz uso de dispositivo auxiliar [Tipoia]";

- "Evento que levou ao trauma [Moto]";

- "Já fez alguma cirurgia do plexo braquial?";

- "Transferência realizada [Oberlin]";

- "Qual o lado operado?";

- "Força muscular avaliada sobre abdução do ombro".

A Figura 6.19 apresenta as acurácias das florestas envolvidas no processo de seleção de atributos, e a Figura 6.20 apresenta o diagrama de caixas dos valores de importância dos atributos selecionados, calculados pelas 25 árvores.

Para este modelo, os atributos "Se faz uso de dispositivo auxiliar [Suporte de Ombro]" e "Se faz uso de dispositivo auxiliar [Tipoia]" também apresentaram contribuições relativamente parecidas com as dos modelos prognóstico de flexão do cotovelo (Figura 6.15) e de abdução do ombro (Figura 6.11): o valor "Não aplicável" apresentou contribuições positivas para ambos atributos, como vemos na Figura 6.21. 


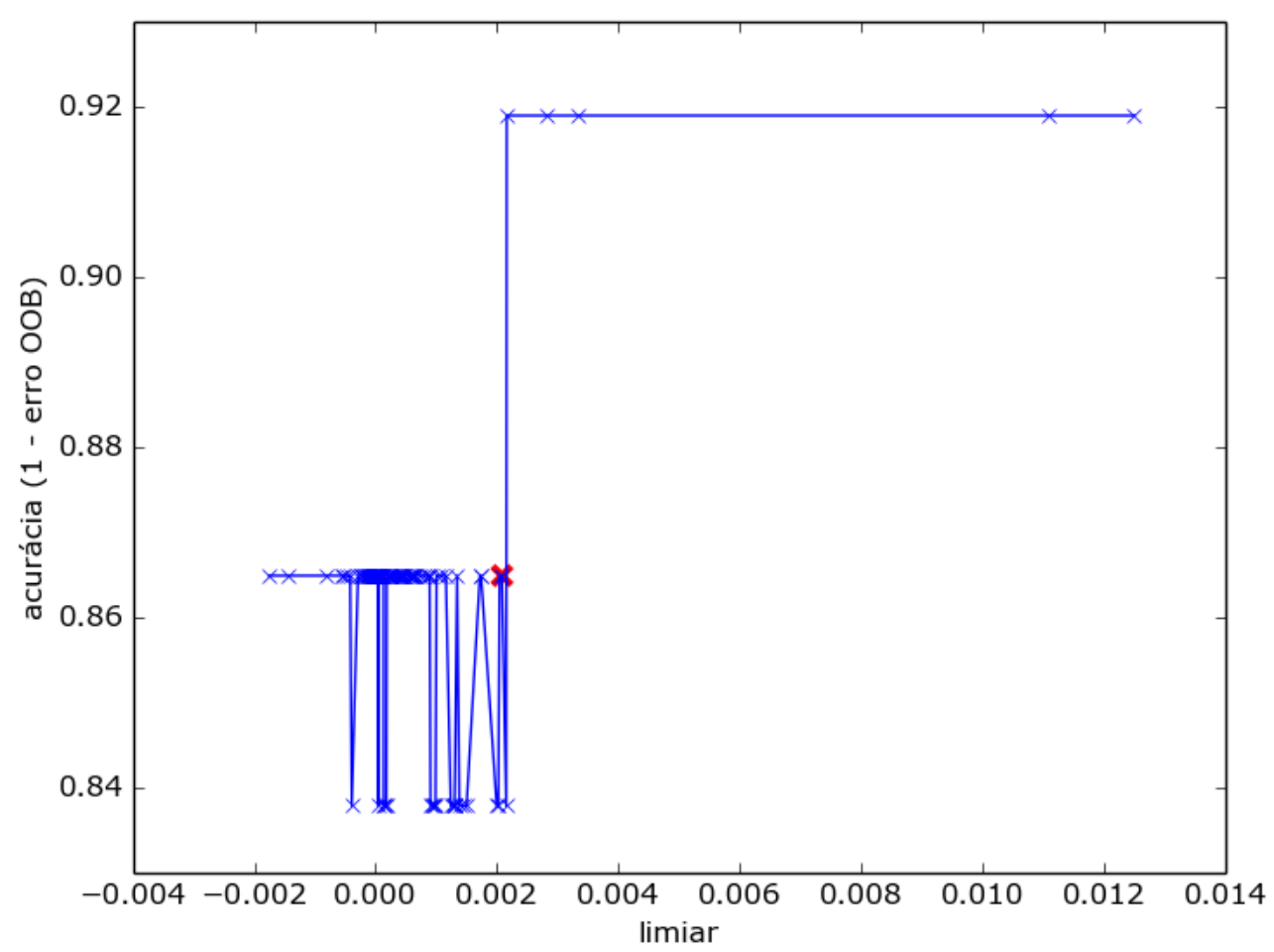

Figura 6.19: Acurácias das florestas aleatórias quando aplicadas sobre atributos de importância média superior a cada valor de limiar, para o modelo prognóstico de força avaliada sobre rotação externa do ombro.

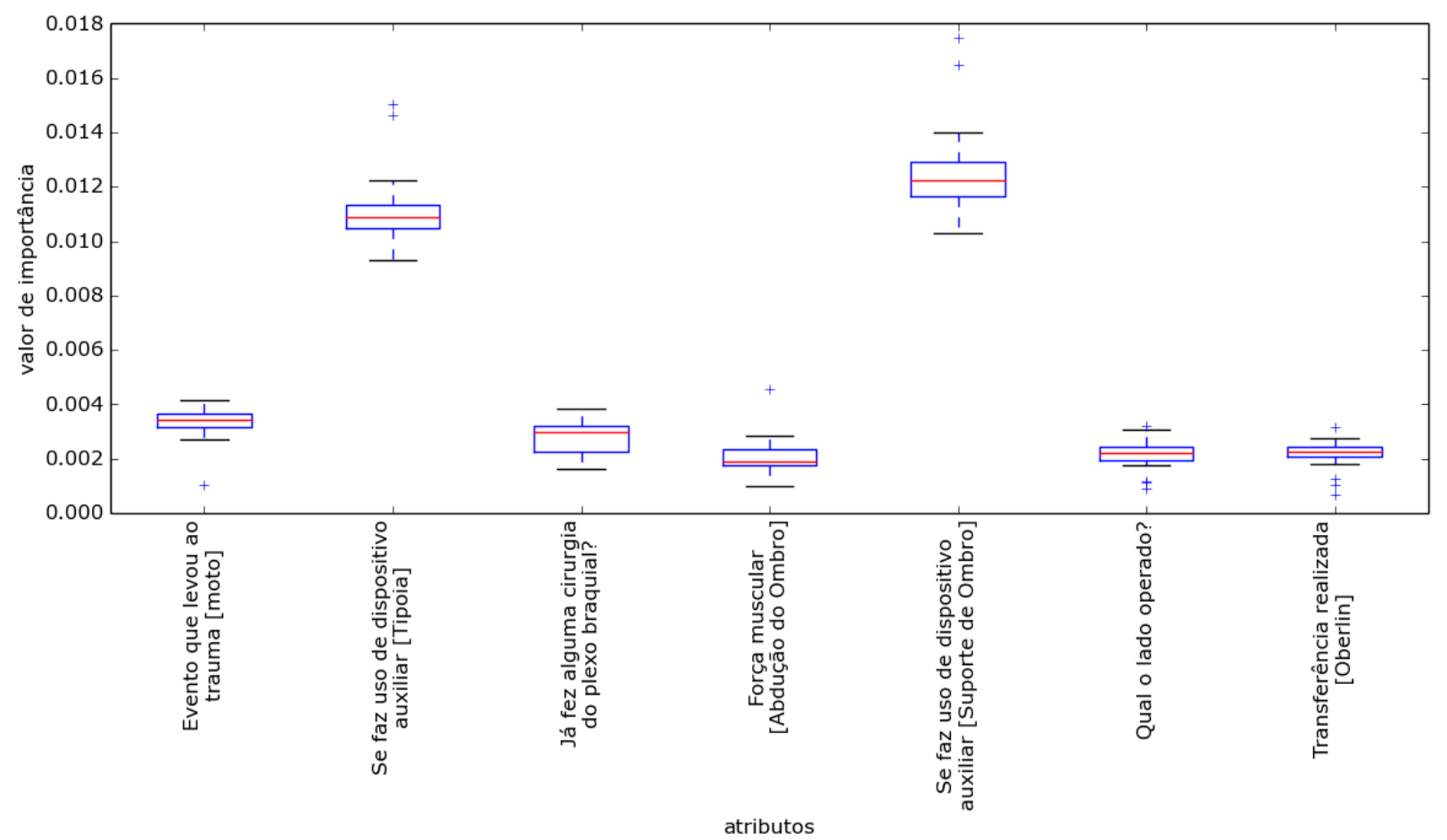

Figura 6.20: Diagrama de caixa sobre os valores de importância para cada atributo, calculados com 25 florestas aleatórias, para a criação do modelo prognóstico de força muscular rotação externa do ombro.

Ao analisarmos a Figura 6.22, podemos ver que o atributo "Qual o lado operado?" foi selecionado para compor o modelo final pela relevância do seu valor "Não aplicável", relacionada à não realização 

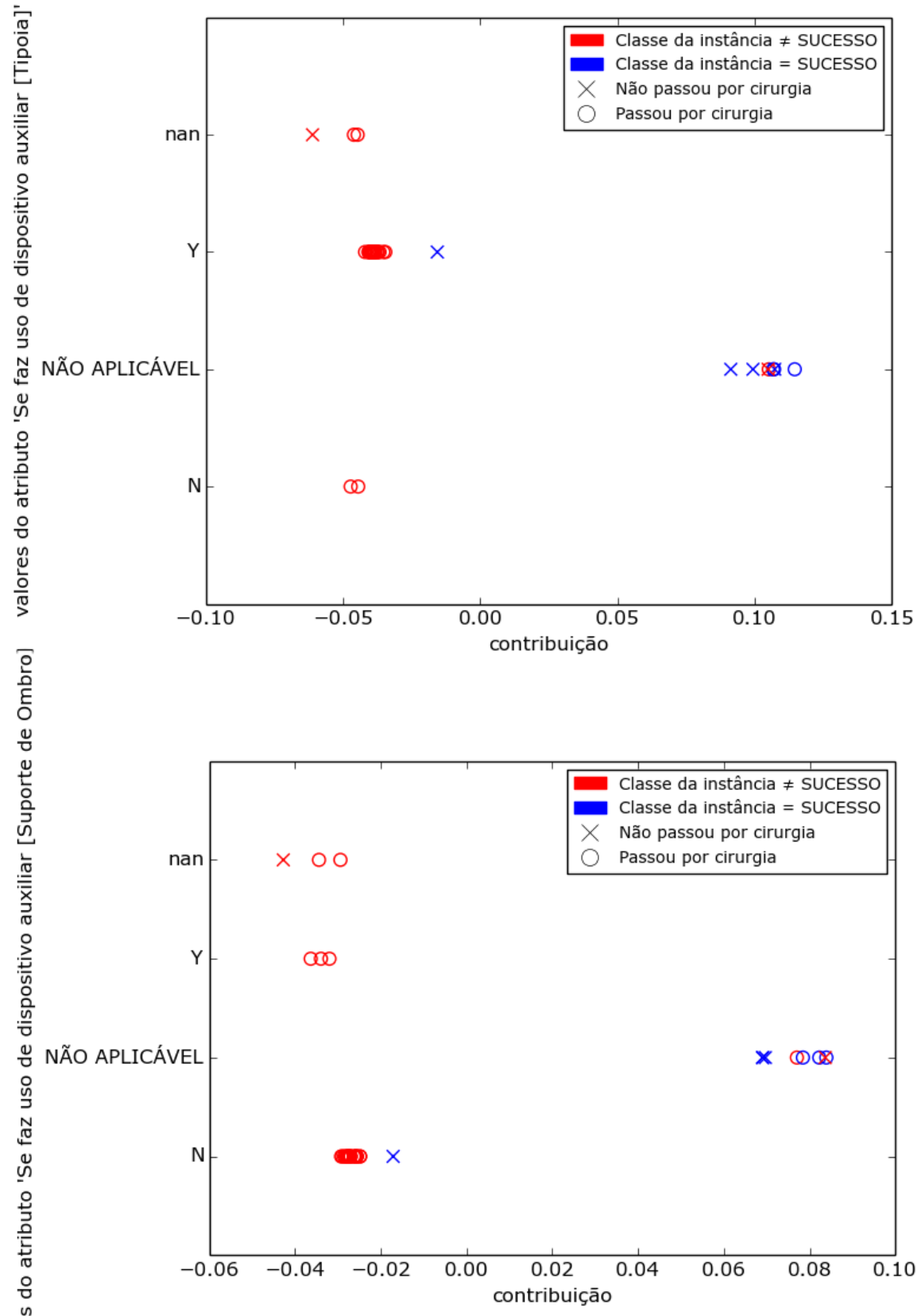

Figura 6.21: Contribuição dos valores dos atributos "Se faz uso de dispositivo auxiliar [Suporte de Ombro]" e "Se faz uso de dispositivo auxiliar [Tipoia]" para cada paciente, para o modelo prognóstico de força muscular avaliada sobre rotação externa do ombro.

de uma cirurgia. Ao comparar as contribuições de seus valores com as do atributo "Fez alguma cirurgia do plexo braquial?", percebe-se uma clara correlação.

Da mesma forma que o valor "Não Aplicável" para atributo o "Transferência realizada [Oberlin]" apresentou contribuições positivas no modelo prognóstico de flexão do cotovelo, vemos também contribuições positivas para o valor "Não Aplicável" para os atributos "Qual o lado operado?" e "Transferência realizada [Oberlin]", que está totalmente correlacionado ao valor "Não" para o atributo "Fez alguma cirurgia do plexo braquial?".

Apesar de o atributo "Força muscular avaliada sobre rotação externa do ombro" não ter sido selecionado, o atributo relativo à abdução do ombro, que possui certa correlação com a rotação externa do ombro uma vez que são inervados pelas mesmas raízes, esteve presente no conjunto retornado. A contribuição de seus valores se encontra na Figura 6.23 


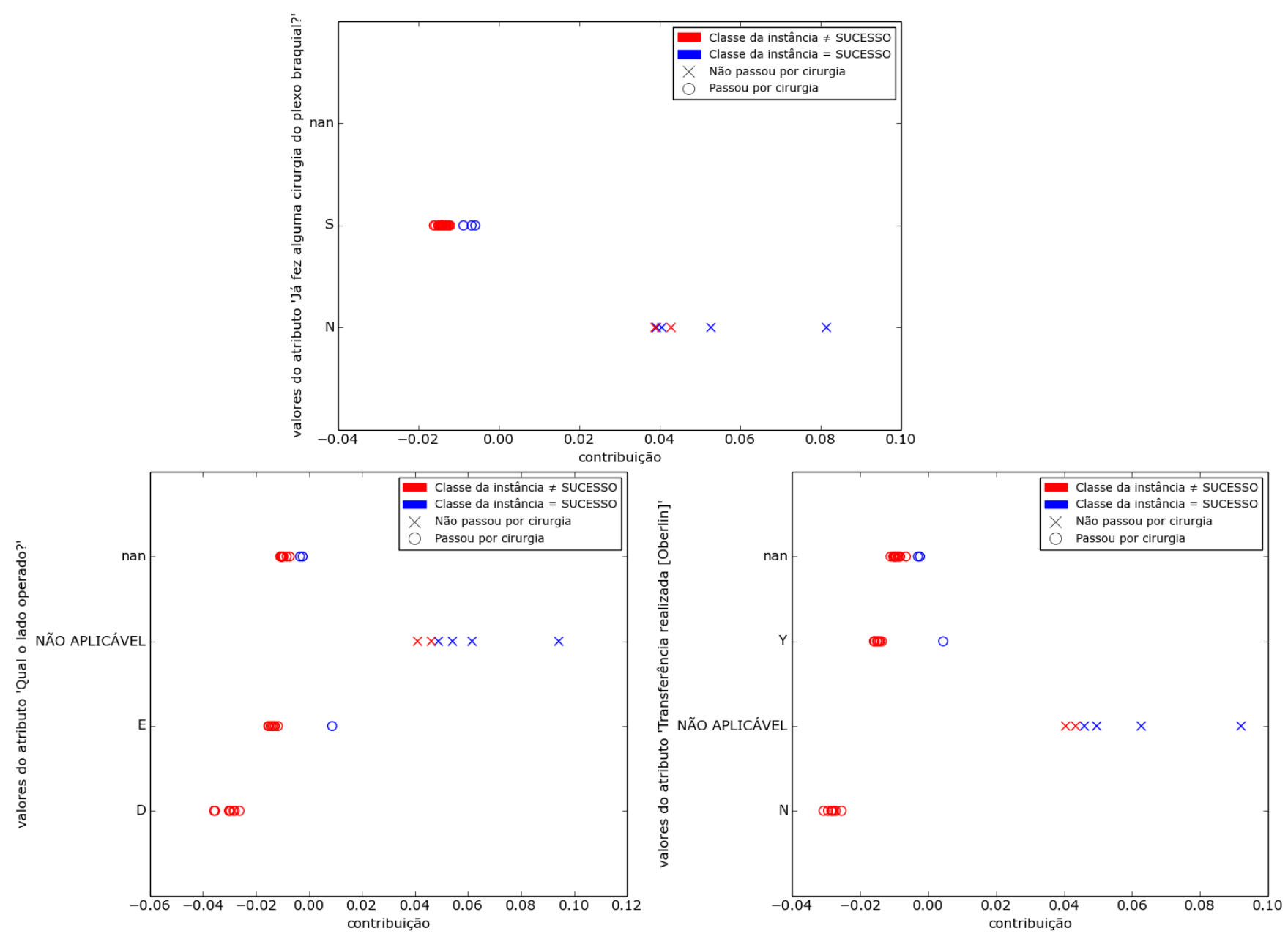

Figura 6.22: Contribuição dos valores dos atributos "Já fez alguma cirurgia do plexo braquial?" e "Qual o lado operado?" para cada paciente, para o modelo prognóstico de força muscular avaliada sobre rotação externa do ombro.

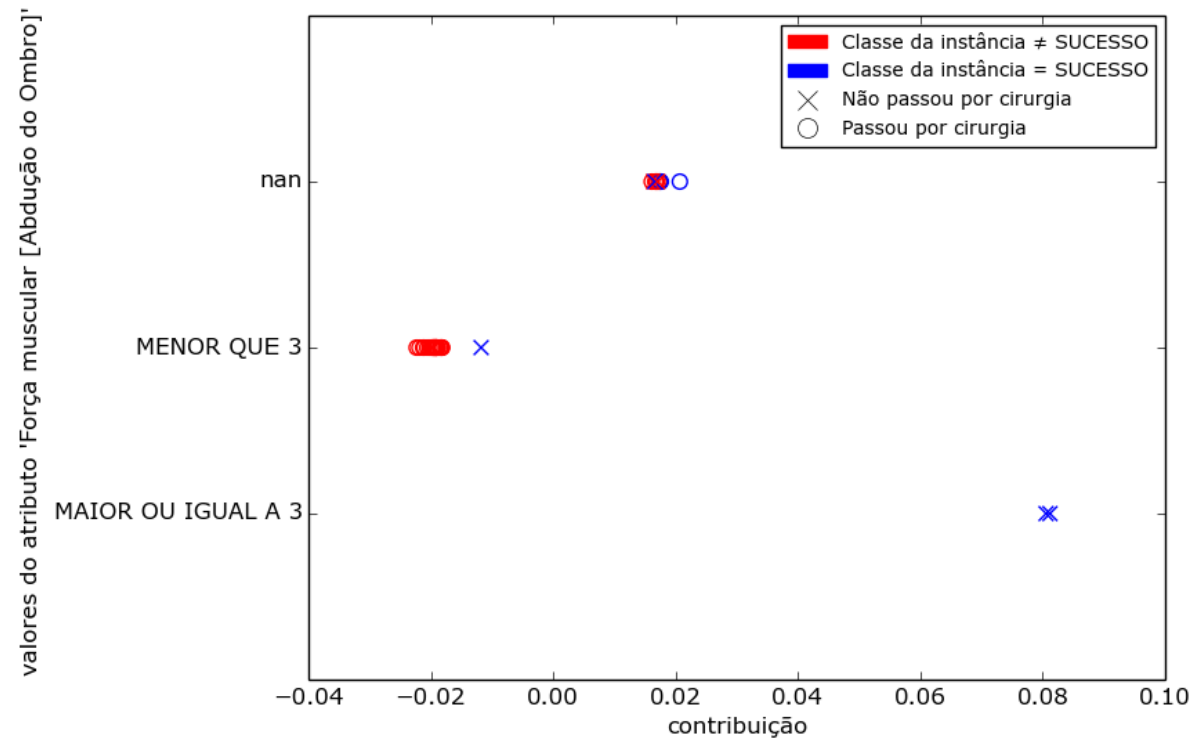

Figura 6.23: Contribuição dos valores do atributo "Força muscular avaliada sobre abdução do ombro" para cada paciente, para o modelo prognóstico de força muscular avaliada sobre rotação externa do ombro. 
Com relação ao atributo "Evento que levou ao trauma [Moto]" (Figura 6.24), as contribuições de seus valores neste modelo também foram bem similares aos do modelo prognóstico de abdução do ombro (Figura 6.12), com exceção de duas instâncias que apresentaram contribuições bastante negativas para o valor "Sim", e que não passaram por nenhuma cirurgia do plexo.

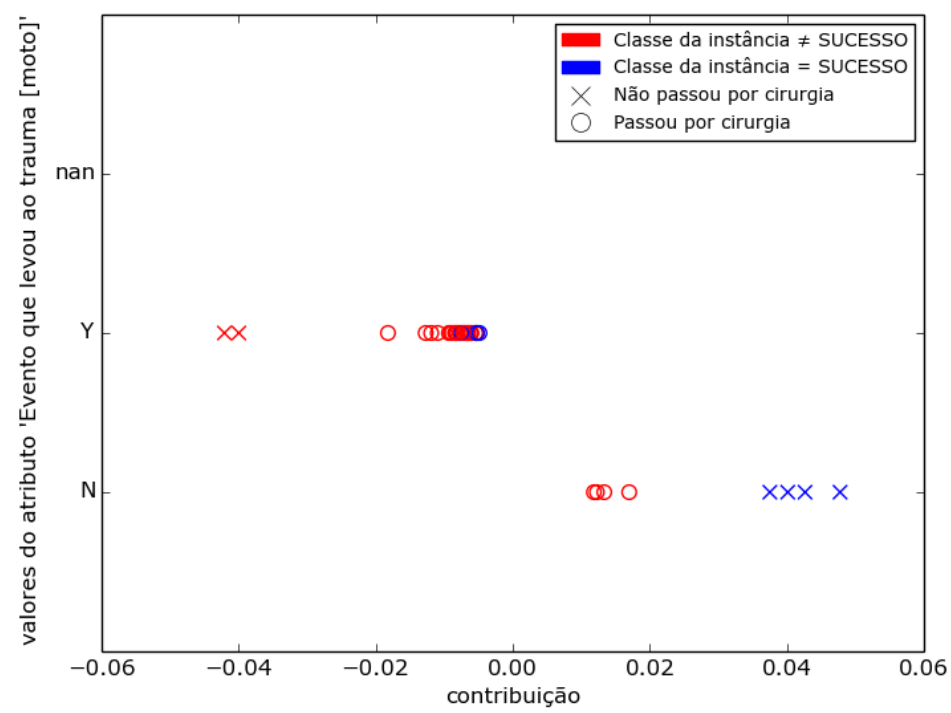

Figura 6.24: Contribuição dos valores do atributo "Evento que levou ao trauma [Moto]" para cada paciente, para o modelo prognóstico de força muscular avaliada sobre rotação externa do ombro.

A acurácia do modelo final obtido pela criação de uma floresta aleatória utilizando os atributos selecionados, calculada utilizando o método de validação cruzada LOOCV, foi de $84,21 \%$. A Tabela 6.4 apresenta o desempenho do modelo final avaliado sobre acurácia, precisão, cobertura e medida-F.

\begin{tabular}{|c|c|c|c|c|}
\hline Classe & Acurácia & Precisão & Cobertura & Medida-F \\
\hline Sucesso & $84,21 \% \pm 0,3646$ & $42,86 \%$ & $60 \%$ & $50 \%$ \\
\hline Insatisfatório & $84,21 \% \pm 0,3646$ & $87,87 \%$ & $93,55 \%$ & $90,62 \%$ \\
\hline
\end{tabular}

Tabela 6.4: Desempenho do modelo prognóstico de força avaliada sobre rotação externa do ombro, em termos de acurácia média (e seu desvio padrão), precisão, cobertura e medida-F, considerando as respectivas classes como positivas. 


\subsection{Classificação de Pacientes}

Para ilustrar o processo de classificação de novos pacientes, foram selecionados dados do preenchimento dos questionários de Avaliação de Entrada e de Avaliação Cirúrgica de um paciente que não possui preenchimento para a ficha de Avaliação de Seguimento (e que portanto não foi utilizado para a construção de nenhum dos modelos uma vez que seu estado de recuperação é desconhecido). Além disso, para cada modelo, as contribuições dos valores dos atributos do paciente no processo de sua classificação foram calculadas.

Cada modelo retorna um valor de probabilidade juntamente com a predição, que é calculado pela proporção de votos que a classe retornada recebeu (i.e., número de árvores que classificaram a instância como pertencente à classe retornada dividido pelo número total de árvores na floresta).

\subsubsection{Modelo Prognóstico de Dor}

O paciente considerado apresenta os seguintes valores para os atributos do modelo final:

• "Sente dor após a lesão?": "Não"

- "Sensibilidade superficial tátil [C7]": "Alterada"

- "Transferência realizada: Oberlin": "Não"

- "Sensibilidade superficial dolorosa [C7]": "Alterada"

- "Sensibilidade superficial tátil [C8]": "Alterada"

- "Período entre a lesão e a primeira consulta no INDC": "7 a 12 meses"

- "Sensibilidade superficial tátil [C6]" : "Alterada"

- "Força muscular avaliada sobre flexão dos dedos": "Menor que 3"

- "Sensibilidade superficial dolorosa [C8]": "Alterada"

- "Tem história prévia de fratura?": "Não"

- "Sensibilidade superficial tátil [T1]": "Alterada"

- "Força muscular avaliada sobre adução dos dedos": "Não informado/ Não avaliado"

- "Teve fratura associada à lesão": "Sim"

A predição foi dada para a classe "Insatisfatório", com 78,84\% de probabilidade.

A contribuição dos valores assumidos pela instância que representa o paciente está ilustrada na Figura 6.25. Apesar de o valor "Não" para o atributo "Sente dor após a lesão?" do questionário apresentar uma contribuição bastante positiva para a classe "Sucesso", todos os atributos referentes às sensibilidades superficiais dolorosa e tátil apresentaram contribuições negativas, assim como "Teve fratura associada à lesão?", "Transferência realizada: Oberlin" e "Força muscular avaliada sobre flexão dos dedos". Assim, a classificação da instância foi dada por "Insatisfatório" por conta desses valores. 


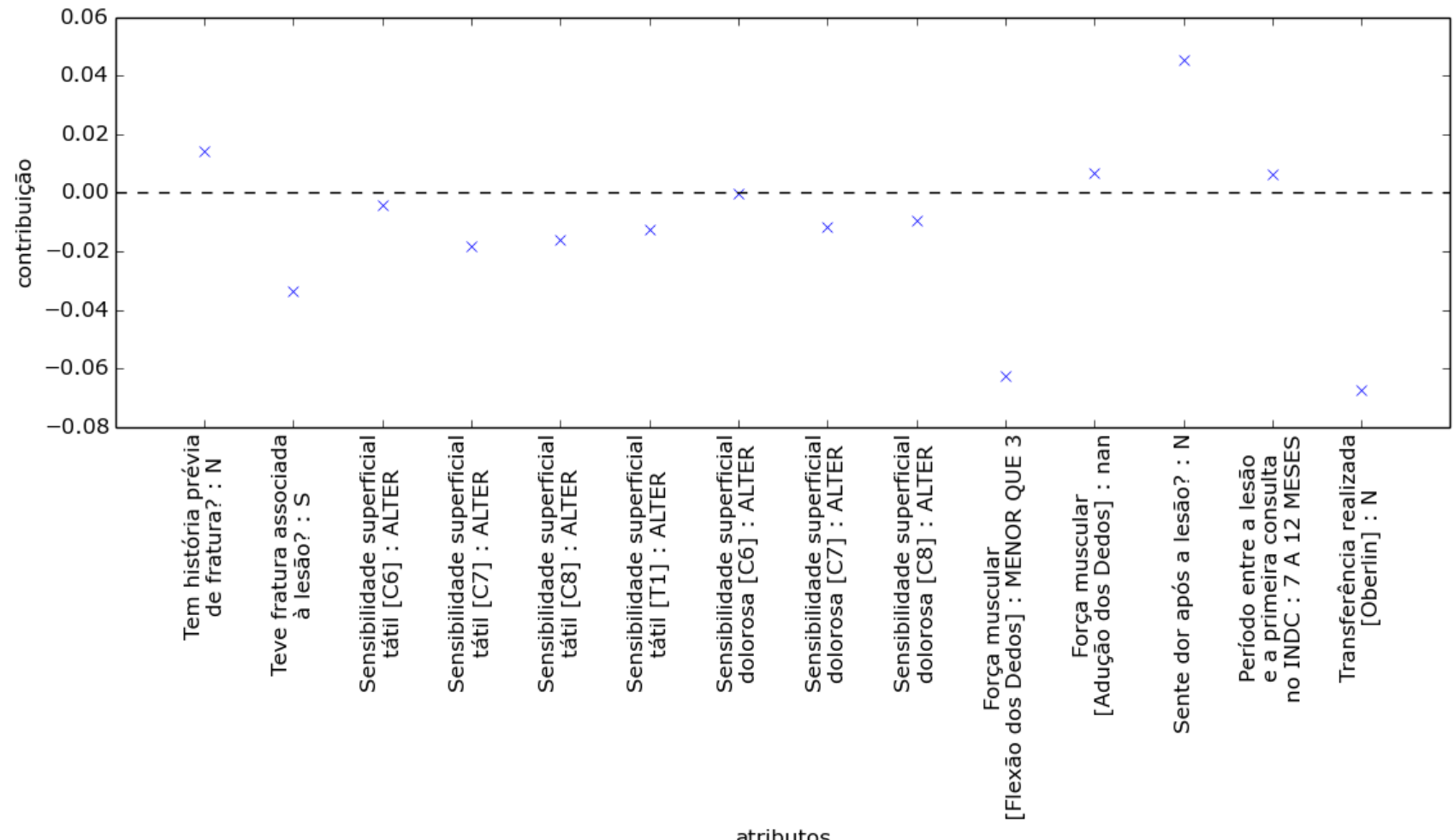

Figura 6.25: Valores de contribuição dos atributos de um dos pacientes do INDC para o modelo prognóstico de dor.

\subsubsection{Modelo Prognóstico de Força Muscular Avaliada sobre Abdução do Om- bro}

Considerando o mesmo paciente, para o modelo prognóstico de abdução do ombro temos os seguintes valores para os atributos:

- "Evento que levou ao trauma [Moto]": "Sim"

- "Se faz uso de dispositivo auxiliar [Suporte de Ombro]": "Não informado/ Não avaliado"

• "Se faz uso de dispositivo auxiliar [Tipoia]": "Não informado/ Não avaliado"

A contribuição de cada um desses valores no processo de classificação está apresentada na Figura 6.26, onde podemos ver que os valores faltantes para os atributos relativos ao uso de dispositivo auxiliar apresentaram contribuições bastante negativas. Apesar de isso ser uma situação indesejável, vale notar que apenas o valor "Não Aplicável" para esses atributos apresentaria contribuições positivas na classificação da instância, conforme o padrão observado na Figura 6.11, e desse modo valores "Sim" ou "Não" para essas respostas não alterariam a classificação final do paciente.

Para essa instância, o modelo retornou "Insatisfatório" com probabilidade de 94,7\%. 


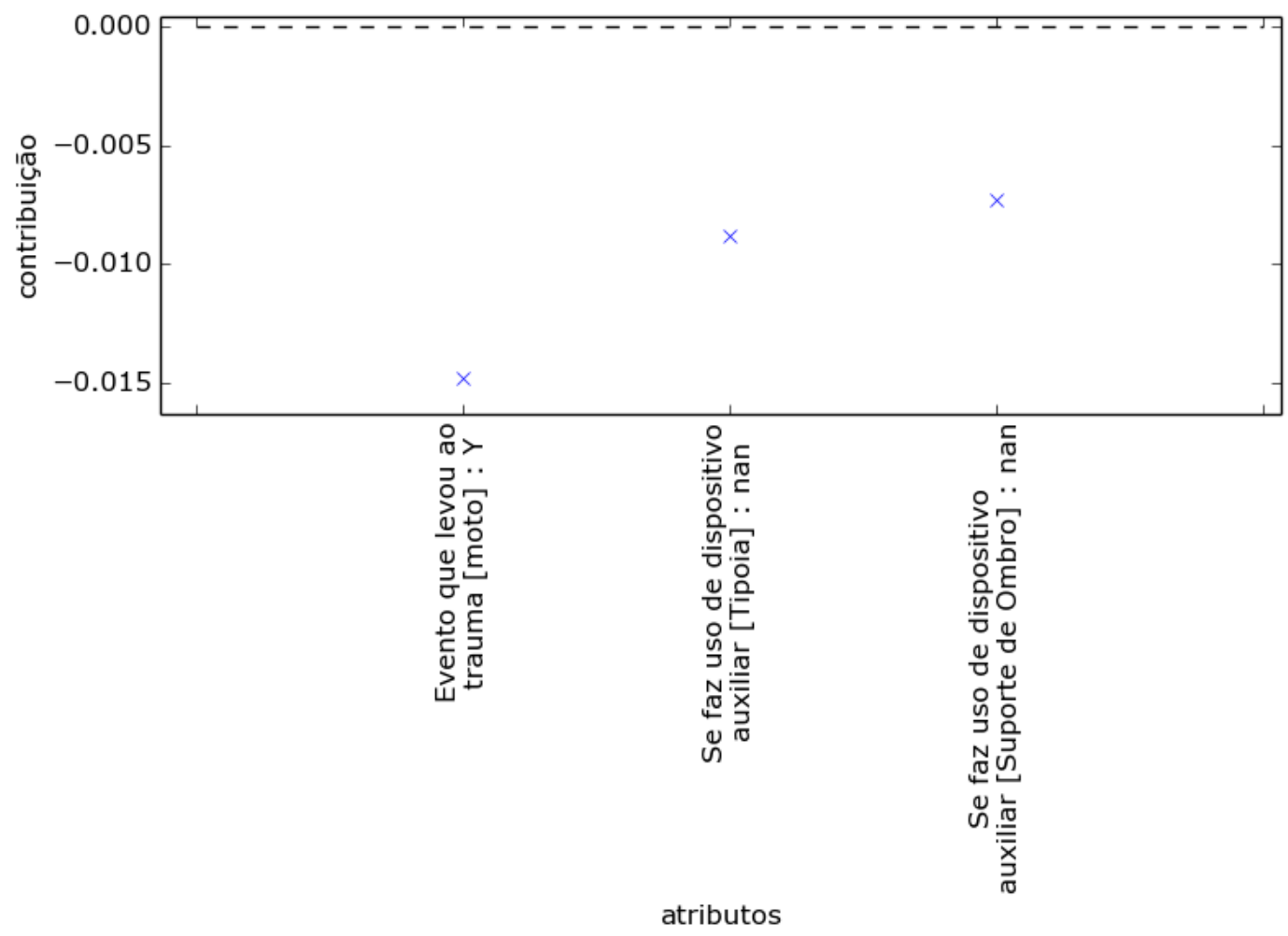

Figura 6.26: Valores de contribuição dos atributos de um dos pacientes do INDC para o modelo prognóstico de força muscular avaliada sobre abdução do ombro.

\subsubsection{Modelo Prognóstico de Força Muscular Avaliada sobre Flexão do Cotovelo}

Considerando o modelo prognóstico de flexão do cotovelo, o paciente apresenta os seguintes valores para os atributos:

- "Se faz uso de dispositivo auxiliar [Suporte de Ombro]" : "Não informado/Não avaliado"

- "Se faz uso de dispositivo auxiliar [Tipoia]": "Não informado/Não avaliado"

- "Força muscular avaliada sobre flexão do cotovelo": "Não informado/ Não avaliado"

- "Ficou desacordado?": "Sim"

- "Transferência realizada [Oberlin]": "Não"

Para essa instância, o modelo retornou "Insatisfatório", que foi o resultado da classificação de $100 \%$ das árvores na floresta. Como ilustrado na Figura 6.27, todos os valores para essa instância apresentaram contribuições negativas. 


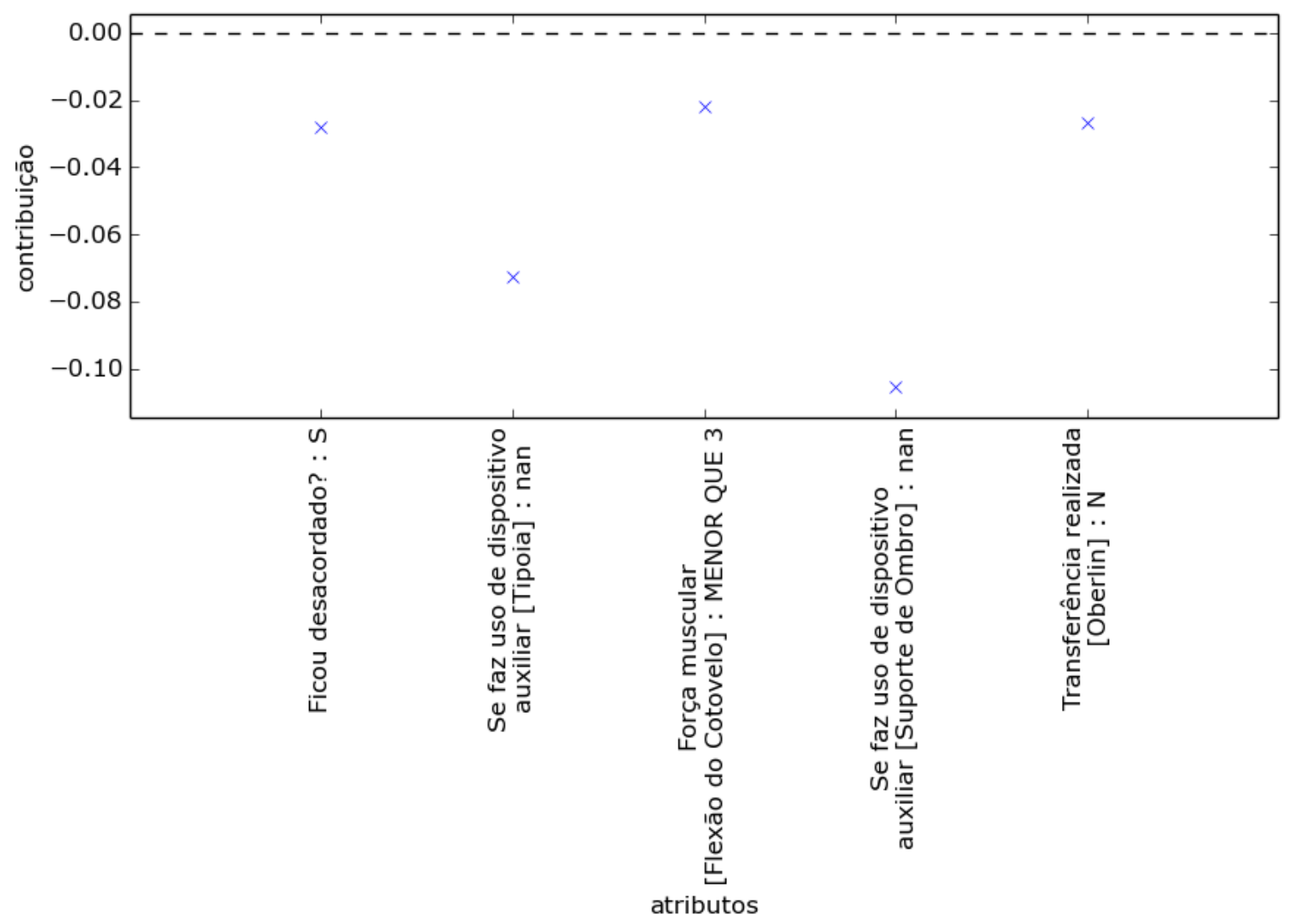

Figura 6.27: Valores de contribuição dos atributos de um dos pacientes do INDC para o modelo prognóstico de força muscular avaliada sobre flexão do cotovelo.

\subsubsection{Modelo Prognóstico de Força Muscular Avaliada sobre Rotação Externa do Ombro}

Para o modelo prognóstico de rotação externa do ombro o paciente apresenta os seguintes valores para os atributos:

- "Se faz uso de dispositivo auxiliar [Suporte de Ombro]": "Não informado/ Não avaliado"

- "Se faz uso de dispositivo auxiliar [Tipoia]": "Não informado/ Não avaliado"

- "Evento que levou ao trauma [Moto]": "Sim"

• "Já fez alguma cirurgia do plexo braquial?": "Sim"

- "Transferência realizada [Oberlin]": "Não"

- "Qual o lado operado?": "Direito"

- "Força muscular avaliada sobre abdução do ombro": "Maior ou igual a 3"

Para essa instância, o modelo retornou "Insatisfatório" com probabilidade de 88,5\%.

Da mesma forma que houve uma similaridade entre as contribuições dos atributos relativos ao uso de dispositivo auxiliar para os modelos prognósticos de força muscular (Figuras 6.11, 6.15 e 6.21), era de se esperar que esses atributos também apresentassem contribuições negativas no processo de classificação da instância pelo modelo relativo à rotação externa do ombro, como podemos ver na Figura 6.28.

Com relação aos demais atributos, apenas a questão "Força muscular avaliada sobre abdução do ombro" (de valor "Maior ou igual a 3") apresentou contribuição positiva, enquanto os demais apresentaram valores negativos. 


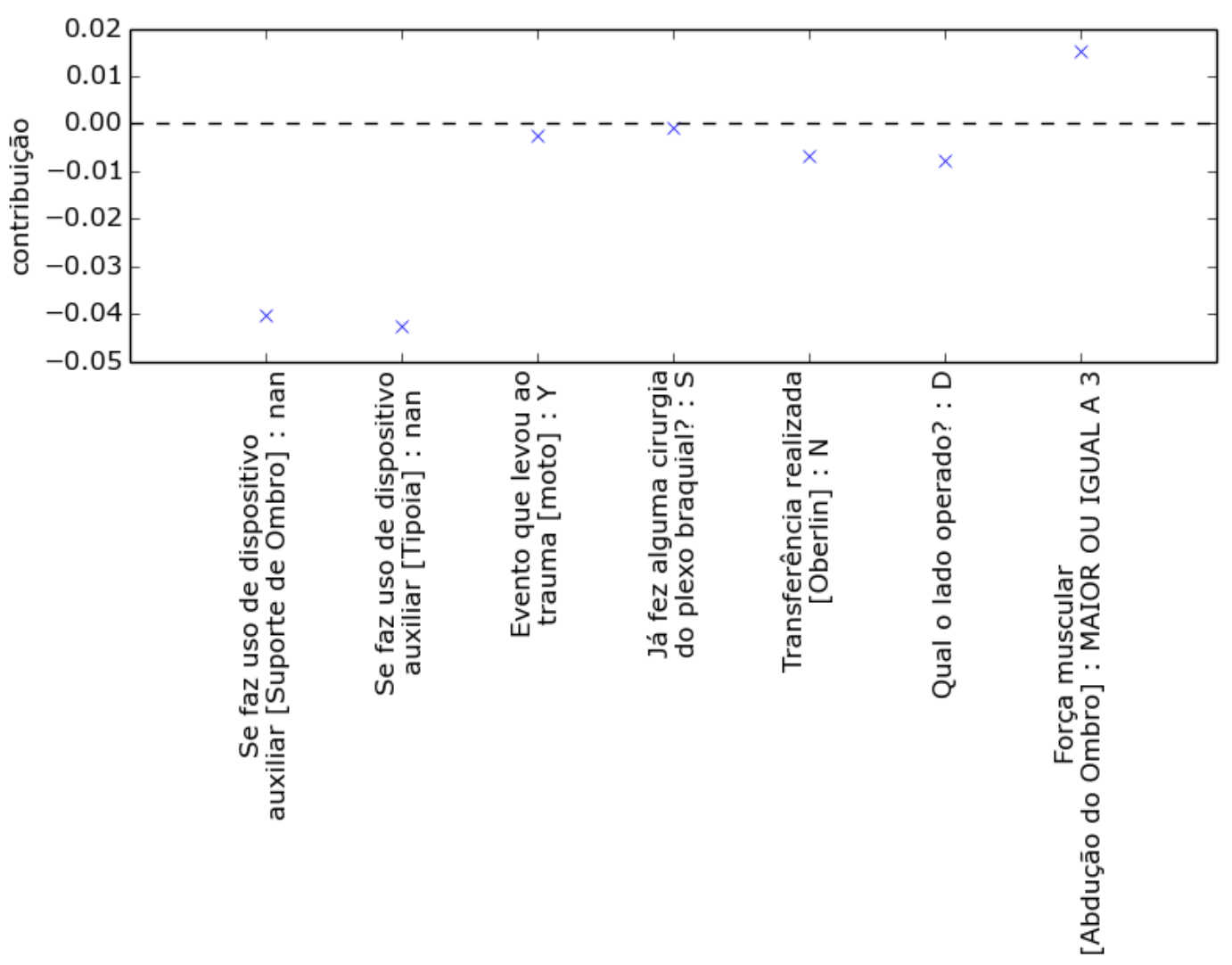

atributos

Figura 6.28: Valores de contribuição dos atributos de um dos pacientes do INDC para o modelo prognóstico de força muscular avaliada sobre rotação externa do ombro.

\subsection{Considerações sobre os Resultados}

Neste capítulo foram apresentados os resultados da aplicação dos métodos descritos no Capítulo 5 para a criação dos modelos prognósticos, bem como um exemplo do funcionamento do processo de classificação de pacientes.

Para o modelo prognóstico de dor, entre os preditores identificados, destacam-se os atributos relacionados às sensibilidades superficiais dolorosa e táteis, enquanto não foi selecionado nenhum atributo referente a sensibilidade profunda (como por exemplo cinestesia ou palestesia). Além disso, destaca-se também a contribuição positiva para o resultado de sucesso com relação aos pacientes terem realizado o procedimento de transferência de Oberlin, indicando uma possível correlação entre a recuperação motora e de dor.

Com relação ao modelo de força muscular avaliada sobre abdução do ombro, foram selecionados apenas três preditores: um relativo ao trauma ter sido causado por acidente de moto, e dois relativos ao uso de dispositivo auxiliar - que também foram selecionados para os modelos prognósticos referentes à flexão do cotovelo e à rotação externa do ombro. Uma vez que existe uma dependência entre os valores "Não aplicável" para esses dois atributos, e que esse valor apresentou contribuições positivas nos três modelos, pode-se dizer que houve uma certa redundância na escolha de ambos os atributos para compor esses modelos. Essa redundância pode ter sido ocasionada por conta do método de importância de atributos utilizado no processo de seleção, que por vezes superestima as importâncias de atributos altamente correlatos [GPTM10]. De qualquer modo, são indícios de que existem correlações entre a imobilização ocasionada pelo uso de dispositivos auxiliares e a recuperação motora dos pacientes. Ainda, para o modelo de força muscular avaliada sobre flexão do cotovelo, destaca-se também a escolha do atributo "Ficou desacordado?" como um preditor.

Com relação ao modelo prognóstico de força muscular avaliada sobre rotação externa do ombro, 
alguns dos preditores selecionados estão relacionados à realização de algum procedimento do plexo braquial. Por exemplo, o atributo "Qual o lado operado?" foi selecionado para compor o modelo final, apesar de ser correlacionado ao atributo "Fez alguma cirurgia do plexo braquial?" - mais uma redundância entre os atributos selecionados como preditores para este modelo.

Apesar de os modelos resultantes terem apresentados bons valores de acurácia, essa estimativa do poder de generalização pode apresentar um certo viés, uma vez que todos os dados são utilizados na construção de cada floresta. Sendo assim, o ideal seria realizar uma validação dos modelos com dados de novos pacientes.

Além disso, a escolha "automática" dos valores de limiar (considerando o maior limiar que atingiu a acurácia mais próxima da de maior valor subtraída do erro padrão das acurácias) pode levar à seleção de um número muito reduzido de atributos, como o ocorrido para o modelo prognóstico de força muscular avaliada sobre abdução do ombro, de forma a excluir outros possíveis preditores que poderiam levar a um mesmo poder de generalização.

Vale ressaltar ainda que as análises conduzidas neste capítulo foram feitas de forma simplificada, não levando em conta correlações mais complexas entre diferentes fatores. O objetivo dessa exploração corresponde a abrir caminhos para que outras análises possam ser feitas, visando validar ou refutar os indícios apontados pelos resultados aqui apresentados. 


\section{Capítulo 7}

\section{Conclusões}

Lesões traumáticas do plexo braquial em adultos (LTPBA) são doenças que possuem impacto emocional, social e econômico, uma vez que podem causar fraqueza, perda de sensibilidade, dor e prejuízo funcional dos membros superiores, comprometendo diversas atividades profissionais, do dia-a-dia e de lazer. Assim, como ainda não existem preditores prognósticos bem definidos para essas lesões, seria proveitosa a criação de modelos que permitissem a sua identificação a partir da análise de dados clínicos de pacientes, bem como fornecesse uma estimativa para a evolução de sua lesão.

Neste projeto, utilizando dados de pacientes do INDC diagnosticados com LTPBA, foram desenvolvidos quatro modelos prognósticos para esse tipo de lesão - um para cada alvo de recuperação, sendo eles dor e forças musculares avaliadas sobre abdução do ombro, flexão do cotovelo e rotação externa do ombro - com o objetivo de prever se, para um determinado paciente, haverá sucesso em sua recuperação ou se será insatisfatória. A criação de modelos separados para cada alvo foi realizada por conta da hipótese de que os preditores poderiam não ser os mesmos para todos os modelos.

Assim, para a criação de cada modelo foi aplicado um método de seleção de atributos que utiliza florestas aleatórias de forma a escolher o conjunto de atributos que leva a uma melhor acurácia em termos do erro OOB - um método de estimativa do poder de generalização de modelos gerados por florestas aleatórias. A melhor acurácia foi definida como sendo a mais próxima da de maior valor subtraída pelo erro padrão das acurácias obtidas. Após o processo de seleção, uma nova floresta foi criada utilizando apenas os atributos selecionados, e sua acurácia foi estimada utilizando o método LOOCV, que apesar de apresentar em geral uma alta variância [HTF09], é mais viável para aplicações com poucas instâncias disponíveis [RTL09]. Isso foi necessário uma vez que os dados relativos ao prognóstico são provenientes de apenas 44 pacientes do INDC. A Tabela 7.1 sumariza as acurácias obtidas para cada um dos modelos.

\begin{tabular}{|l|c|}
\hline Modelo & Acurácia \\
\hline Dor & $77,27 \%$ \\
\hline AbdOmbro & $80,95 \%$ \\
\hline FlexCotovelo & $88,63 \%$ \\
\hline RotEOmbro & $84,21 \%$ \\
\hline
\end{tabular}

Tabela 7.1: Acurácia dos modelos prognósticos de dor e de forças musculares avaliadas sobre abdução do ombro (AbdOmbro), flexão do cotovelo (FlexCotovelo) e rotação externa do ombro (RotEOmbro).

Uma vez que valores faltantes são frequentes nos dados dos pacientes do INDC, foi desenvolvida uma adaptação da técnica de florestas aleatórias, de forma a incluir esses valores no processo de criação de suas árvores. Ainda, para a interpretação dos modelos resultantes, foi aplicado o método de contribuição de atributos desenvolvido por Palczewska et al. [PPRN13], que viabiliza a análise da relevância dos valores que cada atributo assume para o processo de criação do modelo. Além disso, esse método provê uma transparência no modelo, de modo que seja possível avaliar a influência de 
cada valor para os atributos de uma nova instância no processo de sua classificação.

Com relação à contribuição dos valores dos atributos de cada modelo, o fator mais relevante apontado para o prognóstico de recuperação de força sobre abdução do ombro foi o trauma ter sido causado por acidentes de moto, enquanto que para os modelos de força avaliada sobre flexão de cotovelo e rotação externa do ombro foram apontados como mais importantes os atributos relativos ao uso de tipoia e de suporte de ombro e à força avaliada sobre seus movimentos na primeira avaliação feita no INDC. Já para o modelo relativo à dor, o atributo identificado como o mais relevante foi a constatação de presença de dor pelos pacientes quando chegam ao INDC logo pela primeira vez.

Dentre os preditores que merecem investigações estatísticas futuras destacam-se os atributos relativos à sensibilidade superficial e dolorosa para o modelo de dor, bem como os relativo à realização do procedimento Oberlin de transferência e à existência de fraturas prévias ou associadas à lesão. Com relação aos modelos prognósticos de força muscular, destaca-se o uso de dispositivos auxiliares (no caso, tipoia e suporte de ombro). Em particular, para os modelos relativos à abdução do ombro e à rotação externa do ombro também é válida a investigação da correlação entre resultados insatisfatórios com relação à recuperação e o trauma ter sido causado por acidentes de moto. Por fim, para o modelo prognóstico relativo à flexão do cotovelo, também destaca-se o atributo "Ficou desacordado?", cujas respostas "Sim" apresentaram correlações com o resultado insatisfatório de recuperação.

\subsection{Principais Contribuições}

As principais contribuições deste trabalho podem ser resumidas em:

- Criação de quatro modelos prognósticos de LTPBA utilizando Florestas Aleatórias e métodos de Mineração de Dados;

- Identificação de possíveis preditores de cada um dos modelos prognósticos de LTPBA que ainda não foram explorados neste contexto, e que apresentam opções de estudo e análise futura com o objetivo de confirmá-los ou refutá-los como indicadores prognósticos;

- Implementação de métodos desenvolvidos para a interpretação dos modelos gerados por Florestas Aleatórias, visando sua transparência em termos de sua criação e do seu processo de classificação;

- Adaptação da técnica de Florestas Aleatórias para viabilizar a aplicação de seus métodos de interpretação sobre dados caracterizados pela presença de valores faltantes.

\subsection{Limitações do Trabalho}

Dentre as limitações deste projeto, destaca-se a escassez de instâncias dentro do conjunto de dados disponíveis para a análise, que faz surgir a dúvida em relação aos dados utilizados serem suficientemente representativos, ou se os preditores identificados neste projeto são relevantes apenas para a amostra disponível até o momento em que essa dissertação foi concluída.

Vale ressaltar, porém, que se existissem dados clínicos publicamente disponíveis para análise, provenientes de diferentes instituições, talvez fosse possível realizar uma integração dos dados e conduzir a análise utilizando amostras de diferentes distribuições.

De qualquer forma, o aperfeiçoamento dos modelos poderá ser feito com aquisição contínua de dados de novos pacientes em tratamento do INDC, até que possam ser utilizados como parte de um sistema de apoio à decisão clínica.

Outras limitações que devem ser mencionadas são o viés envolvido no cálculo de generalização do modelo, que envolveu todas as instâncias utilizadas no processo de sua criação, e a não consideração de correlações mais complexas entre atributos (por exemplo, no cálculo de suas contribuições) no processo de discussão da análise dos resultados. 


\subsection{Sugestões para Pesquisas Futuras}

Os resultados deste trabalho podem ser interpretados como um indício de que existem fatores que podem ser relevantes em termos prognósticos e que ainda não foram objetivamente explorados, incentivando assim o desenvolvimento de estudos e análises estatísticas com o objetivo de validá-los ou refutá-los.

Com relação à criação dos modelos prognósticos por meio de florestas aleatórias, podem ser exploradas a utilização de outros tipos de árvores que compõem as florestas, como as árvores de inferência condicional [HHZ06], bem como de outros métodos cálculos de importância para a etapa inicial do processo de seleção de atributos [ATSL10]. Ainda, neste trabalho os preenchimentos dos pacientes do INDC para o questionário de seguimento não puderam ser utilizados (com exceção dos relativos à classe de cada modelo), uma vez que se relacionavam ao estado prognóstico. Porém, esses dados poderiam auxiliar no processo de aprendizagem em forma de tarefas adicionais, com a aplicação de Aprendizado Multitarefas [Car97] - uma técnica de aprendizado simultâneo de diferentes tarefas de classificação com o objetivo de obter modelos com maior poder de generalização. Com a aquisição de novos dados, os modelos prognósticos poderiam se beneficiar da integração dessa técnica às Florestas Aleatórias. Além disso, os registros eletrofisiológicos dos pacientes também poderiam ser utilizados para a criação dos modelos prognósticos por meio da aplicação de técnicas de aprendizado de máquina [HMR13].

Ainda, para viabilizar a utilização dos modelos aqui desenvolvidos em termos práticos pelos profissionais do INDC, seria pertinente o desenvolvimento de uma plataforma para um sistema de apoio à decisão clínica, de forma a incluir não apenas uma interface para o uso dos modelos preditivos, mas também para a interpretação de seus resultados, utilizando as técnicas aqui apresentadas ou outras adicionais. 


\section{Glossário}

aprendizado não supervisionado Categoria de técnicas de aprendizado de máquina cujos dados de entrada não possuem rótulos ou etiquetas associados. Compreende tarefas de agrupamento. 7

aprendizado supervisionado Categoria de técnicas de aprendizado de máquina cujos dados de entrada possuem rótulos associados. Compreende tarefas de classificação e regressão. 7

atributo Elementos que caracterizam uma instância, também denominado por característica. 5

classe Atributo especial sobre o qual se deseja realizar previsões, também denominado por rótulo, etiqueta ou saída. 7

cobertura Métrica de avaliação de modelos complementar à métrica de precisão, cujo valor corresponde ao número de instâncias corretamente classificadas como pertencentes à uma determinada classe $Y$ dividido pelo número total de instâncias que realmente pertencem à classe $Y$. Também é denominada de sensibilidade ou revocação. 8, 52, 60, 63, 65, 72

conjunto OOB Conjunto formado pelas instâncias que não foram utilizadas na construção de uma árvore de decisão dentro de uma floresta aleatória. 19, 42, 51

erro OOB Estimativa da capacidade de generalização fornecida pela técnica de Florestas Aleatórias, realizada com base nas instâncias do conjunto OOB de cada árvore. 19, 50, 54

instância Um elemento ou objeto da amostra de dados, também denominado por exemplo, caso, registro ou entrada. 6

medida-F Métrica de avaliação de modelos calculada por uma média harmônica sobre a precisão e a cobertura do modelo. 8, 9, 52, 60, 63, 65, 72

MRC Medical Research Council. Escala muscular que varia de 0 a 5, sendo 0 correspondente a ausência de contração muscular, 1 a contração muscular visível (mas sem movimento), 2 a movimento ativo presente desde que eliminada a gravidade, 3 a movimento ativo presente contra a gravidade (mas não contra uma resistência), 4 a movimento ativo contra a gravidade e resistência (porém ainda aquém do normal) e 5 a força normal . 46, 53, 65

precisão Métrica de avaliação de modelos complementar à métrica de cobertura, cujo valor corresponde ao número de instâncias corretamente classificadas como pertencentes à uma determinada classe $Y$ dividido pelo número total de instâncias classificadas como $Y$. 8, 52, 60, 63, 65,72

validação cruzada Técnica para avaliar a capacidade de generalização de um modelo, baseandose em um particionamento iterativo do conjunto de dados entre conjuntos de treino (sobre os quais o modelo é criado) e de validação (sobre os quais a capacidade de generalização do modelo é avaliada). 8, 42, 49, 52, 63 
Apêndice A

Excertos de Questionários do INDC-UFRJ 


\section{Avaliação de Entrada - Unificada}

História da doença pregressa

História da doença atual

Exame Físico

Olá, você está sendo avaliado(a) em relação a lesão do plexo braquial que o(a) trouxe para este atendimento. Queremos saber alguns detalhes sobre como ela aconteceu, através das perguntas que se seguem. Se certifique que elas sejam respondidas da melhor forma possível.

Há 184 perguntas neste questionário

\section{História de Doença Pregressa}

Para maiores informações da HDP consultar aba "Avaliação Médica".

\section{[]Tem HISTÓRIA PRÉVIA de FRATURA? *}

Favor escolher apenas uma das opções a seguir:

Sim

Não

Não informado / Não avaliado

\section{[]Indique o(s) SÍTIO(S) da(s) FRATURA(S) PRÉVIA(S): *}

Só responder essa pergunta sob as seguintes condições:

A resposta foi 'Sim' na questão '1 [snFxPr]' (Tem HISTÓRIA PRÉVIA de FRATURA?)

Por favor, escolha as opções que se aplicam:
Face
Crânio
Escápula
Clavícula
Costela

Membro Superior

Membro Inferior

Vértebra Cervical

Vértebra Torácica

Vértebra Lombar

Sacro e/ou Cóccix

Pelve

Não informado / Não avaliado 


\section{[]Tem HISTÓRIA PRÉVIA de CIRURGIA CEREBRAL? *}

Favor escolher apenas uma das opções a seguir:

Sim

○ Não

Não informado / Não avaliado

\section{[]Tem HISTÓRIA PRÉVIA de CIRURGIA de NERVO em membro superior? *}

Favor escolher apenas uma das opções a seguir:
Sim
Não
Não informado / Não avaliado

\section{[]Se CIRURGIA PRÉVIA de NERVO em membro superior, *}

Só responder essa pergunta sob as seguintes condições:

A resposta foi 'Sim' na questão '38 [snCnerPr]' (Tem HISTÓRIA PRÉVIA de CIRURGIA de NERVO em membro superior?)

Favor escolher apenas uma das opções a seguir:

Direito

Esquerdo

Ambos

Não informado / Não avaliado

\section{[]Se CIRURGIA PRÉviA de NERVO de membro superior DIREITO, *}

Só responder essa pergunta sob as seguintes condições:

A resposta foi 'Ambos' ou 'Direito' na questão '39 [opcLdCnerPr]' (Se CIRURGIA PRÉVIA de NERVO em membro superior,)

Por favor, escolha as opções que se aplicam:
Nervo Musculocutâneo
Nervo Axilar
Nervo Radial
Nervo Interósseo Posterior
Nervo Mediano
Nervo Interósseo Anterior
Nervo Ulnar
Não avaliado / Não informado 
[]Se CIRURGIA PRÉVIA de NERVO de membro superior ESQUERDO, *

Só responder essa pergunta sob as seguintes condições:

A resposta foi 'Ambos' ou 'Esquerdo' na questão '39 [opcLdCnerPr]' (Se CIRURGIA PRÉVIA de NERVO em membro superior,)

Por favor, escolha as opções que se aplicam:

Nervo Musculocutâneo

Nervo Axilar

Nervo Radial

Nervo Interósseo Posterior

Nervo Mediano

Nervo Interósseo Anterior

Nervo Ulnar

Não avaliado / Não informado

\section{[]Tem HISTORIA PRÉVIA de TRAUMATISMO CRANIOENCEFÁLICO? *}

Favor escolher apenas uma das opções a seguir:

Sim

Não

Não informado / Não avaliado

\section{[]Tem HISTÓRIA PRÉVIA de TRAUMATISMO RAQUIMEDULAR? *}

Favor escolher apenas uma das opções a seguir:

Sim

○ Não

Não informado / Não avaliado

\section{[]Se TRAUMATISMO RAQUIMEDULAR PRÉVIO, *}

Só responder essa pergunta sob as seguintes condições:

A resposta foi 'Sim' na questão '43 [snTRMPr]' (Tem HISTÓRIA PRÉVIA de TRAUMATISMO RAQUIMEDULAR?)

Por favor, escolha as opções que se aplicam:

Cervical

Torácico

Lombar

Não informado / Não avaliado

\section{[]Tem HISTÓRIA PRÉVIA de DOR? *}

Favor escolher apenas uma das opções a seguir:

Sim

○ Não

Não informado / Não avaliado 


\section{História da Doença Atual}

Olá, você está sendo avaliado(a) em relação a lesão do plexo braquial que o(a) trouxe para este atendimento. Queremos saber alguns detalhes sobre como ela aconteceu, através das perguntas que se seguem. Se certifique que elas sejam respondidas da melhor forma possível.

\section{[]DATA da LESÃO:}

Favor informar uma data:

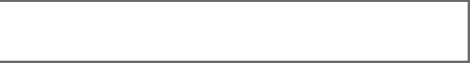

\section{[]DATA de NASCIMENTO:}

Favor informar uma data:

\section{[] $\{($ strtotime(datLesao)-strtotime $($ datNasc $)) / 60 / 60 / 24 / 365.25\} *$}

[]

Calcular IDADE por ocasião da LESÃO: \{(strtotime(datLesao)strtotime(datNasc)) $/ 60 / 60 / 24 / 365.25\}$

Só responder essa pergunta sob as seguintes condições:

$\{$ (strtotime(datLesao) - strtotime(datNasc)) / $60 / 60 / 24 / 365.25\}$

A IDADE por ocasião da lesão é a diferença entre a data da lesão e a data de nascimento

\section{[]HISTÓRIA da DOENÇA ATUAL:}

Por favor, coloque sua resposta aqui:

\section{[]Qual o LADO da LESÃO? *}

Favor escolher apenas uma das opções a seguir:

Direito

Esquerdo

Ambos

Não informado / Não avaliado 
[]Identifique o EVENTO que levou ao TRAUMA de PLEXO BRAQUIAL DIREITO. É possível marcar mais do que um evento, *

Só responder essa pergunta sob as seguintes condições:

A resposta foi 'Direito' ou 'Ambos' na questão '54 [opcLdLesao]' (Qual o LADO da LESÃO?)

Por favor, escolha as opções que se aplicam:

Acidentes automobilísticos

Acidentes motociclísticos

Acidentes ocupacionais

Lesão por arma de fogo

Lesão por objeto pérfuro-cortante

Lesão cirúrgica

Lesão por efeito de radiações

Lesão por atropelamento

Lesão por queimadura

Lesão por tumor

Lesão por estiramento

Não informado / Não avaliado

Outros:

Marque uma ou mais opções que identificam o(s) evento(s) traumático(s) que lesaram o seu plexo braquial.

[]Identifique o EVENTO que levou ao TRAUMA de PLEXO BRAQUIAL ESQUERDO. É possível marcar mais do que um evento, *

Só responder essa pergunta sob as seguintes condições:

A resposta foi 'Esquerdo' ou 'Ambos' na questão '54 [opcLdLesao]' (Qual o LADO da LESÃO?)

Por favor, escolha as opções que se aplicam:

Acidentes automobilísticos

Acidentes motociclísticos

Acidentes ocupacionais

Lesão por arma de fogo

Lesão por objeto pérfuro-cortante

Lesão cirúrgica

Lesão por efeito de radiações

Lesão por atropelamento

Lesão por queimadura

Lesão por tumor

Lesão por estiramento

Não informado / Não avaliado

Outros:

Marque uma ou mais opções que identificam o(s) evento(s) traumático(s) que lesaram o seu plexo braquial. 


\section{Exame Físico}

\section{[]INSPEÇÃO *}

Por favor, escolha a resposta adequada para cada item:

DIREITO

ESQUERDO

Não avaliado / Avaliação inconclusiva

Subluxação glenoumeral

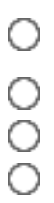

Edema

Cicatriz da cirurgia de plexo

Alteração de trofismo

$\begin{array}{ll}0 & 0 \\ 0 & 0 \\ 0 & 0 \\ 0 & 0 \\ 0 & 0 \\ 0 & 0\end{array}$

Não avaliado /

Avaliação

Presente Ausente inconclusiva

\section{[]Se EDEMA a DIREITA, indique a LOCALIZAÇÃO,}

Só responder essa pergunta sob as seguintes condicões:

A resposta foi 'Presente' na questão '134 [opclnspecao]' (INSPEÇÃO (Edema Rótulo DIREITO))

Por favor, escolha as opções que se aplicam:

Região escapular

Região glenoumeral

Braço

Antebraço

Mão

Dedos

Segmento não especificado

\section{[]Se EDEMA a ESQUERDA, indique a LOCALIZAÇÃO， *}

Só responder essa pergunta sob as seguintes condições:

A resposta foi 'Presente' na questão '134 [opclnspecao]' (INSPEÇÃO (Edema Rótulo ESQUERDO))

Por favor, escolha as opções que se aplicam:

Região escapular

Região glenoumeral

Braço

Antebraço

Mão

Dedos

Segmento não especificado 


\section{[]Se SINAL DE TINEL a ESQUERDA, indique a LOCALIZAÇÃO,}

Só responder essa pergunta sob as seguintes condições:

A resposta foi 'Presente' na questão '142 [opcTinel]' (SINAL DE TINEL (Sinal de Tinel Rótulo ESQUERDO))

Por favor, escolha as opções que se aplicam:

\section{Região cervical}

Região supraclavicular

Região infraclavicular

Região escapular

Parede torácica

Região glenoumeral

Braço

Antebraço

Mão

Dedos

Segmento não especificado

\section{[]SENSIBILIDADE: *}

Por favor, escolha a resposta adequada para cada item:

DIREITO

Não avaliada / Avaliação

Avaliada

Sensibilidade superficial tatil

Sensibilidade superficial dolorosa

Propriocepção: Artrestesia

Propriocepção: Cinestesia

Palestesia
ESQUERDO

Não avaliada / Avaliação

Avaliada inconclusiva

$\begin{array}{ll}0 & 0 \\ 0 & 0 \\ 0 & 0 \\ 0 & 0 \\ 0 & 0\end{array}$<smiles>[CH-]</smiles><smiles>[O]</smiles><smiles>[O]</smiles>

\section{[]Se SENSIBILIDADE SUPERFICIAL TATIL foi avaliada a DIREITA, indique, *}

Só responder essa pergunta sob as seguintes condições:

A resposta foi 'Avaliada' na questão '145 [opcSensi]' (SENSIBILIDADE: (Sensibilidade superficial tatil Rótulo DIREITO))

Por favor, escolha a resposta adequada para cada item:

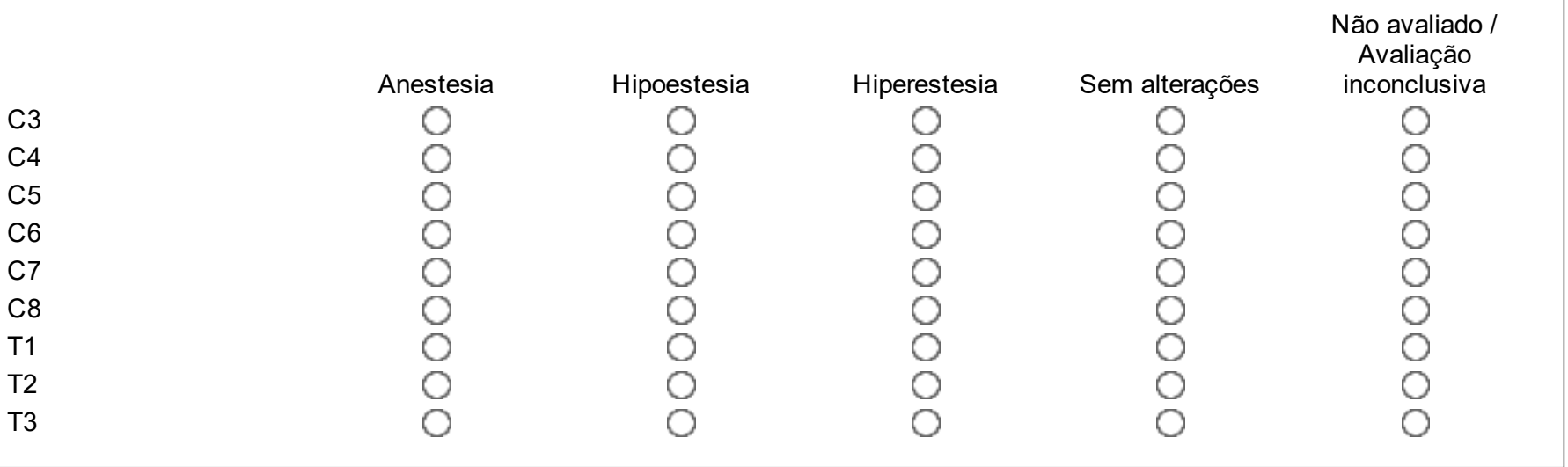




\section{[]Se SENSIBILIDADE SUPERFICIAL TATIL foi avaliada a ESQUERDA, indique, *}

Só responder essa pergunta sob as seguintes condições:

A resposta foi 'Avaliada' na questão '145 [opcSensi]' (SENSIBILIDADE: (Sensibilidade superficial tatil Rótulo ESQUERDO))

Por favor, escolha a resposta adequada para cada item:

$\begin{array}{lccccc} & & & & \text { Não avaliado / } \\ \text { Avaliação } \\ \text { inconclusiva }\end{array}$

\section{[]Se SENSIBILIDADE SUPERFICIAL DOLOROSA foi avaliada a DIREITA, indique, *}

Só responder essa pergunta sob as seguintes condições:

A resposta foi 'Avaliada' na questão '145 [opcSensi]' (SENSIBILIDADE: (Sensibilidade superficial dolorosa Rótulo DIREITO))

Por favor, escolha a resposta adequada para cada item:

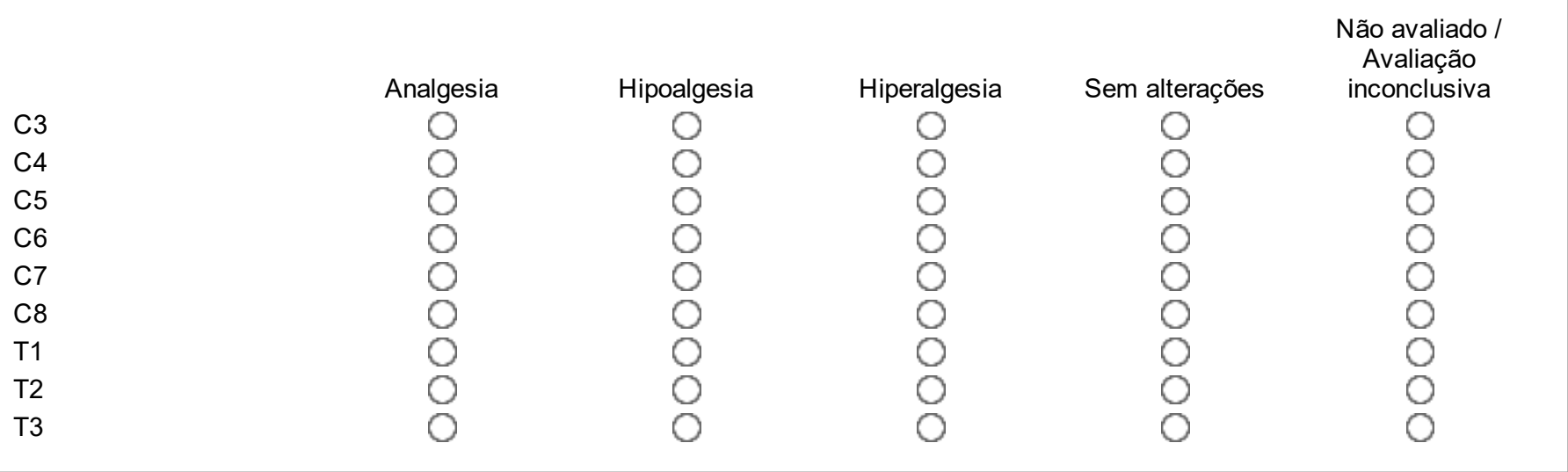

\section{[]Se SENSIBILIDADE SUPERFICIAL DOLOROSA foi avaliada a ESQUERDA, indique, *}

Só responder essa pergunta sob as seguintes condições:

A resposta foi 'Avaliada' na questão '145 [opcSensi]' (SENSIBILIDADE: (Sensibilidade superficial dolorosa Rótulo ESQUERDO))

Por favor, escolha a resposta adequada para cada item:

C3

C4

C5

C6

C7

C8

T1

T2

T3
Sem alterações
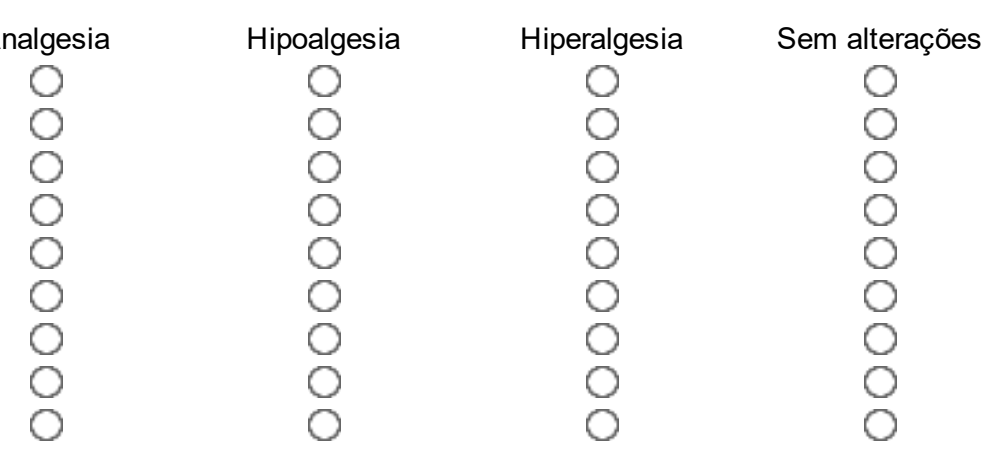

Não avaliado /

Avaliação

inconclusiva

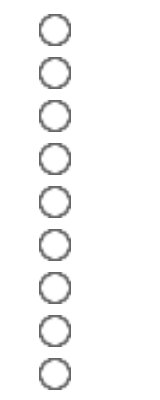




\section{[]Se propriocepção: ARTRESTESIA foi avaliada a DIREITA, indique *}

Só responder essa pergunta sob as seguintes condições:

A resposta foi 'Avaliada' na questão '145 [opcSensi]' (SENSIBILIDADE: (Propriocepção: Artrestesia Rótulo DIREITO))

Por favor, escolha a resposta adequada para cada item:

$\begin{array}{lccc} & \text { Preservada } & \text { Alterada } & \begin{array}{c}\text { Não avaliado / Avaliação } \\ \text { inconclusiva }\end{array} \\ \text { Interfalangeana } & 0 & 0 & 0 \\ \text { Proximal (Indicador) } & 0 & 0 & 0 \\ \text { Cotovelo } & 0 & 0 & 0\end{array}$

\section{[]Se propriocepção: ARTRESTESIA foi avaliada a ESQUERDA, indique *}

Só responder essa pergunta sob as seguintes condições:

A resposta foi 'Avaliada' na questão '145 [opcSensi]' (SENSIBILIDADE: (Propriocepção: Artrestesia Rótulo ESQUERDO))

Por favor, escolha a resposta adequada para cada item:

$\begin{array}{lcc} & \text { Alterada } & 0 \\ \text { Interfalangeana } & \text { Preservada } & \text { Avaliado / Avaliação } \\ \text { Proximal (Indicador) } & 0 & 0 \\ \text { Cotovelo } & 0 & 0\end{array}$

\section{[]Se propriocepção: CINESTESIA foi avaliado a DIREITA, indique *}

Só responder essa pergunta sob as seguintes condições:

A resposta foi 'Avaliada' na questão '145 [opcSensi]' (SENSIBILIDADE: (Propriocepção: Cinestesia Rótulo DIREITO))

Por favor, escolha a resposta adequada para cada item:

$\begin{array}{lcc} & \text { Preservada } & \text { Alterada } \\ \text { Interfalangeana } & 0 & 0 \\ \text { Proximal (Indicador) } & 0 & 0 \\ \text { Cotovelo } & 0 & 0 \\ \text { Ombro } & 0\end{array}$

Não avaliado / Avaliação inconclusiva

\section{[]Se propriocepção: CINESTESIA foi avaliado a ESQUERDA, indique *}

Só responder essa pergunta sob as seguintes condições:

A resposta foi 'Avaliada' na questão '145 [opcSensi]' (SENSIBILIDADE: (Propriocepção: Cinestesia Rótulo ESQUERDO))

Por favor, escolha a resposta adequada para cada item:

$\begin{array}{lcc} & \text { Preservada } & \text { Alterada } \\ \text { Interfalangeana } & 0 & 0 \\ \text { Proximal (Indicador) } & 0 & 0 \\ \text { Cotovelo } & 0 & 0 \\ \text { Ombro } & 0\end{array}$

Não avaliado / Avaliação

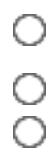
inconclusiva

\section{[]Se PALESTESIA foi avaliada a DIREITA, indique *}

Só responder essa pergunta sob as seguintes condições:

A resposta foi 'Avaliada' na questão '145 [opcSensi]' (SENSIBILIDADE: (Palestesia Rótulo DIREITO))

Por favor, escolha a resposta adequada para cada item:

\begin{tabular}{|c|c|c|c|c|}
\hline & Presente & Apalestesia & Hipopalestesia & $\begin{array}{c}\text { Não Avaliado / } \\
\text { Avaliação } \\
\text { inconclusiva }\end{array}$ \\
\hline $\begin{array}{l}\text { Terço Lateral da } \\
\text { Clavícula }\end{array}$ & 0 & 0 & 0 & 0 \\
\hline $\begin{array}{l}\text { Epicôndilo Lateral do } \\
\text { Úmero }\end{array}$ & 0 & 0 & 0 & 0 \\
\hline Cabeça da UIna & 0 & 0 & 0 & 0 \\
\hline
\end{tabular}




\section{[]Se PALESTESIA foi avaliada a ESQUERDA, indique *}

Só responder essa pergunta sob as seguintes condições:

A resposta foi 'Avaliada' na questão '145 [opcSensi]' (SENSIBILIDADE: (Palestesia Rótulo ESQUERDO))

Por favor, escolha a resposta adequada para cada item:

Não Avaliado /

Avaliação

Presente

Apalestesia

Hipopalestesia

inconclusiva

Terço Lateral da

Clavícula

Epicôndilo Lateral do

Úmero

Cabeça da UIna

$\begin{array}{cc}0 & 0 \\ 0 & 0 \\ 0 & 0\end{array}$

ESQUERDO

DIREITO

Não avaliada / Avaliação

Avaliada inconclusiva

Não avaliada / Avaliação inconclusiva

Amplitude de

movimento

Força

\section{[]Se AMPLITUDE DE MOVIMENTO avaliada a DIREITA: *}

Só responder essa pergunta sob as seguintes condições:

A resposta foi 'Avaliada' na questão '156 [opcMotor]' (MOTRICIDADE: (Amplitude de movimento Rótulo DIREITO))

Por favor, escolha a resposta adequada para cada item:

Flexão de Ombro

Extensão de Ombro

Abdução de Ombro

Rotação Externa de

Ombro

Flexão de Cotovelo

Extensão de Cotovelo

Supinação de Antebraço

Pronação de Antebraço

Flexão de Punho

Extensão de Punho
Avaliado

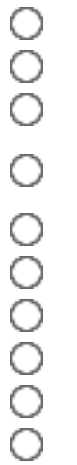

Não avaliado / Avaliação inconclusiva

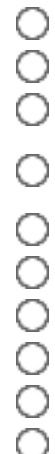

\section{[]Se AMPLITUDE DE MOVIMENTO avaliada a ESQUERDA: *}

Só responder essa pergunta sob as seguintes condições:

A resposta foi 'Avaliada' na questão '156 [opcMotor]' (MOTRICIDADE: (Amplitude de movimento Rótulo ESQUERDO))

Por favor, escolha a resposta adequada para cada item:
Flexão de Ombro
Extensão de Ombro
Abdução de Ombro
Rotação Externa de
Ombro
Flexão de Cotovelo
Extensão de Cotovelo
Supinação de Antebraço
Pronação de Antebraço
Flexão de Punho
Extensão de Punho

Avaliado

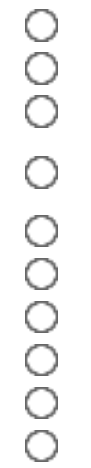

Não avaliado / Avaliação inconclusiva<smiles></smiles> 


\section{[]Flexão de ombro direito (em graus):}

Só responder essa pergunta sob as seguintes condições:

A resposta foi 'Avaliado' na questão '157 [opcADMD]' (Se AMPLITUDE DE MOVIMENTO avaliada a DIREITA: (Flexão de Ombro))

Apenas números podem ser usados nesse campo.

Por favor, coloque sua resposta aqui:

\section{[]Flexão de ombro esquerdo (em graus): *}

Só responder essa pergunta sob as seguintes condições:

A resposta foi 'Avaliado' na questão '158 [opcADME]' (Se AMPLITUDE DE MOVIMENTO avaliada a ESQUERDA: (Flexão de Ombro))

Apenas números podem ser usados nesse campo.

Por favor, coloque sua resposta aqui:

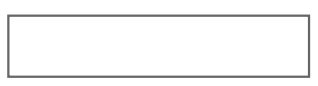

\section{[]Extensão de ombro direito (em graus): *}

Só responder essa pergunta sob as seguintes condições:

A resposta foi 'Avaliado' na questão '157 [opcADMD]' (Se AMPLITUDE DE MOVIMENTO avaliada a DIREITA: (Extensão de Ombro))

Apenas números podem ser usados nesse campo.

Por favor, coloque sua resposta aqui:

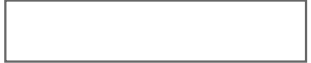

\section{[]Extensão de ombro esquerdo (em graus):}

Só responder essa pergunta sob as seguintes condições:

A resposta foi 'Avaliado' na questão '158 [opcADME]' (Se AMPLITUDE DE MOVIMENTO avaliada a ESQUERDA: (Extensão de Ombro))

Apenas números podem ser usados nesse campo.

Por favor, coloque sua resposta aqui:

\section{[]Abdução de ombro direito (em graus): *}

Só responder essa pergunta sob as seguintes condições:

A resposta foi 'Avaliado' na questão '157 [opcADMD]' (Se AMPLITUDE DE MOVIMENTO avaliada a DIREITA: (Abdução de Ombro))

Apenas números podem ser usados nesse campo.

Por favor, coloque sua resposta aqui:

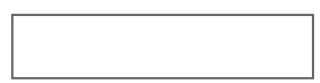




\section{[]Abdução de ombro esquerdo (em graus): *}

Só responder essa pergunta sob as seguintes condições:

A resposta foi 'Avaliado' na questão '158 [opcADME]' (Se AMPLITUDE DE MOVIMENTO avaliada a ESQUERDA: (Abdução de Ombro))

Apenas números podem ser usados nesse campo

Por favor, coloque sua resposta aqui:

\section{[]Rotação Externa de ombro direito (em graus): *}

Só responder essa pergunta sob as seguintes condições:

A resposta foi 'Avaliado' na questão '157 [opcADMD]' (Se AMPLITUDE DE MOVIMENTO avaliada a DIREITA: (Rotação Externa de Ombro))

Apenas números podem ser usados nesse campo.

Por favor, coloque sua resposta aqui:

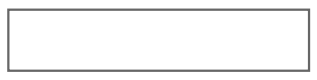

\section{[]Rotação Externa de ombro esquerdo (em graus): *}

Só responder essa pergunta sob as seguintes condições:

A resposta foi 'Avaliado' na questão '158 [opcADME]' (Se AMPLITUDE DE MOVIMENTO avaliada a ESQUERDA: (Rotação Externa de Ombro))

Apenas números podem ser usados nesse campo.

Por favor, coloque sua resposta aqui:

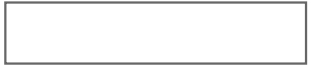

\section{[]Flexão de cotovelo direito (em graus): *}

Só responder essa pergunta sob as seguintes condições:

A resposta foi 'Avaliado' na questão '157 [opcADMD]' (Se AMPLITUDE DE MOVIMENTO avaliada a DIREITA: (Flexão de Cotovelo))

Apenas números podem ser usados nesse campo.

Por favor, coloque sua resposta aqui:

\section{[]Flexão de cotovelo esquerdo (em graus): *}

Só responder essa pergunta sob as seguintes condições:

A resposta foi 'Avaliado' na questão '158 [opcADME]' (Se AMPLITUDE DE MOVIMENTO avaliada a ESQUERDA: (Flexão de Cotovelo))

Apenas números podem ser usados nesse campo.

Por favor, coloque sua resposta aqui:

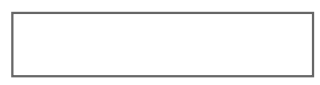




\section{[]Se FORÇA MUSCULAR avaliada a DIREITA: *}

Só responder essa pergunta sob as seguintes condições:

A resposta foi 'Avaliada' na questão '156 [opcMotor]' (MOTRICIDADE: (Força Rótulo DIREITO))

Por favor, escolha a resposta adequada para cada item:

Não

Avaliado /

Avaliação

Flexão do Ombro

Abdução do Ombro

Rotação Externa do

Ombro

Rotação Interna do Ombro

Elevação da Escápula

Abdução e Rotação

Superior da Escápula

Flexão do Cotovelo

Extensão do Cotovelo

Extensão de Punho

Flexão de Punho

Flexão dos Dedos

Extensão dos Dedos

Abdução dos Dedos

Adução dos Dedos

Oponência do Polegar

$\begin{array}{ll}0 & 1 \\ 0 & 0 \\ 0 & 0 \\ 0 & 0 \\ 0 & 0 \\ 0 & 0 \\ 0 & 0 \\ 0 & 0 \\ 0 & 0 \\ 0 & 0 \\ 0 & 0 \\ 0 & 0 \\ 0 & 0 \\ 0 & 0 \\ 0 & 0 \\ 0 & 0\end{array}$

2

3

4

5

0

0

0

0

inconclusiva

O

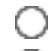

0

0

0

0

0

0

0

0

0

0

$0 \quad 0$

0

0

0

0

0

0

0

0

0

\section{[]Se FORÇA MUSCULAR avaliada a ESQUERDA:}

Só responder essa pergunta sob as seguintes condições:

A resposta foi 'Avaliada' na questão '156 [opcMotor]' (MOTRICIDADE: (Força Rótulo ESQUERDO))

Por favor, escolha a resposta adequada para cada item:

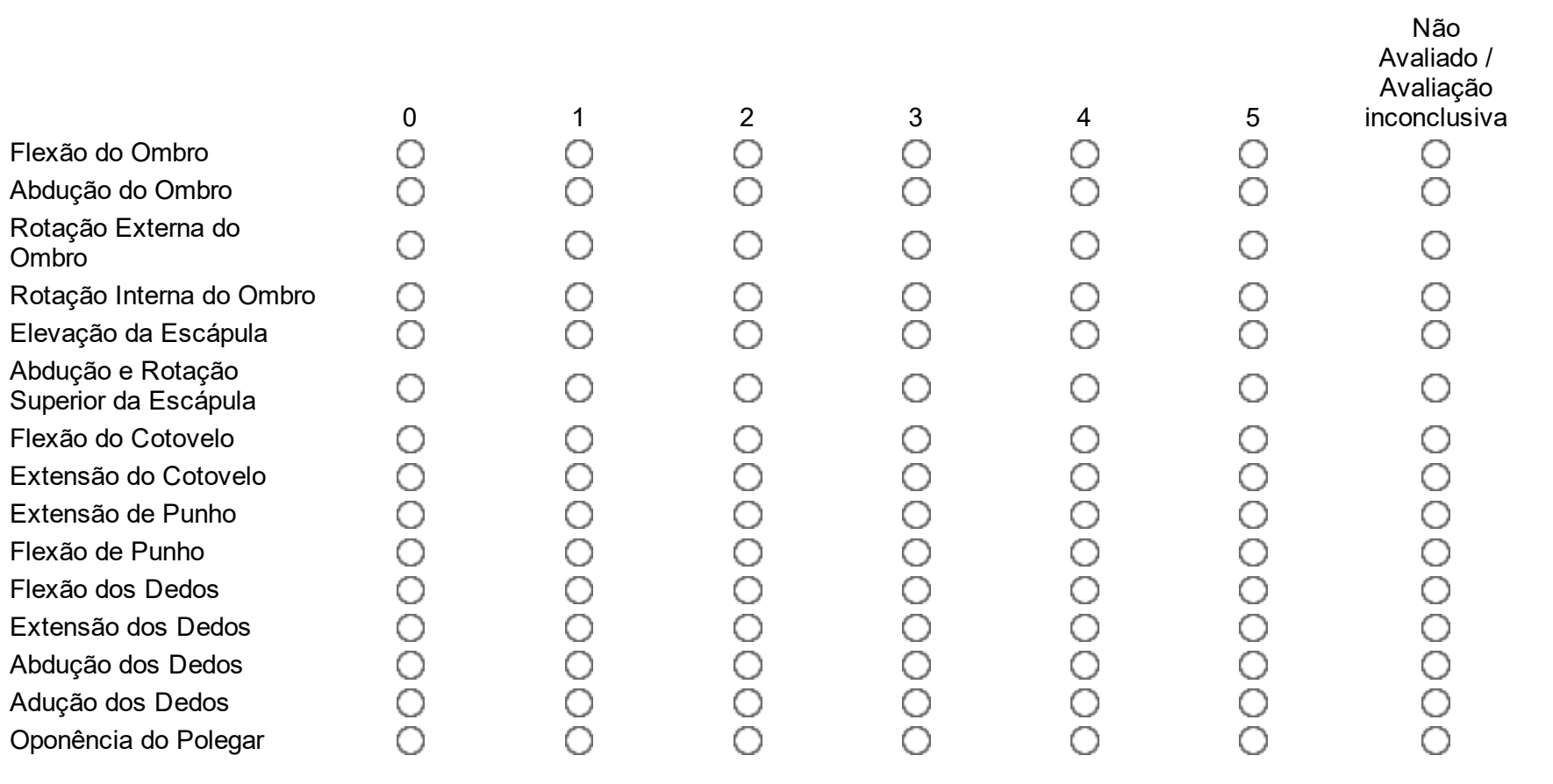

\section{[]Você sente DOR APÓS a LESÃO? *}

Favor escolher apenas uma das opções a seguir:
O $\operatorname{sim}$
Não
Não avaliado / Avaliação inconclusiva 


\section{Avaliação Cirúrgica - Unificada}

Confecção em 31/05/2016 as 21:30

Há 249 perguntas neste questionário

\section{Dados cirúrgicos}

\section{Em um centro participante do estudo \\ Em outro local \\ Não informado / Não avaliado}

[]Em que local a cirurgia foi realizada? *

Comentar apenas quando você selecionar uma resposta.

Por favor, escolha as opções que se aplicam e faça um comentário:

\section{[]Data da cirurgia:}

Favor informar uma data:

\section{[]Data da lesão de plexo:}

Favor informar uma data:

Caso haja dúvida, a resposta para essa pergunta pode ser consultada na ficha de entrada unificada.

\section{[]$\{($ strtotime(datcirurgia)-strtotime(datLesao))/60/60/24\}}

[]O intervalo entre a lesão e a cirurgia foi de \{(strtotime(datcirurgia)strtotime(datLesao))/60/60/24\} dias

\section{[ ]Qual o lado operado? *}

Favor escolher apenas uma das opções a seguir:

Direito

Esquerdo

Ambos

Não avaliado / Não informado 


\section{[]Procedimento(s) cirúrgico(s) realizado(s): *}

Por favor, escolha as opções que se aplicam:

\section{Neurólise}

Transferência de nervo

Enxertia

Dissecção de neuroma

Não informado

\section{[]}

\section{Neurólise em qual(is) nível(eis)? *}

Só responder essa pergunta sob as seguintes condições:

A resposta foi na questão '35 [lisprocedimentos]' (Procedimento(s) cirúrgico(s) realizado(s):)

Por favor, escolha as opções que se aplicam:

Raiz

Tronco

Divisão

Cordão

$\square$ Nervo

Não informado

Outros:

[]

\section{Neurólise de qual(is) raiz(es)? *}

Só responder essa pergunta sob as seguintes condições:

A resposta foi na questão '36 [lisneurolise]' ( Neurólise em qual(is) nível(eis)? )

Por favor, escolha as opções que se aplicam:

\section{C4 \\ C5 \\ C6 \\ C7 \\ C8 \\ $\mathrm{T} 1$ \\ T2}

Outros: 


\section{[]Neurólise de qual(is) nervo(s)? *}

Só responder essa pergunta sob as seguintes condições:

A resposta foi na questão '36 [lisneurolise]' ( Neurólise em qual(is) nível(eis)? )

Por favor, escolha as opções que se aplicam:

Nervo escapular dorsal

Nervo subclavio

$\square$ Nervo supraescapular

$\square$ Nervo peitoral lateral

$\square$ Nervo peitoral medial

$\square$ Nervo cutâneo braquial medial

$\square$ Nervo cutâneo antebraquial medial

$\square$ Nervo torácico longo

$\square$ Nervo subescapular superior

$\square$ Nervo subescapular inferior

$\square$ Nervo toracodorsal (subescapular medial)

$\square$ Nervo musculocutâneo

$\square$ Nervo axilar

$\square$ Nervo radial

$\square$ Nervo mediano

$\square$ Nervo ulnar

$\square$ Nervo frênico

Nervo acessório

\section{$1^{\circ}$ Nervo intercostal}

Não informado

$\square$ Outros:

Nervos do plexo braquial e/ou extraplexuais. 


\section{[]Transferência(s) realizada(s): *}

Só responder essa pergunta sob as seguintes condições:

A resposta foi na questão '35 [lisprocedimentos]' (Procedimento(s) cirúrgico(s) realizado(s):)

Por favor, escolha as opções que se aplicam:

Acessório-SE por via anterior

Acessório-SE por via posterior

Oberlin (fasciculo ulnar-musculocutâneo)

Intercostais - musculocutâneo

Acessório - musculocutâneo

Peitoral medial - musculocutâneo

$\square$ Peitoral medial - axilar

Tríceps (Lo/M/La) - axilar (tronco/divisão anterior)

$\square$ Frênico - musculocutâneo

$\square$ Intercostais - axilar (tronco/divisão anterior)

$\square$ Frênico - acessório

Mediano - musculocutâneo

Mediano - ramo braquial

C7 ipsolateral

C7 contralateral

$\square$ Dupla transferência

Não informado

Outra transferência

\section{[]Qual transferência foi realizada?}

Só responder essa pergunta sob as seguintes condições:

A resposta foi na questão '42 [opctransferencias]' (Transferência(s) realizada(s):)

Por favor, coloque sua resposta aqui: 


\section{[]Enxerto de qual(is) nervo(s)? *}

Só responder essa pergunta sob as seguintes condições:

A resposta foi na questão '129 [lisenxerto]' ( Enxertia em qual(is) nível(eis)? )

Por favor, escolha as opções que se aplicam:

Nervo escapular dorsal

$\square$ Nervo subclavio

$\square$ Nervo supraescapular

$\square$ Nervo peitoral lateral

$\square$ Nervo peitoral medial

$\square$ Nervo cutâneo braquial medial

$\square$ Nervo cutâneo antebraquial medial

$\square$ Nervo torácico longo

$\square$ Nervo subescapular superior

$\square$ Nervo subescapular inferior

$\square$ Nervo toracodorsal (subescapular medial)

$\square$ Nervo musculocutâneo

$\square$ Nervo axilar

$\square$ Nervo radial

$\square$ Nervo mediano

$\square$ Nervo ulnar

$\square$ Nervo frênico

Nervo acessório

\section{$1^{\circ}$ Nervo intercostal}

Não informado

Outros:

Nervos do plexo braquial e/ou extraplexuais.

\section{[]Origem do(s) enxerto(s) para Nervo escapular dorsal: *}

Só responder essa pergunta sob as seguintes condições:

A resposta foi na questão '172 [lisenxertonervos]' (Enxerto de qual(is) nervo(s)?)

Por favor, escolha as opções que se aplicam:

n sural

Não informado

$\square$ Outros: 


\section{[]Dissecção do neuroma de qual(is) raíz(es)? *}

Só responder essa pergunta sob as seguintes condições:

A resposta foi na questão '35 [lisprocedimentos]' (Procedimento(s) cirúrgico(s) realizado(s):)

Por favor, escolha as opções que se aplicam:

C4

C5

C6

C7

C8

$\mathrm{T} 1$

$\mathrm{T} 2$

$\square$ Não informado 


\section{Avaliação de Seguimento - Unificada}

História da doença atual

Exame Físico

Olá, você está sendo avaliado(a) em relação a lesão do plexo braquial que o(a) trouxe para este atendimento. Queremos saber alguns detalhes sobre como ela aconteceu, através das perguntas que se seguem. Se certifique que elas sejam respondidas da melhor forma possível.

Há 84 perguntas neste questionário

\section{História da Doença Atual}

Olá, você está sendo avaliado(a) em relação a lesão do plexo braquial que o(a) trouxe para este atendimento. Queremos saber alguns detalhes sobre como ela aconteceu, através das perguntas que se seguem. Se certifique que elas sejam respondidas da melhor forma possível.

\section{[]Fez alguma CIRURGIA DE PLEXO BRAQUIAL desde a última avaliação? *}

Favor escolher apenas uma das opções a seguir:
Sim
Não
Não informado / Não avaliado

[]Para cada cirurgia feita preencher uma FICHA DE CIRURGIA DE PLEXO correspondente na sessão QUESTIONÁRIOS, no NES.

Só responder essa pergunta sob as seguintes condições:

A resposta foi 'Sim' na questão '1 [snCplexoAt]' (Fez alguma CIRURGIA DE PLEXO BRAQUIAL desde a última avaliação?)

\section{[]Fez alguma CIRURGIA DE DOR desde a última avaliação? *}

Favor escolher apenas uma das opções a seguir:
O $\operatorname{sim}$
Não
Não informado / Não avaliado

[]Para cada cirurgia feita preencher uma FICHA DE CIRURGIA DE DOR correspondente na sessão QUESTIONÁRIOS, nO NES.

Só responder essa pergunta sob as seguintes condições:

A resposta foi 'Sim' na questão '3 [snCdorAt]' (Fez alguma CIRURGIA DE DOR desde a última avaliação?)

\section{[]Fez alguma CIRURGIA ORTOPEDICA ou CRANIOFACIAL desde a última avaliação? *}

Favor escolher apenas uma das opções a seguir:
$\operatorname{Sim}$
Não
Não informado / Não avaliado 


\section{[]Pronação de antebraço esquerdo (em graus): *}

Só responder essa pergunta sob as seguintes condições:

A resposta foi 'Avaliado' na questão '61 [opcADME]' (Se AMPLITUDE DE MOVIMENTO avaliada a ESQUERDA: (Pronação de Antebraço))

Apenas números podem ser usados nesse campo.

Por favor, coloque sua resposta aqui:

\section{[]Flexão de punho direito (em graus): *}

Só responder essa pergunta sob as seguintes condições:

A resposta foi 'Avaliado' na questão '60 [opcADMD]' (Se AMPLITUDE DE MOVIMENTO avaliada a DIREITA: (Flexão de Punho))

Apenas números podem ser usados nesse campo.

Por favor, coloque sua resposta aqui:

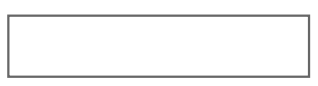

\section{[]Flexão de punho esquerdo (em graus): *}

Só responder essa pergunta sob as seguintes condições:

A resposta foi 'Avaliado' na questão '61 [opcADME]' (Se AMPLITUDE DE MOVIMENTO avaliada a ESQUERDA: (Flexão de Punho))

Apenas números podem ser usados nesse campo.

Por favor, coloque sua resposta aqui:

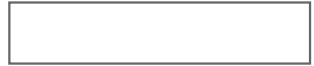

\section{[]Extensão de punho direito (em graus): *}

Só responder essa pergunta sob as seguintes condições:

A resposta foi 'Avaliado' na questão '60 [opcADMD]' (Se AMPLITUDE DE MOVIMENTO avaliada a DIREITA: (Extensão de Punho))

Apenas números podem ser usados nesse campo.

Por favor, coloque sua resposta aqui:

\section{[]Extensão de punho esquerdo (em graus): *}

Só responder essa pergunta sob as seguintes condições:

A resposta foi 'Avaliado' na questão '61 [opcADME]' (Se AMPLITUDE DE MOVIMENTO avaliada a ESQUERDA: (Extensão de Punho))

Apenas números podem ser usados nesse campo.

Por favor, coloque sua resposta aqui: 


\section{Referências Bibliográficas}

[AH98] Sarabjot S. Anand e John G. Hughes. Hybrid data mining systems: The next generation, páginas 13-24. Springer Berlin Heidelberg, Berlin, Heidelberg, 1998. 47

[AMMIL12] Yaser S. Abu-Mostafa, Malik Magdon-Ismail e Hsuan-Tien Lin. Learning From Data. AMLBook, 2012. 6, 7, 8

[AR00] Douglas G Altman e Patrick Royston. What do we mean by validating a prognostic model? Statistics in Medicine, 19(4):453-473, 2000. 23

[ASS ${ }^{+}$02] Peter JD Andrews, Derek H Sleeman, Patrick FX Statham, Andrew McQuatt, Vincent Corruble, Patricia A Jones, Timothy P Howells e Carol SA Macmillan. Predicting recovery in patients suffering from traumatic brain injury by using admission variables and physiological data: a comparison between decision tree analysis and logistic regression. Journal of Neurosurgery, 97(2):326-336, 2002. 25, 26

[Ass12] Fernando Assunção. Estratégias para tratamento de variáveis com dados faltantes durante o desenvolvimento de modelos preditivos. Master thesis, nstituto de Matemática e Estatística, Universidade de São Paulo, São Paulo, 2012, 2012. 10

[ATSL10] André Altmann, Laura Toloşi, Oliver Sander e Thomas Lengauer. Permutation importance: A corrected feature importance measure. Bioinformatics, 26(10):13401347, 2010. 81

[BAAE16] Sabri Boughorbel, Rashid Al-Ali e Naser Elkum. Model comparison for breast cancer prognosis based on clinical data. PLoS ONE, 11(1), 2016. 27

$\left[\mathrm{BBL}^{+} 07\right]$ V. S. Bourdes, S. Bonnevay, P. J. G. Lisboa, M. S. H. Aung, S. Chabaud, T. Bachelot, D. Perol e S. Negrier. Breast cancer predictions by neural networks analysis: a comparison with logistic regression. Em 2007 29th Annual International Conference of the IEEE Engineering in Medicine and Biology Society, páginas 5424-5427, 2007. 25

[BFOS84] L. Breiman, J. Friedman, R. Olshen e C. Stone. Classification and Regression Trees. Wadsworth and Brooks, Monterey, CA, 1984. 12

[BGOD11] S. C. Berney, I. R. Gordon, H. I. Opdam e L. Denehy. A classification and regression tree to assist clinical decision making in airway management for patients with cervical spinal cord injury. Spinal Cord, 49:244-250, 2011. 26

[BI12] Prantik Bordoloi e Nazrul Islam. Knowledge Management Practices and Healthcare Delivery: A Contingency Framework. The Electronic Journal of Knowledge Management, 10(2):110-120, 2012. 22

[BL97] Michael J. Berry e Gordon Linoff. Data Mining Techniques: For Marketing, Sales, and Customer Support. John Wiley \& Sons, Inc., New York, NY, USA, 1997. 5 
$\left[\mathrm{BMD}^{+} 16\right]$ Fraser J.H. Brims, Tarek M. Meniawy, Ian Duffus, Duneesha de Fonseka, Amanda Segal, Jenette Creaney, Nicholas Maskell, Richard A. Lake, Nick de Klerk e Anna K Nowak. A novel clinical prediction model for prognosis in malignant pleural mesothelioma using decision tree analysis. Journal of Thoracic Oncology, 11(4):573582, 2016. 25

[Bra13] Max Bramer. Principles of Data Mining. Springer Publishing Company Incorporated, 2nd edição, 2013. 10

[Bre01] Leo Breiman. Random forests. Machine Learning, 45(1):5-32, 2001. 18, 19, 20, 27, $28,50,52$

[Bri76] Medical Research Council (Great Britain). Aids to the examination of the peripheral nervous system. H.M. Stationery Off., 1976. 32

[BZ08] Riccardo Bellazzi e Blaz Zupan. Predictive data mining in clinical medicine: current issues and guidelines. International Journal of Medical Informatics, 77(2):81-97, 2008. 2, 22,23

[Car97] Rich Caruana. Multitask Learning. Machine Learning, 28:41-75, 1997. 81

[CLB04] Chao Chen, Andy Liaw e Leo Breiman. Using Random Forest to Learn Imbalanced Data. Relatório técnico, Department of Statistics, University of Berkeley, 2004. 51

[COC09] João Carlos da Silva Cássio Oliveira Camilo. Mineração de dados: Conceitos, tarefas, métodos e ferramentas. Relatório técnico, Universidade Federal de Goiás, Instituto de Informática, 2009. xiii, 6

[CPSK07] Krzysztof J. Cios, Witold Pedrycz, Roman W. Swiniarski e Lukasz A. Kurgan. Data Mining: A Knowledge Discovery Approach. Springer-Verlag New York, Inc., Secaucus, NJ, USA, 2007. 44

[CSRL01] Thomas H. Cormen, Clifford Stein, Ronald L. Rivest e Charles E. Leiserson. Introduction to Algorithms. McGraw-Hill Higher Education, 3rd edição, 2001. 12

[CW07] Joseph A. Cruz e David S. Wishart. Applications of machine learning in cancer prediction and prognosis. Cancer Informatics, 2:59-77, 2007. 26

[dA15] Fernanda Guimarães de Andrade. Funcionalidade em Indivíduos Adultos com Lesão Traumática de Plexo Braquial - Proposta de Instrumento de Avaliação baseado na Classificação Internacional de Funcionalidade (CIF). Tese de Doutorado, Universidade Federal do Rio de Janeiro, 2015. 1

[Die00] Thomas G. Dietterich. Ensemble Methods in Machine Learning, páginas 1-15. 2000. 18

[DOM02] Stephan Dreiseitl e Lucila Ohno-Machado. Logistic regression and artificial neural network classification models: A methodology review. J. of Biomedical Informatics, 35(5/6):352-359, Outubro 2002. 18

[Dom12] Pedro Domingos. A few useful things to know about machine learning. Commun. ACM, 55(10):78-87, 2012. 7

[DPV17] Seguradora Lider DPVAT. Relatório anual. https://www.seguradoralider.com.br/ Centro-de-Dados-e-Estatisticas/Relatorio-Anual, 2017. Acesso em: 17/05/2018. 1

[DUA06] Ramón Díaz-Uriarte e Sara Alvarez De Andrés. Gene selection and classification of microarray data using random forest. BMC Bioinformatics, 7(3), 2006. 19, 28, 51, $52,54,60$ 
[EN12] Issam El Naqa. Machine learning methods for predicting tumor response in lung cancer. Wiley Int. Rev. Data Min. and Knowl. Disc., 2(2):173-181, Março 2012. 25

[FPsS96] Usama Fayyad, Gregory Piatetsky-shapiro e Padhraic Smyth. From data mining to knowledge discovery in databases. AI Magazine, 17:37-54, 1996. xiii, 5, 6

$\left[\mathrm{FSM}^{+} 14\right]$ Wilson Faglioni, Mario G. Siqueira, Roberto S. Martins, Carlos Otto Heise e Luciano Foroni. The epidemiology of adult traumatic brachial plexus lesions in a large metropolis. Acta Neurochirurgica, 156(5):1025-1028, May 2014. 1

[FZTKN12] Rosa L. Figueroa, Qing Zeng-Treitler, Sasikiran Kandula e Long H. Ngo. Predicting sample size required for classification performance. BMC Medical Informatics and Decision Making, 12(1):8, 2012. 9

[GE03] Isabelle Guyon e André Elisseeff. An introduction to variable and feature selection. J. Mach. Learn. Res., 3:1157-1182, 2003. 9, 28

[GL18] Henry Gray e Warren Harmon Lewis. Anatomy of the Human Body. Lea \& Febiger, 1918. xiii, 1

[GPTM10] Robin Genuer, Jean-Michel Poggi e Christine Tuleau-Malot. Variable selection using random forests. 31:2225-2236, 10 2010. 28, 52, 54, 77

[GS98] Susan Garavaglia e Asha Sharma. A smart guide to dummy variables: Four applications and a macro. 1998. 47

[Han05] Jiawei Han. Data Mining: Concepts and Techniques. Morgan Kaufmann Publishers Inc., San Francisco, CA, USA, 2005. 5, 6, 7, 8

[HHUS14] Alexander Hapfelmeier, Torsten Hothorn, Kurt Ulm e Carolin Strobl. A new variable importance measure for random forests with missing data. Statistics and Computing, 24(1):21-34, Jan 2014. 10, 20, 52

[HHZ06] Torsten Hothorn, Kurt Hornik e Achim Zeileis. Unbiased Recursive Partitioning: A Conditional Inference Framework. Journal of Computational and Graphical Statistics, 15(3):651-674, 2006. 81

[HLZ $\left.{ }^{+} 15\right]$ Yun Fei Hou, Yang Lv, Fang Zhou, Yun Tian, Hong Quan Ji, Zhi Shan Zhang e Yan Guo. Development and validation of a risk prediction model for tracheostomy in acute traumatic cervical spinal cord injury patients. European Spine Journal, 24(5):975-984, 2015. 26

[HMR13] Behshad Hosseinifard, Mohammad Hassan Moradi e Reza Rostami. Classifying depression patients and normal subjects using machine learning techniques and nonlinear features from eeg signal. Computer Methods and Programs in Biomedicine, 109(3):339 - 345, 2013. 81

[Ho98] Tin Ham Ho. The Random Subspace Method for Constructing Decision Forests. IEEE Transactions on Pattern Analysis and Machine Intelligence, 20(8):832-844, 1998. 51

[HSWS12] Oh Hyun Soo e Seo Wha Sook. Development of a decision tree analysis model that predicts recovery from acute brain injury. Japan Journal of Nursing Science, 10(1):89-97, 2012. 25

[HTF09] Trevor Hastie, Robert Tibshirani e Jerome Friedman. The Elements of Statistical Learning. Springer, 2 edição, 2009. 11, 52, 79 
[HTTTF13] S. Hosseini Teshnizi, M. Tazhibi e M. Tavasoli Farahi. Comparison of Cox regression and artificial neural network models in prediction of survival in acute leukemia patients. Scientific Journal of Iranian Blood Transfusion Organization, 10(2):154162, 2013. 25

[IND] Instituto de neurologia deolindo couto - universidade federal do rio de janeiro (INDC-UFRJ). http://www.indc.ufrj.br/. Acesso em: 17/05/18. 31

[Jas90] R.B.M. Jaspers. Medical decision support: an approach in the domain of brachial plexus injuries. Tese de Doutorado, Delft University of Technology, 1990. 22, 26

$\left[\mathrm{JBS}^{+}\right.$03] Aleks Jakulin, Ivan Bratko, Dragica Smrke, Janez Demšar e Blaž Zupan. Attribute Interactions in Medical Data Analysis, páginas 229-238. Springer Berlin Heidelberg, Berlin, Heidelberg, 2003. 25

[JSB13] Silke Janitza, Carolin Strobl e Anne-Laure Boulesteix. An AUC-based Permutation Variable Importance Measure for Random Forests. BMC Bioinformatics, 14(1):119, 2013. $20,51,52$

[JvDvdH89] R. B. M. Jaspers, C. van Daalen e F. C. van der Helm. Modelling the rehabilitation of brachial plexus injuries: The PLEXUS system. Journal of Medical Engineering E Technology, 13(2):114 - 118, 1989. 26

[KHBL05] Kensaku Kawamoto, Caitlin A Houlihan, E Andrew Balas e David F Lobach. Improving clinical practice using clinical decision support systems: a systematic review of trials to identify features critical to success. BMJ, 330(7494):765, 2005. 22

[KPAA11] Victor E. Kuz'min, Pavel G. Polishchuk, Anatoly G. Artemenko e Sergey A. Andronati. Interpretation of qsar models based on random forest methods. Molecular Informatics, 30(7):593-603, 2011. 20, 27

$\left[\mathrm{KSK}^{+} 14\right]$ MS Kohn, J Sun, S Knoop, A Shabo, B Carmeli, D Sow, T Syed-Mahmood e W Rapp. Ibm's health analytics and clinical decision support. Yearbook of medical informatics, 9:154-162, 2014. 22

[LCLC17] C. H. Bryan Liu, Benjamin Paul Chamberlain, Duncan A. Little e Ângelo Cardoso. Generalising random forest parameter optimisation to include stability and cost. Em Yasemin Altun, Kamalika Das, Taneli Mielikäinen, Donato Malerba, Jerzy Stefanowski, Jesse Read, Marinka Žitnik, Michelangelo Ceci e Sašo Džeroski, editors, Machine Learning and Knowledge Discovery in Databases, páginas 102-113, Cham, 2017. Springer International Publishing. 19

[lim] LimeSurvey - the free and open-source survey software tool. http://www. limesurvey.org/. Acesso em: 17/05/2018. 31

$\left[L_{L}^{+}{ }^{15}\right]$ Hsueh-Yi Lu, Tzu-Chi Li, Yong-Kwang Tu, Jui-Chang Tsai, Hong-Shiee Lai e LuTing Kuo. Predicting long-term outcome after traumatic brain injury using repeated measurements of glasgow coma scale and data mining methods. Journal of Medical Systems, 39(2):14, 2015. 25

[LTTT12] Tadeusz Lasota, Zbigniew Telec, Bogdan Trawiński e Grzegorz Trawiński. Evaluation of random subspace and random forest regression models based on genetic fuzzy systems. Frontiers in Artificial Intelligence and Applications, 243(August 2015):88-97, 2012. 51

[LW02] A. Liaw e M. Wiener. Classification and regression by random- forest. $R$ News, $2(2): 18-22,2002.19,51$ 
$\left[\mathrm{MCCG}^{+} 13\right]$ Alexis Marcano-Cedeño, Paloma Chausa, Alejandro García, CéSar CáCeres, Josep M Tormos e Enrique J GóMez. Data mining applied to the cognitive rehabilitation of patients with acquired brain injury. Expert Systems with Applications, 40(4):1054-1060, 2013. 25

$\left[\mathrm{MHH}^{+} 08\right]$ Nino A Mushkudiani, Chantal WPM Hukkelhoven, Adrián V Hernández, Gordon D Murray, Sung C Choi, Andrew IR Maas e Ewout W Steyerberg. A systematic review finds methodological improvements necessary for prognostic models in determining traumatic brain injury outcomes. Journal of Clinical Epidemiology, 61(4):331-343, 2008. 25

[Mit97] Thomas M. Mitchell. Machine Learning. McGraw-Hill, Inc., New York, NY, USA, 1 edição, 1997. 6, 11, 12, 16

[MRBB17] Catherine Mercier, Meyke Roosink, Jason Bouffard e Laurent J. Bouyer. Promoting gait recovery and limiting neuropathic pain after spinal cord injury: Two sides of the same coin? Neurorehabilitation and Neural Repair, 31(4):315-322, 2017. PMID: 27913797. 58

[MS09] C. Yu Wai Man e D. Steel. Visual outcome after open globe injury: a comparison of two prognostic models: the ocular trauma score and the classification and regression tree. Eye, 24(1):84 - 89, 2009. 25

[NES] Neuroscience Experiments System (NES). https://github.com/neuromat/nes/. Acesso em: 17/05/2018. 31

[Neu] Centro de Pesquisa, Inovação e Difusão em Neuromatemática (NeuroMat). http: //neuromat.numec.prp.usp.br/. Acesso em: 17/05/2018. 2, 31

[OM97] Lucila Ohno-Machado. A comparison of Cox proportional hazards and artificial neural network models for medical prognosis. Computers in Biology and Medicine, 27(1):55-65, 1997. 25

[pan] pandas: Python Data Analysis Library. http://pandas.pydata.org/. Acesso em: 17/05/2018. 41

[Pau12] Oliver Pauly. Random Forests for Medical Applications. Tese de Doutorado, Department of Informatics, Technical University of Munich, 2012. 18, 27

[PPRN13] A. Palczewska, J. Palczewski, R. M. Robinson e D. Neagu. Interpreting random forest models using a feature contribution method. Em 2013 IEEE 14th International Conference on Information Reuse Integration (IRI), páginas 112-119, Aug 2013. $19,21,27,53,79$

[PVG $\left.{ }^{+} 11\right]$ F. Pedregosa, G. Varoquaux, A. Gramfort, V. Michel, B. Thirion, O. Grisel, M. Blondel, P. Prettenhofer, R. Weiss, V. Dubourg, J. Vanderplas, A. Passos, D. Cournapeau, M. Brucher, M. Perrot e E. Duchesnay. Scikit-learn: Machine learning in Python. Journal of Machine Learning Research, 12:2825-2830, 2011. 41,49

[Pyt] Python (Python Programming Language). http://www.python.org/. Acesso em: 17/05/2018. 41, 49

[Qui86] J. R. Quinlan. Induction of decision trees. MACH. LEARN, 1:81-106, 1986. 12

[Qui93] J. Ross Quinlan. C4.5: Programs for Machine Learning. Morgan Kaufmann Publishers Inc., San Francisco, CA, USA, 1993. 12 
[RCGFCP ${ }^{+}$14] Bruno Reszel Coelho, Amanda Garcia Fabbris, Ana Paula Cardoso Pereira, Renata da Silva Peixoto e Cristina Dutra Ribeiro. Lesões do plexo braquial: a utilização da fisioterapia no tratamento. Ensaios e Ciência: Ciências Biológicas, Agrárias e da Saúde, 16:185-197, 2014. 1

$\left[\mathrm{RCK}^{+} 11\right]$ Ruty Rinott, Boaz Carmeli, Carmel Kent, Daphna Landau, Yonatan Maman, Yoav Rubin e Noam Slonim. Prognostic data-driven clinical decision support - formulation and implications. Studies in health technology and informatics, 169:140 - 144, 2011. 2,25

[RK04] A Rovlias e S Kotsou. Classification and regression tree for prediction of outcome after severe head injury using simple clinical and laboratory variables. Journal of Neurotrauma, 21(7):886-893, 2004. 25

[RT14] Akhlaqur Rahman e Sumaira Tasnim. Ensemble classifiers and their applications: A review. International Journal of Computer Trends and Technology, 10(1):31-35, 2014. 18

[RTL09] Payam Refaeilzadeh, Lei Tang e Huan Liu. Cross-Validation, páginas 532-538. Springer US, Boston, MA, 2009. 8, 52, 79

$\left[\mathrm{SAI}^{+} 13\right]$ Galanakos SP, Zoubos AB, Mourouzis I, Ignatiadis I, Bot AG e Soucacos PN. Prognostic Scoring System for Perhipheral Nerve Repair In The Upper Extremity. Microsurgery, 33(2):105-111, 2013. 46

[SBF79] E. H. Shortliffe, B. G. Buchanan e E. A. Feigenbaum. Knowledge engineering for medical decision making: A review of computer-based clinical decision aids. Proceedings of the IEEE, 67(9):1207-1224, 1979. 25

$\left[\mathrm{SBS}^{+} 13\right]$ Alexander Stojadinovic, Anton Bilchik, David Smith, John S. Eberhardt, Elizabeth Ben Ward, Aviram Nissan, Eric K. Johnson, Mladjan Protic, George E. Peoples, Itzhak Avital e Scott R. Steele. Clinical decision support and individualized prediction of survival in colon cancer: Bayesian belief network model. Annals of Surgical Oncology, 20(1):161-174, 2013. 25

[SBV15] Erwan Scornet, Gérard Biau e Jean-Philippe Vert. Consistency of Random Forests. The Annals of Statistics, 43(4):1716-1741, 2015. 51

[SG02] Joseph L. Schafer e John W. Graham. Missing data: Our view of the state of the art. Psychological Methods, 7(2):147-177, 2002. 10, 11

[Sha48] C E Shannon. A Mathematical Theory of Communication. The Bell System Technical Journal, 27(1):379-423, 1948. 12

[SIL07] Yvan Saeys, Iñaki Inza e Pedro Larrañaga. A review of feature selection techniques in bioinformatics. Bioinformatics, 23(19):2507-2517, 2007. 9

[Sku02] Bagging, boosting and the random subspace method for linear classifiers. Pattern Analysis and Applications, 5(2):121-135, 2002. 51

[SL98] Basilio Sierra e Pedro Larrañaga. Predicting survival in malignant skin melanoma using bayesian networks automatically induced by genetic algorithms. an empirical comparison between different approaches. Artificial Intelligence in Medicine, 14(1):215 - 230, 1998. 25

[SL09] Marina Sokolova e Guy Lapalme. A systematic analysis of performance measures for classification tasks. Information Processing 83 Management, 45(4):427 - 437, 2009. 8 
[SLD $\left.{ }^{+} 17\right]$ Torgyn Shaikhina, Dave Lowe, Sunil Daga, David Briggs, Robert Higgins e Natasha Khovanova. Decision tree and random forest models for outcome prediction in antibody incompatible kidney transplantation. (in press), 2017. 27

$\left[\mathrm{SMP}^{+} 08\right]$ Ewout W Steyerberg, Nino Mushkudiani, Pablo Perel, Isabella Butcher, Juan Lu, Gillian S McHugh, Gordon D Murray, Anthony Marmarou, Ian Roberts, J Dik F Habbema et al. Predicting outcome after traumatic brain injury: development and international validation of prognostic scores based on admission characteristics. PLOS Medicine, 5(8):e165, 2008. 25

[SSBD14] Shai Shalev-Shwartz e Shai Ben-David. Understanding Machine Learning: From Theory to Algorithms. Cambridge University Press, New York, NY, USA, 2014. 6

[vDSTS93] C. van Daalen, H. G. Stassen, R. T. W. M. Thomeer e A. C. J. Slooff. Computer assisted diagnosis and treatment planning of brachial plexus injuries. Clinical Neurology and Neurosurgery, 95:50 - 55, 1993. 1

[Vog09] F. Randy Vogenberg. Predictive and prognostic models: Implications for healthcare decision-making in a modern recession. American Health 85 Drug Benefits, 2(6):218222, 2009. 2, 22, 23

[WA95] Jeremy C Wyatt e Douglas G Altman. Commentary: Prognostic models: clinically useful or quickly forgotten? BMJ, 311(7019):1539-1541, 1995. 2, 22

[WGF $\left.{ }^{+} 12\right]$ Jefferson R. Wilson, Robert G. Grossman, Ralph F. Frankowski, Alexander Kiss, Aileen M. Davis, Abhaya V. Kulkarni, James S. Harrop, Bizhan Aarabi, Alexander Vaccaro, Charles H. Tator, Marcel Dvorak, Christopher I. Shaffrey, Susan Harkema, James D. Guest e Michael G. Fehlings. A clinical prediction model for long-term functional outcome after traumatic spinal cord injury based on acute clinical and imaging factors. Journal of Neurotrauma, 29(13):2263-2271, 2012. 26

[WPDM06] Michael M. Ward, Sinisa Pajevic, Jonathan Dreyfuss e James D. Malley. Short-term prediction of mortality in patients with systemic lupus erythematosus: Classification of outcomes using random forests. Arthritis Care ES Research, 55(1):74-80, 2006. 27

[WYL16] Huazhen Wang, Fan Yang e Zhiyuan Luo. An experimental study of the intrinsic stability of random forest variable importance measures. BMC Bioinformatics, 17(1):60, Feb 2016. 51

[ZJ14] Mohammed J. Zaki e Wagner Meira Jr. Data Mining and Analysis: Fundamental Concepts and Algorithms. Cambridge University Press, New York, NY, USA, 2014. 7,48

[ZOW ${ }^{+}$17] Yucheng Zhang, Anastasia Oikonomou, Alexander Wong, Masoom A. Haider e Farzad Khalvati. Radiomics-based prognosis analysis for non-small cell lung cancer. Scientific Reports, 7, 2017. 28 